\title{
MIXED METAL-ORGANIC DYES WITH DUAL ELECTROPHORES: DESIGNING MORE ROBUST DYES FOR LIGHT-HARVESTING APPLICATIONS
}

\author{
by \\ Jennifer Huynh \\ Bachelor of Science, Chemistry \\ Ryerson University, Toronto, Ontario, Canada, 2014 \\ A thesis presented to Ryerson University \\ in partial fulfillment of the \\ requirements for the degree of Master of Science \\ in the Program of \\ Molecular Science
}

Toronto, Ontario, Canada, 2017

(C) Jennifer Huynh, 2017 


\section{AUTHOR'S DECLARATION}

I hereby declare that I am the sole author of this thesis. This is a true copy of the thesis, including any required final revisions, as accepted by my examiners.

I authorize Ryerson University to lend this thesis to other institutions or individuals for the purpose of scholarly research.

I further authorize Ryerson University to reproduce this thesis by photocopying or by other means, in total or in part, at the request of other institutions or individuals for the purpose of scholarly research.

I understand that my thesis may be made electronically available to the public. 


\title{
Mixed Metal-Organic Dyes with Dual Electrophores: Designing More Robust Dyes for Light-Harvesting Applications
}

\author{
Jennifer Huynh \\ Master of Science, Molecular Science, Ryerson University, 2017
}

\begin{abstract}
Donor- $\pi$-spacer-acceptor architectures are a favourable motif in the design of dyes for light harvesting applications. Organic compounds offer cost-effectiveness and synthetic design versatility, while inorganic compounds possess long term redox stability and wide range for absorption. Uniting both types of molecules allows utilization of these properties. Several projects were undertaken with the theme of a hybrid dye system and study of their redox stability. Chapter 1 gives a brief overview of the inorganic and organic compounds that paved the research in DSSC dyes. Chapter 2 details a review on copper(I) dyes in the literature and preliminary synthesis towards a D- $\pi-A$ templated copper(I) dye. Chapter 3 looks into the robust potential of novel BODIPY dyes that utilize ferrocene as an electron rich donor. Chapter 4 represents a series of BODIPY-redox active donor dyads, the study of their redox stability provide insight on the decomposition pathway of these conjugates.
\end{abstract}




\section{ACKNOWLEDGEMENTS}

I would like to thank my supervisor and mentor Dr. Bryan Koivisto for providing me with opportunities, developing skills both inside and outside of the academic setting, demonstrating patience, honesty and devotion to build value in others to thrive. It takes only one person to believe in you and I cannot imagine standing where I am today if it were not for you letting me join the first summer research experience aka "patio season".

My gratitude goes to my committee members Dr. Robert Gossage and Dr. Russell Viirre for their helpful guidance and feedback. I only wish I had asked for your help more often when I ran into difficulties. I also appreciate Dr. Daniel Foucher for his time and care to review this thesis and having an impact on my academic career. I had the privilege of being taught by each of you and you all brought out my enthusiasm for chemistry.

A great number of people also had an effect on the completion of this thesis. Past and present lab mates who made working in the lab unforgettable, to only name a few, Muhammad Yousaf, Burhan Hussein, Benjamin Fischer, Sahana Sritharan, Omar Abdi, Hardeep Devgan, Sara Abuadas, Paloma Prieto, and Jeanette Adjei. You guys contributed to my personal growth and gave me strength to complete my thesis.

I am also eternally grateful to Jeffrey Pau, Khrystyna Herasymchuk and Nande Wright for being positive influences and encouraging me to pursue research since my undergraduate studies. You are truly extraordinary individuals who I look up to.

I cannot forget the help from the administrators, staff and lab technicians of the Chemistry \& Biology department who help with booking rooms, scheduling exam invigilations, organizing and providing guidance during TAships, and finding equipment and chemicals.

And an extended thanks to my fellow co-workers at Toronto Research Chemicals for motivating me to finish writing. Last, but not least, my family and friends (Jessica Huynh, David Lau, Angelica Lim, Nam Nghiem, Dhayo Khangsar, Tashi Choezom, and Alishea Ally) for their moral support that kept me sane. 
To my parents for their unconditional love and support. 


\section{Table of Contents}

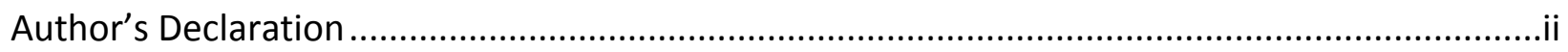

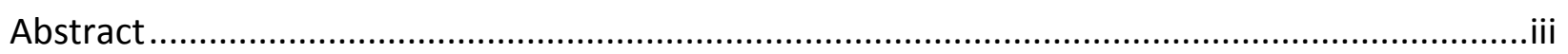

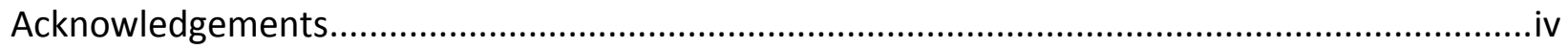

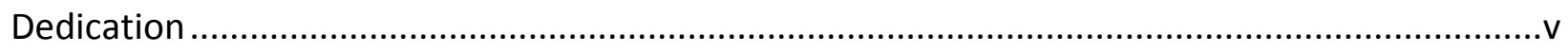

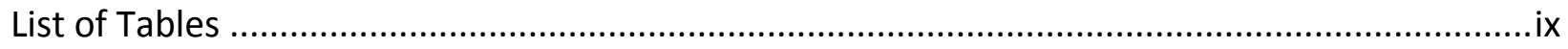

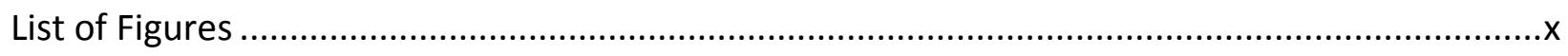

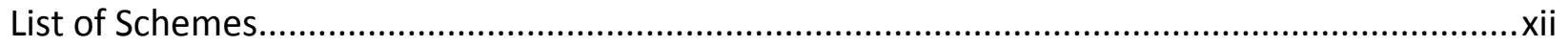

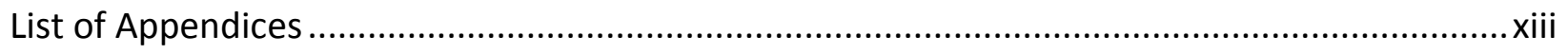

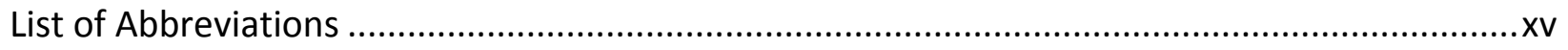

List of Numbered Compounds ........................................................................................

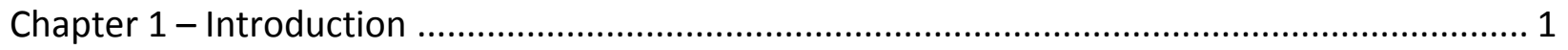

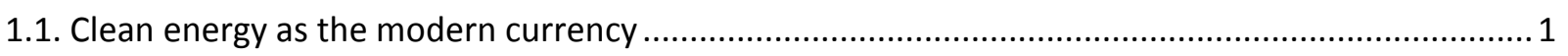

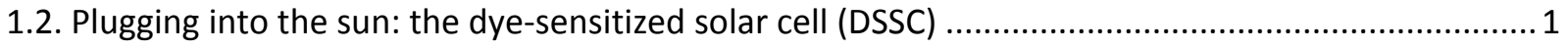

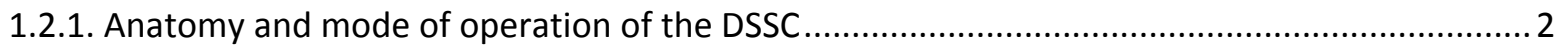

1.2.2. Design features of the dye: the powerhouse of the DSSC ................................................. 4

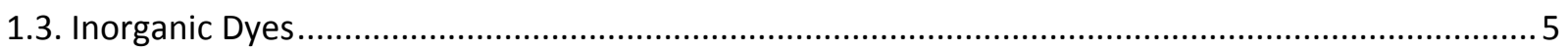

1.3.1. First dyes in DSSC application: Ruthenium complexes ....................................................... 5

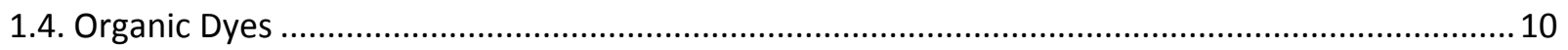

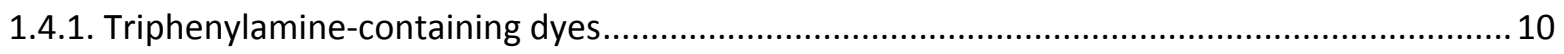

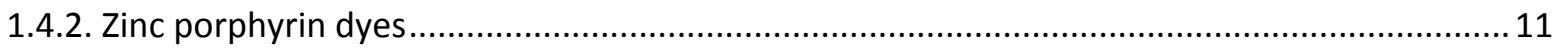

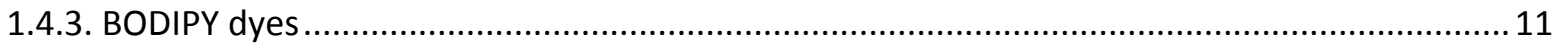

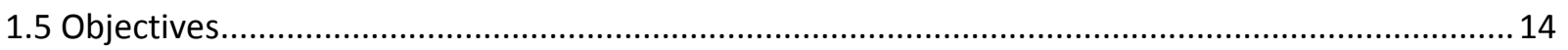

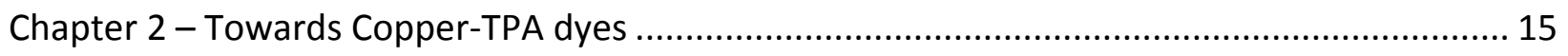

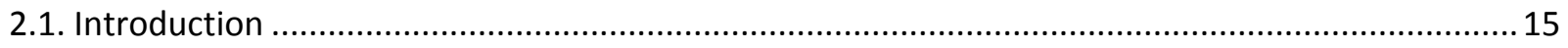

2.1.1. Homoleptic copper(I) complexes for light harvesting applications ...................................... 16

2.1.2. Heteroleptic copper(I) dyes for light harvesting applications ............................................. 18

2.1.3. Controlling the Jahn-Teller effect by modification of substituents at the 2,9-positions of

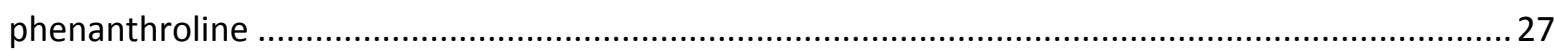




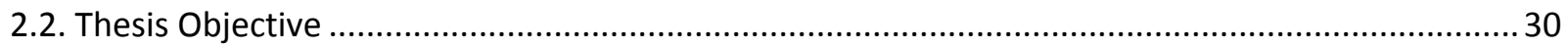

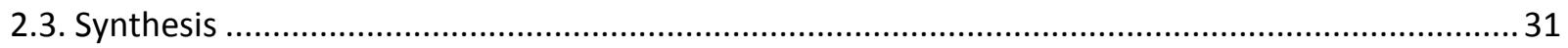

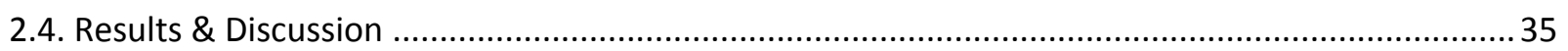

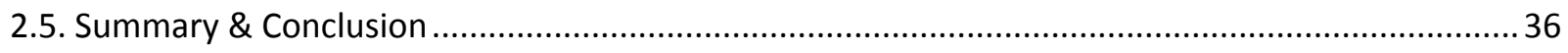

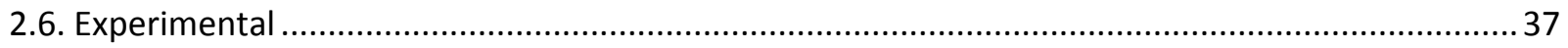

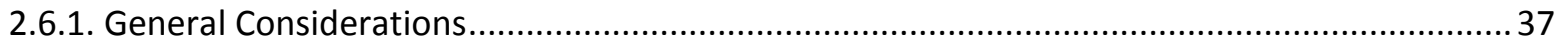

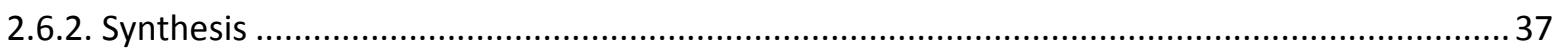

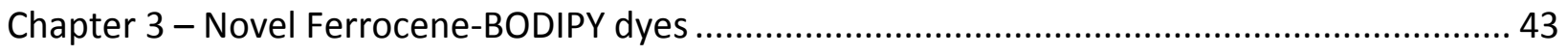

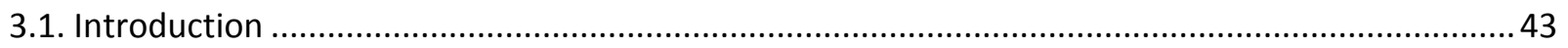

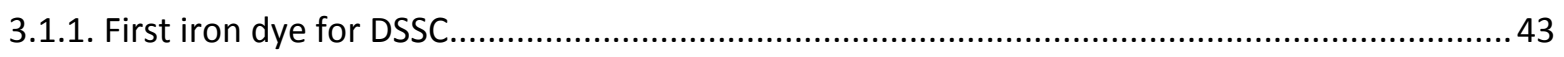

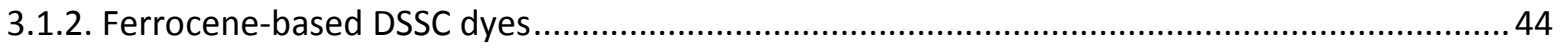

3.1.3. meso-substituted methylated ferrocenyl BODIPY ............................................................. 45

3.1.4. $\alpha, \beta$-unsaturated carbene-BODIPY dyads with varying metals ............................................. 48

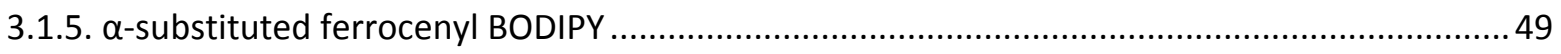

3.1.6. Ferrocene cyclized through a pyridine ring to BODIPY ....................................................... 51

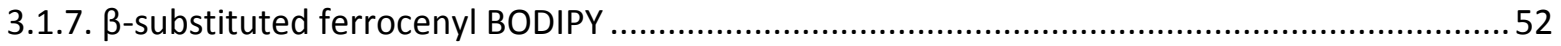

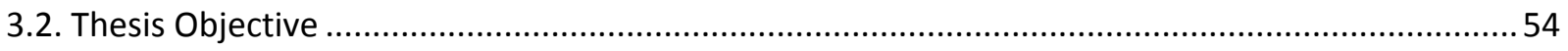

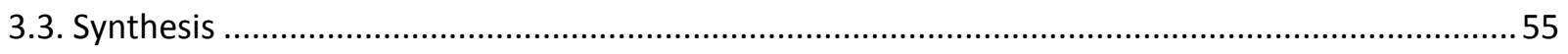

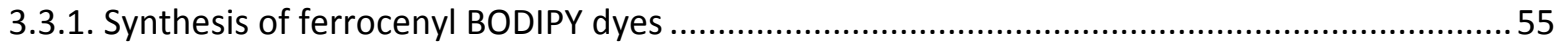

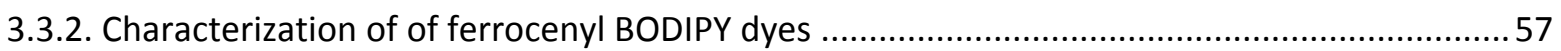

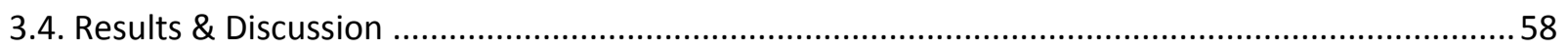

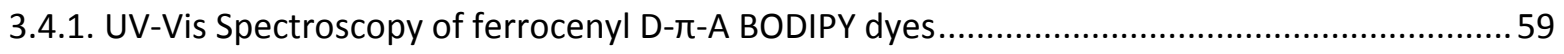

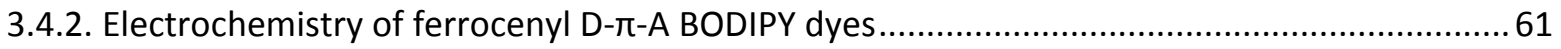

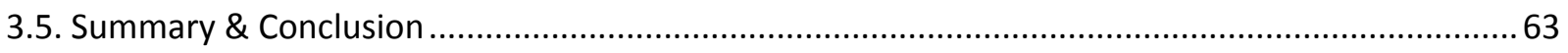

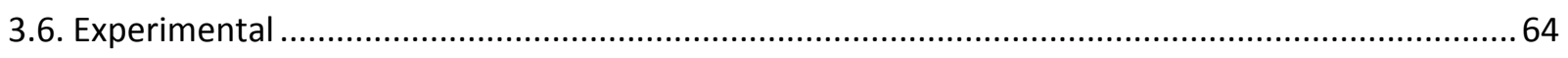

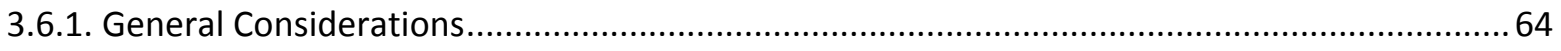

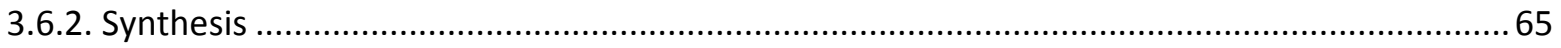

Chapter 4.0 - Exploring the redox interplay in BODIPY-dyads ............................................. 70

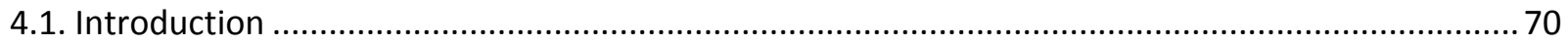

4.1.1. Meso-substituted TPA-BODIPY with varying substituents on TPA ........................................ 70

4.1.2. Meso-substituted nonmethylated BODIPY dyads with polyarylamines and TPA .................... 72 


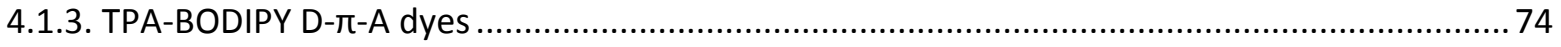

4.1.4. Meso-substituted BODIPY dyads with quinone/hydroquinone as a redox active unit ............77

4.1.5. Meso-substituted BODIPY dyads with phenothiazine as a redox active unit ........................... 78

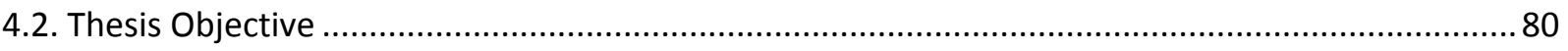

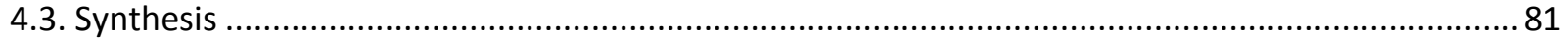

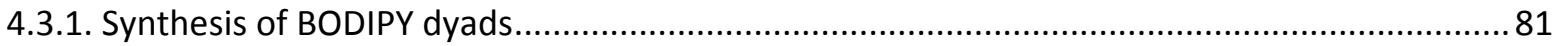

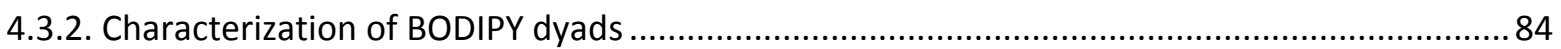

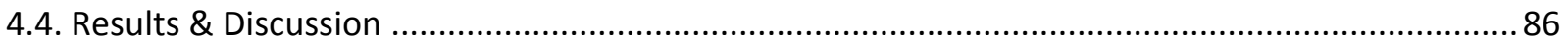

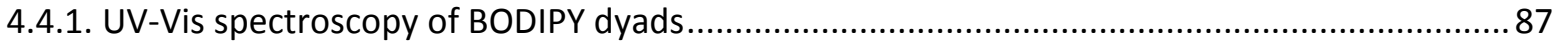

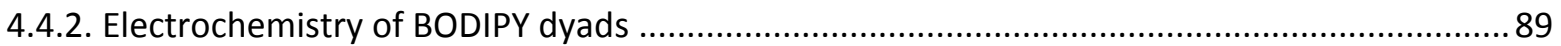

4.4.3. Spectroelectrochemical studies of BODIPY dyads ............................................................ 90

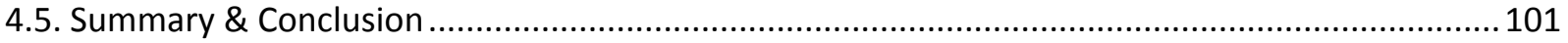

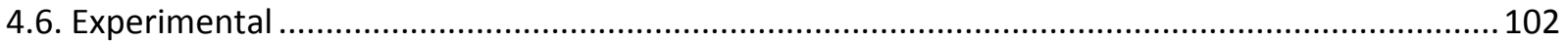

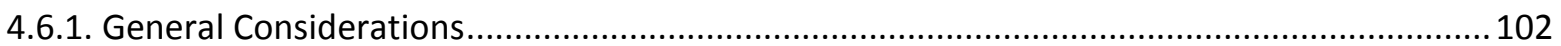

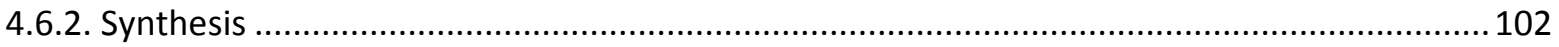

Chapter 5.0 - Conclusions and Future Work ................................................................. 116

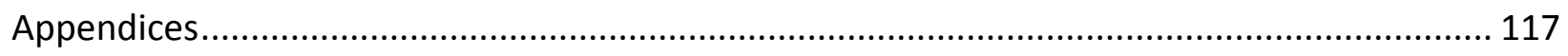

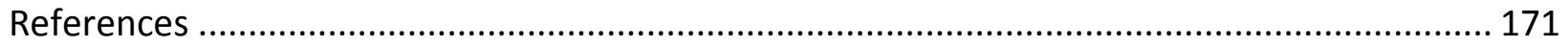




\section{LIST OF TABLES}

\section{Chapter 1}

Table 1.1. Selected ruthenium dyes with high efficiencies .................................................. 9

Table 1.2. Performance parameters of organic dyes from this section ................................... 13

\section{Chapter 2}

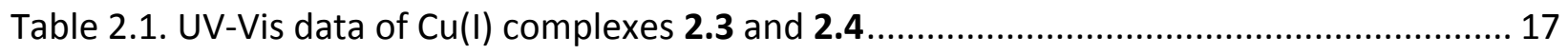

Table 2.2. Device performance data of solar cells by Hewat et $a .^{35}{ }^{35}$.......................................... 21

Table 2.3. DSSC device data of best one or two copper(I) dyes from each study in chapter $2 \ldots 27$

\section{Chapter 3}

Table 3.1. Physico-chemical data of dyes and their efficiencies in a DSSC ............................. 44

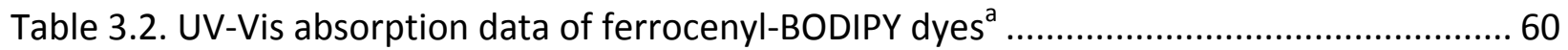

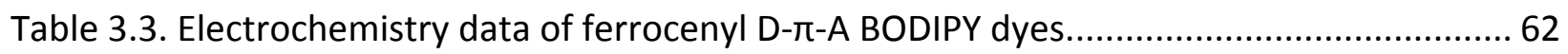

\section{Chapter 4}

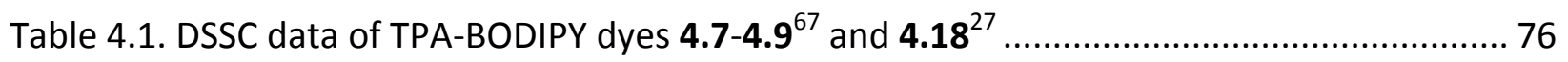

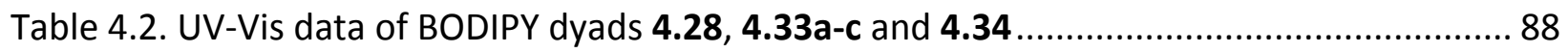

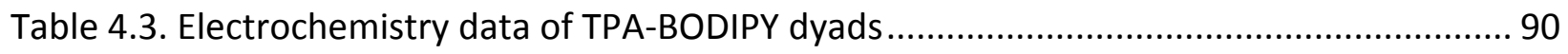




\section{LIST OF FIGURES}

\section{Chapter 1}

Figure 1.1. Schematic of the dye-sensitized solar cell (DSSC) .............................................. 2

Figure 1.2. Diagram of the anatomy of the DSSC .............................................................. 3

Figure 1.3. Donor- $\pi$-spacer-acceptor motif of a dye ................................................................ 4

Figure 1.4. Trimeric ruthenium complex ........................................................................ 6

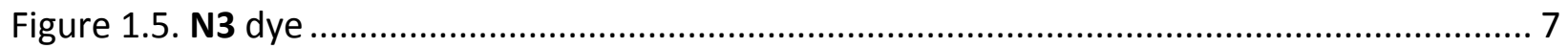

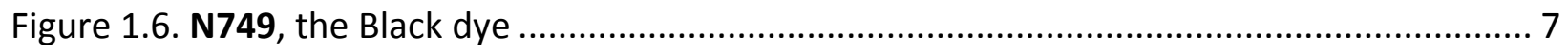

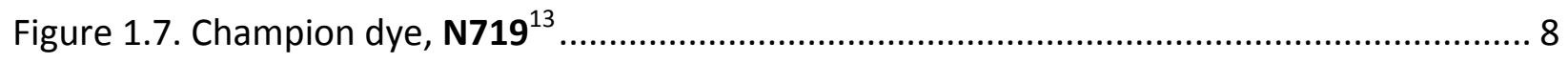

Figure 1.8. Ruthenium dyes that reached champion status in recent years ............................. 9

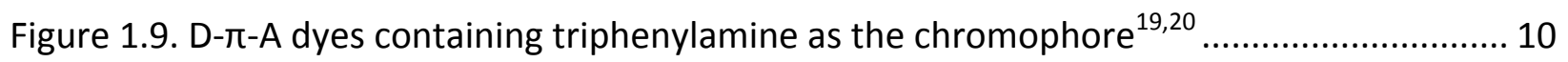

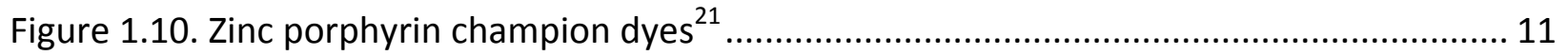

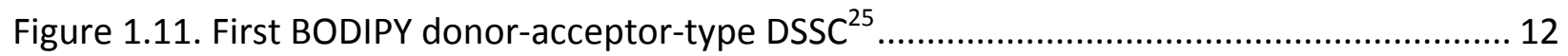

\section{Chapter 2}

Figure 2.1. Jahn-Teller effect of a copper(II) complex .......................................................... 15

Figure 2.2. Homoleptic $\mathrm{Cu}(\mathrm{I})$ complexes analysed by Bessho et al. ${ }^{29}$....................................... 16

Figure 2.3. Various copper(I) biquinoline complexes with differing counterions ...................... 17

Figure 2.4. General schematic of a heteroleptic copper(I) complex ......................................... 19

Figure 2.5. Dipyrrin ligands explored by Hewat et al. ${ }^{32}$.......................................................... 19

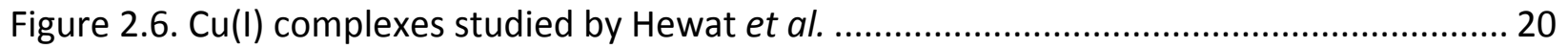

Figure 2.7. Heteroleptic $\mathrm{Cu}(\mathrm{I})$ complexes utilized for performance studies............................... 21

Figure 2.8. Copper complexes studied by the Odobel group, with 2,2'-biquinoline-4,4'-

dicarboxylic acid $\left(\mathrm{dcbqH}_{2}\right)$ as the anchoring ligand

Figure 2.9. Ancillary ligands; $\mathbf{2 . 2 1}$ (first generation dendron) and $\mathbf{2 . 2 2}$ (second generation dendron), anchoring ligands; 2.23 (phosphonic acid), 2.24 (6,6'-dimethyl-[2,2'-bipyridine]-4,4'dicarboxylic acid) and $\mathbf{2 . 2 5}$ (benzoic acid) ...................................................................... 23

Figure 2.10. The heteroleptic $\mathrm{Cu}(\mathrm{I})$ complex synthesized by Bozic-Weber et al. ....................... 25

Figure 2.11. Heteroleptic copper(I) complexes with high efficiencies ...................................... 26

Figure 2.12. Two main $\mathrm{Cu}(\mathrm{I})$ complexes studied by Gothard and colleagues ${ }^{39}$......................... 28

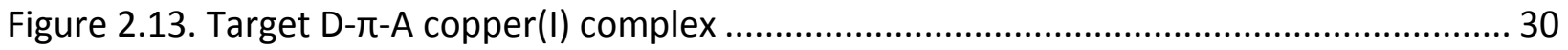




\section{Chapter 3}

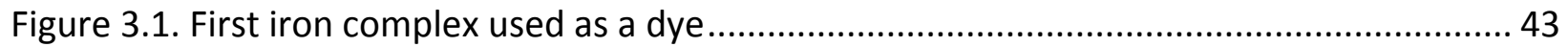

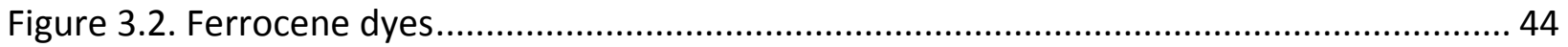

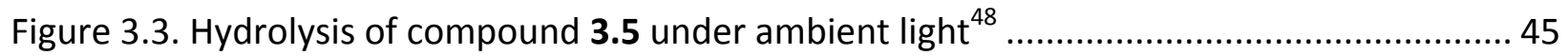

Figure 3.4. meso-substituted ferrocenyl tetramethyl-BODIPY dyads with various

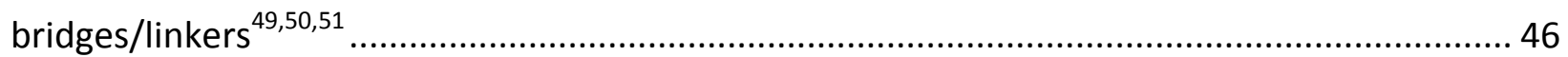

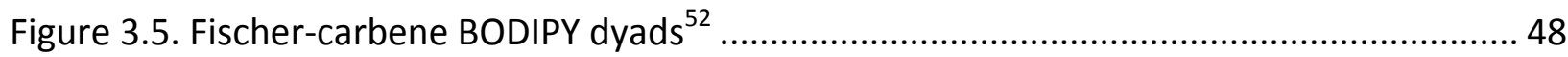

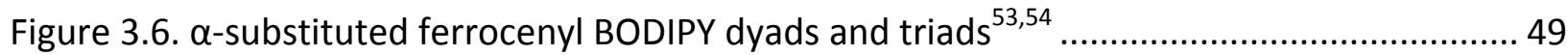

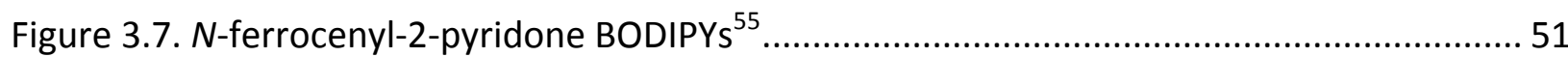

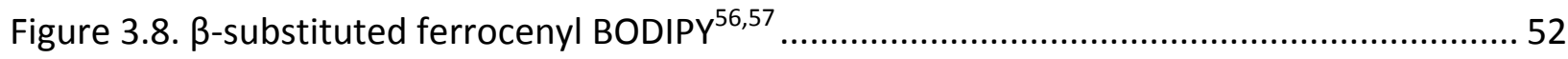

Figure 3.9. Ferrocenyl-BODIPY dyes connected through an ethynyl bridge ............................ 54

Figure 3.10. UV-Vis absorption spectra (a) and MOs (b) of BODIPY-Fc dye $\mathbf{3 . 3 0}$ and $\mathbf{3 . 3 1}$......... 59

Figure 3.11. Cyclic voltammogram of ferrocenyl D-r-A BODIPY dyes................................... 61

\section{Chapter 4}

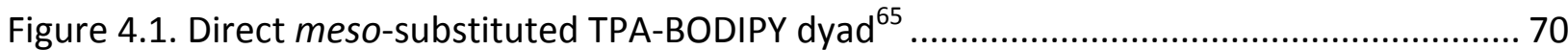

Figure 4.2. Meso-substituted nonmethylated BODIPY with polyarylamines and TPA as redox

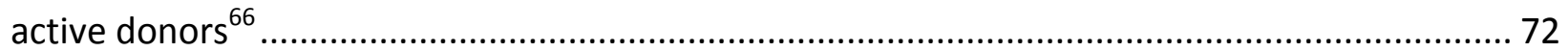

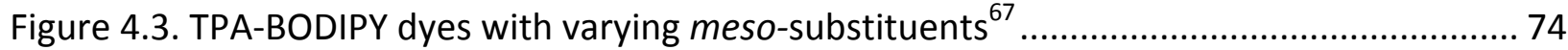

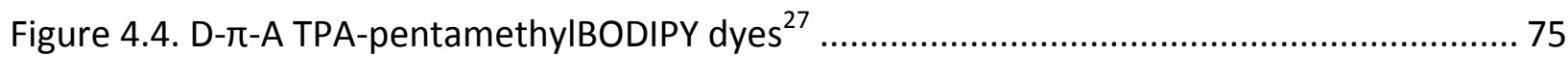

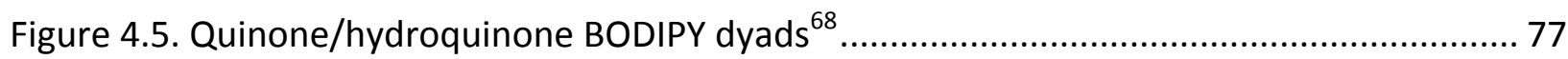

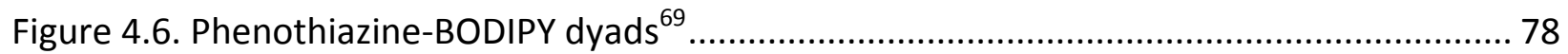

Figure 4.7. UV-Vis absorption spectra (a) and MOs (b) of BODIPY dyads 4.28, 4.33a-c and 4.3487

Figure 4.8. Stacked cyclic voltammogram of TPA-BODIPY dyads ........................................... 89

Figure 4.9. Oxidation of $\mathbf{4 . 2 8}$ - a) oxidation below $0.94 \mathrm{~V}$; b) oxidation above $0.94 \mathrm{~V} . . . . . . . . . . . .991$

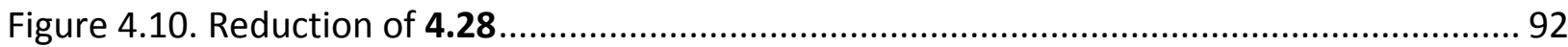

Figure 4.11. Oxidation of 4.34 - a) oxidation below $1.34 \mathrm{~V}$; b) oxidation above $1.34 \mathrm{~V} . . . . . . . . . . .93$

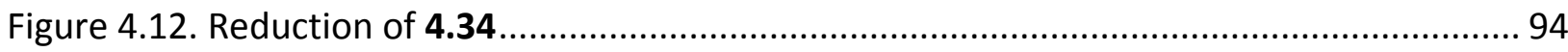

Figure 4.13. Oxidation of $4.33 \mathrm{a}-\mathrm{a}$ ) oxidation below $0.82 \mathrm{~V}$; b) oxidation above $0.82 \mathrm{~V}$........... 95

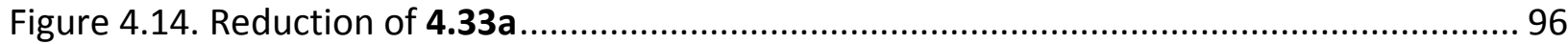

Figure 4.15. Oxidation of $4.33 \mathrm{~b}-\mathrm{a}$ ) oxidation below $0.86 \mathrm{~V}$; b) oxidation above $0.86 \mathrm{~V}$........... 97

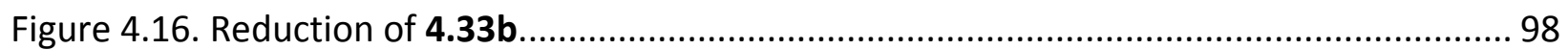

Figure 4.17. Oxidation of $4.33 \mathrm{c}-$ a) oxidation below $0.30 \mathrm{~V}$; b) oxidation above $0.30 \mathrm{~V} \ldots . . . . . . .99$

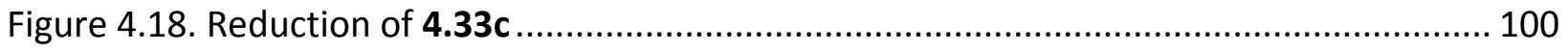




\section{LIST OF SCHEMES}

\section{Chapter 2}

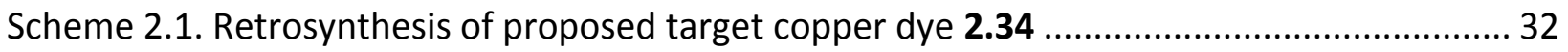

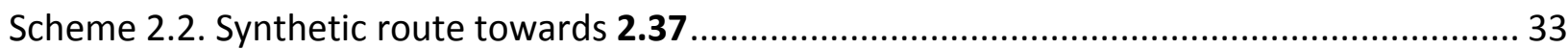

Scheme 2.3. Synthetic route towards donor ligand ........................................................... 34

\section{Chapter 3}

Scheme 3.1. Synthetic scheme towards making ferrocenyl-BODIPY dyes 56

\section{Chapter 4}

Scheme 4.1. Synthetic route towards iodo-BODIPY ........................................................ 82

Scheme 4.2. Reaction towards reference BODIPY dyad 4.28 ............................................ 82

Scheme 4.3. Synthetic route towards ethynyl-TPA moiety. $a=$ commercially available ............. 83

Scheme 4.4. Synthetic route towards BODIPY-ethynyl-TPA molecules ................................... 84

Scheme 4.5. Synthetic scheme towards synthesis of ferrocenyl-ethynyl-BODIPY dyad............. 84 


\section{LIST OF APPENDICES}

Table A1. Electrochemistry data of $\mathbf{4 . 2 8}$ and $\mathbf{4 . 3 4}$.

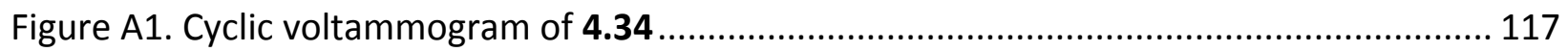

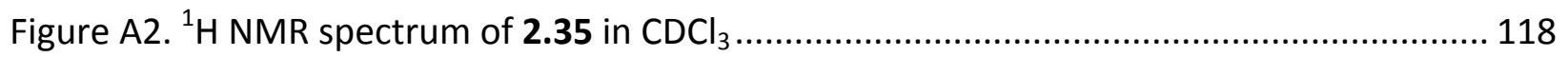

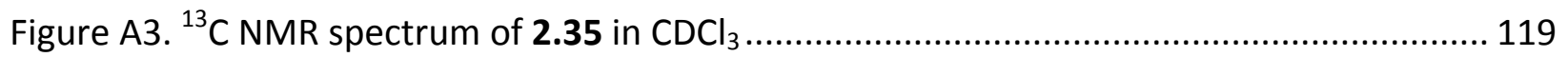

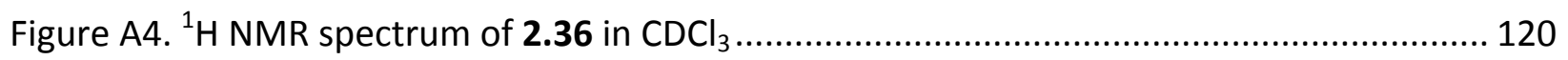

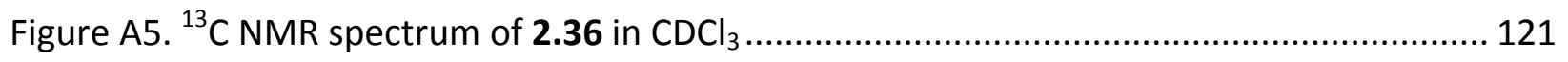

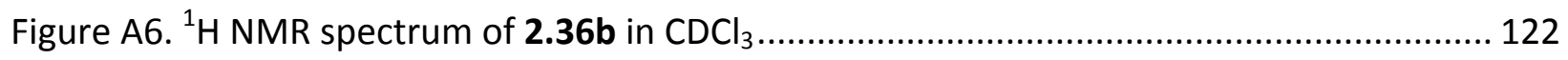

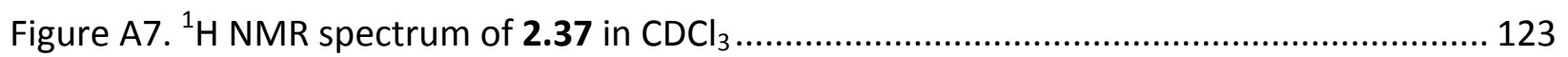

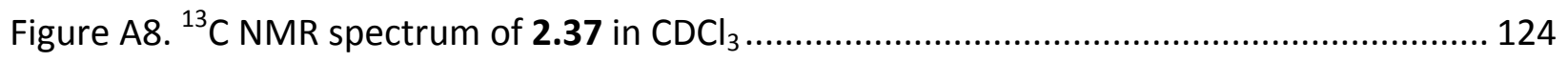

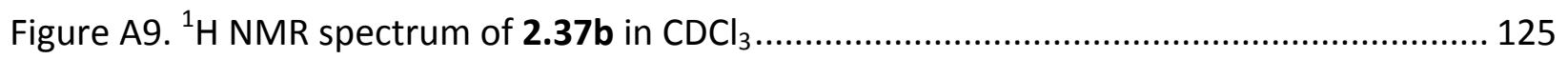

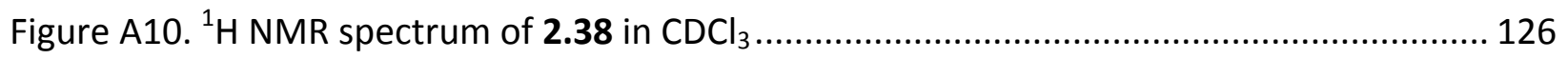

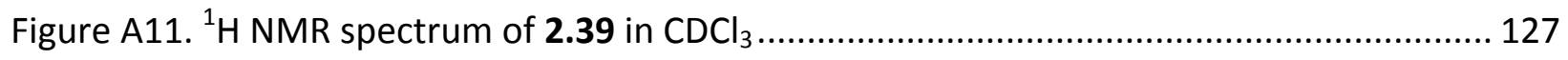

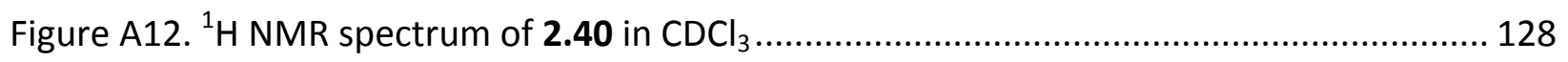

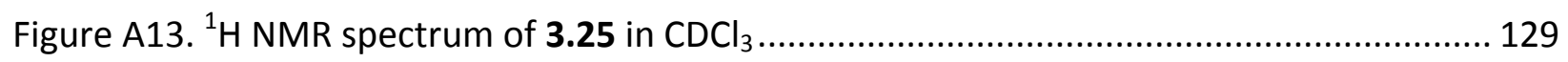

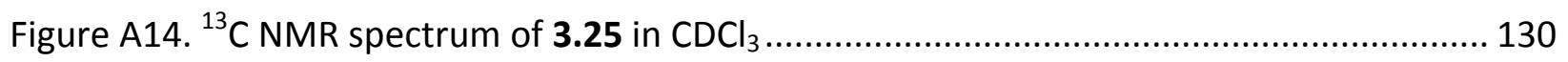

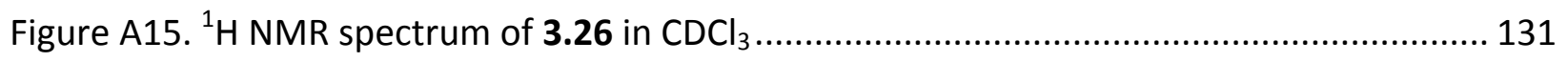

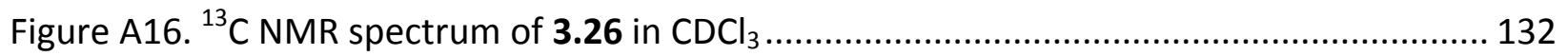

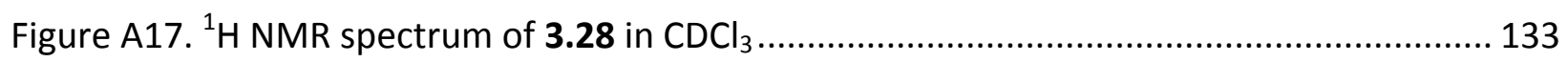

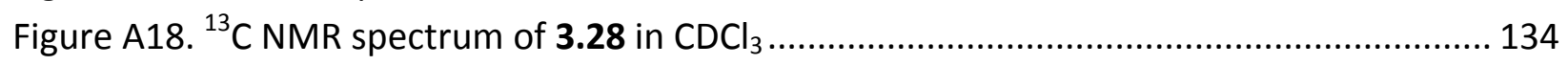

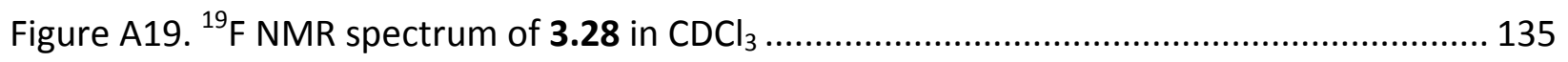

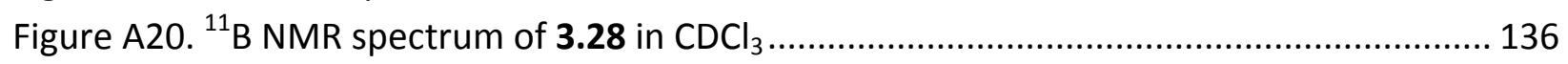

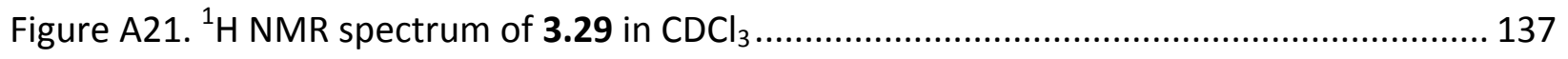

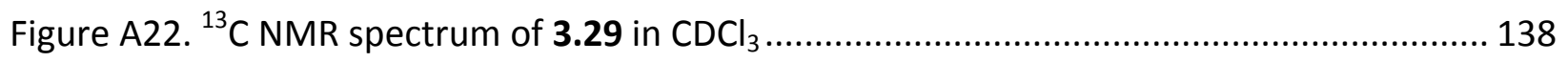

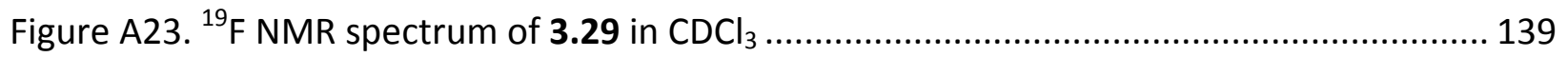

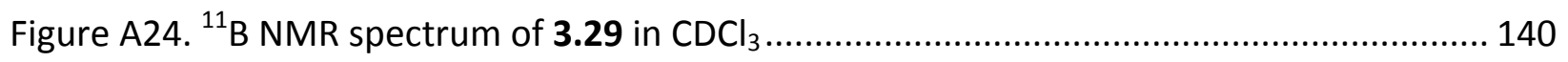

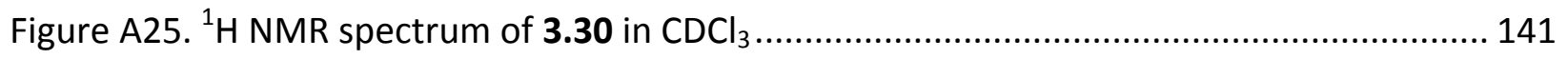

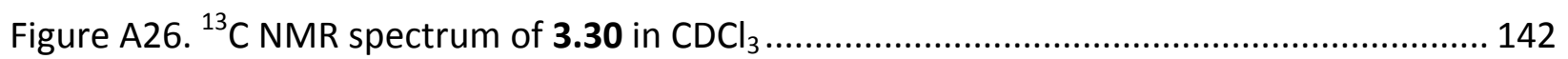

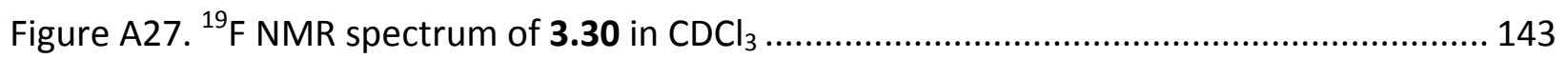

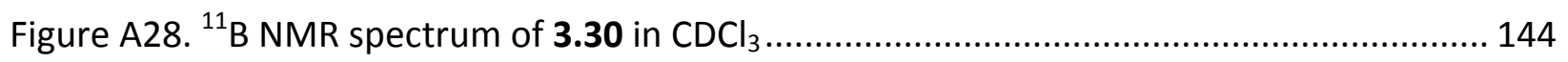

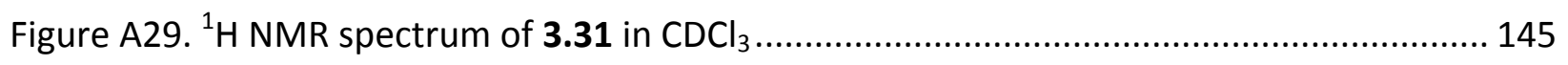

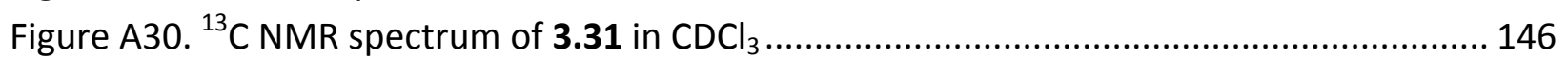

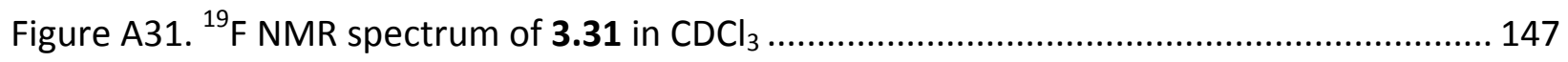

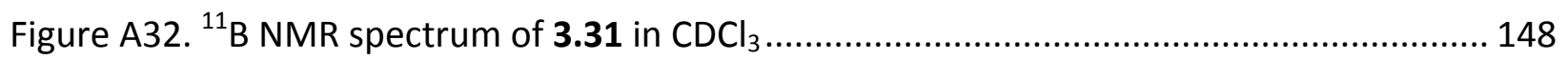

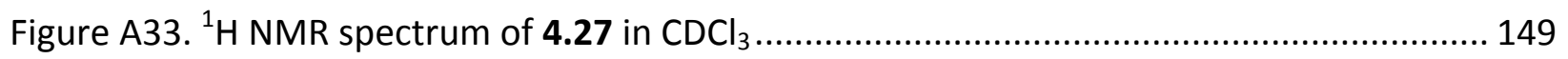




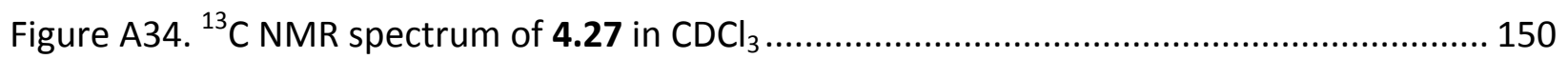

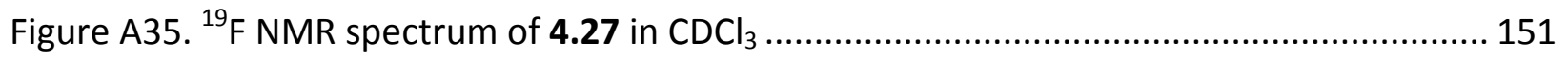

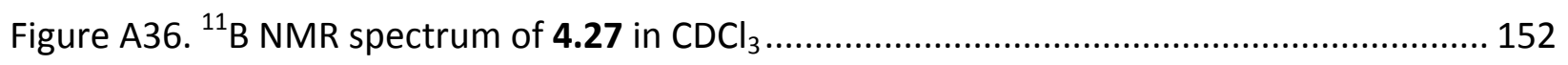

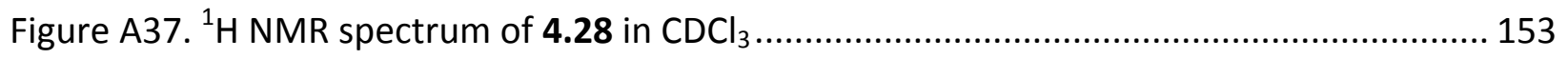

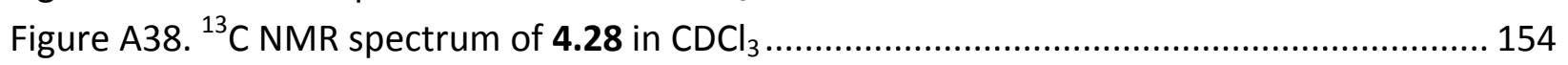

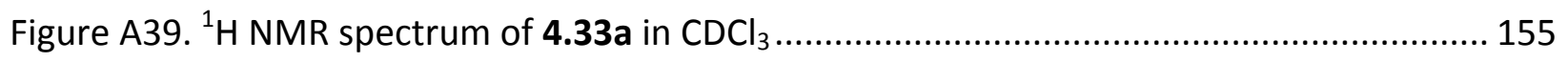

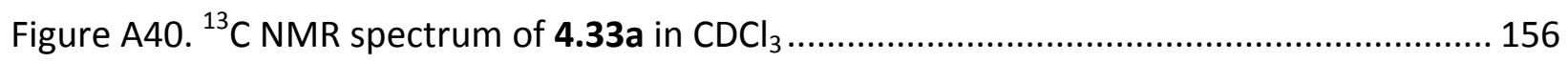

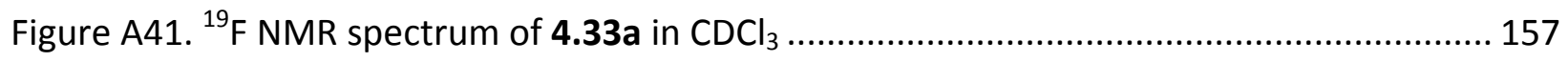

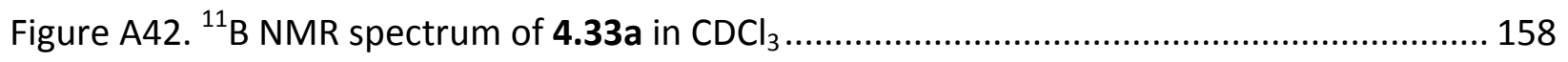

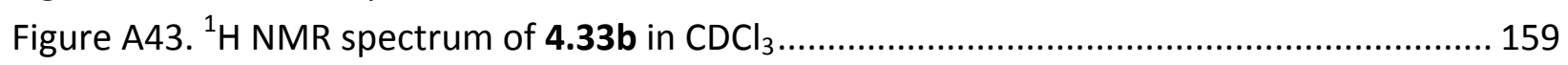

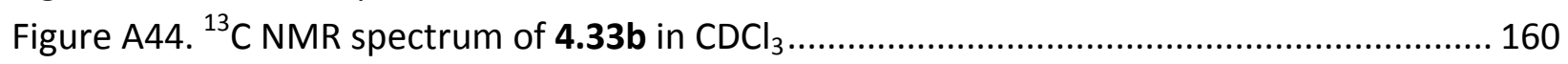

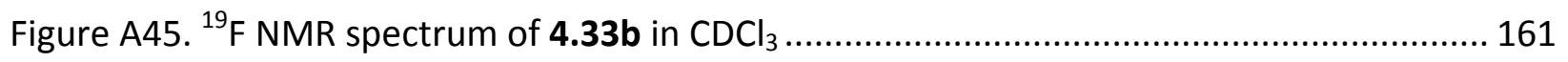

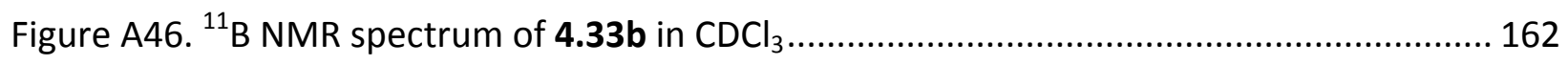

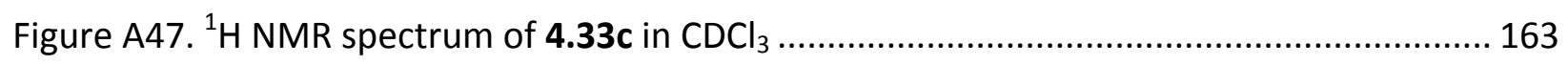

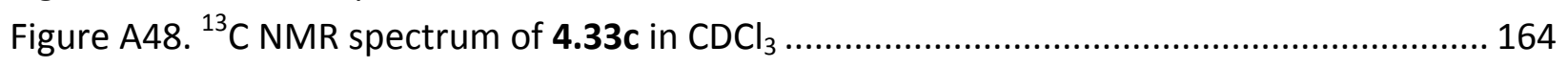

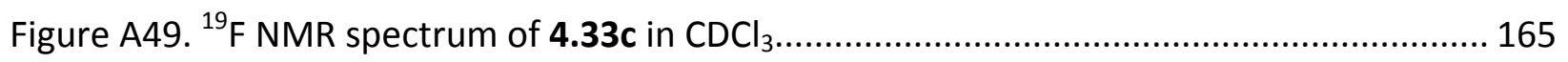

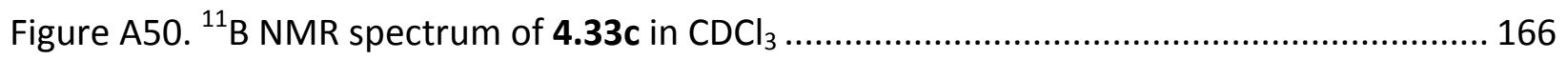

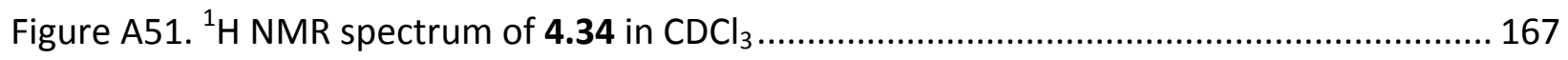

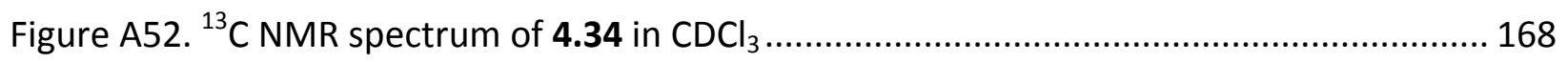

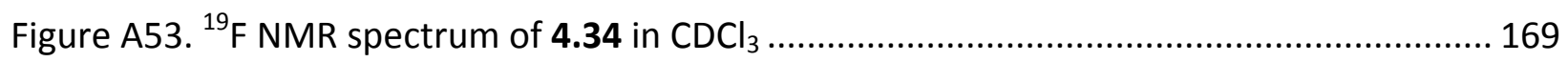

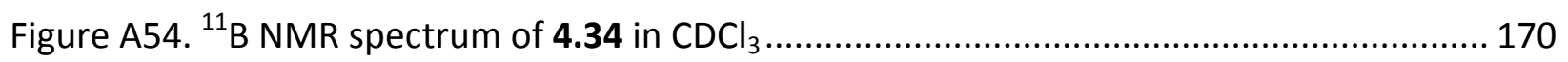




\section{LIST OF ABBREVIATIONS}

MeCN

$\mathrm{AlCl}_{3}$

$\mathrm{NH}_{4} \mathrm{OH}$

B3LYP

dcbqH

$\mathrm{CO}_{2}$

$\delta$

$\mathrm{cp}$

DFT

$\mathrm{CDCl}_{3}$

DCM

BODIPY

dtbp

$\mathrm{D}_{2} \mathrm{O}$

$\mathrm{Et}_{2} \mathrm{O}$

DSSC

EDG
Acetonitrile

Aluminum chloride

Ammonium hydroxide

Becke 3 Lee Yang Parr

2,2' -biquinoline-4,4'-dicarboxylic acid

Carbon dioxide

Chemical shift

cyclopentadiene

Density functional theory

chloroform- $\mathrm{d}_{1}$

Dichloromethane

4,4'-difluoro-4-bora-3a,4a-diaza-s-indacene

di-tert-butyl phenanthroline

Deuterium oxide

Diethyl ether

Dye-sensitized solar cell

Electron donating group 


\begin{tabular}{|c|c|}
\hline EWG & Electron withdrawing group \\
\hline EtOAc & Ethyl acetate \\
\hline Fc & Ferrocene \\
\hline FF & Fill factor \\
\hline $\mathrm{CHO}$ & Formyl \\
\hline Hex & Hexanes \\
\hline HOMO & Highest occupied molecular orbital \\
\hline IPCE & Incident photon-to-current conversion efficiency \\
\hline$P_{\text {in }}$ & Incident power input \\
\hline LUMO & Lowest occupied molecular orbital \\
\hline $\mathrm{MgSO}_{4}$ & Magnesium sulfate \\
\hline $\mathrm{MnO}_{2}$ & Manganese dioxide \\
\hline $\mathrm{MHz}$ & Megahertz \\
\hline $\mathrm{MeOH}$ & Methanol \\
\hline OMe & Methoxy \\
\hline $\mathrm{MLCT}$ & Metal to ligand charge transfer \\
\hline $\mathrm{N}_{2}$ & Nitrogen gas \\
\hline NIS & $N$-iodosuccinimide \\
\hline
\end{tabular}




\begin{tabular}{|c|c|}
\hline NIR & Near-infrared region \\
\hline NHE & Normal hydrogen electrode \\
\hline NMR & Nuclear magnetic resonance \\
\hline $\mathrm{V}_{\mathrm{OC}}$ & Open circuit voltage \\
\hline OTTLE cell & Optically transparent thin layer electrochemical cell \\
\hline $\mathrm{PdCl}_{2}\left(\mathrm{PPh}_{3}\right)_{2}$ & Bis(triphenylphosphine)palladium chloride \\
\hline phen & Phenanthroline \\
\hline PTZ & Phenothiazines \\
\hline $\mathrm{POCl}_{3}$ & Phosphoryl chloride (phosphorus(V) oxychloride) \\
\hline KF & Potassium fluoride \\
\hline RT & Room temperature \\
\hline $\mathrm{J}_{\mathrm{SC}}$ & Short circuit voltage \\
\hline $\mathrm{NaOH}$ & Sodium hydroxide \\
\hline TW & Terawatt \\
\hline THF & Tetrahydrofuran \\
\hline TLC & Thin layer chromatography \\
\hline TD-DFT & Time dependent density functional theory \\
\hline $\mathrm{NEt}_{3}$ & Triethylamine \\
\hline
\end{tabular}


TFA

t-BuLi

tbp

$\mathrm{TiO}_{2}$

TMS

TPA

UV-Vis
Trifluoroacetic acid

tert-butyllithium

tert-butyl phenanthroline

Titania

Trimethylsilyl

Triphenylamine

Ultra-violet-visible 


\section{LIST OF NUMBERED COMPOUNDS}

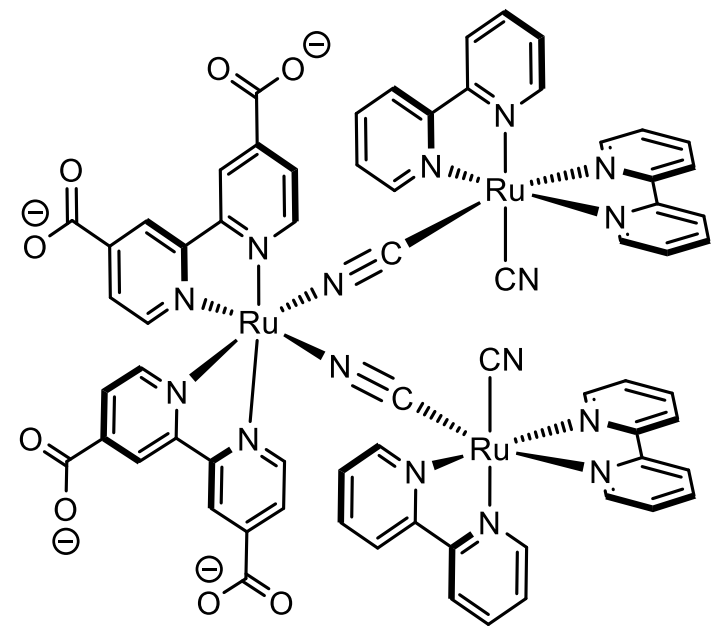

1.1

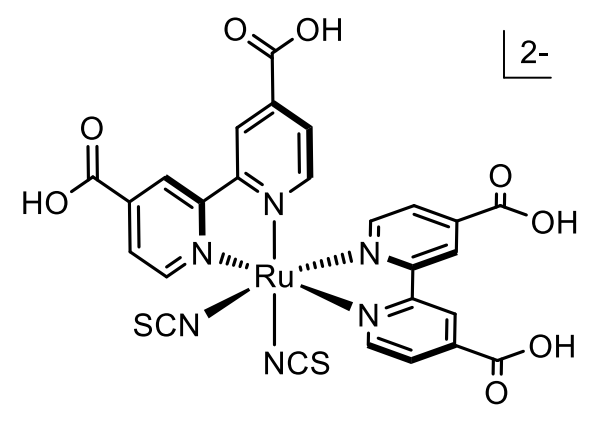

1.2

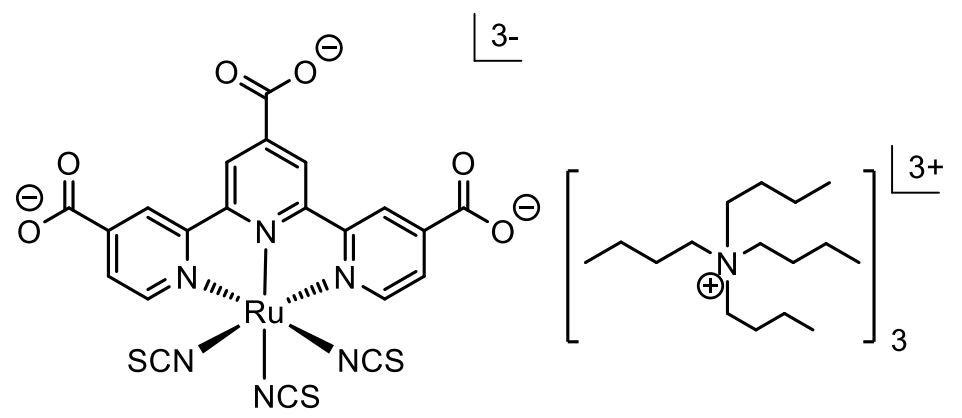

1.3

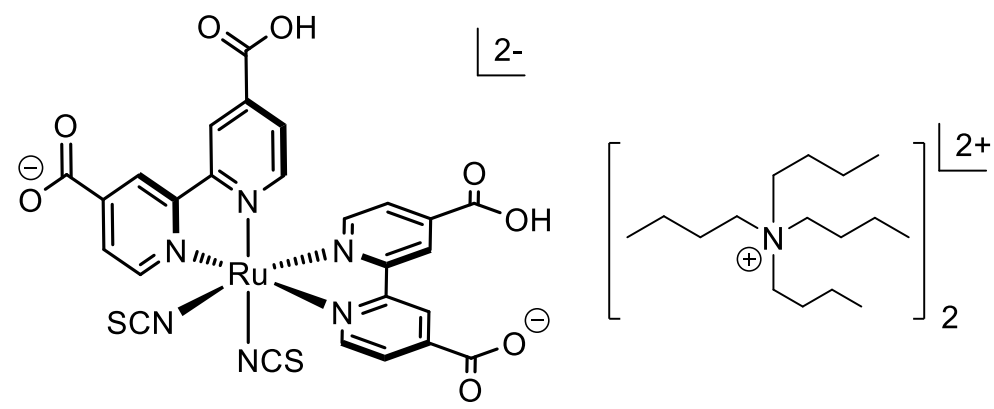




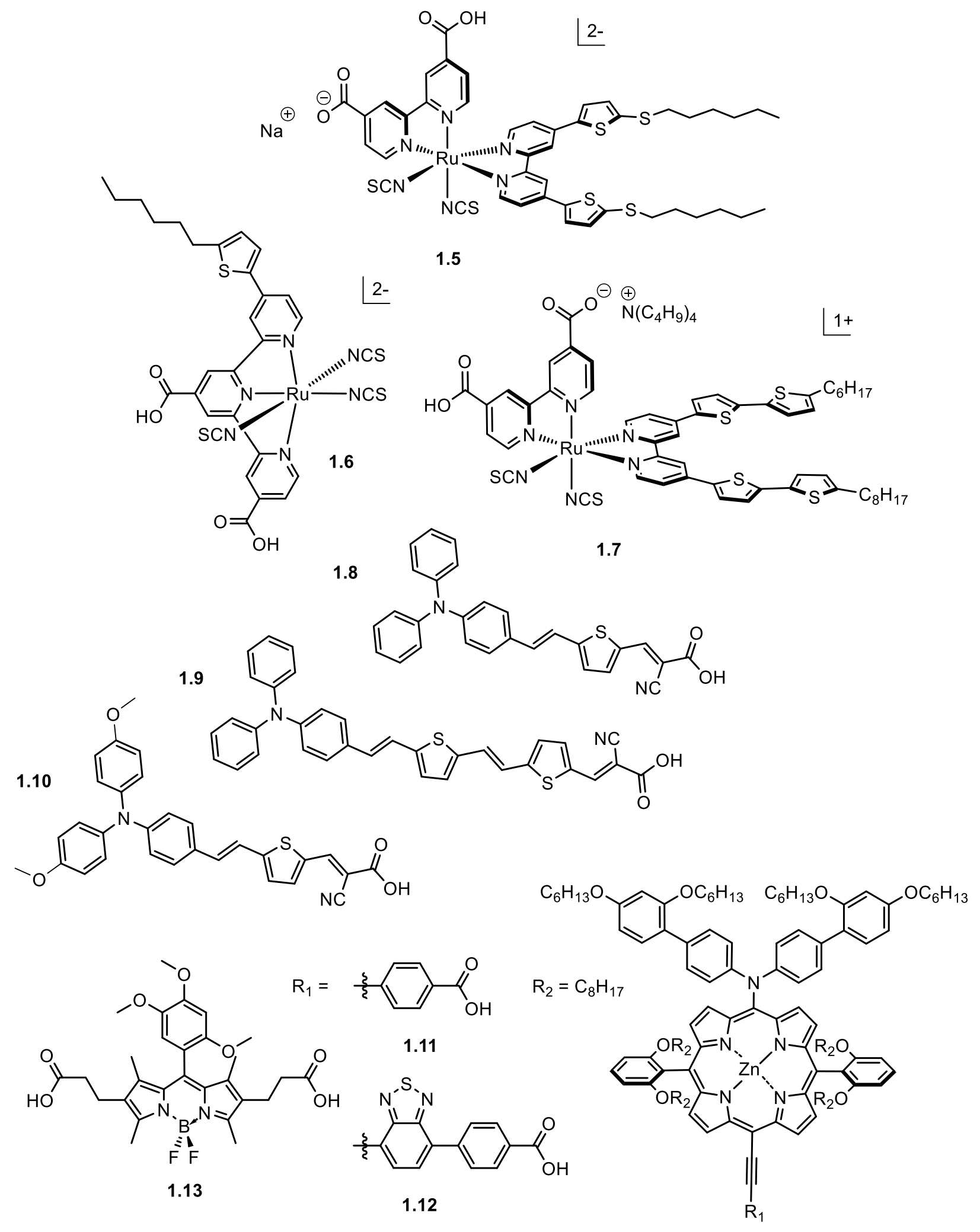




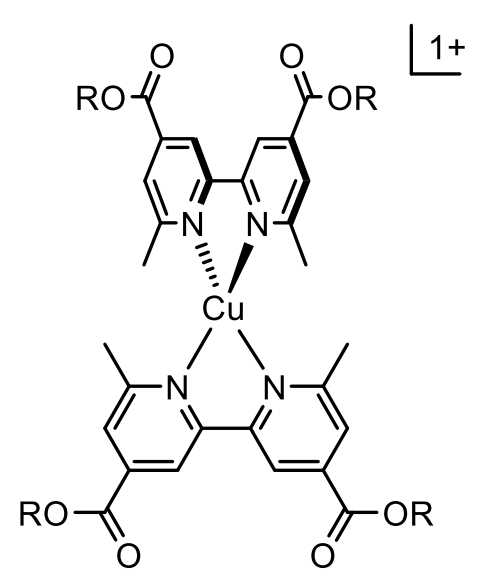

2.1, $\mathrm{R}=\mathrm{H}$

2.3, $R=M e$
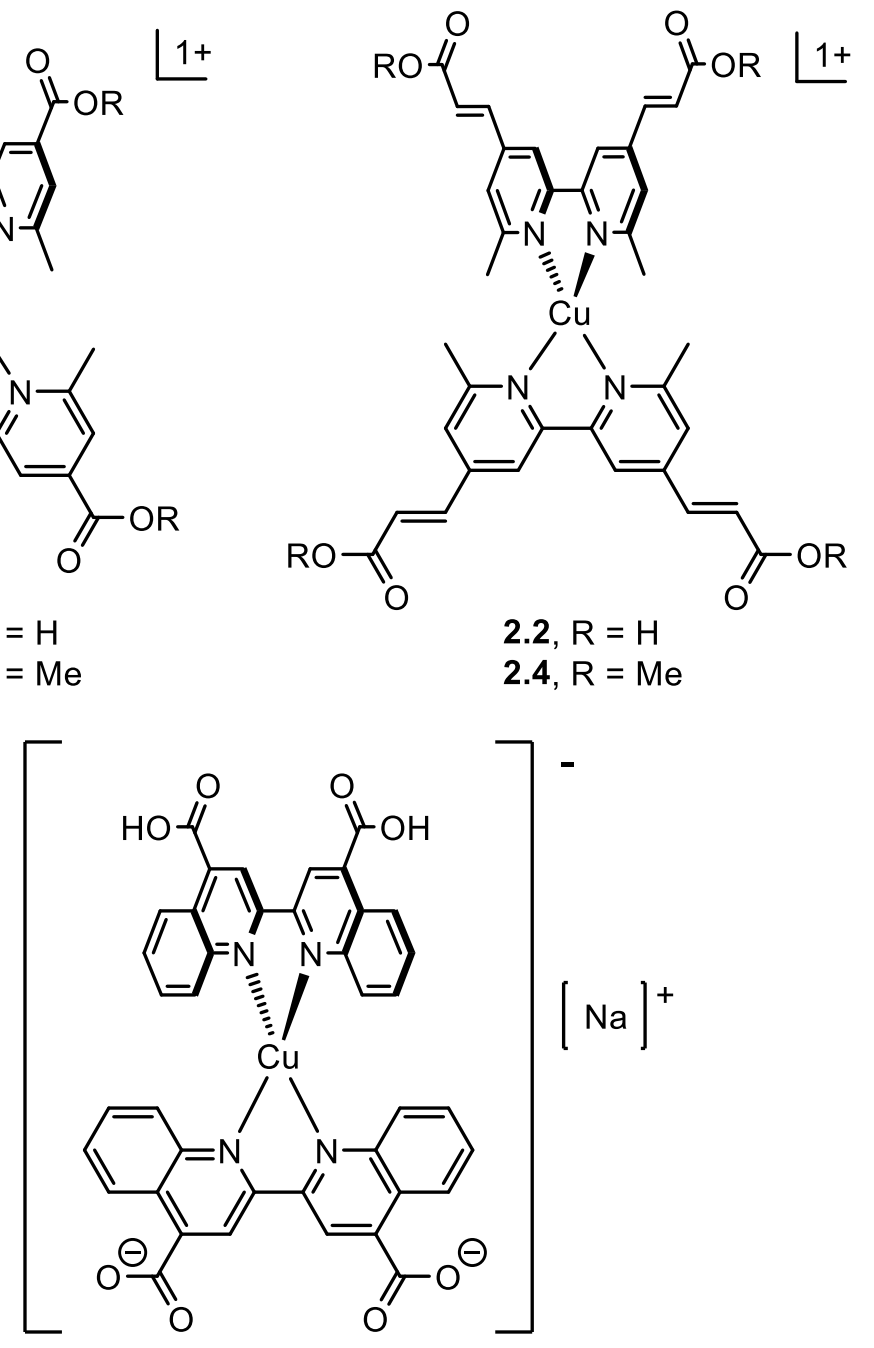

2.5

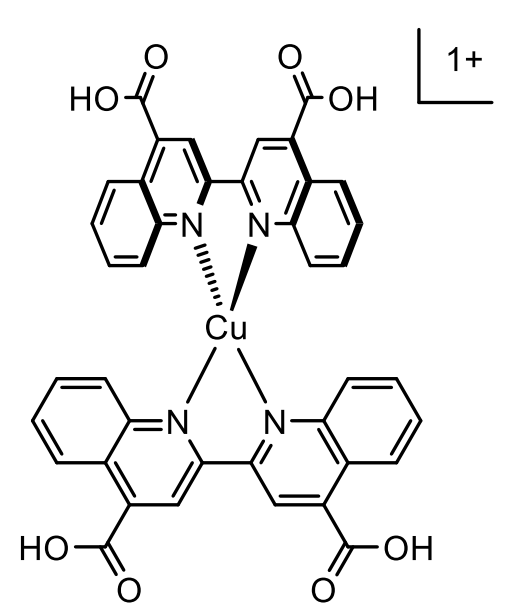

2.6

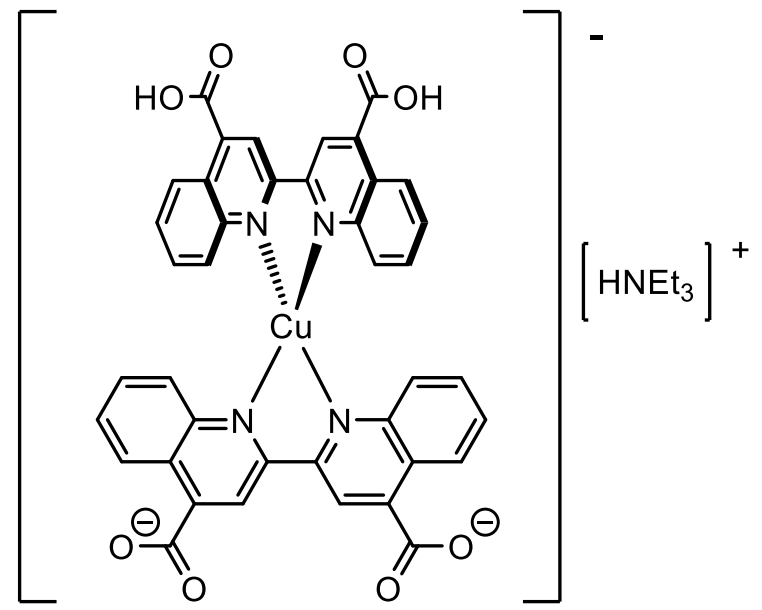

2.7 


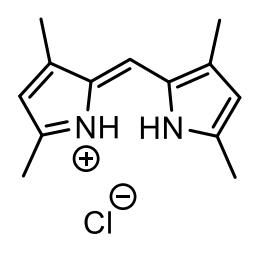

2.8. $\mathrm{HCl}$

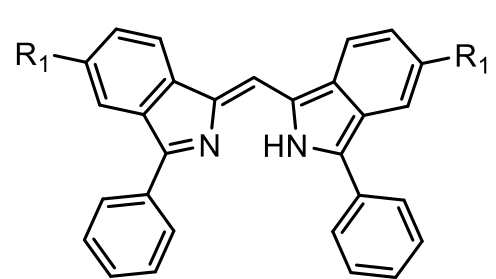

2.9, $\mathrm{R}_{1}=\mathrm{H}$

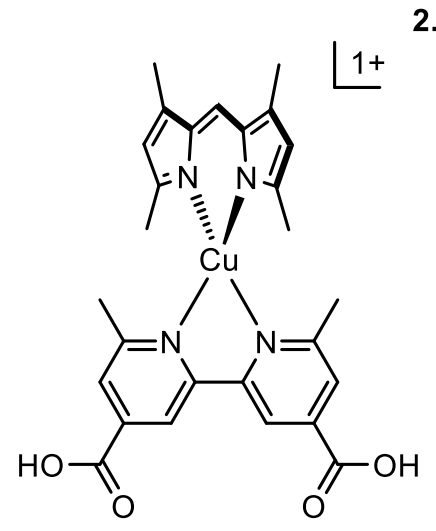

2.16

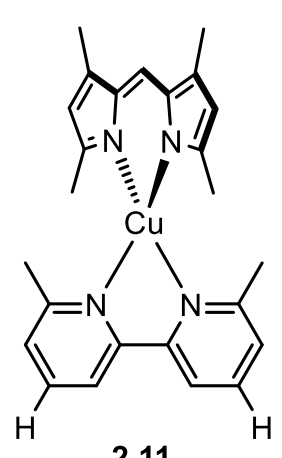

2.11

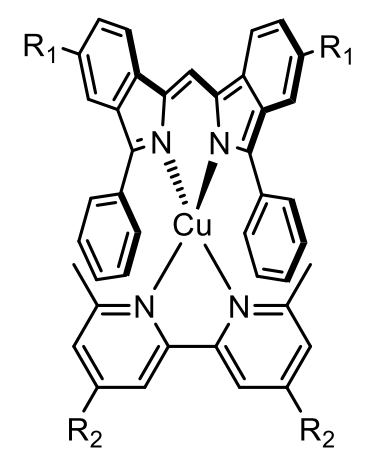

2.12, $\mathrm{R}_{1}=\mathrm{H}, \mathrm{R}_{2}=\mathrm{CH}_{3}$

2.13, $\mathrm{R}_{1}=\mathrm{H}, \mathrm{R}_{2}=\mathrm{CO}_{2} \mathrm{Et}$

2.14, $\mathrm{R}_{1}=\mathrm{CF}_{3}, \mathrm{R}_{2}=\mathrm{CH}_{3}$

2.15, $\mathrm{R}_{1}=\mathrm{CF}_{3}, \mathrm{R}_{2}=\mathrm{CO}_{2} \mathrm{Et}$

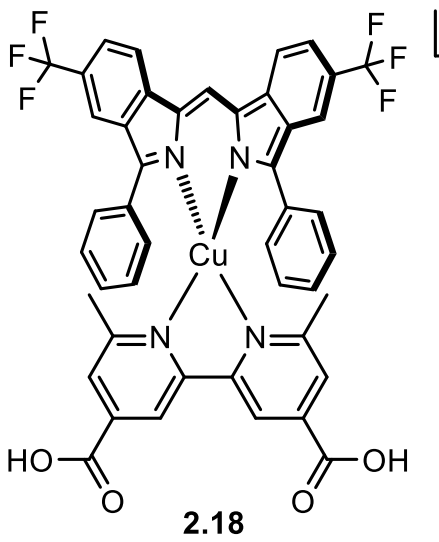

$1+$<smiles>C1CC[OH+]CC1</smiles>

O<smiles>CCC(=O)O</smiles>

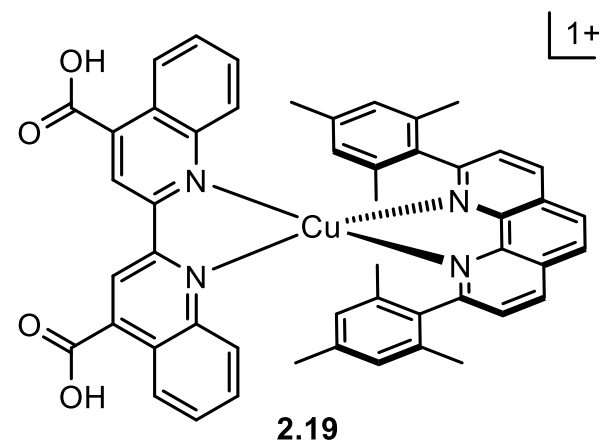

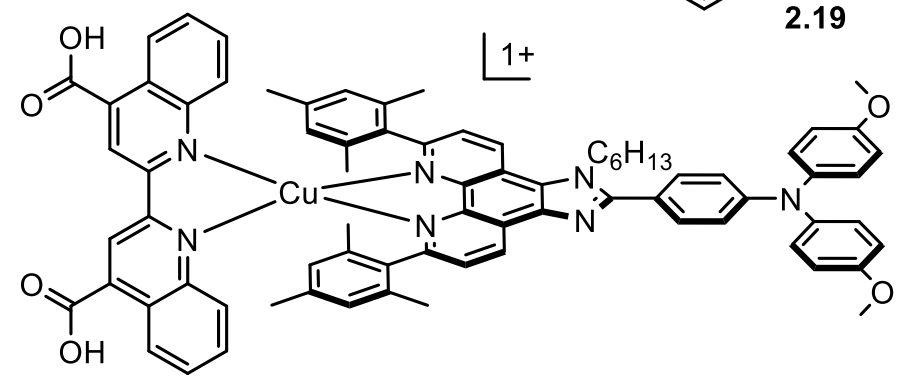

2.20 


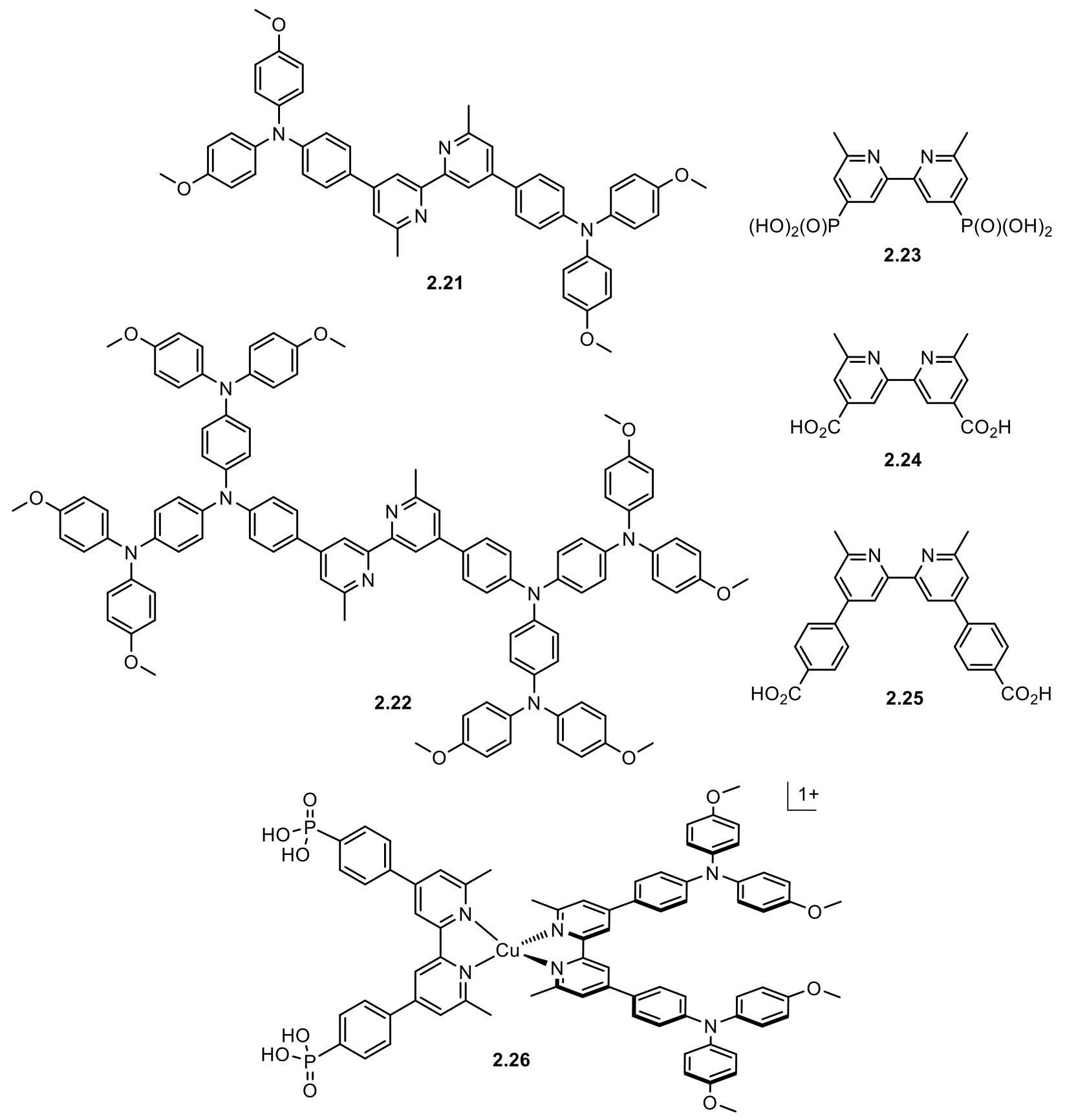




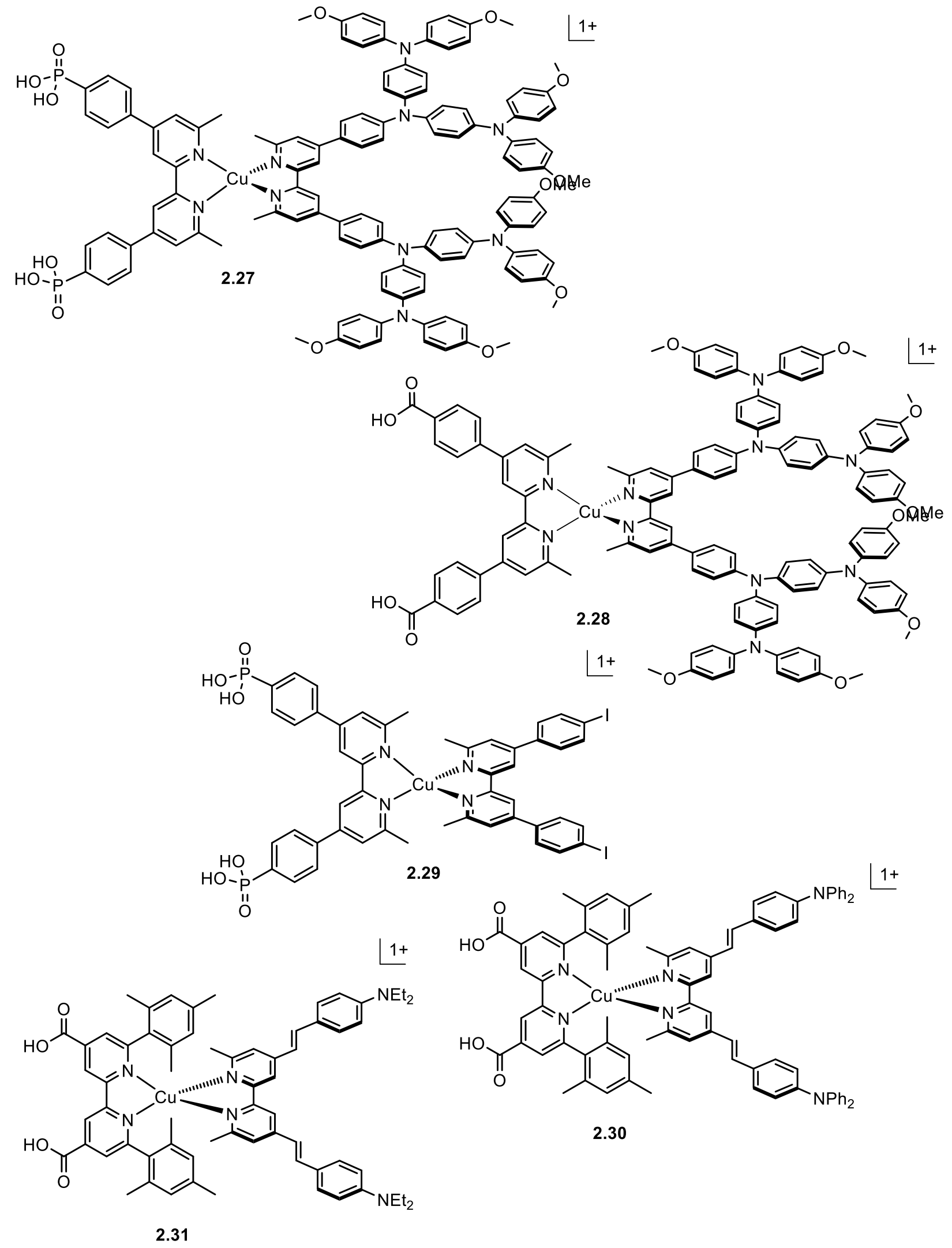




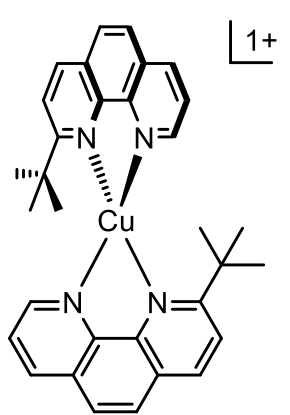

2.32

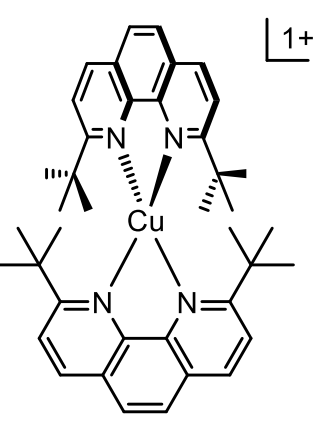

2.33

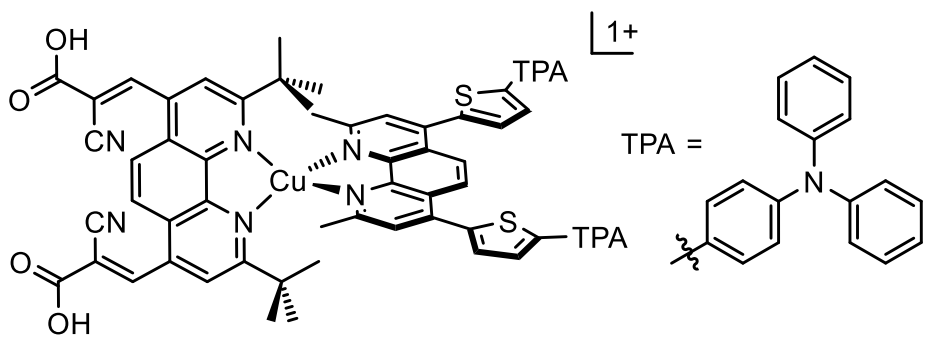

2.34

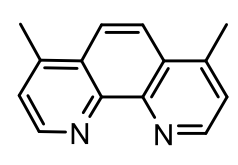

2.35
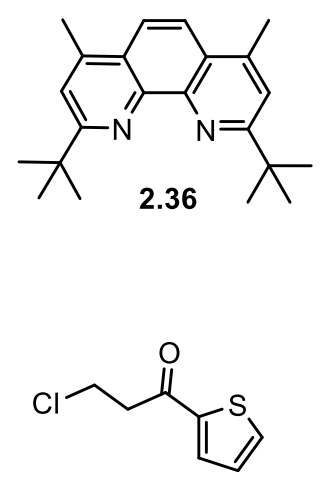
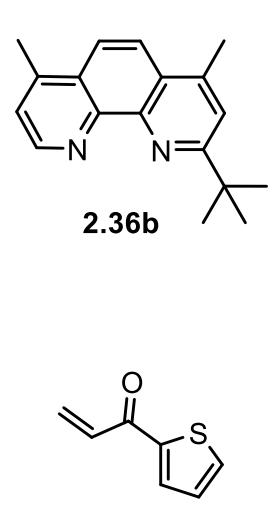

2.39
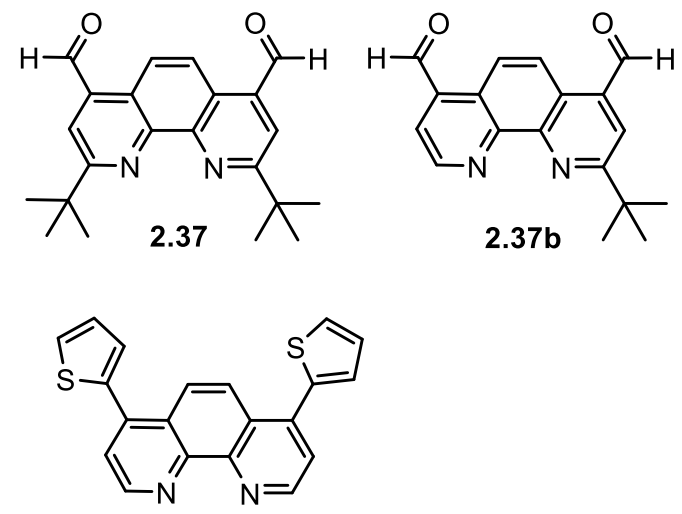

2.38 


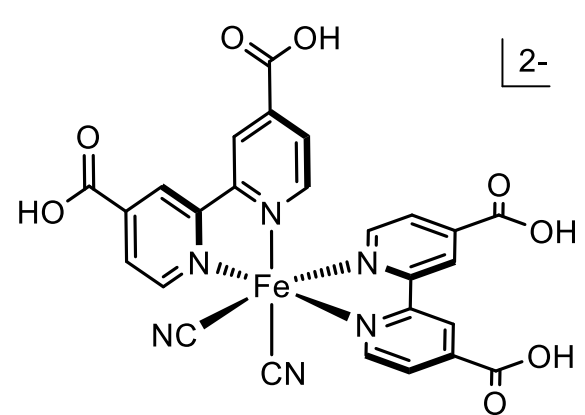

3.1

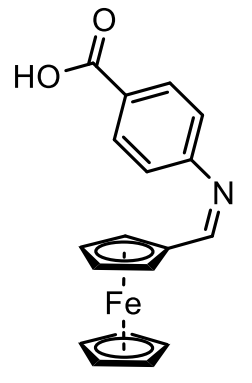

3.2

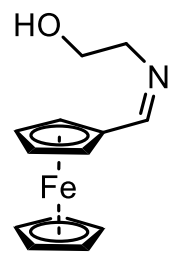

3.3

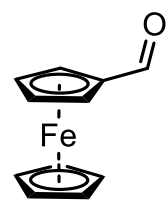

3.4

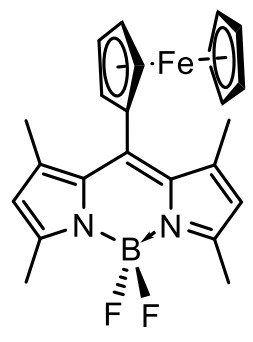

3.5

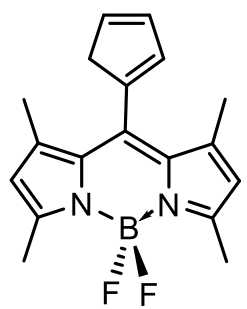

$3.6 a$

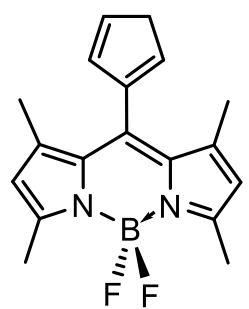

$3.6 \mathrm{~b}$

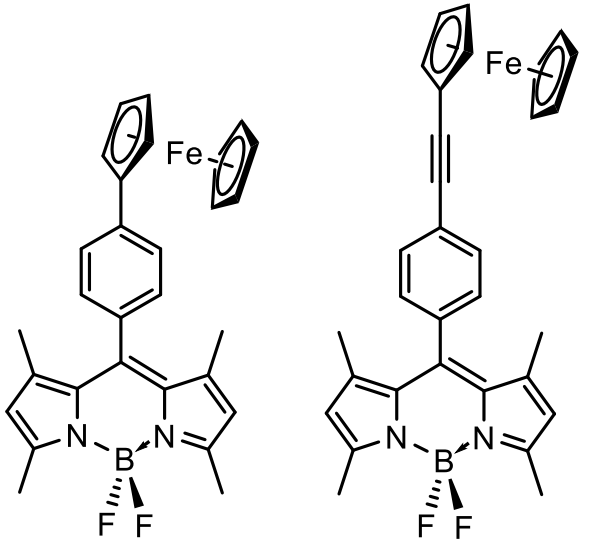

3.7

3.8

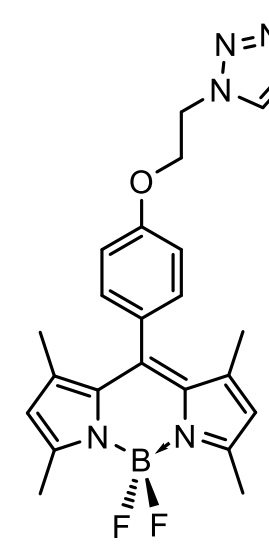

3.9

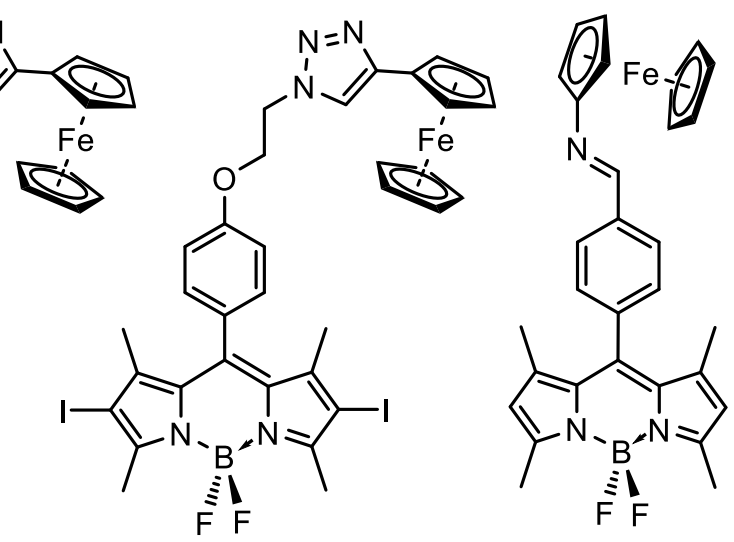

3.10

3.11<smiles></smiles>

3.12<smiles></smiles>

3.13

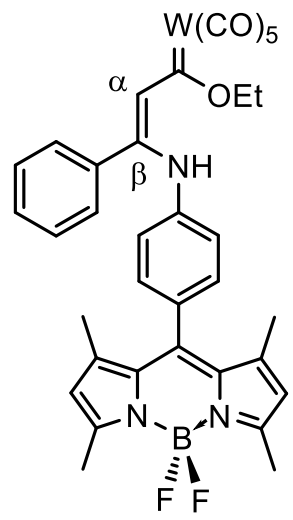

3.14

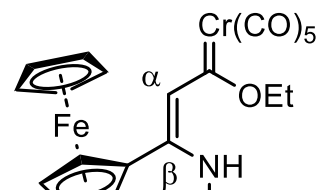<smiles>C=C([P])CNc1ccccc1</smiles><smiles></smiles>

3.15

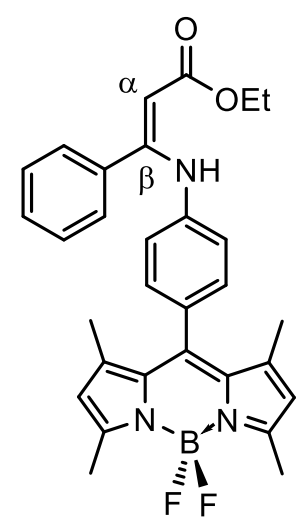

3.16 


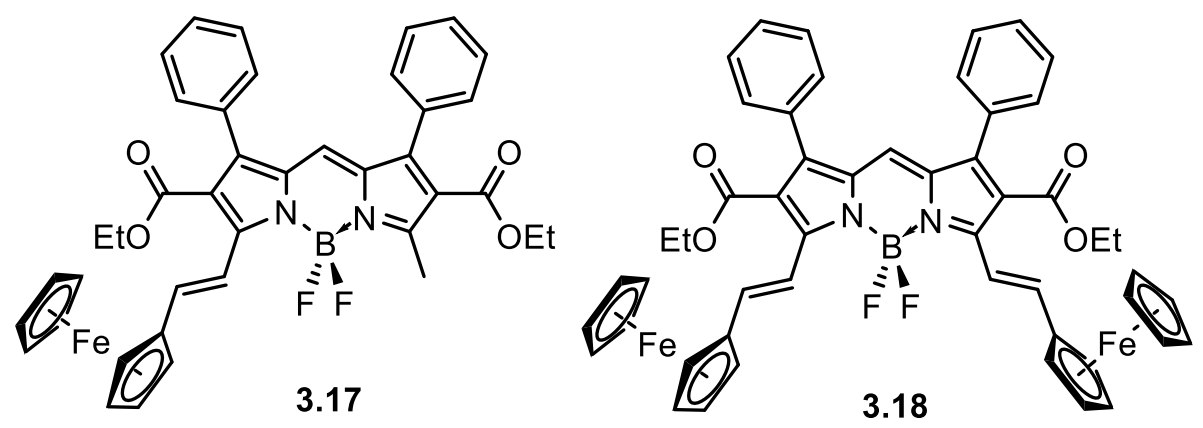

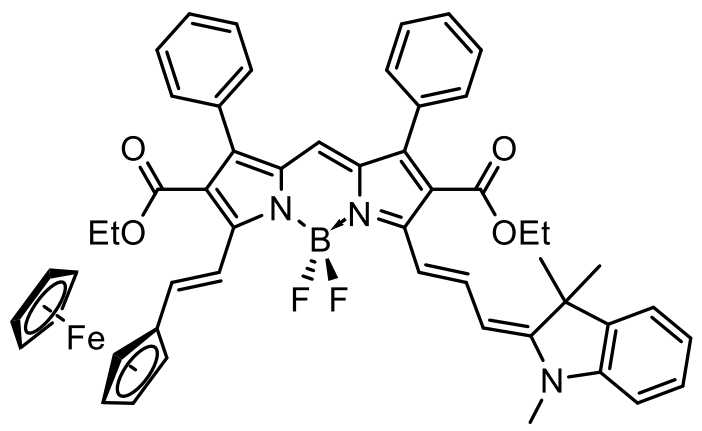

3.19

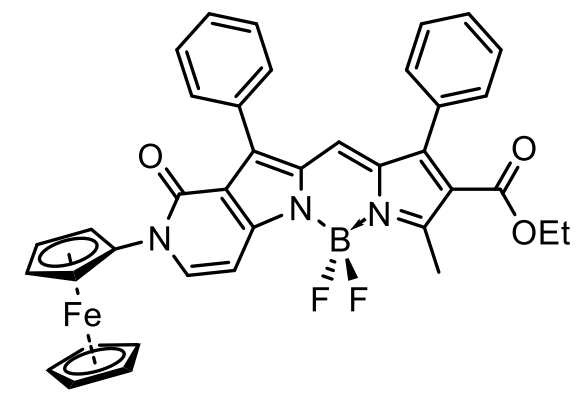

3.21

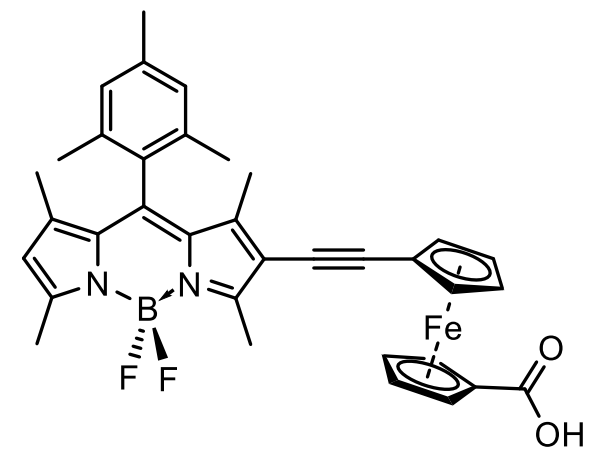

3.23

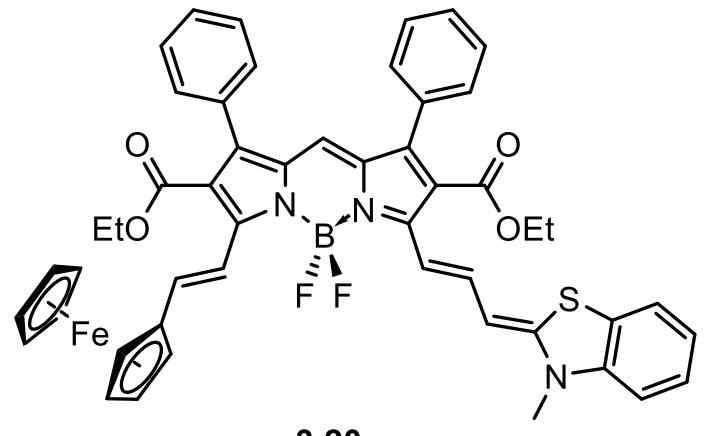

3.20

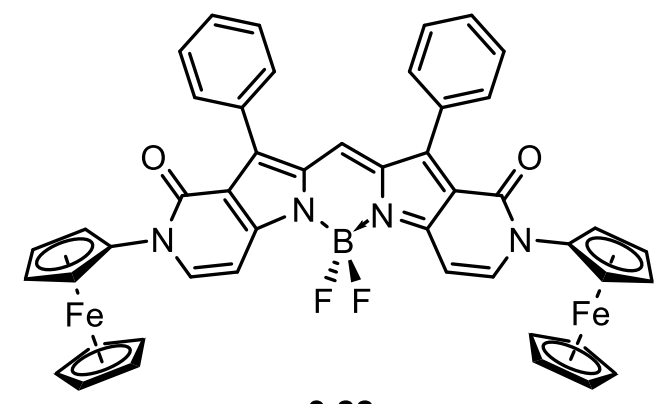

3.22

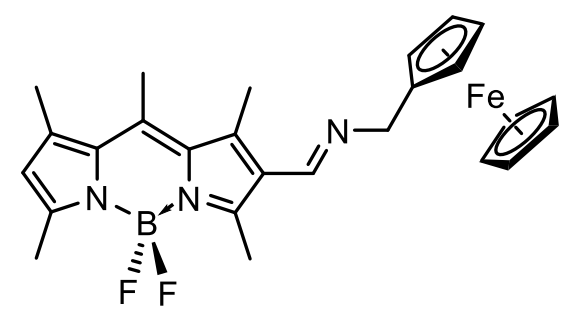

3.24 

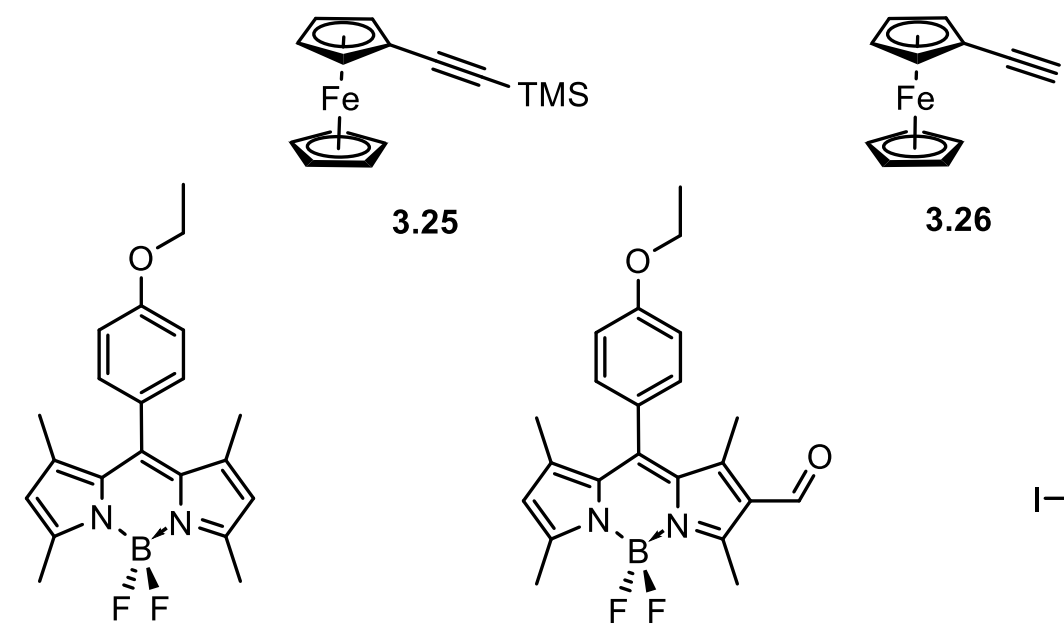

3.25

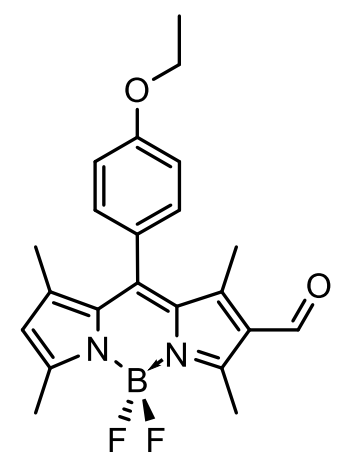

3.26

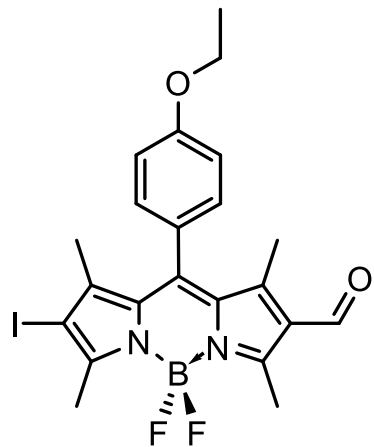

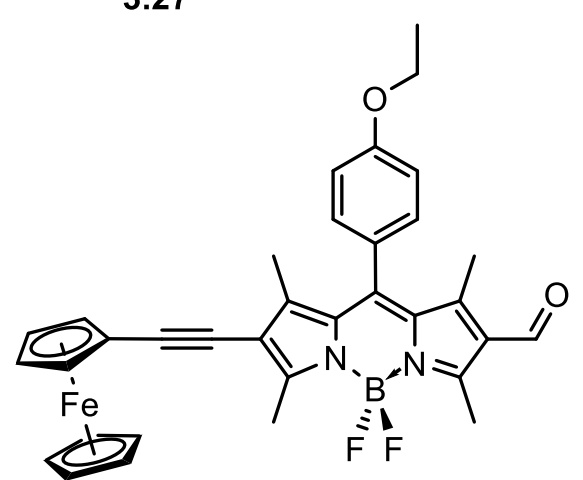

3.30

3.28

3.29

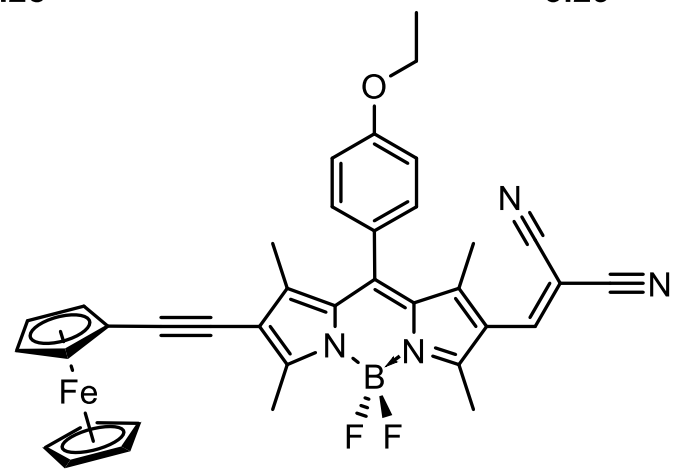

3.31 

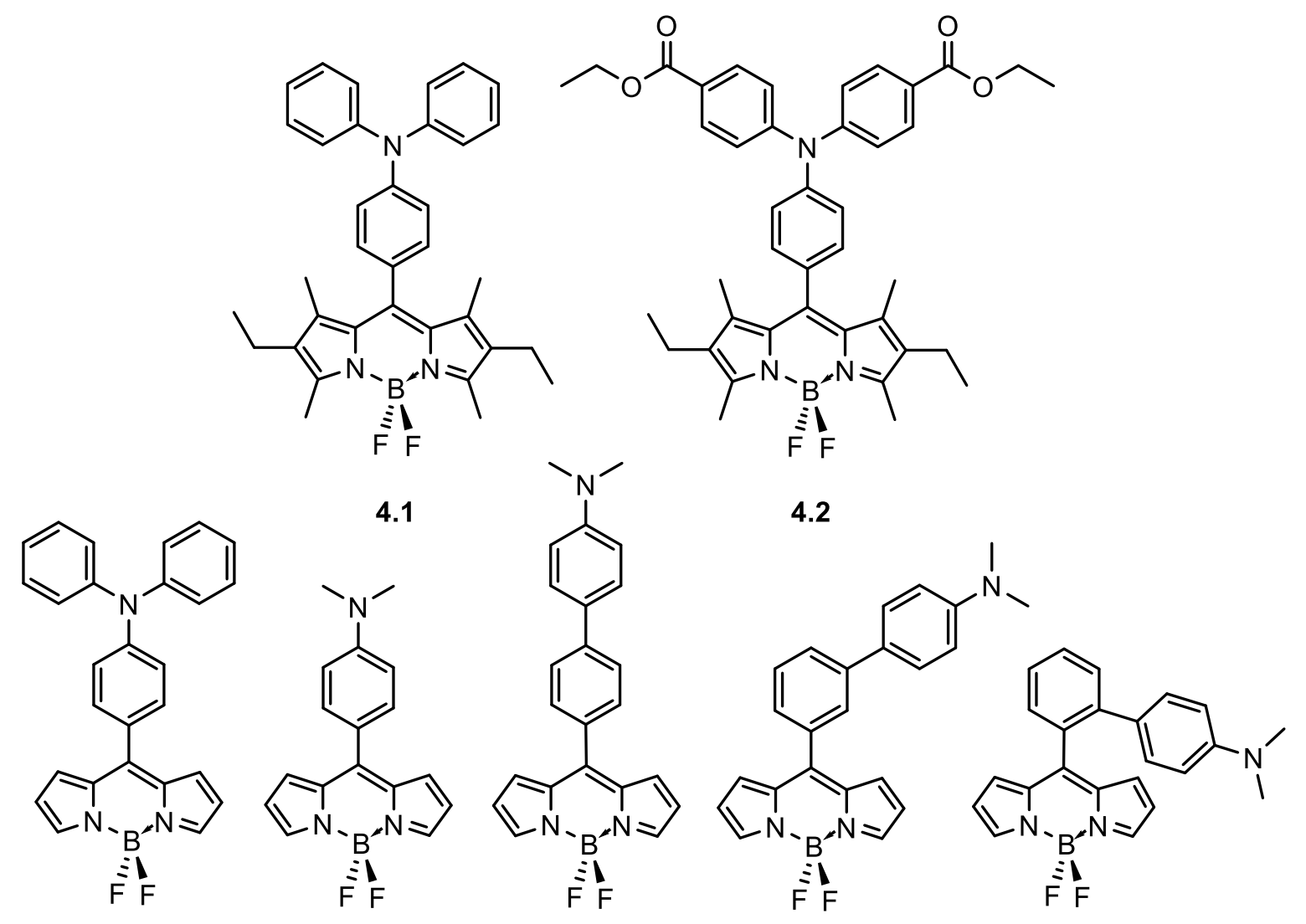

4.3

4.4

4.5

4.6

4.7
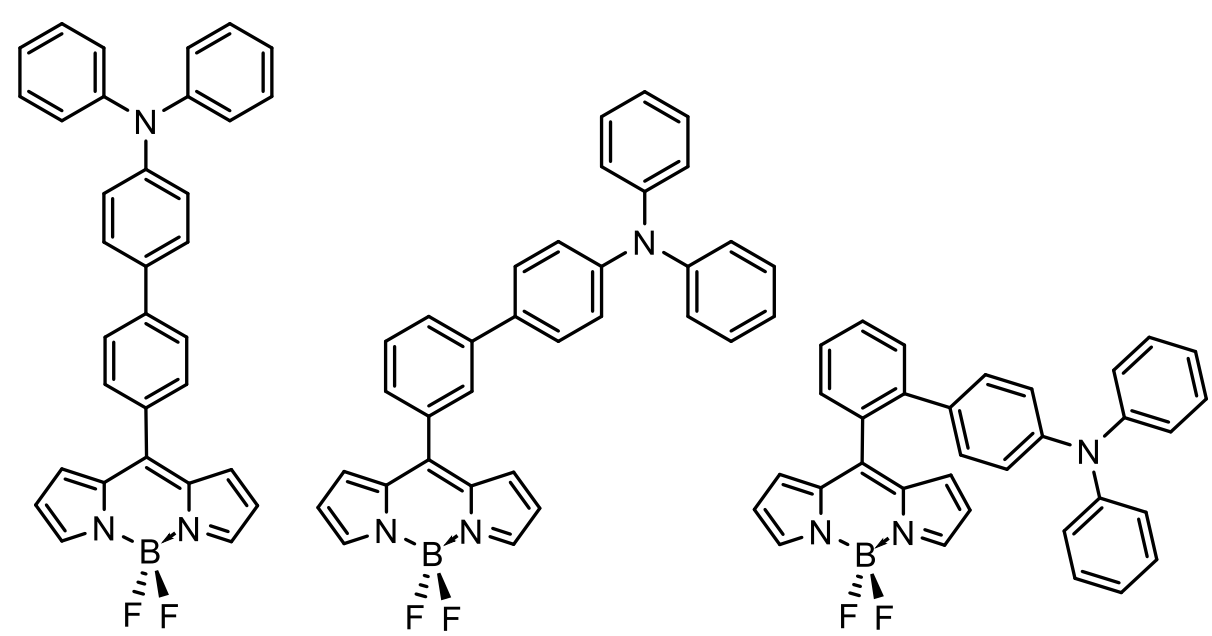

4.8

4.9

4.10 


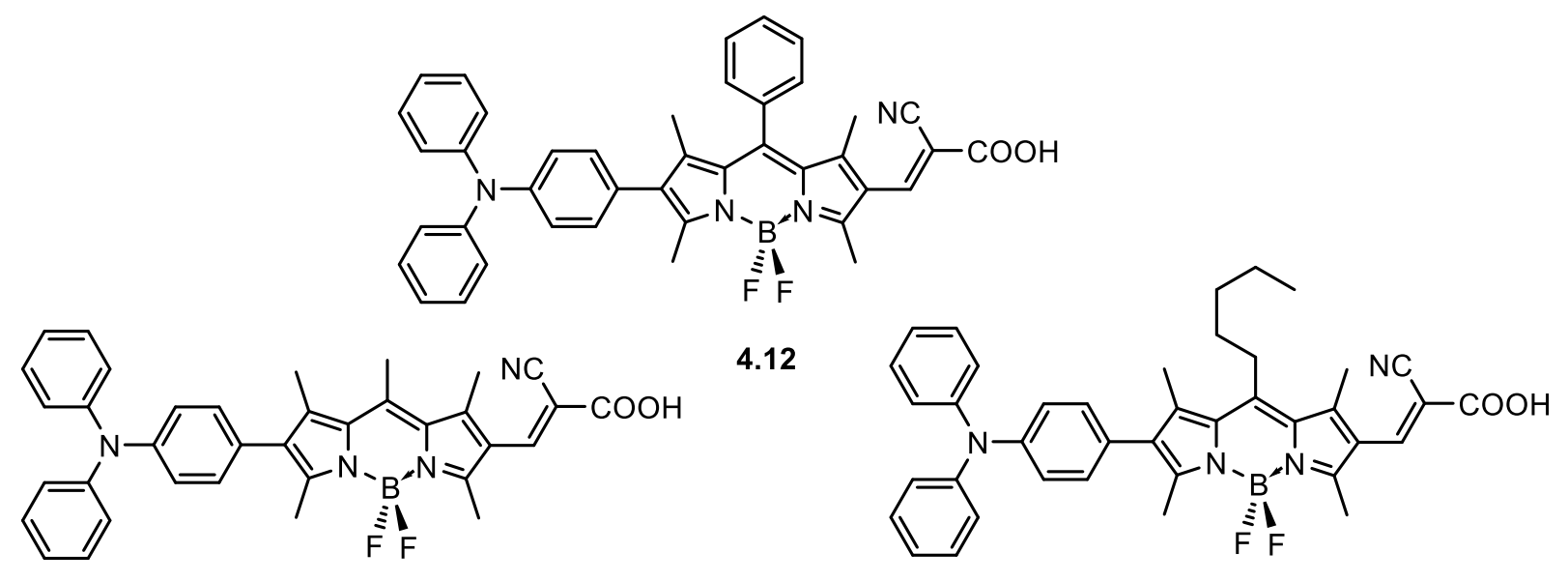

4.11

4.13<smiles></smiles><smiles>[R6]Oc1ccc(N(c2ccc([R20])cc2)c2ccc(-c3c(C)c(C)c4n3B(F)n3c(C)c(/C=C(\C)C(=O)O)c(C)c3C4C)cc2)cc1</smiles>

$$
\begin{array}{ll}
4.14 & \mathrm{R}=\mathrm{CH}_{3} \\
4.15 & \mathrm{R}=\mathrm{C}_{6} \mathrm{H}_{13}
\end{array}
$$

4.16 $\mathrm{R}=\mathrm{CH}_{3}$

4.17 $\mathrm{R}=\mathrm{C}_{6} \mathrm{H}_{13}$<smiles>[R]Oc1ccc(N(c2ccc(O[R2])cc2)c2ccc(-c3ccc(-c4c(C)c5n(c4C)[B-](F)(F)n4c(C)c(-c6ccc(C=C(C#N)C(=O)O)s6)c(C)c4C5=C)s3)cc2)cc1</smiles><smiles></smiles>

4.20<smiles></smiles>

4.21<smiles></smiles>

4.22

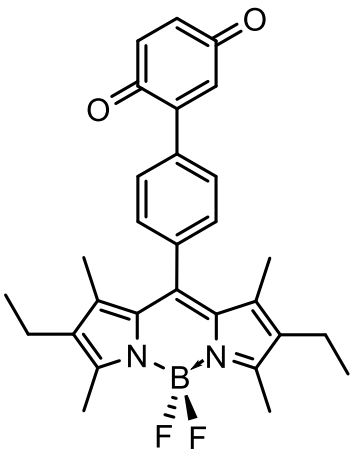

4.23 


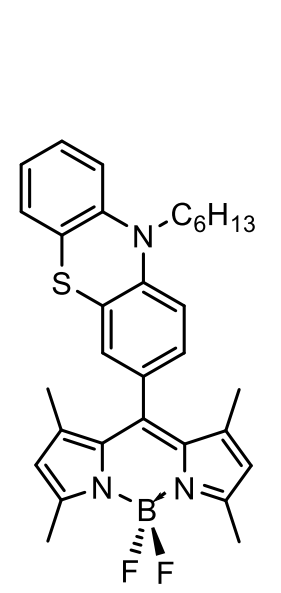

4.24

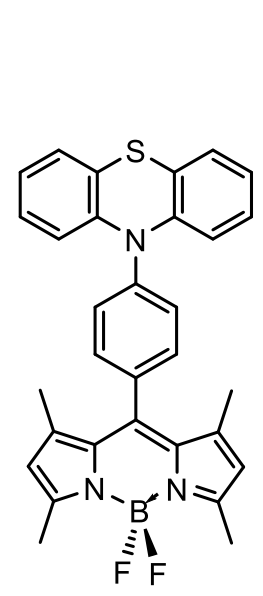

4.25

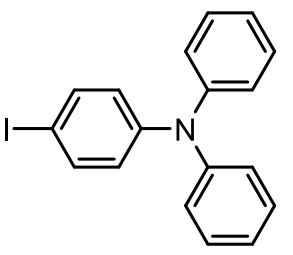

$4.30 \mathrm{a}$

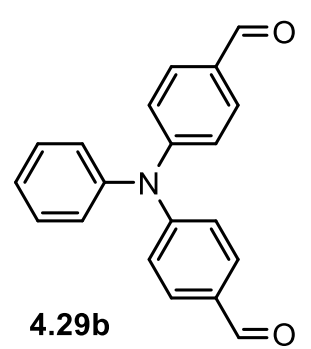<smiles>COc1ccc(N(c2ccccc2)c2ccc(OC)cc2)cc1</smiles><smiles>c1ccc(N(c2ccccc2)c2ccccc2)cc1</smiles>

4.29a
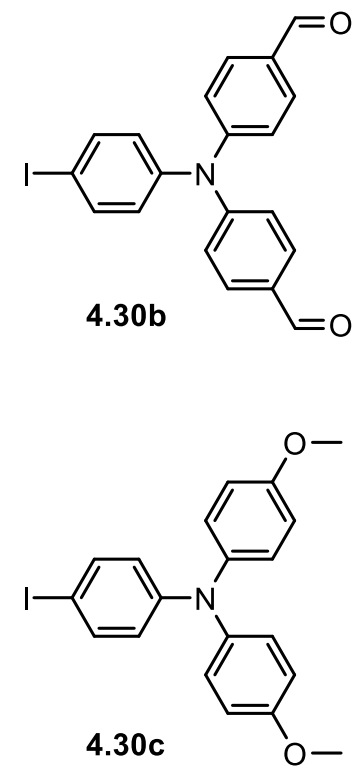

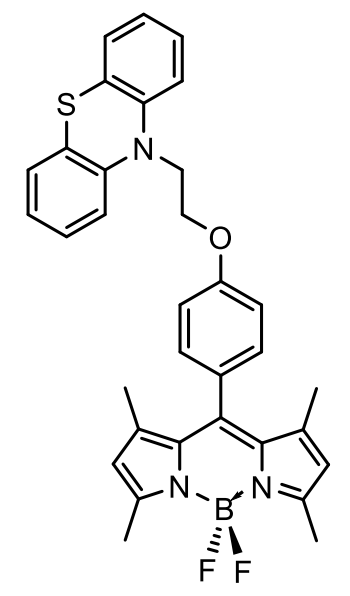

4.26

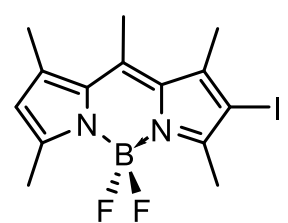

4.27

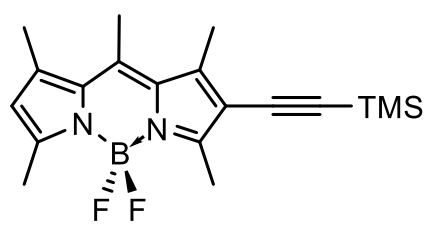

4.28<smiles>CSC#Cc1ccc(N(c2ccccc2)c2ccccc2)cc1</smiles>

4.31a
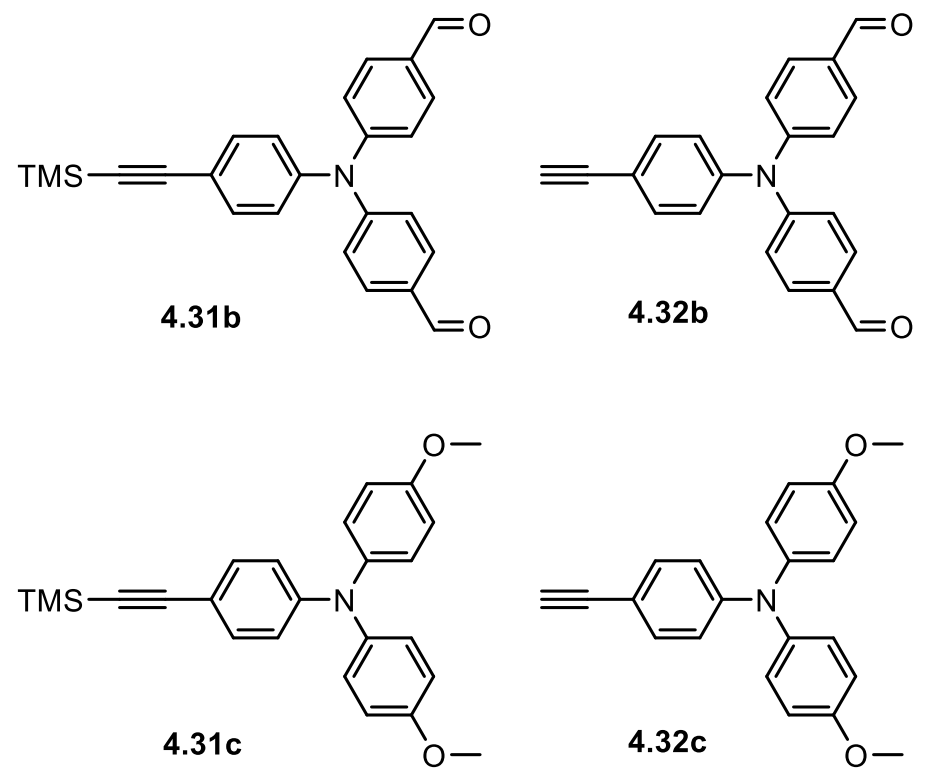


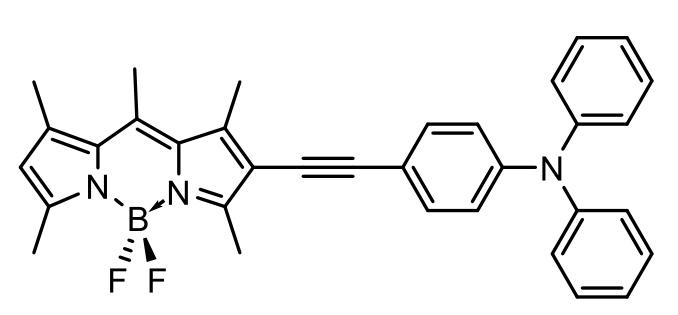

4.33a

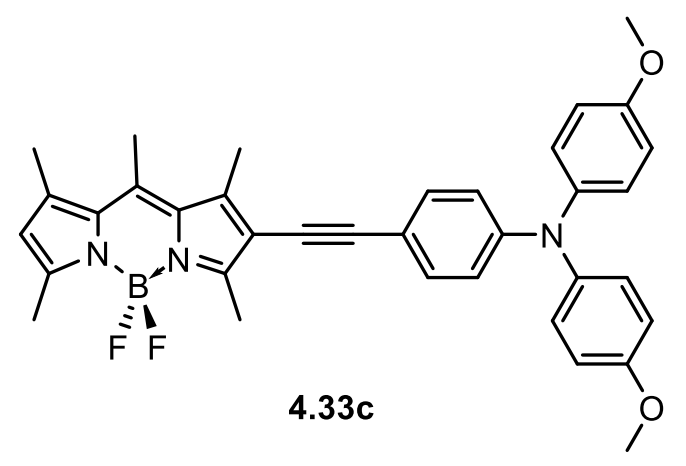

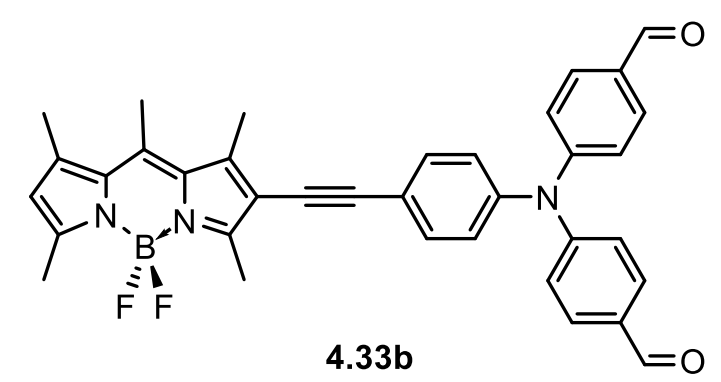

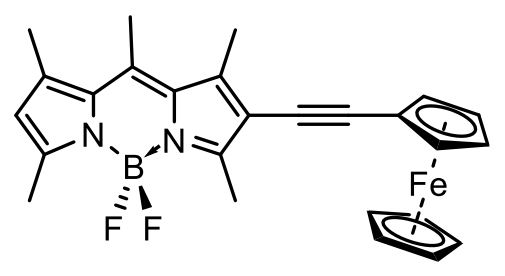

4.34 


\section{CHAPTER 1 - INTRODUCTION}

\subsection{Clean energy as the modern currency}

The fossil fuels in use today, including; oil, natural gas and coal have enough known reserves to supply our energy demand for almost 2000 years. ${ }^{1}$ The main concern is not the scarcity of fossil fuels but the emission of carbon dioxide that is released from burning them. Humanity's utilization of fossil fuels has taken a toll on the earth, largely in the form of anthropogenic global warming. The impact to our environment in turn affects human life as well. It is estimated that our global energy consumption will grow as our world population grows to a predicted 28 TW by the year 2050. Thus, the mission to look for alternative, abundant and carbon-neutral energy is necessary to mitigate $\mathrm{CO}_{2}$ emissions. ${ }^{1,2}$ Fortunately, research towards renewable energy is constantly in pursuit. These advances span from wind, geothermal, solar, biomass, hydroelectric, to tidal with perhaps solar being the most abundant at over 120,000 TW graced upon the earth. ${ }^{1,3}$

\subsection{Plugging into the sun: the dye-sensitized solar cell (DSSC)}

Grätzel and associates were the first to propose and create a photoelectrochemical cell that could harvest sunlight to generate electricity that employs dye molecules as the powerhouse of the cell. ${ }^{4}$ This device is meant to be overall cost-effective compared to the widely commercialized/known silicon solar cell in perspective of the energy payback period. The emergence of the DSSC has opened up an enormous body of academic research towards designing and synthesizing novel chromophores and dyes. The DSSC has so far been commercialized by several industrial companies for small scale applications, but owing to the low efficiencies from current DSSC devices the need for new dyes that reduce the cost of manufacturing opens a breadth of research into improving efficiencies for large scale applications. ${ }^{5}$ 


\subsubsection{Anatomy and mode of operation of the DSSC}

The device comprises of dye molecules adsorbed onto titania nanoparticles sandwiched between two glass substrates connected through an external circuit (Figure 1.1). The glass substrates also serve as the cathode and anode electrode. ${ }^{3}$ The dye molecule undergoes a series of continuous redox reactions that cycle in order to regenerate the oxidation state of the compound. A detailed schematic representation of the DSSC with processes numbered is highlighted in Figure 1.2.

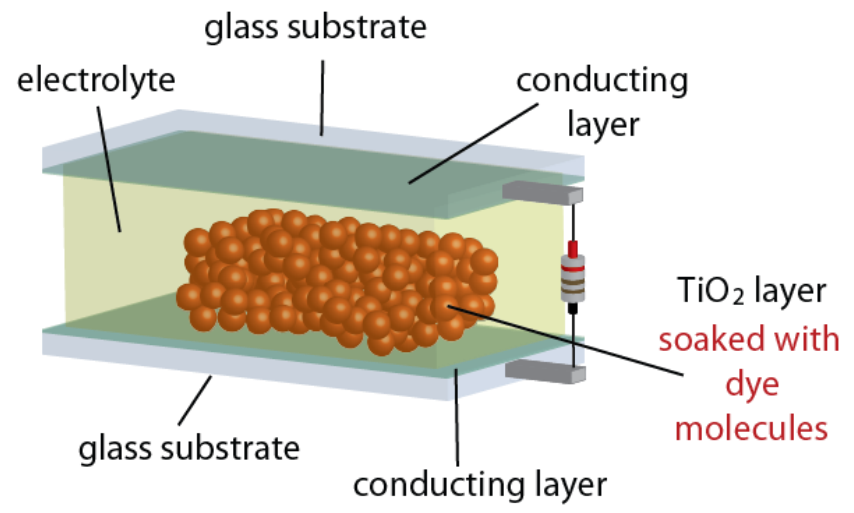

Figure 1.1. Schematic of the dye-sensitized solar cell (DSSC) 


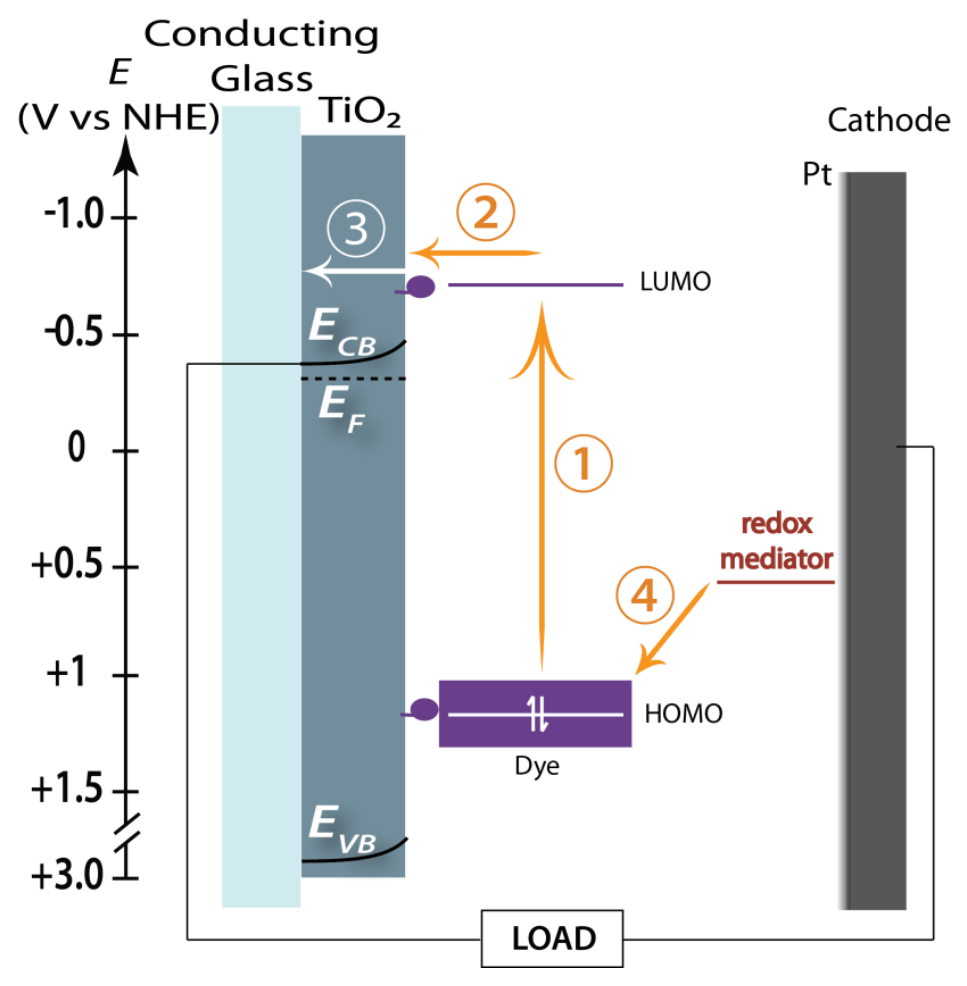

Figure 1.2. Diagram of the anatomy of the DSSC

The dye absorbs photon from a light source resulting in photo-excitation of the dye (1). The electrons from the excited dye percolates into a thin mesoporous semiconducting titania $\left(\mathrm{TiO}_{2}\right)$ film that is coated onto the conducting anode glass (2). The electrons then pass through the load and arrive to the platinized cathode (3). The electrolyte replenishes the electrons lost from the oxidized dye (4). Simultaneously, the electrolyte gets reduced by the electrons from the platinized cathode. ${ }^{4}$ The placement of the HOMO and LUMO energy level of the dye relative to the $\mathrm{TiO}_{2}$ semiconductor is deliberate. To allow for an energetically favourable process upon injection of the excited electron from the $\mathrm{LUMO}$ to $\mathrm{TiO}_{2}$, the energy level of the LUMO of the dye must exceed the energy level of the conduction band of $\mathrm{TiO}_{2}$. Likewise, the HOMO energy level should sit below the energy level of the redox mediator to ensure replenishment of the electrons back to the dye. ${ }^{3}$

The power conversion efficiency of a DSSC device can be measured from a current-voltage curve. The parameters that can be extracted are short circuit current $\left(J_{S C}\right)$, open circuit voltage 
$\left(V_{O C}\right)$ and fill factor $(F F)$. The $V_{O C}$ is the voltage when no current is applied to the device. The short circuit current $\left(J_{S C}\right)$ is the value when the cell voltage is at zero in amperes, this can be improved by broadening and shifting the absorbance into the NIR. The fill factor (FF) is representative of how square the current-voltage curve is. These values along with the incident power input $\left(P_{\text {in }}\right)$ from the light irradiated onto the device can be used in the equation below to generate the efficiency as a percentage. ${ }^{6}$

$$
\eta=\frac{J_{S C} V_{O C} F F}{P_{\text {in }}}
$$

The performance of a dye can also be determined by measuring the IPCE (incident photon-tocurrent conversion efficiency). The IPCE is the spectral response from irradiation of monochromatic light divided by the photon flux that hits the solar cell device. This value in percent can be calculated using the following equation where e is the elementary charge. ${ }^{6}$

$$
I P C E=\frac{J_{S C}(\lambda)}{e \phi(\lambda)}=1240 \frac{J_{S C}(\lambda)\left[\mathrm{Acm}^{-2}\right]}{\lambda[\mathrm{nm}] P_{\text {in }}(\lambda)\left[W \mathrm{~cm}^{-2}\right]}
$$

\subsubsection{Design features of the dye: the powerhouse of the DSSC}

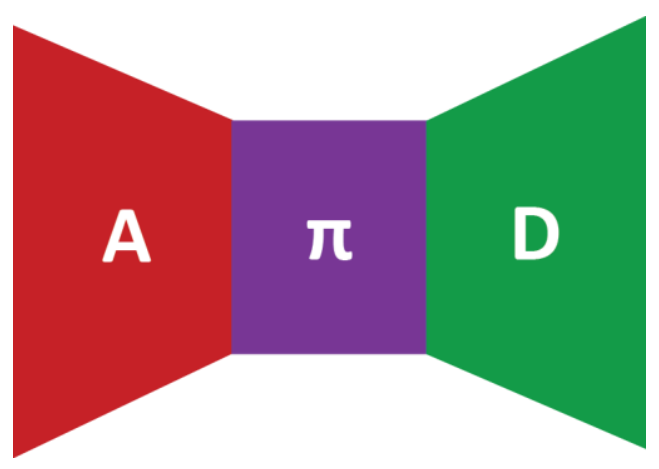

Figure 1.3. Donor- $\pi$-spacer-acceptor motif of a dye

Typical dye design involves a push-pull system, and possesses a donor- $\pi$-spacer-acceptor motif

(Figure 1.3). ${ }^{7}$ This system allows for directionality from one end of the molecule (donor-D) to 
the other end (acceptor-A) and enhancing the lifetime of the charge separated state. The acceptor is usually composed of acidic groups that can chemically bind to $\mathrm{TiO}_{2} \cdot{ }^{3}$ Carboxylic acid groups are also ideal because they also act as electron withdrawing groups that can pull electrons from the donor part of the chromophore to the $\mathrm{TiO}_{2}$ in order to enter the conduction band of the DSSC (improves the charge injection/ improves photo-cross section to prevent recombination of the dye). The donor with its heavy electron density is meant to be electron rich and redox active capable of sustaining a photo-oxidized charge. The $\pi$-spacer establishes a charge-separation between the acceptor and donor units and also extends conjugation. ${ }^{7}$ Ideally the DSSC would be able to provide the world with a cost-effective device that can harvest solar energy and convert that into electricity. The challenges facing the DSSC involves broadening the absorption to achieve panchromatic absorption of the visible spectrum of light, long term stability and attain high efficiency. ${ }^{6}$ The aim is to build a robust device that can triumph in these three categories.

\subsection{Inorganic Dyes}

Due to the robust redox active nature of many transition metals, inorganic complexes have received significant attention in the design of DSSC dyes. For the choices of the metal, they must have the ability to undergo a reversible one electron process. Some metals that are able to do this are copper, ruthenium, iridium, and iron..$^{8,9}$

\subsubsection{First dyes in DSSC application: Ruthenium complexes}

Historically, ruthenium-based dyes have been most studied in the literature and a component of the first inorganic chromophores to reach champion ( $>10 \%$ efficiency) status for a dye. The ruthenium-based dyes have since gone onto commercial applications. The advantages are that they have a broad absorption of the visible spectrum, long-lived excited states and long term redox stability. ${ }^{9}$ 


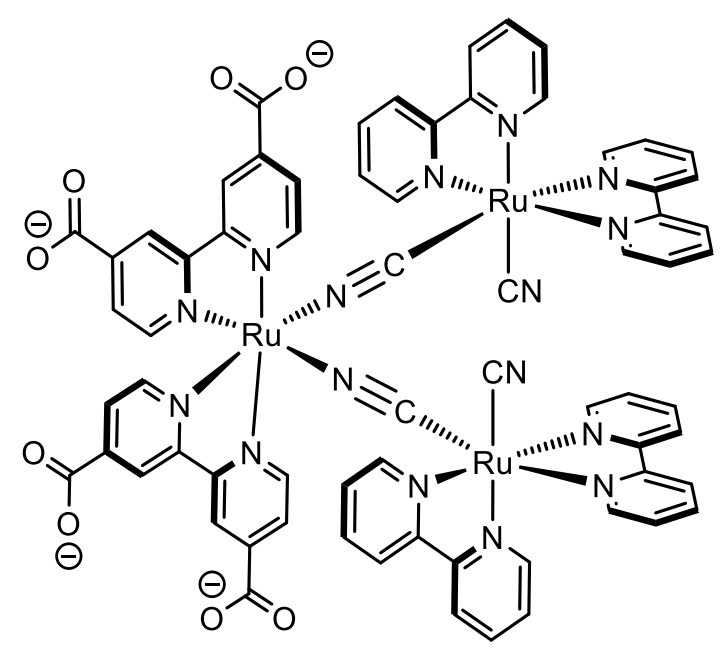

1.1

Figure 1.4. Trimeric ruthenium complex

The first paper on the DSSC in 1991 employed a trinuclear ruthenium complex as the sensitizer (Figure 1.4)..$^{4,10}$ Prior to this paper, studies were done on ruthenium complexes for use as possible light harvesters. One study that led to compound $\mathbf{1 . 1}$ aimed at improving the light adsorption from the dye by adding an antenna. In context to the study, an antenna is a molecule that has a strong affinity for absorbing sunlight and can transfer that energy towards the sensitizer. The cyano-bridge ruthenium complexes with the bipyridine ligands are the antenna, while the ruthenium complex with carboxylate ligands is the sensitizer. Comparing the photocurrent spectra of the trinuclear complex to a mononuclear complex showed that there was presence of two strong absorption bands versus one weaker absorption band, respectively. The second absorption band indicates that the antenna substituent does absorb more light and the strong intensity of the bands mean there is electron transfer to the sensitizer. ${ }^{10}$ With this antenna-sensitizer, the first DSSC achieved an efficiency of $7.90 \% .{ }^{4}$ 


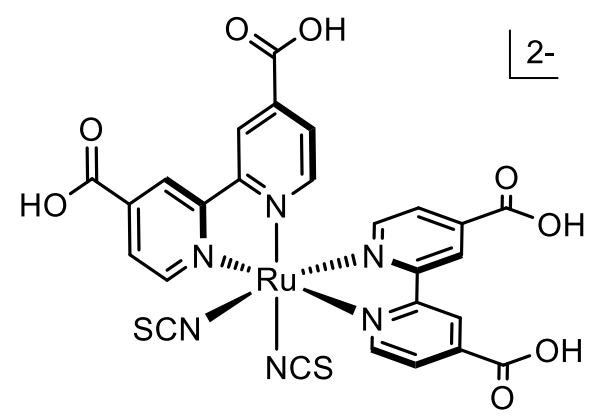

1.2

Figure 1.5. N3 dye

However, the first champion dye N3 (Figure 1.5) achieved efficiency of $10.3 \%$ as a mononuclear species. The drastic difference in structure to compound $\mathbf{1 . 1}$ was the replacement of the ruthenium-bypyridine complexes with thiocyanato groups. ${ }^{11}$ From then on, the research direction on mononuclear ruthenium complexes continued.

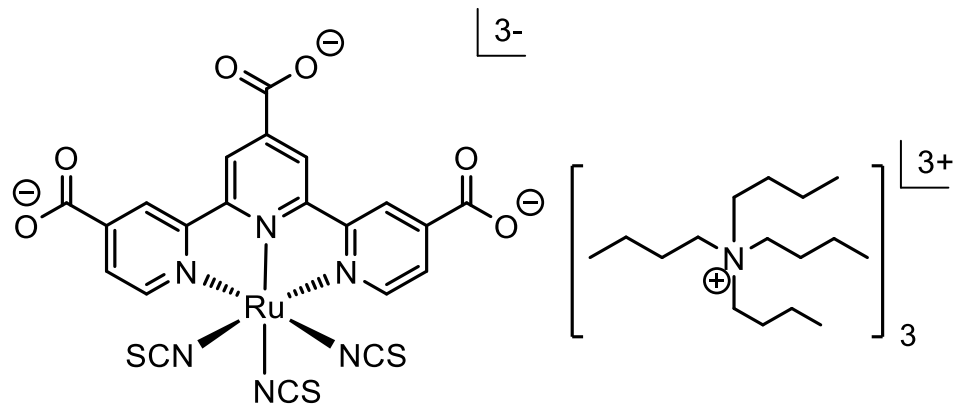

1.3

Figure 1.6. N749, the Black dye

The first of its kind to have panchromatic properties was the Black dye, N749 (Figure 1.7). Structurally, this dye contains a terpyridyl ligand with carboxylate groups and three thiocyanate groups. This dye displays improved absorption in the near-IR region which resulted in two-fold 
of the short circuit voltage, $\mathrm{J}_{\mathrm{Sc}}$, compared to $\mathbf{N} 3$ (Table 1.1), which could be attributed to the pyridine groups. $^{12}$

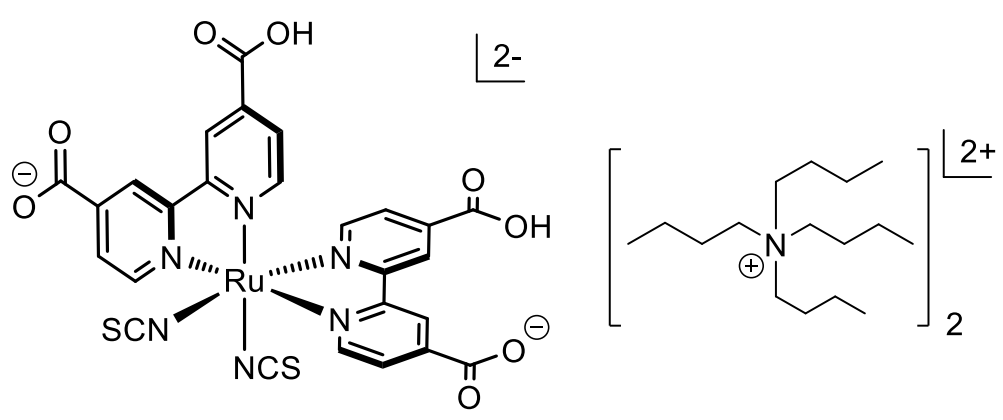

1.4

Figure 1.7. Champion dye, N719 ${ }^{13}$

The first ruthenium dye to reach $11 \%$ conversion was N719, this dye resembles N3 with some subtle differences such as the addition of two tetrabutylammonium ions and a carboxylate anion on each of the pyridine ligands. Since then, variations of this dye have been presented and several have achieved efficiencies exceeding the $\mathbf{N 7 1 9}$ champion dye (Figure 1.8). Table 1.1 shows device data of high efficiency ruthenium(II) dyes in the literature. The drawback to ruthenium dyes is their expense due to low abundancy of ruthenium and their inability to absorb at longer wavelengths (NIR). ${ }^{14}$ Subsequent to the inorganic dyes, research in organic dyes have proven to be worthy alternatives. 


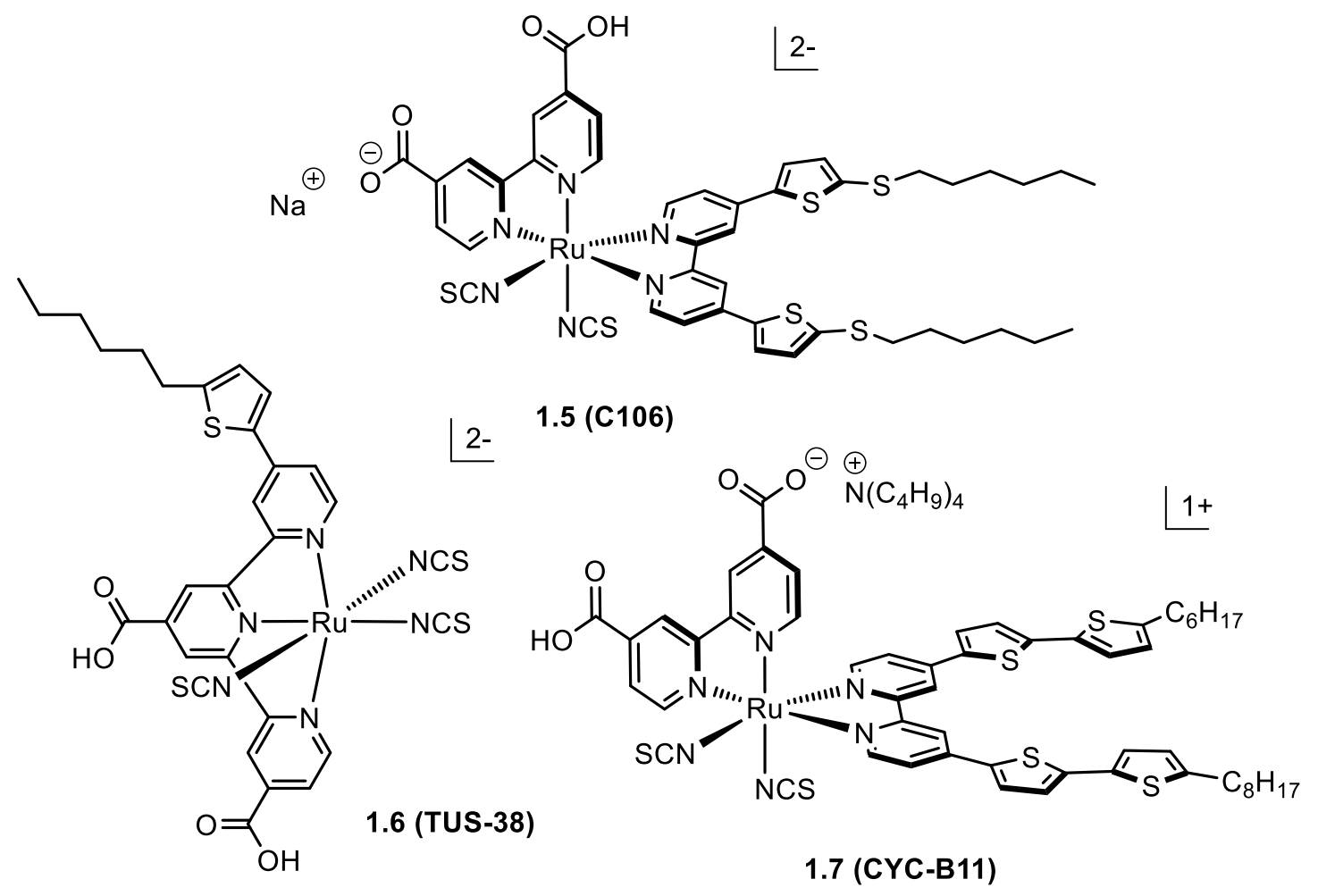

Figure 1.8. Ruthenium dyes that reached champion status in recent years

Table 1.1. Selected ruthenium dyes with high efficiencies

\begin{tabular}{llllll}
\hline Ru dye & $\boldsymbol{V}_{\text {oc }}(\mathrm{mV})$ & $\boldsymbol{J}_{\text {sc }}\left(\mathrm{mA} \mathrm{cm} \mathbf{c m}^{-\mathbf{2}}\right)$ & FF & $\boldsymbol{\eta}(\%)$ & year \\
\hline $\mathbf{1 . 1}^{4}$ & - & - & 0.76 & 7.9 & 1991 \\
$\mathbf{1 . 2}$ (N3) $^{11}$ & 670 & 11.50 & 0.74 & 10.3 & 1993 \\
$\mathbf{1 . 3}$ (N749) $^{12}$ & 720 & 20.50 & 0.70 & 10.4 & 2001 \\
$\mathbf{1 . 4}$ (N719) $^{15}$ & 840 & 17.73 & 0.74 & 11.2 & 2005 \\
$\mathbf{1 . 7}$ (CYC-B11) $^{16,17}$ & 743 & 20.05 & 0.77 & 11.5 & 2009 \\
$\mathbf{1 . 5}$ (C106) $^{18}$ & 740 & 10.63 & 0.81 & 12.0 & 2010 \\
$\mathbf{1 . 6}$ (TUS-38) $^{19}$ & 702 & 23.43 & 0.72 & 11.9 & 2016
\end{tabular}




\subsection{Organic Dyes}

Organic molecules with conjugated $\pi$-systems have gained momentum due to their low cost compared to their inorganic counterparts, ease of synthetic modifications and the advantage of $\pi-\pi^{*}$ electronic transitions that can shift absorption to longer wavelengths. ${ }^{3}$ This section will highlight three notable organic compounds that have established research efforts towards the synthesis and study of their derivatives.

\subsubsection{Triphenylamine-containing dyes}

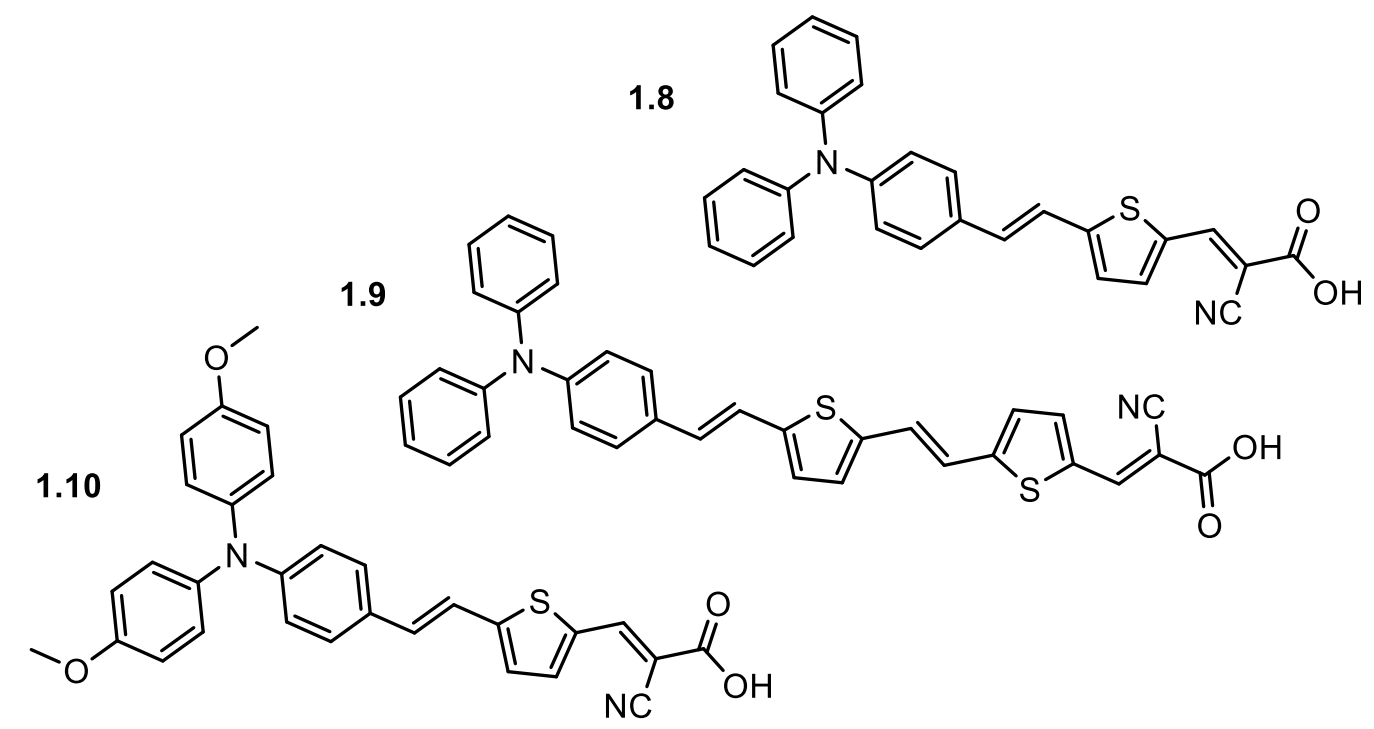

Figure 1.9. $D-\pi-A$ dyes containing triphenylamine as the chromophore $e^{20,21}$

Hagberg et al. synthesized organic dyes containing triphenylamine with varying thiophene vinyl linkages as the $\pi$-spacer (Figure 1.9). ${ }^{20}$ What was learned from the study was that an extended linker did not correlate to better efficiency. ${ }^{20}$ A year later, Hagberg et al. modified the TPA unit of dye 1.8 to form 1.10. The addition of methoxy substituents on TPA more than doubled the efficiency (Table 1.2). ${ }^{21}$ These set of dyes led a multitude of research focussing on organic chromophores as candidates for the DSSC. 


\subsubsection{Zinc porphyrin dyes}

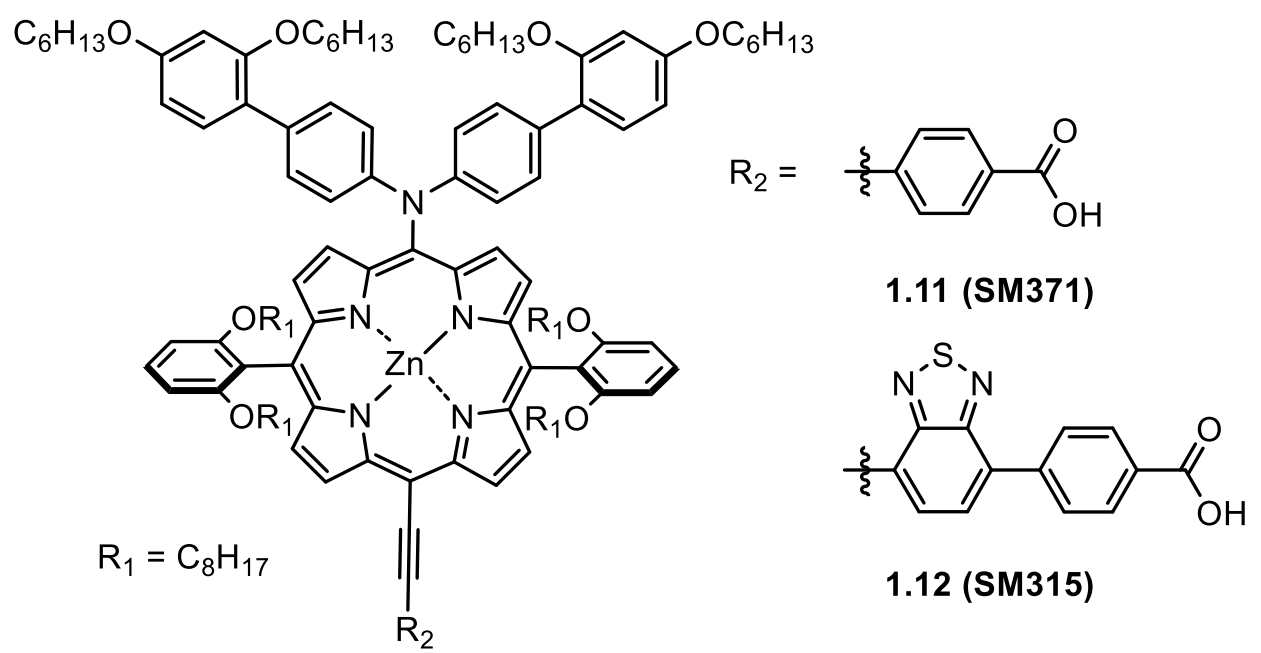

Figure 1.10. Zinc porphyrin champion dyes ${ }^{22}$

Structurally similar to chlorophyll, the porphyrin ring possesses light harvesting properties that appeal as dyes for the DSSC. ${ }^{23}$ Zinc porphyrins in particular have dominated the DSSC realm owing to their rigid skeletal backbone, strong absorption and ease of tuning the electronic properties through structural modification. ${ }^{24}$ The research group led by Dr. Grätzel produced two champion zinc porphyrin dyes that employ the D- $\pi-A$ motif. Porphyrin 1.12 (SM315) surpasses 1.11 (SM371) as the winner with the addition of a benzothiadiazole next to the carboxylic acid anchoring unit (13.0\% vs. 12.0\%, Table 1.2). Porphyrin 1.12 (SM315) currently holds the highest efficiency out of all organic-based dyes thus far. ${ }^{22}$

\subsubsection{BODIPY dyes}

The pyrrolic rings that encapsulate the boron metal center on BODIPY (4,4'-difluoro-4-bora3a,4a-diaza-s-indacene) are complementary to the porphyrin ring structure-wise such that they can be regarded as a "demi-porphyrin". BODIPY is a strongly absorbing fluorophore that was 
first synthesized by Treibs and Kreuzer in 1968. BODIPY was extensively studied in biological imaging due to its intense absorption, high quantum yield, high tolerance to changes in $\mathrm{pH}$, absorption profile that does not overlap with other chromophores in the body, and molecular symmetry. ${ }^{25}$ Zinc porphyrin-BODIPY dyads had been found to go through photo-induced electron transfer, with BODIPY's role as an antenna that absorbs photons and transfers energy the zinc porphyrin. In 2005, Hattori and colleagues reported that a non-fluorescent BODIPY derivative (Figure 1.11) can initiate the photo-induced electron transfer without being tethered to a porphyrin. ${ }^{26}$

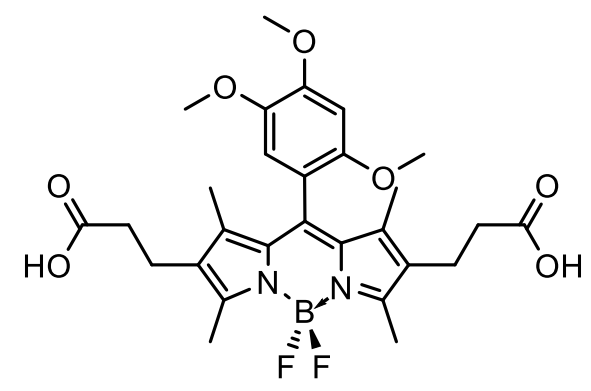

1.13

Figure 1.11. First BODIPY donor-acceptor-type DSSC ${ }^{26}$

A donor group is attached on the meso-position and the alkyl carboxylic acid acceptor groups are attached on the 2,8- positions of tetra-methyl-BODIPY. In addition to the photochemical characteristics that make BODIPY an ideal molecular probe, they are also easily tunable, function as a non-innocent $\pi$-spacer, redox active, soluble in a wide range of organic solvents, and possess long excited-state lifetimes. ${ }^{26,27}$ When BODIPY 1.13 was made into a device with $\mathrm{TiO}_{2}$ with an optically transparent electrode as the counter electrode, the device exhibited a power conversion efficiency of $0.13 \%$ likely owing to the non-conjugated anchoring units. ${ }^{26}$ Though a small value, this discovery recognized the versatility for BODIPY as a DSSC dye. Since then, BODIPY dye design was sought out to improve on DSSC device efficiencies. More elaborate introductions can be found in the beginning in each of the following chapters. 
Table 1.2. Performance parameters of organic dyes from this section

\begin{tabular}{llllll}
\hline Organic dye & $V_{\text {oc }}(\mathrm{mV})$ & $J_{\text {SC }}\left(\mathrm{mA} \mathrm{cm}^{-\mathbf{2}}\right)$ & $\mathrm{FF}$ & $\eta(\%)$ & year \\
\hline $\mathbf{1 . 1 3}^{26}$ & 470 & 0.41 & 0.68 & 0.13 & 2005 \\
$\mathbf{1 . 8}^{20}$ & 710 & 6.42 & 0.68 & 3.08 & 2007 \\
& & & & & \\
$\mathbf{1 . 9}^{20}$ & 580 & 4.56 & 0.64 & 1.70 & 2007 \\
$\mathbf{1 . 1 0 ^ { 2 1 }}$ & 694 & 14.0 & 0.71 & 6.90 & 2008 \\
$\mathbf{1 . 1 1}^{28,22}$ & 960 & 15.9 & 0.79 & 12.0 & 2011 \\
$\mathbf{1 . 1 2}^{22}$ & 910 & 18.1 & 0.78 & 13.0 & 2014
\end{tabular}




\subsection{Objectives}

To bring together the best qualities from inorganic and organic dyes, there are ongoing studies to incorporate a transition metal into the organic dye framework. The purpose of this thesis is to explore the use of first row transition metals (copper and iron) within hybrid organic dyemotifs. The following chapters reflect on three distinct projects towards this goal.

- The first project was an introduction to the newcomer copper dyes. The target copper complex envisioned adopted the D- $\pi-A$ motif that many DSSC dyes possess in order to mitigate recombination processes. Though the project was halted, some preliminary groundwork is discussed.

- The second project was a contribution to a project led by another graduate student (Burhan Hussein). Ferrocene was incorporated as a redox active chromophore to stabilize the BODIPY $\pi$-spacer. As a result, a series of ferrocene-BODIPY dyes were synthesized. However, the dyes were found to decompose overtime in the presence of light. This opened up the discussion of tuning the HOMO of the ferrocene to determine effects on the overall stability of the BODIPY core.

- The third project which makes up the bulk of this thesis stemmed from the suspicion that triphenylamine-BODIPY dyes synthesized previously could also experience decomposition if there was an ethynyl bridge between TPA and BODIPY units. To examine this idea, the secondary redox chromophore was tuned to look in depth at the effects on stability of BODIPY dyads under redox processes. 


\section{CHAPTER 2 - TOWARDS COPPER-TPA DYES}

\subsection{Introduction}

Alternative redox active metals to ruthenium-based dyes have been highly sought after. Copper(I) complexes have found their role as redox mediators in DSSC applications ${ }^{29}$, however these complexes have also shown promise as light harvesters due to possessing similar photophysical properties to ruthenium(II) complexes. Copper(I) complexes do pose a challenge as their inherent distorted tetrahedral geometry ( $D_{2 d}$ symmetry) can undergo a conformation change to a square planar geometry ( $D_{2}$ symmetry) upon photo-oxidation owing to the JahnTeller effect. Going from a copper(I) to copper(II) species lowers the energy which in effect stabilizes the oxidized form. ${ }^{30}$ Copper(II) complexes are not effective at reducing back to regenerate the copper(I) oxidation state of the dye which lowers device performance drastically. Furthermore, the copper(II) square planar complex has up to two coordination sites that are susceptible to binding by other ligands or solvent molecules forming an exciplex. The flattening of the complex can be mitigated by design of bulky ligands which will be elaborated over the course of this section. ${ }^{30,31}$

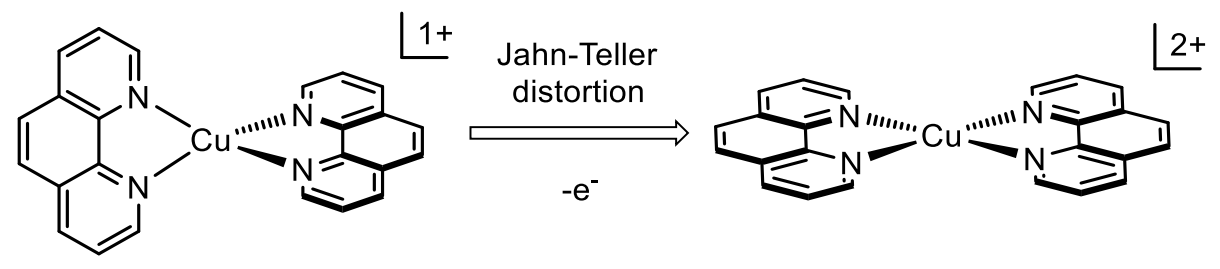

Figure 2.1. Jahn-Teller distortion of a copper(I) complex 


\subsubsection{Homoleptic copper(I) complexes for light harvesting applications}

During the initial stages of copper(I) dye design for DSSCs, complexes with homoleptic chelating ligands were employed. The bipyridine ligand is a common moiety used in the construction of copper(I) complexes for dyes in solar conversion devices. One of the earliest collection of copper dyes were studied by Bessho et al. each containing carboxylate-derived anchoring groups (Figure 2.2). Complex $\mathbf{2 . 1}$ and $\mathbf{2 . 3}$ share a similar backbone, the only difference was that 2.1 possessed carboxylic acid anchoring groups and $\mathbf{2 . 3}$ was the methyl-ester derivative. Complex $\mathbf{2 . 2}$ and $\mathbf{2 . 4}$ possessed a more conjugated structure with extension of the anchor groups following $\mathbf{2 . 1}$ and $\mathbf{2 . 3}$, respectively. ${ }^{32}$

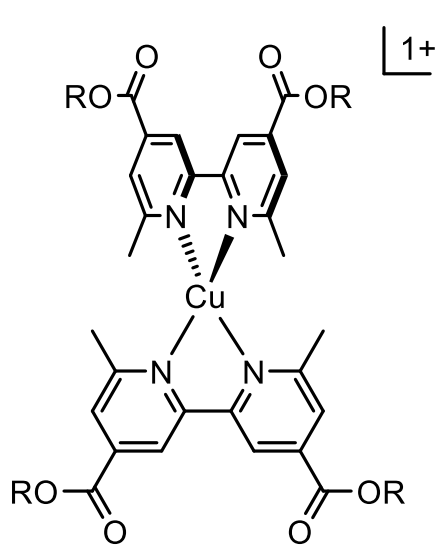

2.1, $\mathrm{R}=\mathrm{H}$

2.3, $\mathrm{R}=\mathrm{Me}$

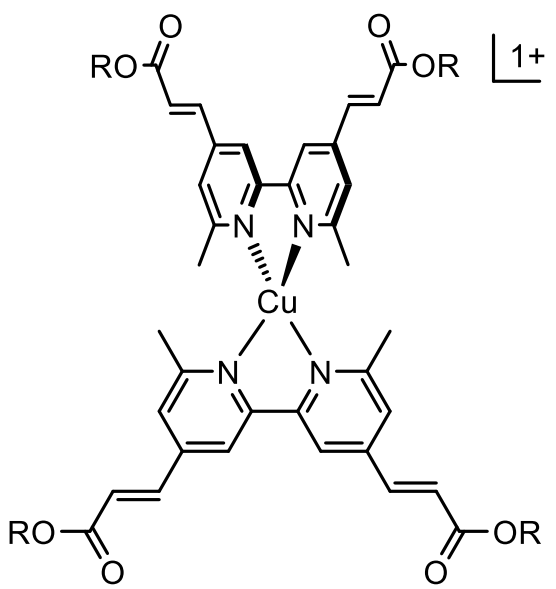

2.2, $\mathrm{R}=\mathrm{H}$

2.4, $\mathrm{R}=\mathrm{Me}$

Figure 2.2. Homoleptic $\mathrm{Cu}(\mathrm{I})$ complexes analysed by Bessho et al. $^{32}$

UV-Vis measurements of $\mathbf{2 . 3}$ and $\mathbf{2 . 4}$ showed a $\lambda_{\max }$ that corresponded to a metal to ligand charge transfer (MLCT) transition. Extension of the conjugation on $\mathbf{2 . 4}$ causes the absorption to bathochromically shift relative to $\mathbf{2 . 3}$ (Table 2.1). The red-shift was accompanied by a high molar absorption coefficient $(\varepsilon)$ more than 8 times that of complex 2.3. These results were predicted for complex $\mathbf{2 . 1}$ and $\mathbf{2 . 2}$ and further supported when the $\lambda_{\max }$ of $\left[\mathrm{Cu}(\mathbf{2 . 2})_{2}\right]\left[\mathrm{PF}_{6}\right]$ was found to be $515 \mathrm{~nm}, \varepsilon=6740 \mathrm{M}^{-1} \mathrm{~cm}^{-1}$. Even though the complexes containing methyl-ester groups show an improvement in absorption, $\mathbf{2 . 4}$ did not bind to $\mathrm{TiO}_{2}$. However, $\mathbf{2 . 3}$ did bind to $\mathrm{TiO}_{2}$, likely due to hydrolysis upon contact with the $\mathrm{TiO}_{2}$ surface. ${ }^{32}$ 
Table 2.1. UV-Vis data of $\mathrm{Cu}(\mathrm{I})$ complexes 2.3 and $\mathbf{2 . 4}$

\begin{tabular}{lll}
\hline Complexes & $\lambda_{\max }(\mathrm{nm})$ & $\varepsilon\left(\mathrm{M}^{-1} \mathrm{~cm}^{-1}\right)$ \\
\hline $\mathbf{2 . 3}$ & 495 & 450 \\
$\mathbf{2 . 4}$ & 506 & 3650
\end{tabular}

Device studies were performed on $\mathbf{2 . 1}$ and 2.2, and molar extinction coefficients were found to be proportional to IPCE. Compound $\mathbf{2 . 2}$ had an IPCE of 50\%, while $\mathbf{2 . 1}$ had a $38 \%$. Complex 2.2 had a greater $J_{S C}$ and improved fill factor when compared to 2.1. The copper dye that demonstrated the best efficiency was $2.2, \eta=2.30 \%{ }^{32}$

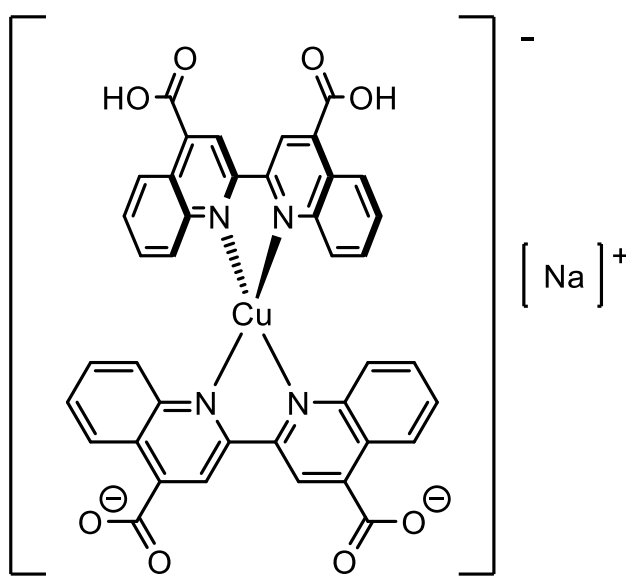

2.5

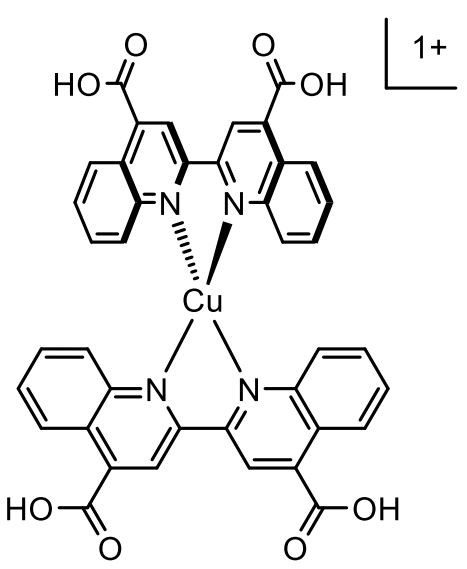

2.6

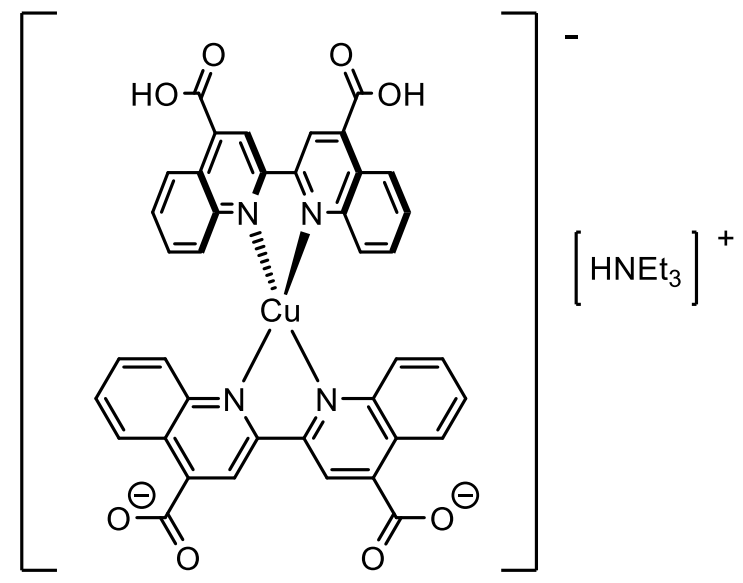

2.7

Figure 2.3. Various copper(I) biquinoline complexes with differing counterions 
While homoleptic $\mathrm{Cu}(\mathrm{I})$ complexes coordinated to two 2,2'-biquinoline-4,4'-dicarboxylic acid ligands has been previously reported for use in biological assays, Wills et al. has investigated the plausibility of biquinoline-based copper complexes for photovoltaic applications (Figure 2.3). ${ }^{33}$ The UV-vis characteristic of $\mathbf{2 . 7}$ displayed ligand-based absorption bands at $345 \mathrm{~nm}$ and $357 \mathrm{~nm}$, and a MLCT transition absorption at $564 \mathrm{~nm} .^{33}$

Variable-speed cyclic voltammetry was performed for 2.7 in a $\mathrm{MeOH}$ solution and when adsorbed onto $\mathrm{TiO}_{2}$. The separation between the oxidation and reduction peaks of $\mathbf{2 . 7}$ were wide $(\sim 650 \mathrm{mV})$ in solution, compared to the surface-bound dye of $\mathrm{TiO}_{2}(\sim 300 \mathrm{mV})$. This difference suggests that the adsorbed dye is easier to reduce back to the tetrahedral copper(I) state, due to the restricted environment on $\mathrm{TiO}_{2}$ surface versus the dye in solution with a higher degree of freedom to change conformation. In solution, as the scan rates increase, the reduction peak eventually depleted. Low DSSC efficiencies were found to range from 0.06$0.10 \%$ for the complexes in Figure 2.3 indicating that thoughtful design of the biquinoline ligands can improve the effciency. ${ }^{33}$

\subsubsection{Heteroleptic copper(I) dyes for light harvesting applications}

One feature that helps improve electron injection of the dye to $\mathrm{TiO}_{2}$ is when the chromophore possesses a dipole. Figure 2.4 shows the primary sphere of a copper(I) complex with two different chelating ligands. One of the ligands is functionalized with anchoring groups to adsorb onto $\mathrm{TiO}_{2}$. While the other ligand has electron donating groups attached. ${ }^{34}$ Heteroleptic copper dyes are not just limited to the 4,6-positions of bipyridine, the entire skeletal backbone of the ligand can also be interchanged as well as the bulky groups at the 2,9-positions of bypyridine or similar ligands can be modified. Heteroleptic copper(I) dyes have more freedom of design than their homoleptic analogues. 


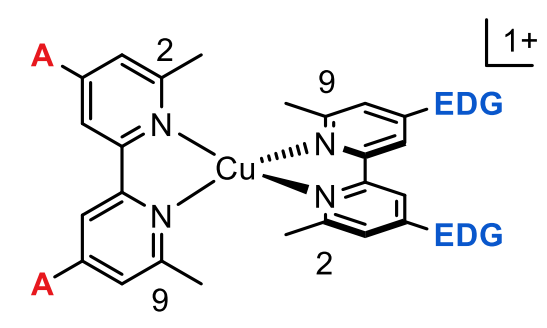

$A=$ anchoring group

EDG = electron donating group

Figure 2.4. General schematic of a heteroleptic copper(I) complex

Hewat et al., prepared a series of five heteroleptic $\mathrm{Cu}(\mathrm{I})$ complexes functionalized with a dipyrrin-based ligand (2.8) scaffold (Figure 2.5). ${ }^{35}$ The dipyrrin ancillary ligand is an attractive choice owing to its strong light absorption and electron donating ability. In this work, the researchers extended the conjugation of the dipyrrin by incorporating fused aromatics, within the motif (2.9). Phenyl rings were also added to the 1,7 positions to increase the steric bulk around the copper centre. This was also complemented by the presence of electron withdrawing $\mathrm{CF}_{3}$ groups in 2.10. Significant bathochromic shifts were observed (by UV-Vis) going from 2.8 to 2.9; however, the presence of electron-withdrawing $\mathrm{CF}_{3}$ on $\mathbf{2 . 1 0}$ caused a blue-shift, relative to $2.9 .^{35}$

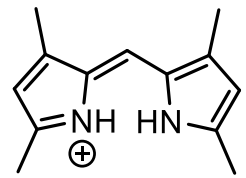

$\mathrm{Cl}^{\ominus}$

2.8. $\mathrm{HC}$

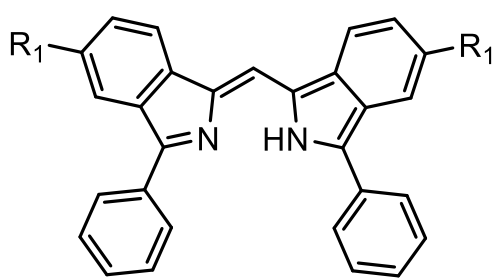

2.9, $\mathrm{R}_{1}=\mathrm{H}$

2.10, $\mathrm{R}_{1}=\mathrm{CF}_{3}$

Figure 2.5. Dipyrrin ligands explored by Hewat et al. ${ }^{35}$

To examine the efficacy of these ligands, a series of five $\mathrm{Cu}(\mathrm{I})$ based complexes were prepared (2.11-2.15, Figure 2.6). Molecular orbital calculations indicate that the electron density in the LUMO of $\mathbf{2 . 1 1}$ is located on both the bipyridine and dipyrrin ligand due to their similar $\pi$ accepting capabilities. For 2.12, the HOMO is localised in the dipyrrin ligand, but the dominant 
absorption is observed to be a ligand-centered transition and not MLCT. In complex 2.13, the HOMO is localised in the dipyrrin-based orbitals and the LUMO localised predominantly on the bipyridine; this being the most ideal for DSSC applications. Unfortunately, according to electrochemical characterization, the oxidation potentials of 2.11-2.13 are not positive enough to allow rapid regeneration of the dye. $\mathrm{CF}_{3}$ electron withdrawing groups were incorporated in both 2.14 and $\mathbf{2 . 1 5}$ for the purpose of increasing the oxidation potential. While this was successful at stabilizing the $\mathrm{HOMO}$, it also made the dipyrrin a stronger accepting ligand, and this negatively affects charge separation as it moves the electron density away from the $\mathrm{TiO}_{2}$ surface. $^{35}$

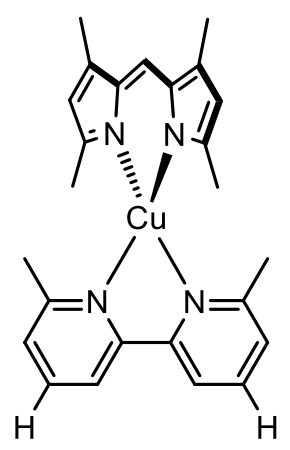

2.11

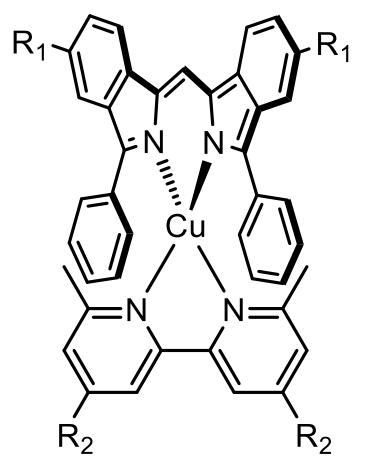

2.12, $\mathrm{R}_{1}=\mathrm{H}, \mathrm{R}_{2}=\mathrm{CH}_{3}$

2.13, $R_{1}=\mathrm{H}, \mathrm{R}_{2}=\mathrm{CO}_{2} \mathrm{Et}$

2.14, $\mathrm{R}_{1}=\mathrm{CF}_{3}, \mathrm{R}_{2}=\mathrm{CH}_{3}$

2.15, $\mathrm{R}_{1}=\mathrm{CF}_{3}, \mathrm{R}_{2}=\mathrm{CO}_{2} \mathrm{Et}$

Figure 2.6. $\mathrm{Cu}(\mathrm{I})$ complexes studied by Hewat et al. ${ }^{35}$

To further examine these complexes, carboxylic acid derivatives of the dyes were then used in device studies (Figure 2.7). Ligand modification from $\mathrm{H}$ to $\mathrm{CF}_{3}$ showed an improvement in the

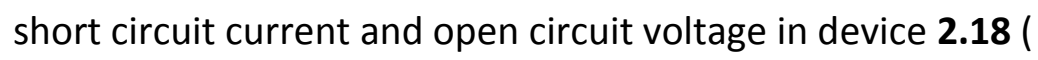

Table 2.2). ${ }^{35}$ Methyl and phenyl groups are just two types of substituents that can be used to mitigate charge recombination processes. Due to a number of possible combinations of substituents from each ligand, coordination chemistry of these complexes can lead to challenges. 

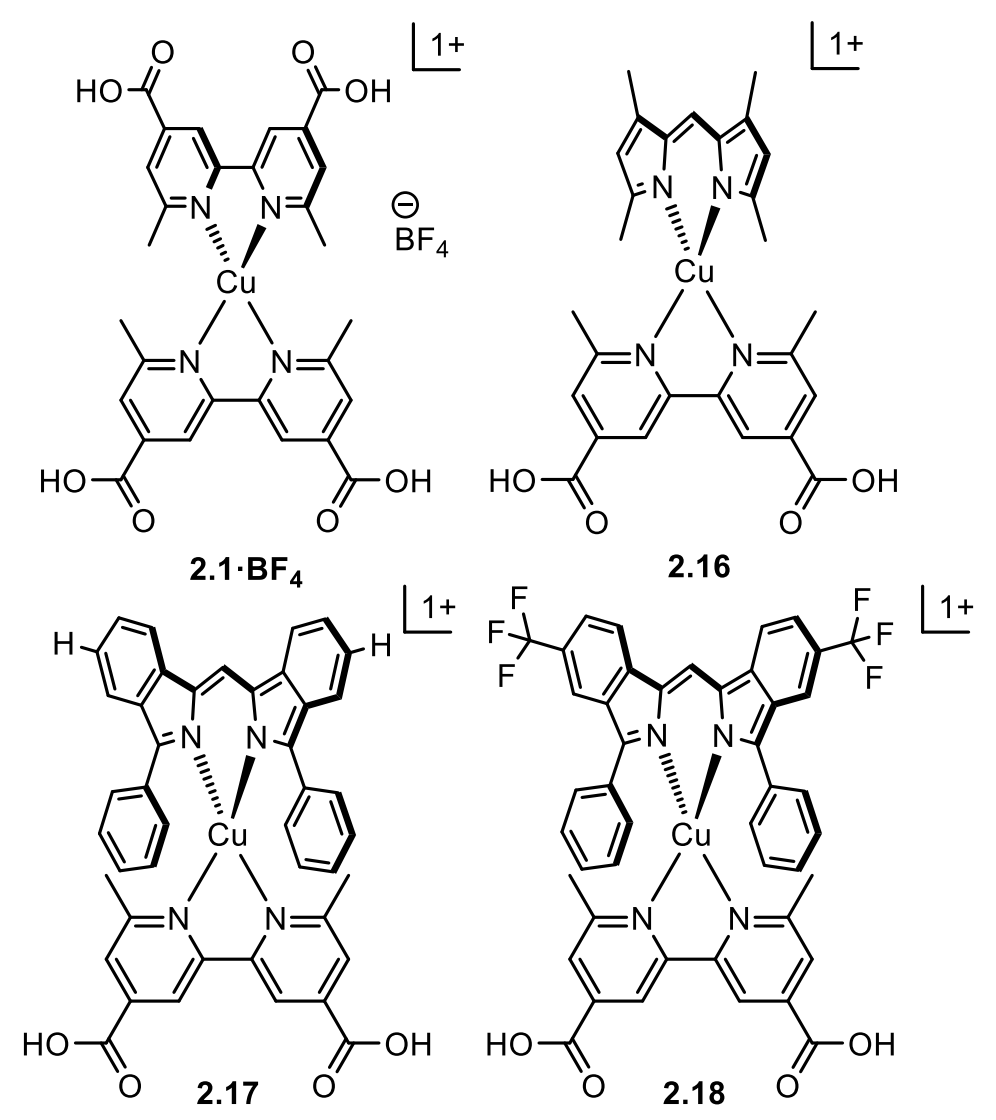

Figure 2.7. Heteroleptic $\mathrm{Cu}(\mathrm{I})$ complexes utilized for performance studies

Table 2.2. Device performance data of solar cells by Hewat et al. ${ }^{35}$

\begin{tabular}{lllll}
\hline Complex & $V_{\text {oc }}(\mathrm{mV})$ & $J_{\text {SC }}\left(\mathrm{mA} \mathrm{cm}^{-2}\right)$ & $\boldsymbol{F F}$ & $\eta(\%)$ \\
\hline $\mathbf{2 . 1 \cdot \mathrm { BF } _ { 4 }}$ & 530 & 2.33 & 0.68 & 0.83 \\
$\mathbf{2 . 1 6}$ & 520 & 0.40 & 0.62 & 0.13 \\
$\mathbf{2 . 1 7}$ & 510 & 0.91 & 0.68 & 0.31 \\
$\mathbf{2 . 1 8}$ & 520 & 1.21 & 0.64 & 0.41
\end{tabular}

The Odobel group adopted the HETPHEN method by Schmittel et al. to make a copper(I) dye with a biquinoline ligand and a phenanthroline ligand with bulky mesityl groups. ${ }^{34,36}$ The HETPHEN strategy works by utilizing bulky groups at the 2 and 9 positions of a 2,2'-bipyridine or 
1,10-phenanthroline ligand. The steric nature of these types of ligands prevents formation of homoleptic complexes and promotes formation of their heteroleptic counterparts. ${ }^{37}$ Using the HETPHEN strategy, the Odobel group tested out this theory on $\mathrm{Cu}(\mathrm{I})$ complexes. In the synthesis of the complexes (Figure 2.8), the more bulky ligands (LO and $\mathbf{L} \mathbf{1}$ in Figure 2.8) are reacted with $\left[\mathrm{Cu}\left(\mathrm{CH}_{3} \mathrm{CN}\right)_{4}\right] \mathrm{PF}_{6}$ first and then a solution of the anchoring ligand is suspended into the mixture. The 2,2'-biquinoline-4,4'-dicarboxylic acid $\left(\mathrm{dcbqH}_{2}\right)$ ligand (Figure 2.8$)$ proved to be a strong electron acceptor, thus a suitable anchor to $\mathrm{TiO}_{2} \cdot{ }^{34}$

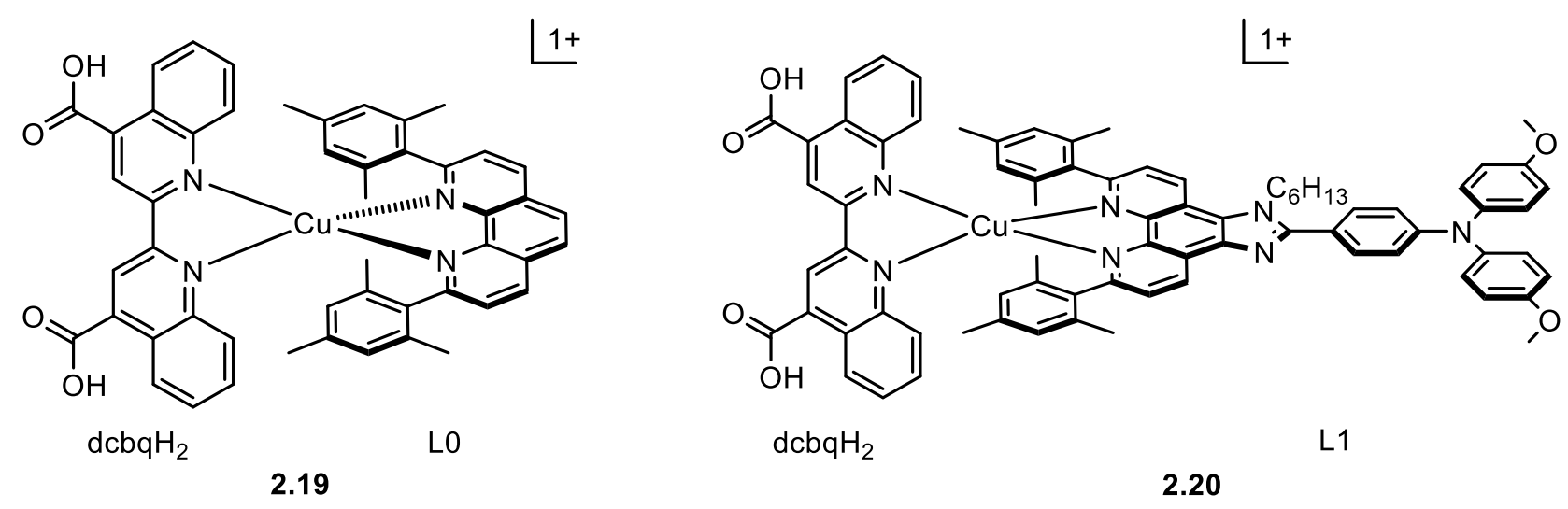

Figure 2.8. Copper complexes studied by the Odobel group, with 2,2'-biquinoline-4,4'dicarboxylic acid $\left(\mathrm{dcbqH}_{2}\right)$ as the anchoring ligand

Strong electron accepting character was observed in the anchor by DFT, and significant electron delocalization to the anchor was observed between the HOMO-LUMO by TD-DFT. In the UV-Vis, a red-shift is observed for $\mathbf{2 . 2 0}$ compared to $\mathbf{2 . 1 9}$ as a result of the improved electron donating ability of the donating triarylamine moiety on 2.20. Even though the efficiencies of $\mathbf{2 . 1 9}$ and 2.20 are poor ( $\eta=0.25 \%$ and $0.71 \%$, respectively), heteroleptic copper $(I)$ complexes following the motif outlined in Figure 2.4 remain plausible light harvesters. ${ }^{34}$ With a small jump in efficiency of 2.20, research in adding TPA to the ligand structure has continued. 
Copper(I) complexes with triphenylamine incorporated in the ligand framework reported by Odobel et al were elaborated by Constable and Housecroft who incorporated first and second generation triphenylamine (TPA)-based dendrons as ligands in heteroleptic $\mathrm{Cu}(\mathrm{I})$ complexes (Figure 2.9). ${ }^{38}$ Inclusion of TPA-based dendrons lowers the probability of recombination and the synthesis of these complexes were done using a ligand exchange method with a series of three anchoring ligands (Figure 2.9). The anchor ligands are bound to $\mathrm{TiO}_{2}$ and then dipped into a DCM solution of the homoleptic $\mathrm{Cu}(\mathrm{I})$ complex. $^{38}$

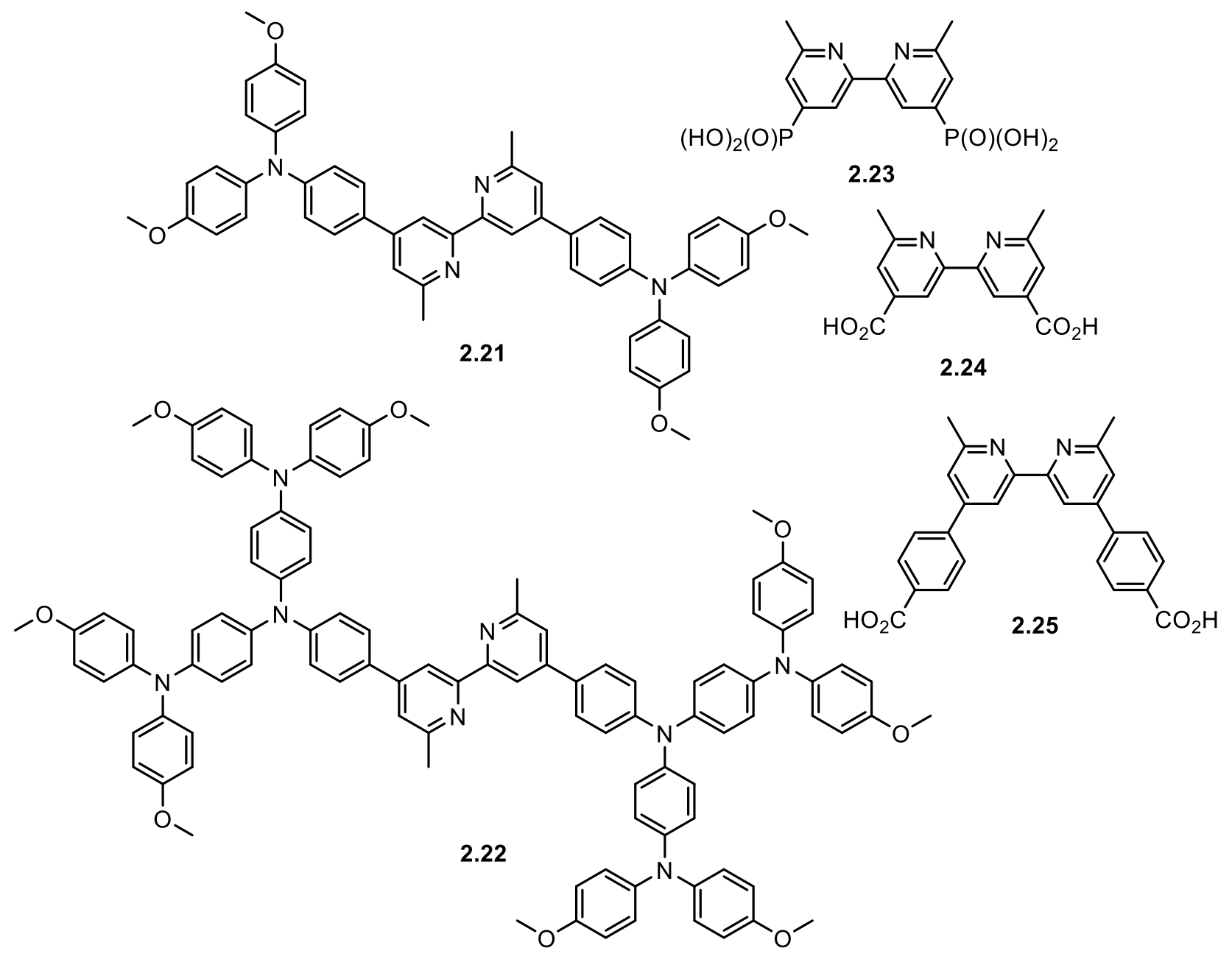

Figure 2.9. Ancillary ligands; 2.21 (first generation dendron) and $\mathbf{2 . 2 2}$ (second generation dendron), anchoring ligands; 2.23 (phosphonic acid), 2.24 (6,6'-dimethyl-[2,2'-bipyridine]-4,4'dicarboxylic acid) and $\mathbf{2 . 2 5}$ (benzoic acid) 
In device studies, an enhancement in efficiency going from complexes with anchor groups $\mathbf{2 . 2 4}$ to $\mathbf{2 . 2 5}$ was observed, as a result of extended conjugation. However, higher efficiencies were demonstrated for complexes that contained phosphonic acid as the anchoring groups (2.23) rather than the carboxylic acid due to their strong adsorption to $\mathrm{TiO}_{2 .}{ }^{38,39}$ The best performing DSSC dye is represented in Figure 2.10, which had an $\eta=3.77 \% .^{38}$ For this dye, the anchored $\mathrm{TiO}_{2}$ was dipped into an MeCN solution of the homoleptic complex instead of a DCM solution. The effects of different dipping solvents in the assembly of the DSSC are currently employed for further studies. 


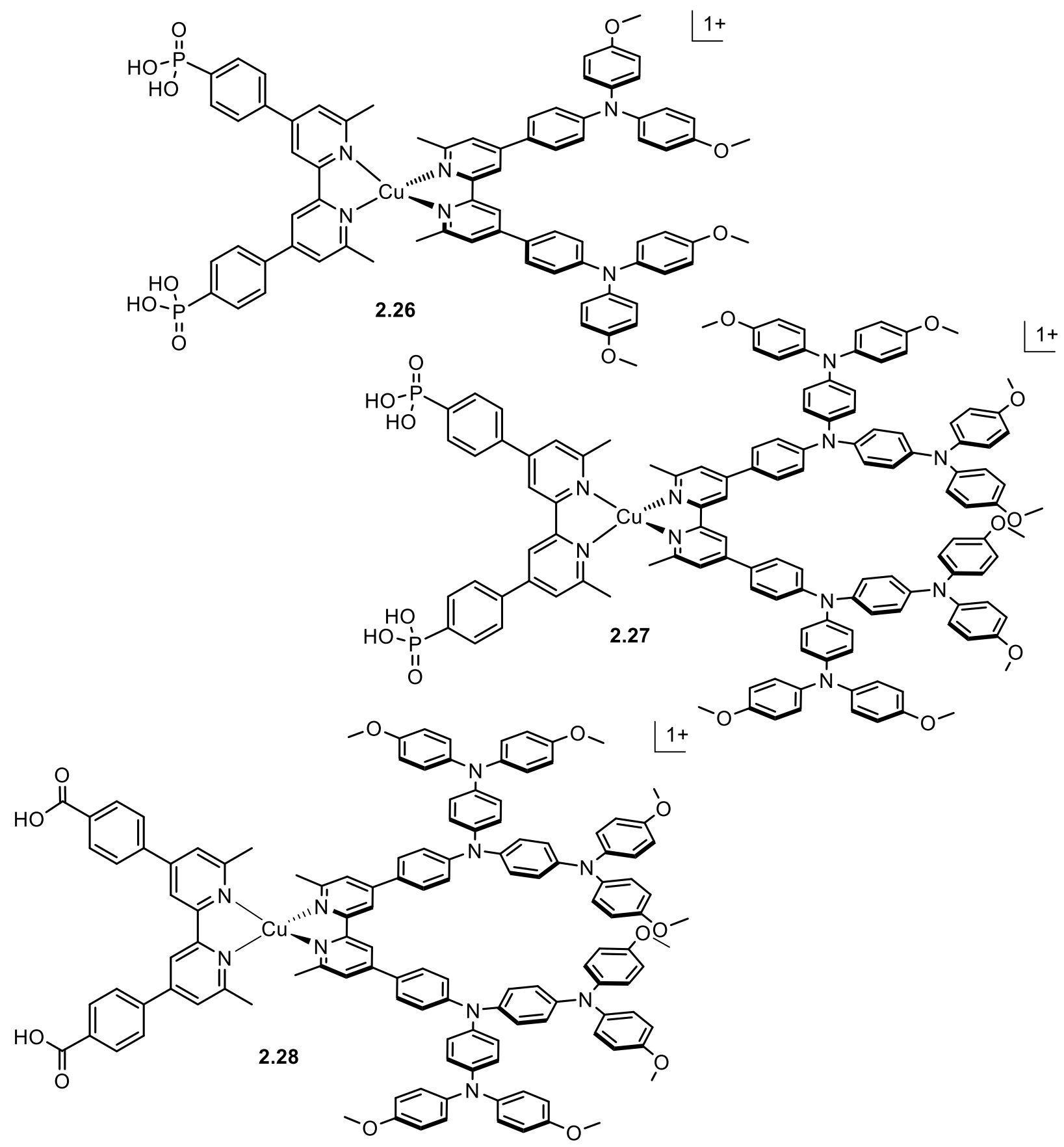

Figure 2.10. The heteroleptic $\mathrm{Cu}(\mathrm{I})$ complex synthesized by Bozic-Weber et al.

The presence of a second generation dendron on the complexes $\mathbf{2 . 2 7}$ and $\mathbf{2 . 2 8}$ (Figure 2.10) did not demonstrate a better efficiency compared to the first generation dendron 2.26. In 
retrospect, the addition of a conjugated TPA moiety to the bipyridine ligands yield a high efficiency compared to complexes without the TPA moiety (2.1 and 2.2).

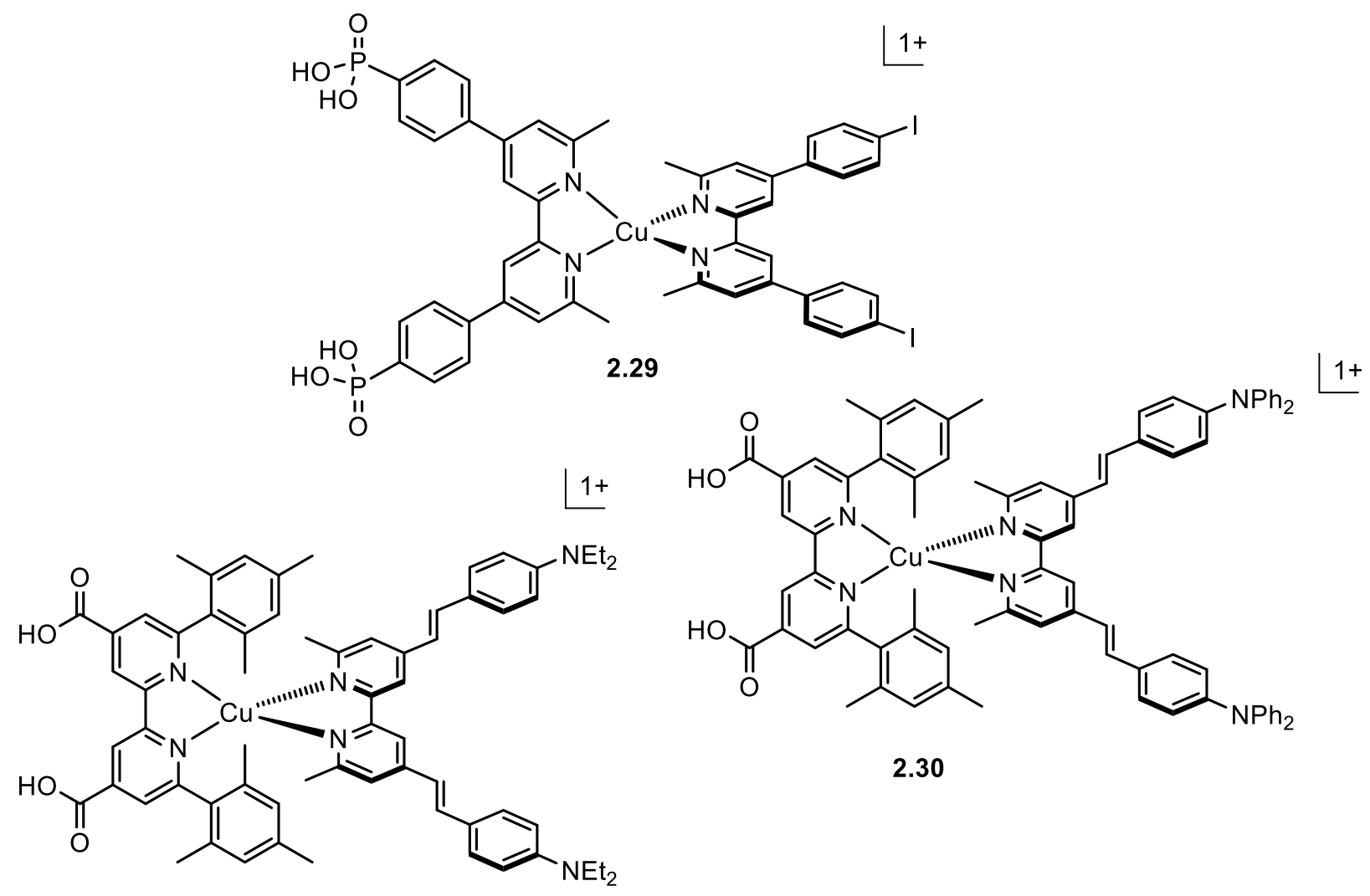
2.31

Figure 2.11. Heteroleptic copper(I) complexes with high efficiencies

Complex 2.26 and complexes in Figure 2.11 demonstrate the highest efficiencies for copper(I) dyes as of yet. Table 2.3 highlight device data of select dyes from this chapter. Dye $\mathbf{2 . 2 6}$ and 2.29 have shown that methyl groups are appropriate substituents to use in the design of these dyes to mitigate recombination processes. 
Table 2.3. DSSC device data of best one or two copper(I) dyes from each study in chapter 2

\begin{tabular}{llllll}
\hline Dye & $\boldsymbol{J}_{\text {SC }}\left(\mathrm{mA} \mathrm{cm}^{-\mathbf{2}}\right)$ & $\boldsymbol{V}_{\text {oc }}(\mathrm{mV})$ & FF & $\boldsymbol{\eta}$ (\%) & Ref. \\
\hline $\mathbf{2 . 1}$ & 5.25 & 566 & 0.64 & 1.90 & {$\left[{ }^{32}\right]$} \\
$\mathbf{2 . 2}$ & 5.90 & 556 & 0.70 & 2.30 & {$\left[{ }^{32}\right]$} \\
$\mathbf{2 . 5}$ & 0.224 & 623 & 0.72 & 0.10 & {$\left[{ }^{33}\right]$} \\
$\mathbf{2 . 6}$ & 0.235 & 511 & 0.66 & 0.08 & {$\left[{ }^{33}\right]$} \\
$\mathbf{2 . 7}$ & 0.20 & 528 & 0.69 & 0.07 & {$\left[{ }^{33}\right]$} \\
$\mathbf{2 . 1 6}$ & 0.40 & 520 & 0.62 & 0.13 & {$\left[{ }^{35}\right]$} \\
$\mathbf{2 . 1 7}$ & 0.91 & 510 & 0.68 & 0.31 & {$\left[{ }^{35}\right]$} \\
$\mathbf{2 . 1 8}$ & 1.21 & 520 & 0.64 & 0.41 & {$\left[{ }^{35}\right]$} \\
$\mathbf{2 . 1 9}$ & 2.17 & 475 & 0.69 & 0.71 & {$\left[{ }^{34}\right]$} \\
$\mathbf{2 . 2 0}$ & 0.82 & 465 & 0.66 & 0.25 & {$\left[{ }^{34}\right]$} \\
$\mathbf{2 . 2 6}$ & 9.55 & 593 & $n / a$ & 3.77 & {$\left[{ }^{38}\right]$} \\
$\mathbf{2 . 2 7}$ & 5.25 & 578 & 0.66 & 2.02 & {$\left[{ }^{38}\right]$} \\
$\mathbf{2 . 2 8}$ & 4.56 & 530 & 0.70 & 1.69 & {$\left[{ }^{38}\right]$} \\
$\mathbf{2 . 2 9}$ & 7.10 & 604 & 0.74 & 3.16 & {$\left[{ }^{40}\right]$} \\
$\mathbf{2 . 3 0}$ & 10.13 & 625 & 0.70 & 4.42 & {$\left[{ }^{41}\right]$} \\
$\mathbf{2 . 3 1}$ & 10.86 & 605 & 0.71 & 4.66 & {$\left[{ }^{41}\right]$}
\end{tabular}

\subsubsection{Controlling the Jahn-Teller effect by modification of substituents at the 2,9-positions of} phenanthroline

The physical influence of bulkier substituents on the 2, 9- positions of the phenanthroline ligands were previously analysed. The excited state kinetics were monitored for a series of three copper(I) diimine complexes using transient absorption spectroscopy (Figure 1). ${ }^{30}$ 


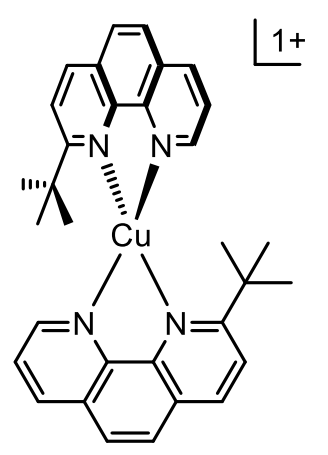

$\left[\mathrm{Cu}^{\prime}(\text { tbp })_{2}\right]^{+}$

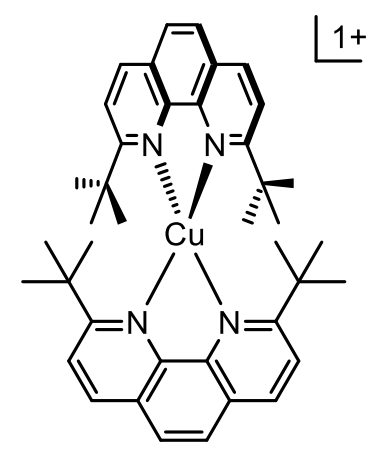

$\left[\mathrm{Cu}^{\prime}(\mathrm{dtbp})_{2}\right]^{+}$

2.32

2.33

Figure 2.12. Two main $\mathrm{Cu}(\mathrm{I})$ complexes studied by Gothard and colleagues ${ }^{30}$

Significant differences in the change in absorbance between 0 to 10 ps for $\mathbf{2 . 3 2}$ and $\mathbf{2 . 3 3}$ was observed. While $\mathbf{2 . 3 3}$ displayed gradual changes in absorbance that decreased over time, 2.32 showed gradual changes in absorbance that increased over time, and it was determined that these trends were consistent at various probe wavelengths. ${ }^{30}$ As a result, Jahn-Teller flattening distortion does not occur in $\mathbf{2 . 3 3}$ after excitation, however the phenomenon is present in 2.32. This indicates that the tert-butyl groups on 2,9-positions of the ligands play a significant role in minimizing geometric changes upon excitation. Conversely, 2.32 which only has one bulky group per phenanthroline ligand, was less effective at minimizing Jahn-Teller flattening. ${ }^{30}$

Flattening of the copper(I) complex can open up a site for a solvent molecule to coordinate to the metal centre, therefore stabilizing the exciplex. This stabilization leads to a shorter MLCT excited state. Observance of the MLCT state dynamics for $\mathbf{2 . 3 3}$ showed that it has a long-lived excited state lifetime compared to $2.32 .{ }^{30}$ As such, tert-butyl groups are viable substituents to lock the tetrahedral geometry of the copper(I) complex for efficient light harvesting applications. ${ }^{30}$

With more attention over the years, transition towards a heteroleptic architecture found effectiveness in charge separation and electron transfer. The target copper dye that was proposed has a few design features. Mixing the idea of a D- $\pi-A$ motif into a copper complex 
framework was novel during the time of the proposal. The majority of the copper complexes in the literature involved bipyridine ligands that are flexible and capable of rotation. Taking a rigid ligand such as phenanthroline was a tactic towards preventing recombination processes. Phenanthroline was an ideal choice due to its planarity, coordinating nitrogen atoms, conjugated system and likeness to the bipyridine ligands commonly studied in the literature. 


\subsection{Thesis Objective}

The copper(I) dye proposed for this project has a number of design features in the hopes of generating a high performing dye for the DSSC (Figure 2.13). Phenanthroline ligands are employed as their $\pi$-system offers rigidity. Thiophene as a $\pi$-spacer coupled between the phenanthroline ligand and triphenylamine moiety should improve the photo-cross section, preventing recombination processes of the dye. The cyanoacetic acid groups as anchoring units extend conjugation and direct electron density towards $\mathrm{TiO}_{2}$. The tert-butyl and methyl substituents should be sufficient to restrict square planar distortion. In addition to this target molecule, the triphenylamine redox active chromophore can be modified to tune the electrochemical properties of the system.

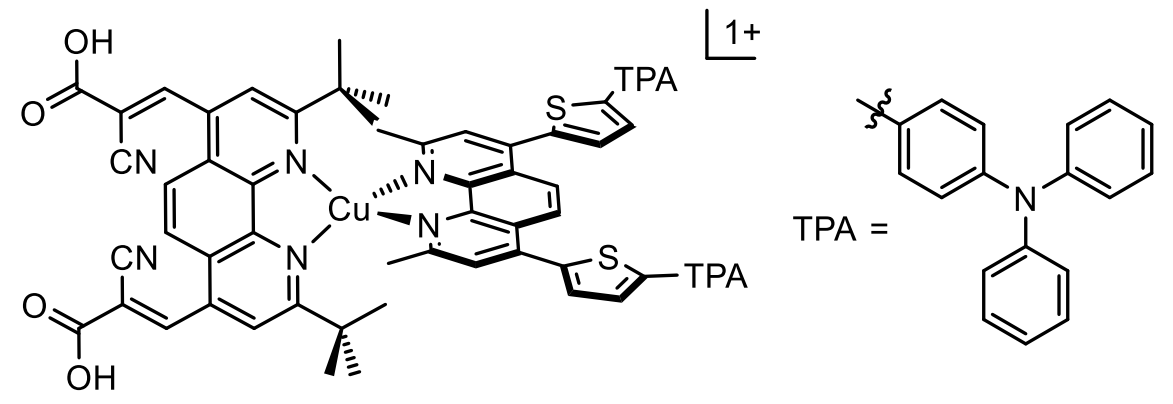

2.34

Figure 2.13. Target $D-\pi-A$ copper(I) complex 


\subsection{Synthesis}

A retrosynthetic scheme is proposed towards the target copper complex with TPAphenanthroline ligands in Scheme 2.1. 


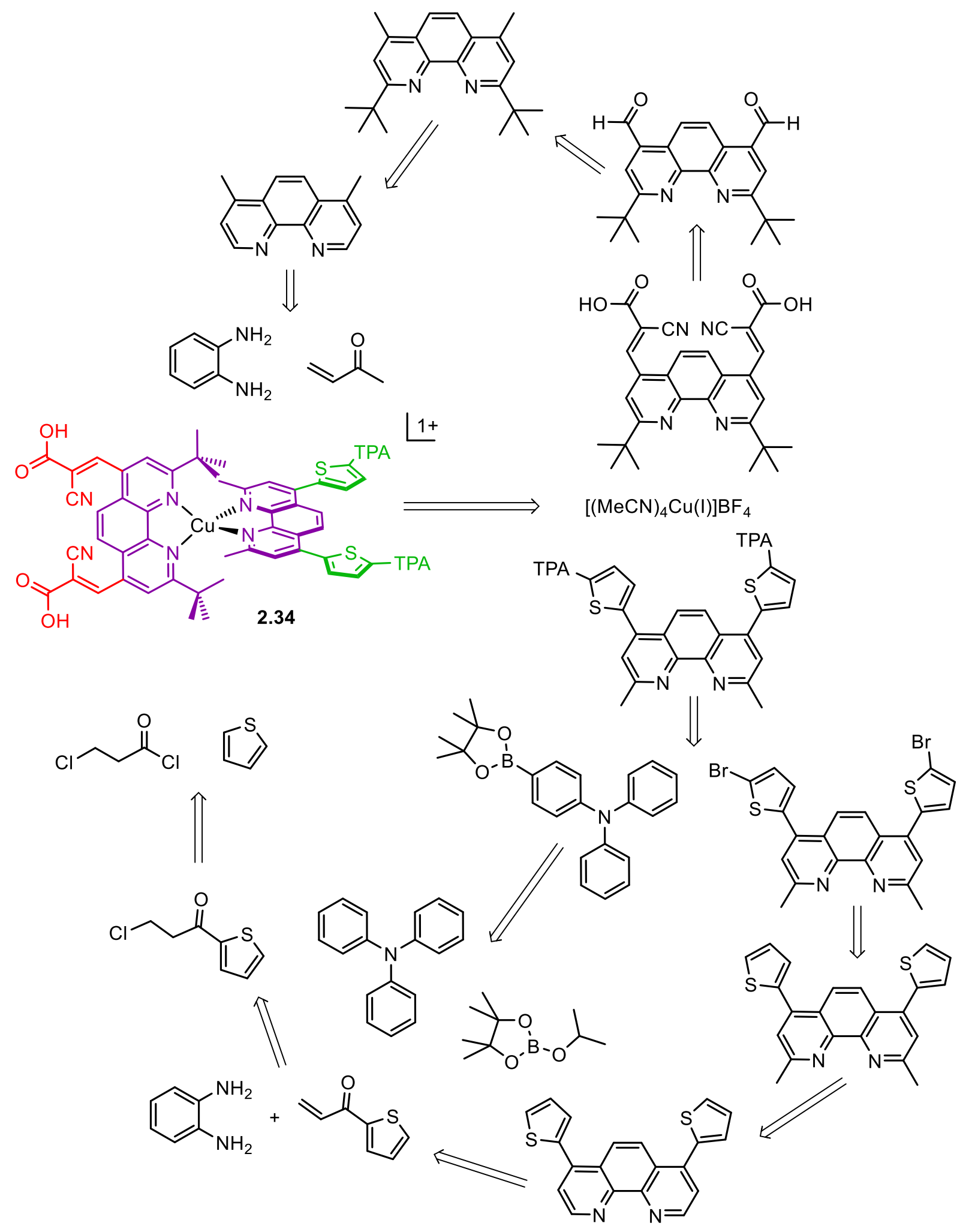

Scheme 2.1. Retrosynthesis of proposed target copper dye $\mathbf{2 . 3 4}$ 
The starting material $\mathbf{2 . 3 5}$ was synthesized from commercially available $\boldsymbol{o}$-phenylenediamine and excess methyl vinyl ketone (Scheme 2.2). The modified Skraup-Doebner-von Miller synthesis was carried out under reflux and heated to $80^{\circ} \mathrm{C} .{ }^{42}$ Workup via extraction with saturated ammonia to basify the acidic reaction mixture was difficult due to presence of a polymeric by-product generated from the heating of methyl vinyl ketone. ${ }^{43}$ However, yield from this synthesis is low, an attempt at using less methyl vinyl ketone did not suffice. The reaction was attempted at room temperature, however no product was obtained.

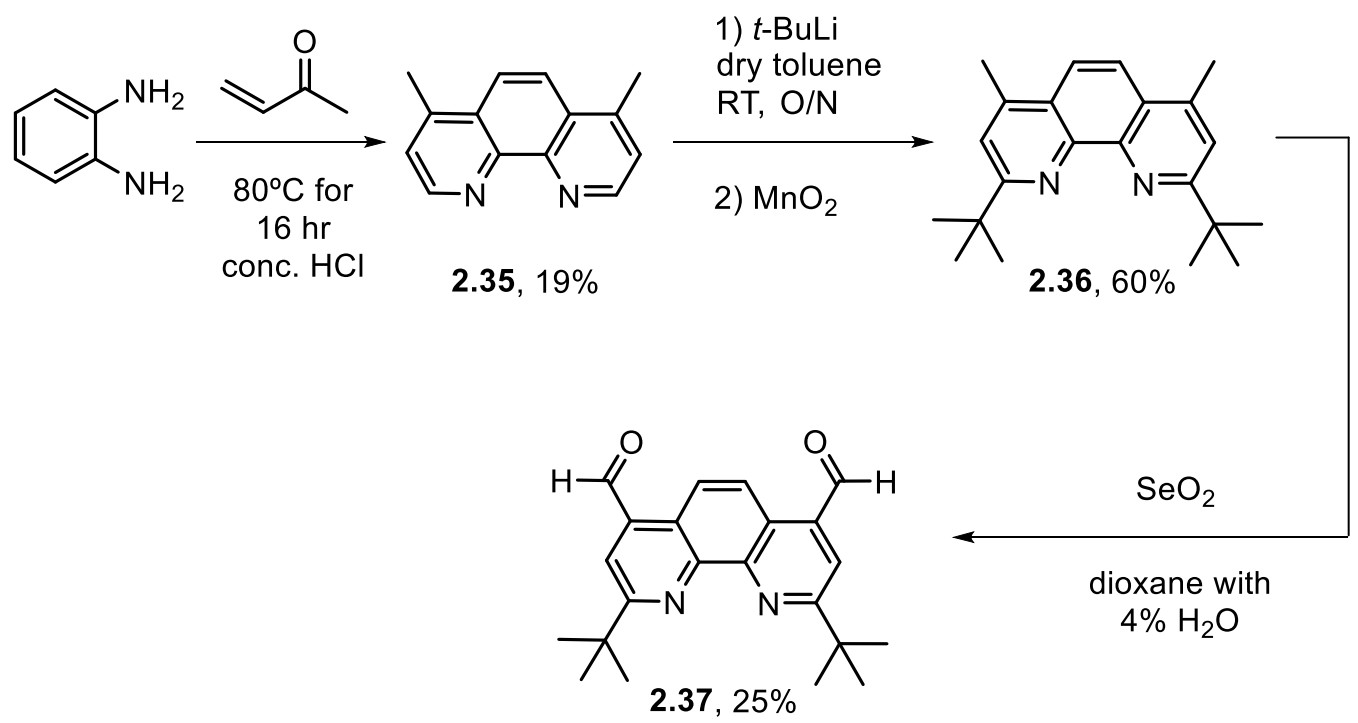

Scheme 2.2. Synthetic route towards $\mathbf{2 . 3 7}$

Towards the synthesis of compound 2.36, it was found that drop-wise addition of the $t$-BuLi reagent at $-78^{\circ} \mathrm{C}$ only installed one tert-butyl group (2.36b, Figure A6), while addition under room temperature produced the desired product $2.36 .{ }^{44}$ Formation of aldehydes from methyl groups on the 4,7-positions was carried out by oxidation with selenium dioxide to form $2.37 .^{45}$ 
1) $\mathrm{AlCl}_{3}, \mathrm{RT} 15 \mathrm{~min}$<smiles>O=C(Cl)CCCl</smiles>

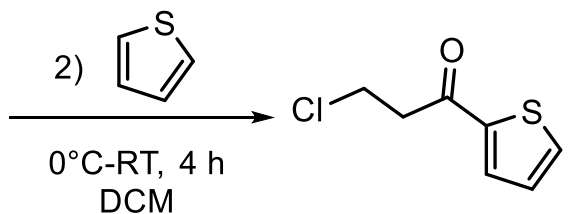

2.38, $88 \%$

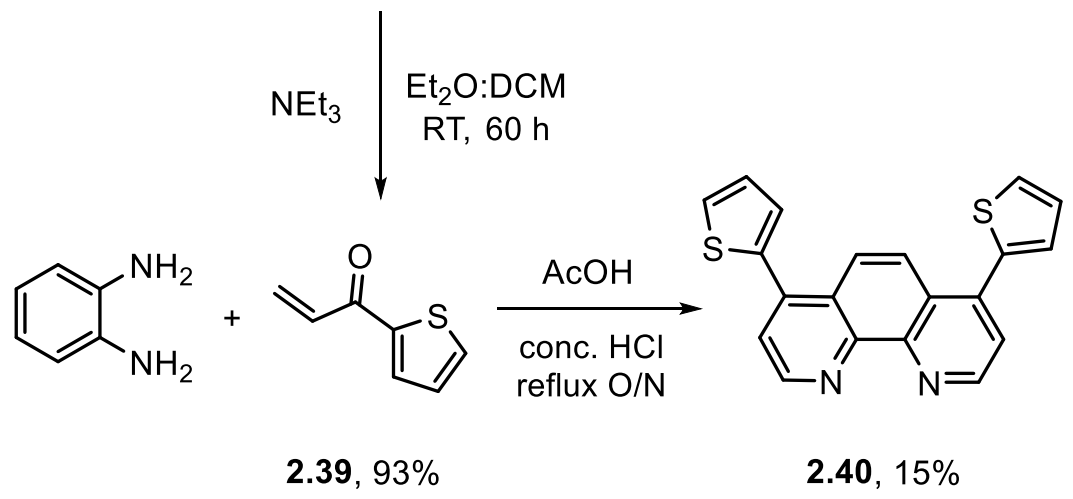

Scheme 2.3. Synthetic route towards donor ligand

The synthesis for the donor ligand was approached by Paloma Prieto (ICE research assistant). Compound $\mathbf{2 . 3 8}$ was made through a Friedel-Crafts acylation. ${ }^{46,47}$ An elimination (E2) reaction with triethylamine was carried out to generate $\mathbf{2 . 3 9}$ in high yield. ${ }^{46}$ Synthesis of $\mathbf{2 . 4 0}$ from $\mathbf{O}^{-}$ phenylenediamine and $\mathbf{2 . 3 9}$ was carried out using a patent procedure. ${ }^{48}$ Bromination of the thiophene arms on compound $\mathbf{2 . 4 0}$ was attempted using NBS, however the reaction was unsuccessful. 


\subsection{Results \& Discussion}

A few novel phenanthroline derivatives were synthesized in an attempt to produce the donor and acceptor ligands. The ${ }^{1} \mathrm{H}$ NMR of $\mathbf{2 . 3 5}$ (Figure A2) was similar to the literature with three singlets in the aromatic region integrating for 2 protons each and a singlet in the aliphatic region integrating for 6 protons assigned to the two methyl groups. The simplicity of the ${ }^{1} \mathrm{H}$ NMR spectrum is due to the symmetrical nature of the compound. Installing a single tert-butyl group on the 2- position shows up as a singlet at $1.58 \mathrm{ppm}$ integrating for 9 protons (Figure A6). Due to a break in symmetry, the aromatic protons have unique electronic environments compared to the ${ }^{1} \mathrm{H}$ NMR spectrum for $\mathbf{2 . 3 6}$ (Figure A4). No significant changes were found in the chemical shifts transforming $\mathbf{2 . 3 5}$ to $\mathbf{2 . 3 6}$ except for the absence for the singlet peak at 9.05 $\mathrm{ppm}$ and presence of the singlet at $1.60 \mathrm{ppm}$ for the installed tert-butyl groups. Substituting the methyl groups for carboxylic acid groups to form 2.37 shifted the aromatic peaks by 0.6-1.1 ppm downfield due to the electron withdrawing effect from the aldehyde groups. There is no literature line-listing record for compound 2.40, however the ${ }^{1} H$ NMR spectrum and mass spectrometry data are characteristic of the structure. 


\subsection{Summary \& Conclusion}

A lot of time was invested in this project with minimal success; few phenanthroline derivatives were synthesized as a result of this project. In an attempt at synthesizing phenanthroline anchoring and donor ligands, the workup and purification steps were problematic. The first step to synthesize $\mathbf{2 . 3 5}$ favoured the production of a polymeric by-product. ${ }^{43}$ Despite addition of excess methyl vinyl ketone to push the reaction forward, high yields were not attainable. The polymer by-product made isolation of $\mathbf{2 . 3 5}$ difficult. For the success of this project, a protocol for synthesizing novel ligands would need to be set in place, however to synthesize these novel ligands in a short amount of steps would require high costing starting materials and catalyst. If upon synthesis of novel ligands was successful, coordination chemistry would have to be explored to synthesize the penultimate target dye complex 2.34. Even then, the feasibility of the dye is unknown. Testing a proof of concept would supplement the proposed project by studying structure-property relationship of a series of simple copper(I) dyes composed of simple ligands (phenanthroline-TPA or phenanthroline-thiophene). Starting from a low yield in the first step towards synthesizing the phenanthroline ligands was not cost-effective. If time was given to optimize the reaction conditions, then this project could be a worthwhile venture. From a pragmatic standpoint, the project was not pursued further. 


\subsection{Experimental}

\subsubsection{General Considerations}

All reagents were purchased commercially and used without further purification. Solvents used for anhydrous reactions were retrieved from either the mBraun Solvent Purification System (SPS) or from commercial jugs (Sigma Aldrich); no further purification was done, unless stated otherwise. Purification by column chromatography was carried out using silica (Silicycle; ultrapure flash silica). Thin-layer chromatography was performed on aluminum-backed sheets precoated with silica 60 F254 adsorbent (250 $\mu \mathrm{m}$ thickness; SiliCycle) and visualized under UV light. Routine ${ }^{1} \mathrm{H}$ and ${ }^{13} \mathrm{C}\{1 \mathrm{H}\}$ spectroscopic data was obtained at 400 and $100 \mathrm{MHz}$, respectively, on a Bruker Avance II 400 instrument at ambient temperature using deuterated solvent from Sigma Aldrich. Chemical shifts $(\delta)$ are reported in parts per million (ppm) from low to high field and referenced to a residual nondeuterated solvent $\left(\mathrm{CHCl}_{3}\right)$ for ${ }^{1} \mathrm{H}$ and ${ }^{13} \mathrm{C}$ nuclei, $\mathrm{BF}_{3} \bullet \mathrm{OEt}_{2}\left({ }^{11} \mathrm{~B}\right.$ nucleus; $\left.\delta=0 \mathrm{ppm}\right)$ and $\mathrm{C}_{6} \mathrm{~F}_{6}\left({ }^{19} \mathrm{~F}\right.$ nucleus; $\left.\delta=0 \mathrm{ppm}\right)$. Standard abbreviations indicating multiplicity are used as follows: $\mathrm{s}=$ singlet; $\mathrm{d}=$ doublet; $\mathrm{q}=$ quartet, $\mathrm{br}=$ broad and $\mathrm{m}$ = multiplet. High resolution mass spectrometry (HRMS) results were obtained from Queens University, Kingston Ontario. Electron impact (EI) mass spectrometry and electrospray ionization (ESI) techniques were used for the ionization; time of flight (TOF) was used for analysis.

\subsubsection{Synthesis}

\section{4,7-dimethyl-1,10-phenanthroline (2.35)}

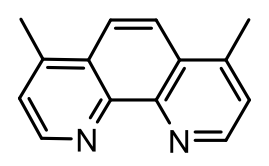

To a two-neck $500 \mathrm{~mL}$ round bottom flask, o-phenylenediamine $(6.50 \mathrm{~g}, 60.10 \mathrm{mmol})$ was dissolved in $50 \mathrm{~mL}$ of conc. $\mathrm{HCl}$. The mixture was heated to reflux, followed by drop-wise addition of methyl vinyl ketone $(25 \mathrm{~mL}, 308.18 \mathrm{mmol})$ over a span of $45 \mathrm{~min}$. The mixture was 
then heated at $80^{\circ} \mathrm{C}$ for $16 \mathrm{~h}$. The reaction mixture was let to cool to RT, followed by addition of $25.0 \mathrm{~mL}$ of distilled water and extraction with DCM. The initial organic layer was discarded. To the aqueous layer (set in an ice bath) was slowly added ca. $100 \mathrm{~mL}$ of conc. ammonium hydroxide with constant stirring. The oily suspension was extracted with chloroform, the combined organic layers dried over $\mathrm{MgSO}_{4}$ and filtered. The solvent was concentrated under reduced pressure to afford a viscous crude oil. The crude was purified by 'dry flash' column chromatography using 4.5:0.5 EtOAc:MeOH $\left(R_{f}=0.15\right)$ as an eluent to afford the product as a light brown powder $(2.40 \mathrm{~g}, 19 \%) .{ }^{1} \mathrm{H}$ NMR $\left(400 \mathrm{MHz}, \mathrm{CDCl}_{3}\right): \delta=9.04(\mathrm{~d}, J=4.80 \mathrm{~Hz}, 2 \mathrm{H}), 8.03$ $(\mathrm{s}, 2 \mathrm{H}), 7.45(\mathrm{~d}, J=4.40 \mathrm{~Hz}, 2 \mathrm{H}), 2.79(\mathrm{~s}, 6 \mathrm{H}) .{ }^{13} \mathrm{C}\left\{{ }^{1} \mathrm{H}\right\} \mathrm{NMR}\left(100 \mathrm{MHz}, \mathrm{CDCl}_{3}\right): \delta=149.88,146.19$, $144.21,127.80,124.01,122.06,19.06$. Spectroscopic data is slightly consistent with the literature. ${ }^{42}$

\section{2-(tert-butyl)-4,7-dimethyl-1,10-phenanthroline (2.36b)}

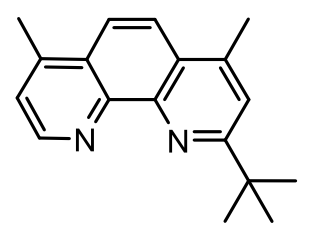

Under an atmosphere of $\mathrm{N}_{2}$, a solution of $2.35(0.417 \mathrm{~g}, 2.00 \mathrm{mmol})$ was prepared in $20 \mathrm{~mL}$ of dry THF in a dried $250 \mathrm{~mL}$ Schlenk flask equipped with a stir bar and cooled at ca. $-90^{\circ} \mathrm{C}$ to $116^{\circ} \mathrm{C}$ (EtOH and liquid nitrogen bath). To the solution, $t$-butylithium $(2.40 \mathrm{~mL}, 4.10 \mathrm{mmol}$ ) was added drop-wise at ca. $-116^{\circ} \mathrm{C}$. The reaction was let to stir for $19 \mathrm{~h}$ at RT. The reaction was cooled to $0^{\circ} \mathrm{C}$ and then slowly quenched with $10 \mathrm{~mL}$ of water. The reaction mixture was extracted with DCM $(3 \times 30 \mathrm{~mL})$. To the combined organic layers was added $\mathrm{MnO}_{2}(20.0 \mathrm{~g}, 230.0$ $\mathrm{mmol}$ ) and stirred for $30 \mathrm{~min}$. The mixture was dried over $\mathrm{MgSO}_{4}$ and stirred for an additional $30 \mathrm{~min}$. The mixture was filtered and volatiles were removed in vacuo. Column chromatography using EtOAc:Hex (9:1, $\left.R_{f}=0.19\right)$ as an eluent afforded the product as a beige solid (0.10 g, 20\%). ${ }^{1} \mathrm{H} \mathrm{NMR}\left(400 \mathrm{MHz}, \mathrm{CDCl}_{3}\right): \delta=9.05(\mathrm{~d}, J=4.40 \mathrm{~Hz}, 1 \mathrm{H}), 7.97(\mathrm{~d}, J=9.60 \mathrm{~Hz}, 1 \mathrm{H}), 7.93(\mathrm{~d}, J=9.20$ 
$\mathrm{Hz}, 1 \mathrm{H}), 7.57(\mathrm{~s}, 1 \mathrm{H}), 7.40(\mathrm{~d}, J=4.4 \mathrm{~Hz}, 1 \mathrm{H}), 2.76(\mathrm{~s}, 6 \mathrm{H}), 1.59$ (s, 9H). HRMS (EI-TOF): $m / z$ 264.1631 ( $\mathrm{M}^{+}$) calculated for $\mathrm{C}_{18} \mathrm{H}_{20} \mathrm{~N}_{2}: m / z 264.1626$.

\section{2-(tert-butyl)-1,10-phenanthroline-4,7-dicarbaldehyde (2.37b)}

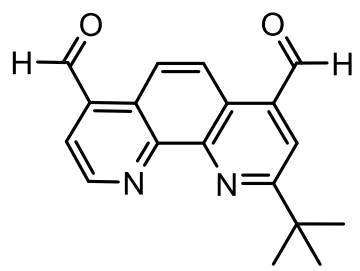

A mixture of $2.36 \mathrm{~b}(0.10 \mathrm{~g}, 0.39 \mathrm{mmol})$ and selenium dioxide $(0.17 \mathrm{~g}, 1.56 \mathrm{mmol})$ in dioxane containing $4 \% \mathrm{H}_{2} \mathrm{O}(20 \mathrm{~mL})$ was heated under reflux for $3 \mathrm{~h}$. The mixture was hot filtered through a pad of Celite. The filtrate was cooled to RT and extracted with sat. sodium bicarbonate and $\mathrm{DCM}(2 \times 30 \mathrm{~mL})$, dried over $\mathrm{MgSO}_{4}$, filtered, and the solvent removed in vacuo. The solid crude was triturated in hexanes to afford a light orange solid $\left(7.40 \times 10^{-3} \mathrm{~g}\right.$, 6.5\%). ${ }^{1} \mathrm{H}$ NMR $\left(400 \mathrm{MHz}, \mathrm{CDCl}_{3}\right): \delta=10.64(\mathrm{~d}, J=8.0 \mathrm{~Hz}, 2 \mathrm{H}), 9.55(\mathrm{~d}, J=4.4 \mathrm{~Hz}, 1 \mathrm{H}), 9.15$ (q, $J$ $=9.2 \mathrm{~Hz}, 2 \mathrm{H}), 8.19(\mathrm{~s}, 1 \mathrm{H}), 8.04(\mathrm{~d}, J=4.4 \mathrm{~Hz}, 1 \mathrm{H}), 1.66(\mathrm{~s}, 9 \mathrm{H})$. HRMS was not obtained.

\section{2,9-di-tert-butyl-4,7-dimethyl-1,10-phenanthroline (2.36)}

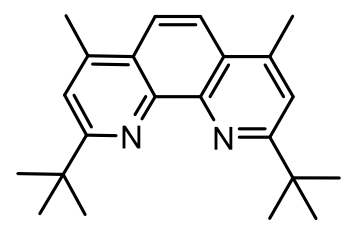

Under an atmosphere of $\mathrm{N}_{2}$, a solution of $2.35(0.48 \mathrm{~g}, 2.31 \mathrm{mmol})$ in $40 \mathrm{~mL}$ of dry toluene was prepared in a $250 \mathrm{~mL}$ Schlenk flask equipped with a stir bar. To the stirring solution, $t$ butylithium $(5.70 \mathrm{~mL}$ ) was added drop-wise over a duration of 25 min while maintaining a temperature below $30^{\circ} \mathrm{C}$. The reaction was left to stir for $4 \mathrm{~h}$. The reaction was slowly quenched with $12 \mathrm{~mL}$ of distilled water and then extracted with DCM $(3 \times 30 \mathrm{~mL})$. To the combined organic layers was added $\mathrm{MnO}_{2}(10.0 \mathrm{~g}, 115.0 \mathrm{mmol})$ over 1-2 g increments portion-wise and stirred for $5 \mathrm{~h}$. The aromatization was monitored by TLC in EtOAc:Hex (8:2). The mixture was dried over $\mathrm{MgSO}_{4}$, filtered and the solvent removed in vacuo. Column chromatography was 
done using EtOAc:Hex $\left(8: 2, R_{f}=0.83\right)$ to afford a light red solid $(0.446 \mathrm{~g}, 60 \%) .{ }^{1} \mathrm{H}$ NMR (400 $\left.\mathrm{MHz}, \mathrm{CDCl}_{3}\right): \delta=7.93(\mathrm{~s}, 2 \mathrm{H}), 7.52(\mathrm{~s}, 2 \mathrm{H}), 2.76(\mathrm{~s}, 6 \mathrm{H}), 1.60(\mathrm{~s}, 18 \mathrm{H}) .{ }^{13} \mathrm{C}\left\{{ }^{1} \mathrm{H}\right\} \mathrm{NMR}(100 \mathrm{MHz}$, $\left.\mathrm{CDCl}_{3}\right): \delta=168.77,145.06,143.63,126.34,121.12,120.56,38.62,30.38,19.53$. HRMS (EI-TOF): $\mathrm{m} / \mathrm{z} 320.2261\left(\mathrm{M}^{+}\right)$calculated for $\mathrm{C}_{22} \mathrm{H}_{28} \mathrm{~N}_{2}: \mathrm{m} / \mathrm{z} 320.2252$.

\section{2,9-di-tert-butyl-1,10-phenanthroline-4,7-dicarbaldehyde (2.37)}

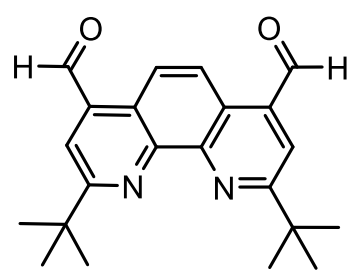

A mixture of 2.36 (160.7 $\mathrm{mg}, 0.5013 \mathrm{mmol})$ and selenium dioxide $(223.4 \mathrm{mg}, 2.0133 \mathrm{mmol})$ in dioxane containing $4 \% \mathrm{H}_{2} \mathrm{O}(20 \mathrm{~mL})$ was heated to reflux for $3 \mathrm{~h}$. The crude was immediately filtered through a pad of Celite. A saturated solution of $\mathrm{NaHCO}_{3}$ was added to the filtrate and stirred for $1 \mathrm{~h}$. The mixture was extracted with chloroform $(2 \times 30 \mathrm{~mL})$. The organic layer was collected, dried over $\mathrm{MgSO}_{4}$, filtered, and most of the solvent removed in vacuo. The crude was precipitated with minimal hexane to yield the product as a light red solid powder $(0.0433 \mathrm{~g}$, 25\%). ${ }^{1} \mathrm{H}$ NMR (400 MHz, $\left.\mathrm{CDCl}_{3}\right): \delta=10.62(\mathrm{~s}, 2 \mathrm{H}), 9.06(\mathrm{~s}, 2 \mathrm{H}), 8.13(\mathrm{~s}, 2 \mathrm{H}), 1.65$ (s, 18H). ${ }^{13} \mathrm{C}\left\{{ }^{1} \mathrm{H}\right\} \operatorname{NMR}\left(100 \mathrm{MHz}, \mathrm{CDCl}_{3}\right): \delta=193.23,170.40,145.92,137.33,124.18,124.08,123.24$, 39.21, 30.27. HRMS (EI-TOF): $m / z 348.1832\left(\mathrm{M}^{+}\right)$calculated for $\mathrm{C}_{22} \mathrm{H}_{24} \mathrm{~N}_{2} \mathrm{O}_{2}: m / z 348.1838$.

\section{3-chloro-1-(thiophen-2-yl)propan-1-one (2.38)}<smiles>O=C(CCCl)c1cccs1</smiles>

Commercially available 3-chloropropionylchloride $(5.00 \mathrm{~g}, 40.0 \mathrm{mmol}$ ) was dissolved in $15.0 \mathrm{~mL}$ of dry DCM. A solution of $\mathrm{AlCl}_{3}(6.16 \mathrm{~g}$, $46 \mathrm{mmol})$ in $25 \mathrm{~mL} \mathrm{DCM}$ was prepared and added dropwise to the reaction mixture. The mixture was let to stir for $15 \mathrm{~min}$ at RT, then cooled to $0^{\circ} \mathrm{C}$ using an ice/water bath followed by slow addition of thiophene $(3.2 \mathrm{~mL}, 40 \mathrm{mmol})$ in $15 \mathrm{~mL}$ 
of DCM solution. The ice/water bath was removed and the reaction stirred for $4 \mathrm{~h}$. The reaction mixture was poured into ca. $100 \mathrm{~mL}$ ice/water mixture and extracted with diethyl ether $(20 \mathrm{~mL}$ $x$ 3). The organic layers were combined, dried over $\mathrm{Na}_{2} \mathrm{SO}_{4}$, filtered and solvent removed in vacuo to afford a dark yellow-green oil $(6.13 \mathrm{~g}, 88 \%)$. ${ }^{1} \mathrm{H} \mathrm{NMR}\left(400 \mathrm{MHz}, \mathrm{CDCl}_{3}\right): \delta=7.72$ (d, $J=$ $4.0 \mathrm{~Hz}, 1 \mathrm{H}), 7.65(\mathrm{~d}, J=4.0 \mathrm{~Hz}, 1 \mathrm{H}), 7.13(\mathrm{t}, J=4.0 \mathrm{~Hz}, 1 \mathrm{H}), 3.88(\mathrm{t}, J=8.0 \mathrm{~Hz}, 2 \mathrm{H}), 3.36(\mathrm{t}, J=8.0$ $\mathrm{Hz}, 2 \mathrm{H})$. Spectroscopic data is consistent with the literature. ${ }^{47}$

\section{1-(thiophen-2-yl)prop-2-en-1-one (2.39)}

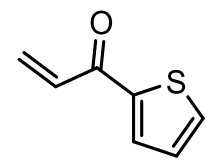

To a $250 \mathrm{~mL}$ RBF, $2.38(2.0 \mathrm{~g}, 11.5 \mathrm{mmol})$ was dissolved in $60 \mathrm{~mL}$ of diethyl ether and $10 \mathrm{~mL}$ of DCM, followed by addition of trimethylamine $(2.3 \mathrm{~mL}, 16.6 \mathrm{mmol})$. The reaction was left to stir for $87 \mathrm{~h}$ at RT. The reaction mixture was washed with $10 \% \mathrm{HCl}$ solution $(2 \times 50 \mathrm{~mL})$, the organic layer was combined. The aqueous layer was combined and back-extracted with diethyl ether ( 2 $\times 20 \mathrm{~mL}$ ), all organic layers were combined, dried over $\mathrm{Na}_{2} \mathrm{SO}_{4}$, filtered and solvent removed in vacuo to afford a dark yellow oil $(1.47 \mathrm{~g}, 93 \%) .{ }^{1} \mathrm{H} \mathrm{NMR}\left(400 \mathrm{MHz}, \mathrm{CDCl}_{3}\right): \delta=7.76(\mathrm{~d}, J=4.0 \mathrm{~Hz}$, $1 \mathrm{H}), 7.66(\mathrm{~d}, J=4.0 \mathrm{~Hz}, 1 \mathrm{H}), 7.13(\mathrm{t}, 1 \mathrm{H}, J=4.0 \mathrm{~Hz}), 7.06(\mathrm{dd}, J=8.0 \mathrm{~Hz}, J=16.0 \mathrm{~Hz}, 1 \mathrm{H}), 6.49$ (d, $J=16.0 \mathrm{~Hz}, 1 \mathrm{H}), 5.85(\mathrm{~d}, J=8.0 \mathrm{~Hz}, 1 \mathrm{H})$. Spectroscopic data is consistent with the literature. ${ }^{49}$

\section{4,7-di(thiophen-2-yl)-1,10-phenanthroline (2.40)}

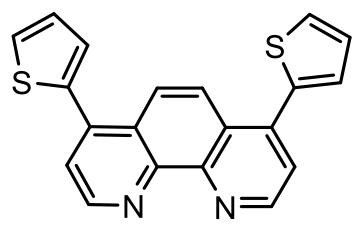

To a $250 \mathrm{~mL}$ RBF, o-phenylenediamine $(2.36 \mathrm{~g}, 21.8 \mathrm{mmol})$ was slowly dissolved in $30.0 \mathrm{~mL}$ of conc. $\mathrm{HCl}(12 \mathrm{M})$ at room temperature. The suspension was heated to $60^{\circ} \mathrm{C}$ for $2 \mathrm{~h}$, the temperature was then increased to $90^{\circ} \mathrm{C}$ and $2.39(7.84 \mathrm{~mL}, 56.7 \mathrm{mmol})$ was added dropwise, 
the mixture stirred for $3 \mathrm{~h}$ followed by addition of acetic acid $(30 \mathrm{~mL}$ ). The reaction was heated to reflux and stirred overnight. The reaction was cooled to room temperature, then placed in a ice bath. To the crude mixture was added ca. mixture of water/ice and basification with sat. NH${ }_{4} \mathrm{OH}$ to a $\mathrm{pH} 8-10$. The crude was washed with $\mathrm{DCM}(100 \mathrm{~mL} \times 3)$. The organic layers were combined, dried over $\mathrm{Na}_{2} \mathrm{SO}_{4}$, filtered and solvent evaporated. The crude material was dissolved with Hexanes, the insoluble material was let to settle and the liquid was decanted and solvent evaporated. The crude was purified by column chromatography using $4 \% \mathrm{MeOH}$ in EtOAc as an eluent $(\mathrm{Rf}=0.15)$ to afford the product as an off-white powder $(62 \mathrm{mg}, 0.82 \%) .{ }^{1} \mathrm{H}$ $\operatorname{NMR}\left(400 \mathrm{MHz}, \mathrm{CDCl}_{3}\right): \delta=9.19(\mathrm{~d}, 2 \mathrm{H}, J=4.8 \mathrm{~Hz}), 8.26(\mathrm{~s}, 2 \mathrm{H}), 7.68(\mathrm{~d}, 2 \mathrm{H}, J=4.8 \mathrm{~Hz}), 7.53(\mathrm{~d}$, $2 \mathrm{H}, J=5.2 \mathrm{~Hz}), 7.38(\mathrm{~d}, 2 \mathrm{H}, J=3.2 \mathrm{~Hz}), 7.23(\mathrm{t}, 2 \mathrm{H}, J=4.4 \mathrm{~Hz})$. HRMS (EI-TOF): $m / z 344.0449\left(\mathrm{M}^{+}\right.$) calculated for $\mathrm{C}_{20} \mathrm{H}_{12} \mathrm{~N}_{2} \mathrm{~S}_{2}: m / z 344.0442$. 


\section{CHAPTER 3 - NOVEL FERROCENE-BODIPY DYES}

\subsection{Introduction}

Iron is an attractive transition metal that could be incorporated into the dye framework. The metal ion can exist in two oxidation states $2+$ and $3+$. Ferrocene was one of the first organometallic compounds with several appealing factors such as good redox stability, robustness, affordability and richness in literature studies. ${ }^{50}$ Integrating ferrocene as a bifunctional redox-active chromophore and donor would make sense. Ferrocene is a ubiquitous organometallic compound, ${ }^{50}$ yet to date, there have been no reports of a BODIPY dye molecule used for DSSC studies bearing a ferrocene moiety. There are however studies of electron transfer between BODIPY and ferrocene which supports these derivatives/systems as plausible dyes for the DSSC.

\subsubsection{First iron dye for DSSC}

The first iron-based dye reported was structurally similar to the ruthenium complex N3, with the metal being substituted for iron(II) and the absence of sulfur atoms on the bipyridine ligands (Figure 3.1). ${ }^{51}$

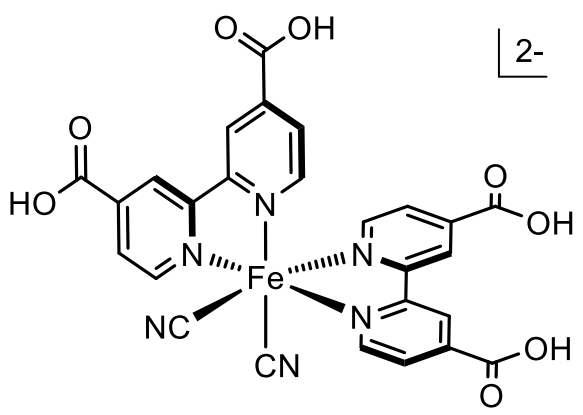

3.1

Figure 3.1. First iron complex used as a dye

This iron complex possesses a short-lived excited state and ability to photosensitize ${ }^{51}$ Upon photoexcitation, iron complexes go through rapid internal conversion resulting in a low electron 
injection probability. Iron complex 3.1 exhibits two absorption bands yet is photosensitized from only one absorption band. Specifically, electron injection into $\mathrm{TiO}_{2}$ is favoured at a high energy MLCT $(\sim 420 \mathrm{~nm})$ rather than at low energy MLCT (600 nm). Nevertheless, the conversion efficiency of this dye at $10 \%$ shows potential as an alternative to the ruthenium dyes. $^{51}$

\subsubsection{Ferrocene-based DSSC dyes}

DSSC dyes containing ferrocene have been studied by Chauhan, et al. with various electron withdrawing groups (Figure 3.2). Electrochemistry studies showed one quasi-reversible oxidation potential at which dye $\mathbf{3 . 2}$ was more easily oxidized than $\mathbf{3 . 3}$ and $\mathbf{3 . 4}$ (Table 3.1). DFT calculations showed that when the dye is oxidized; the electron is ejected from the iron metal center. The oxidation potential may be affected by the appended anchoring groups.

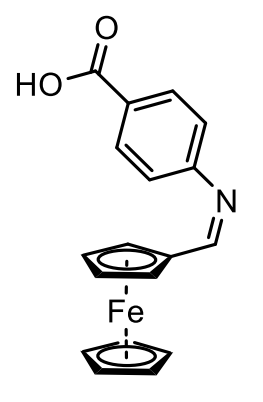

3.2

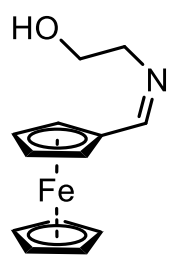

3.3

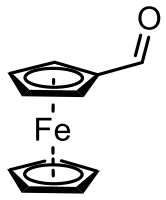

3.4

Figure 3.2. Ferrocene dyes

Table 3.1. Physico-chemical data of dyes and their efficiencies in a DSSC

\begin{tabular}{lll}
\hline Dye & ${E_{\text {ox }}{ }^{\circ \prime}}$ & $\eta(\%)$ \\
\hline 3.2 & 0.34 & 0.81 \\
3.3 & 0.44 & 0.68 \\
3.4 & 0.44 & 0.73
\end{tabular}


A stability test was performed on a DSSC cell with dye 3.2 over $1400 \mathrm{~h}$ under irradiation of 470 $\mathrm{mW} / \mathrm{cm}^{2}$. The open-circuit voltage underwent flux through the first $900 \mathrm{~h}$ and then leveled off. Besides some minor changes, 93\% of the cell's initial output efficiency was retained. Dye $\mathbf{3 . 2}$ had the highest efficiency amongst the ferrocene dyes (Table 3.1). It could be noted that most dyes are anchored to $\mathrm{TiO}_{2}$ through carboxylic acid groups which could have played a role on the efficacy/ efficiency of the dye. Although the efficiencies were below $1 \%$, this study has shown that ferrocene can be integrated to the dye framework for the DSSC. ${ }^{52}$ In the next sections of this chapter, the properties of BODIPY with ferrocene appended to the chromophore will be explored. The scope of the BODIPY-ferrocene compounds will involve methylated BODIPYs with the exception of the $\alpha$-substituted and ferrocene-pyridone BODIPYs, as they exhibit relevance to this thesis project.

\subsection{3. meso-substituted methylated ferrocenyl BODIPY}

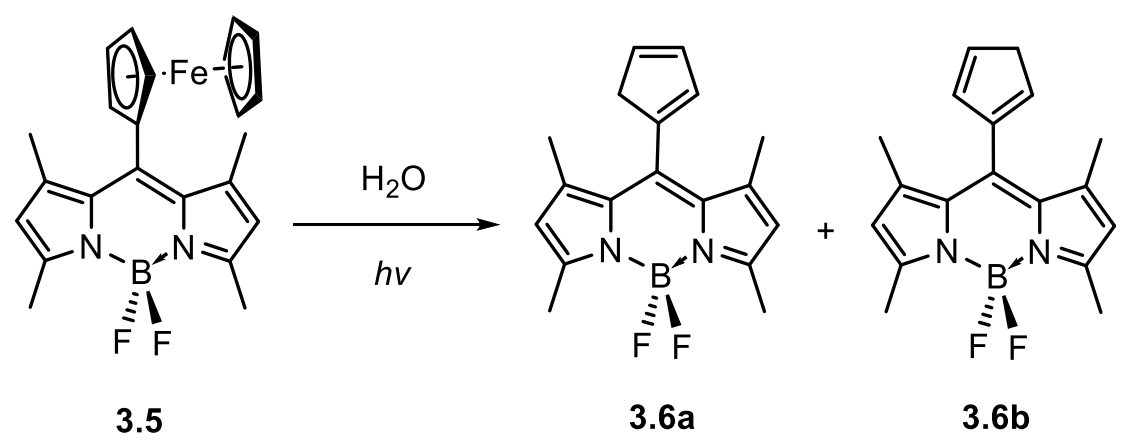

Figure 3.3. Dissociation of compound $\mathbf{3 . 5}$ under reaction with water and ambient light ${ }^{53}$

Chen, Chen, Shi and Ma, et al. were the first to synthesize a BODIPY-ferrocene dyad with ferrocene directly meso to methylated BODIPY (Figure 3.3). Compound 3.5 undergoes a photoinduced electron transfer (PET) process from the ferrocene donor to the BODIPY acceptor with ferrocene being responsible for quenching the fluorescence of BODIPY. In an aqueous medium under ambient light, the cyclopentadiene ring on ferrocene of compound $\mathbf{3 . 5}$ has been 
found to dissociate through hydrolysis. In a solution of $\mathbf{3 . 5} \mathrm{in} \mathrm{THF}$, as the concentration of $\mathrm{H}_{2} \mathrm{O}$ is increased, the absorption at $535 \mathrm{~nm}$ decreases and a new absorption at $503 \mathrm{~nm}$ forms. The blue shift in absorption was due to the reduced conjugation as a result of cleavage of the cyclopentadiene ( $c p)$ ring on ferrocene. The BODIPY-cp radical species reacts with a proton from $\mathrm{H}_{2} \mathrm{O}$ to form 3.6a and $\mathbf{3 . 6 b}$, this was confirmed with $\mathrm{D}_{2} \mathrm{O}$ and characterization by mass spectrometry. Interestingly, the fluorescence of $\mathbf{3 . 6 a}$ and $\mathbf{3 . 6 \mathbf { b }}$ were found to be enhanced. ${ }^{53}$ The findings from this study gave some insight to the BODIPY-ferrocene compounds in section 3.2. Intrigued by these findings, the literature was explored to see if the dissociation of the ferrocene sandwich occurred in other ferrocene-BODIPY compounds.

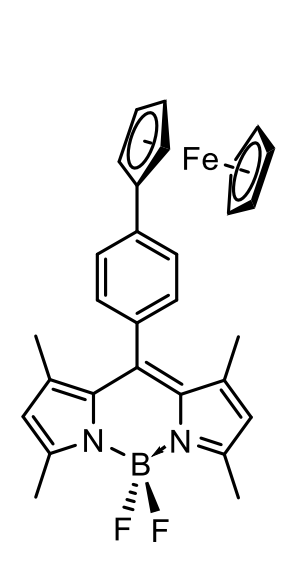

3.7

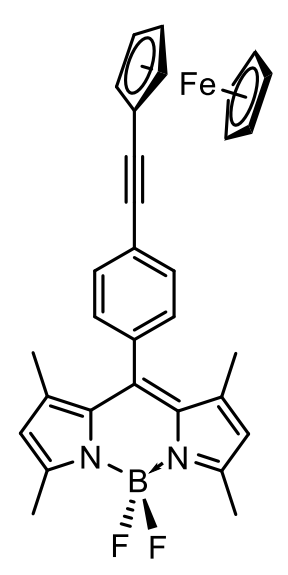

3.8

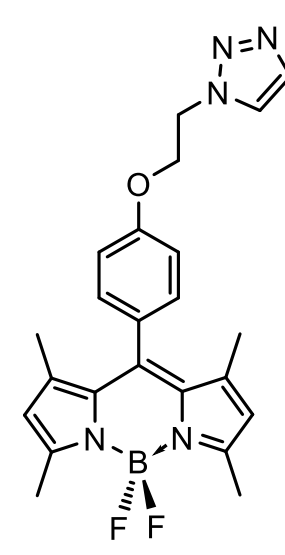

3.9

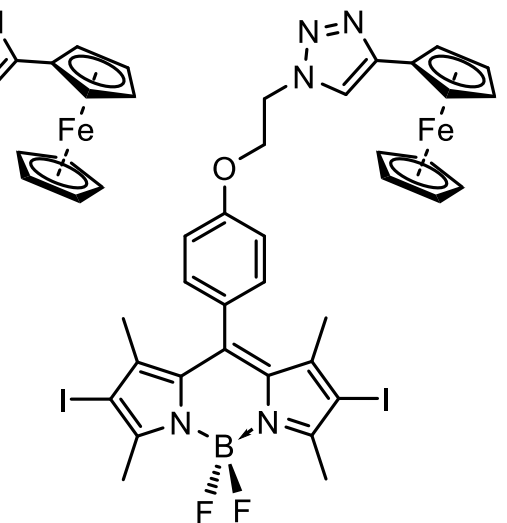

3.10

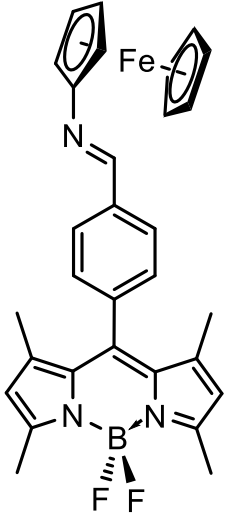

3.11

Figure 3.4. meso-substituted ferrocenyl tetramethyl-BODIPY dyads with various bridges/linkers ${ }^{54,55,56}$

Yin et al. studied two ferrocene-BODIPY dyads with varying bridges (Figure 3.4). From cyclic voltammetry studies, BODIPY 3.8 has a higher oxidation potential than $\mathbf{3 . 7}$ due to the electron withdrawing characteristic of the ethynyl bridge. The fluorescent behaviour upon addition of ethylene glycol and THF to a solution of the BODIPYs were observed, the more viscous the solution became, the greater the fluorescent intensity and quantum yield. This relationship 
went in line with the Förster-Hoffman equation which suggests that the BODIPY with ethynyl group does have the ability to act as a rotor at the bond between the phenyl and ferrocene group. ${ }^{54} \mathrm{Wu}$ and associates synthesized a series of meso-substituted tetra-methylated BODIPY ferrocene with varying linkers as well. Both dyads 3.8-3.10 and references dyads without the ferrocene unit had minor differences in absorption profile and redox potentials which indicate that there is minimal to no electronic communication between the ferrocene and BODIPY in the singlet ground state due to no conjugation. The electron transfer rate constants of $\mathbf{3 . 8}$ $(2.11 \pm 0.11) \times 10^{9} \mathrm{~s}^{-1}$ and $3.9(1.15 \pm 0.06) \times 10^{9} \mathrm{~s}^{-1}$ shows that the electron transfer is affected by the bridges between the ferrocene and BODIPY unit. Quenching of the fluorescence was observed for the emission spectra of 3.8-3.10 in comparison to the reference dyads without the ferrocene unit. The emission profile of dyad $\mathbf{3 . 8}$ and $\mathbf{3 . 9}$ dramatically decreased compared to 3.10. The fluorescence emission of dyads $\mathbf{3 . 8}$ and $\mathbf{3 . 9}$ was enhanced upon electrochemical oxidation. Conversely, the fluorescence emission of oxidized $\mathbf{3 . 8}$ and $\mathbf{3 . 9}$ can be quenched upon electrochemical reduction. It was also found that the triplet excited state of $\mathbf{3 . 1 0}$ undergoes quenching through both photo-induced electron transfer (PET) and triplet-triplet electron transfer (TTET) mechanism. The extent of quenching is faster in polar solvent (acetonitrile) vs. non-polar solvent (toluene).$^{55}$ Kaur et al. studied a ferrocene-BODIPY dyad with an imine linker. Similar to 3.8 and 3.9, the fluorescence emission of $\mathbf{3 . 1 1}$ is low $(\phi=0.00068)$ owing to the electron transfer process from ferrocene to BODIPY. The fluorescence emission of dyad $\mathbf{3 . 1 1}$ was enhanced by chemical oxidation with iron(III) perchlorate $(\phi=0.05487)$ and quenched $(\phi=$ 0.00182 ) using hydrazine hydrate. Dyad 3.11 displays a low anodic peak potential of $1.176 \mathrm{~V}$ compared to a dyad with ferrocene directly appended to a non-methylated BODIPY core, implying that electronic communication is weak between ferrocene and BODIPY with an imine linker. ${ }^{56}$ 


\subsection{4. $\alpha, \beta$-unsaturated carbene-BODIPY dyads with varying metals}

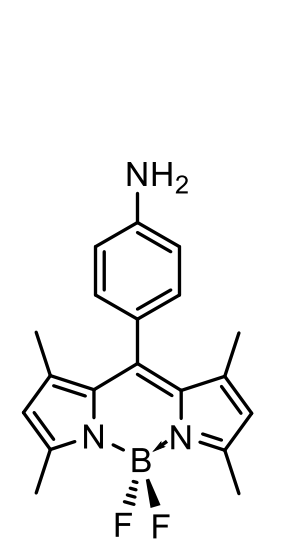

3.12

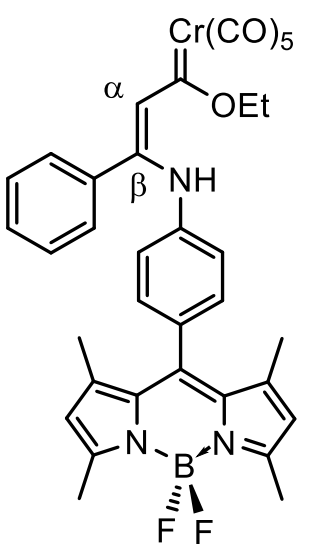

3.13

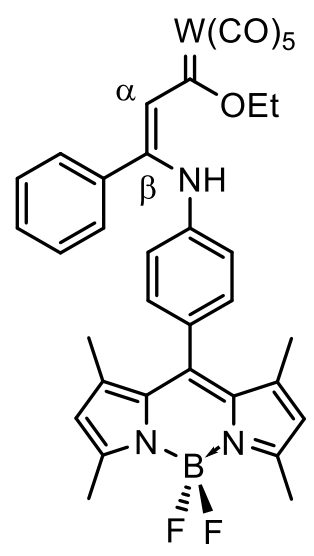

3.14

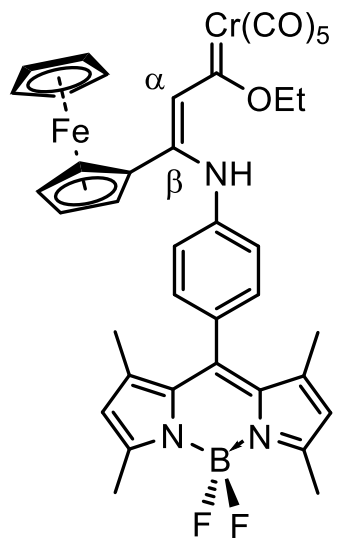

3.15

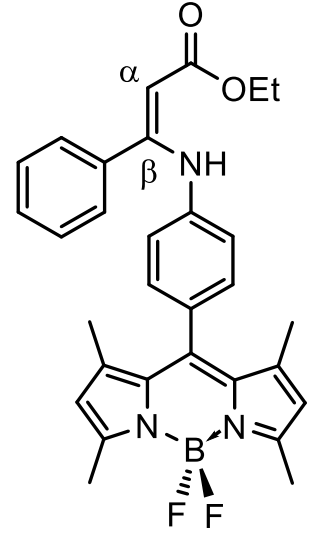

3.16

Figure 3.5. Fischer-carbene BODIPY dyads ${ }^{57}$

A family of Fischer carbene-BODIPY dyads with chromium and tungsten carbonyls were synthesized through a 1,4-addition reaction of $\mathbf{3 . 1 2}$ to a ethynylmetal(0) carbene complex. Modification of substituents on the carbene allowed for tuning of the emissive behaviour of dyads shown in Figure 3.5. From the x-ray crystal structure of dyad 3.14, the dihedral angle between the anilinyl-phenyl moiety attached directly to BODIPY was over $90^{\circ}$, which was attributed to sterics between the methyl groups on BODIPY with the phenyl moiety. It was noted that changes in the dihedral angle were influenced by substituents on the $\beta$-carbon. Irreversible oxidation peaks were assigned for both dyads $\mathbf{3 . 1 3}$ and 3.14, the peak around 0.98 $\mathrm{V}$ was correlated to formation of the radical cation on the pentacarbonyl-transition metal(0) complex. The UV-Vis absorption of 3.13-3.15 showed minimal difference, each exhibit an MLCT and a ligand-field absorption at ca. $350 \mathrm{~nm}$ correlating to the pentacarbonyl-transition metal carbene unit, as well as a $\pi-\pi^{*}$ transition at ca. $500 \mathrm{~nm}$ owing to the BODIPY core. ${ }^{57}$

Dyad 3.13 and 3.15 had a significantly low fluorescence intensity compared to 3.16. A decrease in fluorescence for $\mathbf{3 . 1 3}$ suggests that $\pi$-conjugation does not have a strong effect on the 
emissive properties of these set of dyads. The trend shows that $\pi$-donor groups at the paraposition of the phenyl ring attached to the $\beta$-carbon yield higher intense emission compared to $\pi$-acceptors. As a result, the type of substituent appended to these organometallic BODIPY dyads can tune the emissive properties by $\pi$-conjugation. ${ }^{57}$

\subsection{5. $\alpha$-substituted ferrocenyl BODIPY}

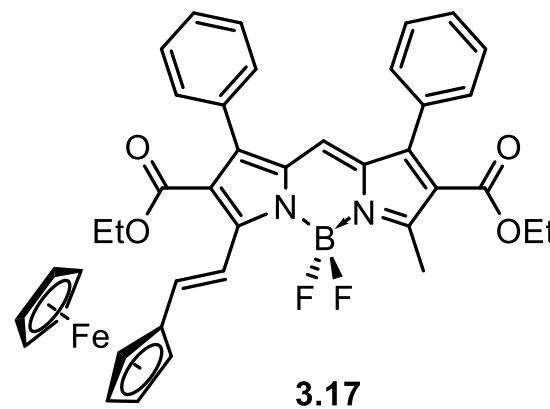

3.17

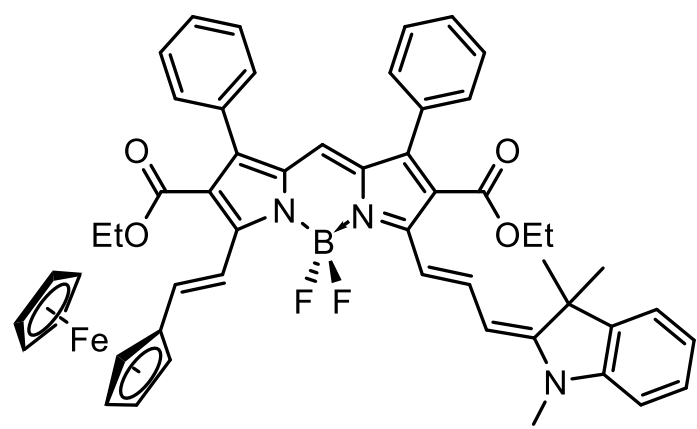

3.19

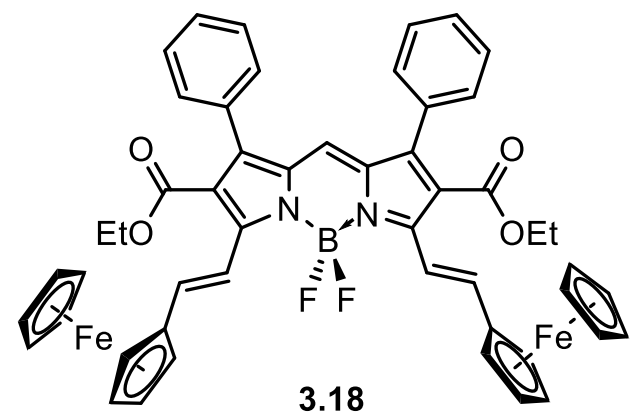

3.18

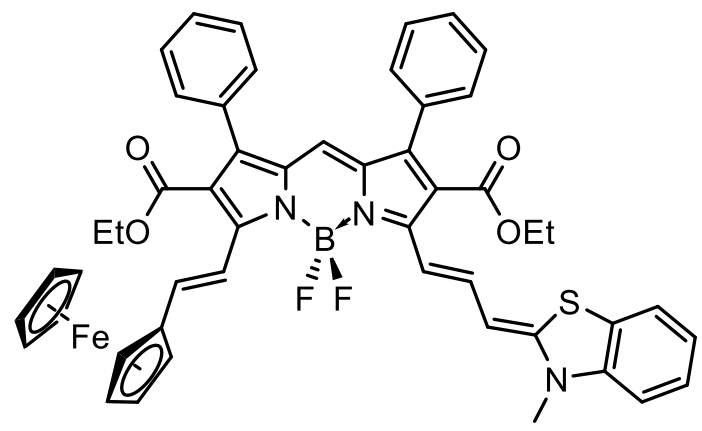

3.20

Figure 3.6. $\alpha$-substituted ferrocenyl BODIPY dyads and triads ${ }^{58,59}$

In a study by Zatsikha et al., donor-acceptor dyads with ferrocene installed on the $\alpha$-position to BODIPY through a vinyl bridge were examined (Figure 3.6). The dyads were found to be unexpectedly stable and the vinyl bridge secured planarity between the BODIPY core and ferrocene substituent with torsion angles ranging from $173.3^{\circ}$ to $177.0^{\circ}$. The UV-Vis absorption spectra of $\mathbf{3 . 1 7}$ and $\mathbf{3 . 1 8}$ show a sharp absorption band from 554 to $613 \mathrm{~nm}$ assigned to $\pi$ to $\pi^{*}$ 
transition of the BODIPY core and a broad absorption band from 673 to $750 \mathrm{~nm}$ assigned to a MLCT transition. Compounds $\mathbf{3 . 1 7}$ and $\mathbf{3 . 1 8}$ each have one quasi-reversible reduction potential and one quasi-reversible oxidation potential, both assigned to BODIPY. 3.17 has one reversible oxidation potential. The first oxidation of $\mathbf{3 . 1 7}$ under spectroelectrochemical conditions shows major changes to the profile of the MLCT transition, in contrast to the $\pi$ to $\pi^{*}$ transition absorption with a small red shift in absorption. The reversible oxidation of $\mathbf{3 . 1 7}$ was assigned to the ferrocene unit. Compound $\mathbf{3 . 1 8}$ has two reversible oxidation potentials owing to both the ferrocene units based on spectroelectrochemical experiments. The fluorescence was found to be enhanced with oxidation of the ferrocene unit using iron(III) perchlorate as an oxidizing agent. ${ }^{58}$ In a recent report, Zatsikha et al. synthesized a duet of ferrocene-BODIPYmerocyanine triads via a sequence of condensation reactions. It was found that the $\alpha$-carbon of the polymethine unit of $\mathbf{3 . 1 9}$ and $\mathbf{3 . 2 0}$ was prone to protonation upon addition of trifluoroacetic acid (TFA), the triads can be restored using an organic base. In contrast to dyads $\mathbf{3 . 1 7}$ and $\mathbf{3 . 1 8 \text { , }}$ triads 3.19 and $\mathbf{3 . 2 0}$ possess a broad absorption in the near-IR region around $800 \mathrm{~nm}$ that may be attributed to energy overlap between the molecular orbitals (MOs) of ferrocene and the $\pi$ orbitals of BODIPYmerocyanine. Similar to $\mathbf{3 . 1 7}$ and 3.18, the reduction potentials of 3.19 and 3.20 are quasi-reversible owing to the BODIPYmerocyanine unit. The first quasi-reversible and second reversible oxidation potentials correlate to merocyanine unit and the ferrocene unit, respectively. ${ }^{59}$ 


\subsubsection{Ferrocene cyclized through a pyridine ring to BODIPY}

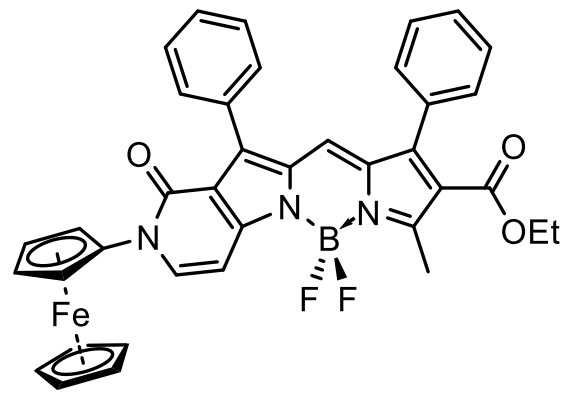

3.21

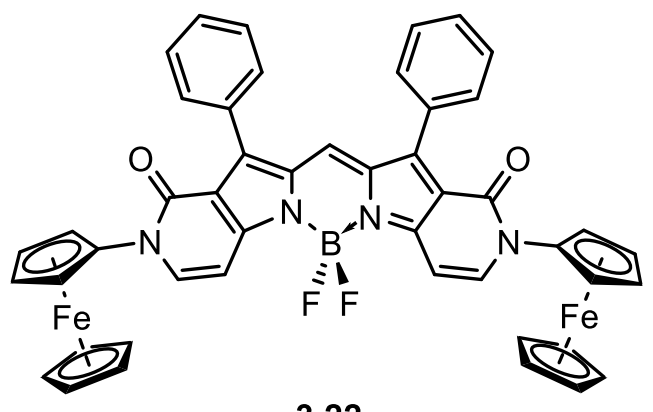

3.22

Figure 3.7. $N$-ferrocenyl-2-pyridone BODIPYs ${ }^{60}$

In a report by Zatsikha et al., $N$-ferrocenyl-2-pyridone BODIPYs (Figure 3.7) were synthesized by ferrocene-enamine cyclization reactions. ${ }^{60}$ Transient absorption spectroscopy data suggests that mono-ferrocene derivative $\mathbf{3} .21$ has a faster regeneration rate (14.6 ps vs. 134.9 ps) compared to di-ferrocene derivative 3.22. This is due to 3.21 having a higher energy HOMO on ferrocene, whereas the $\mathbf{3 . 2 2}$ has electron density distributed between two ferrocene groups that stabilizes the energy of the HOMO. Oxidation of $\mathbf{3 . 2 1}$ under spectroelectrochemical conditions results in decrease of the BODIPY $\pi-\pi^{*}$ transition absorption intensity and a blue shift. As $\mathbf{3 . 2 2}$ is oxidized under spectroelectrochemical conditions, the BODIPY $\pi-\pi^{*}$ transition absorption intensity decreases, blue shifts and splits into two absorption bands. Several new absorption bands increase and this spectroelectrochemical behaviour implies weak electronic communication from one ferrocene to the other ferrocene in compound $\mathbf{3 . 2 2}$ owing to strain between the nitrogen atom and $\mathrm{Cp}$-ring. ${ }^{60}$ 


\subsection{7. $\beta$-substituted ferrocenyl BODIPY}

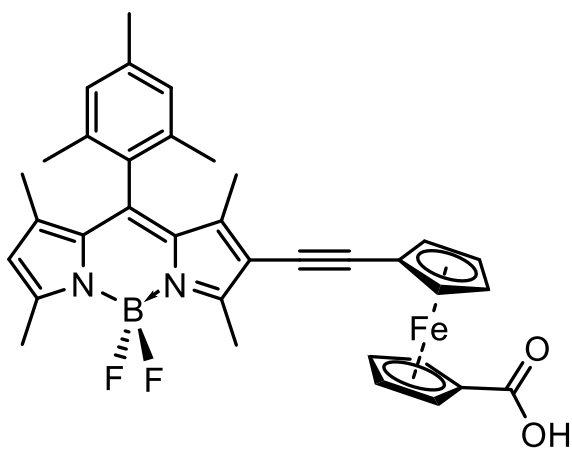

3.23

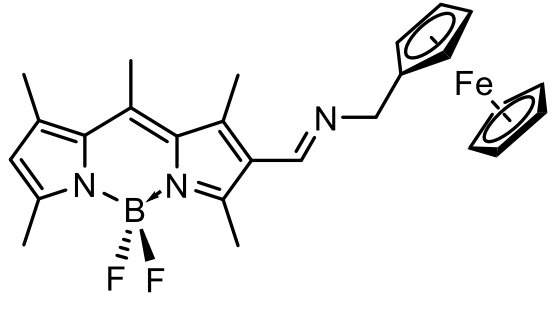

3.24

Figure 3.8. $\beta$-substituted ferrocenyl BODIPY ${ }^{61,62}$

Hofler et al., synthesized $\mathbf{3 . 2 3}$ through a palladium-catalyzed cross-coupling reaction. The UVVis data shows only one absorption at $533 \mathrm{~nm}$, likely corresponding to the BODIPY $\pi-\pi^{*}$ transition. Similar to other ferrocenyl BODIPY dyads, fluorescence intensity was low with a quantum yield less than 0.01 suggesting an electron transfer occurring in the excited state. It is noted that when $\mathbf{3 . 2 3}$ was subjected to a solution of 1,2-dichlorobenzene with $1 \% \mathrm{MeOH}$ and heated to $150^{\circ} \mathrm{C}$, the compound decomposed after $5 \mathrm{~h} .^{61}$

Sritharan et al., synthesized 3.24 using nucleophilic addition reaction to form a Schiff base bridged dyad. ${ }^{62}$ The UV-Vis absorption profile shows a $\pi-\pi^{*}$ transition for BODIPY at $511 \mathrm{~nm}$ and a MLCT absorption band around $560 \mathrm{~nm}$ owing to the ferrocene unit. ${ }^{62}$ Dyad 3.24 was also found to be unstable in solution under ambient conditions over time. ${ }^{53,62}$

As of yet, there are only two reports of methylated BODIPY dyads with ferrocene appended at the $\beta$-position. There exists a series of non-methylated BODIPY with $\alpha$-substituted ferrocene bound through an ethynyl linker, however no other physico-chemical properties were studied. In addition to the decomposition study in section 3.1.3, reports on this phenomena occurring in other ferrocene-BODIPY have yet to be discovered. Since there is limited structure-property 
relationship studies in the literature, this presented an opportunity for our group to embark in filling a gap on these BODIPY-ferrocene systems. 


\subsection{Thesis Objective}

Incorporating ferrocene into the D- $\pi-A$ framework utilizing BODIPY as a $\pi$-spacer was sought out. From a practical standpoint, marrying ferrocene with BODIPY was believed to be an ideal pairing as dyes for the DSSC system (Figure 3.9). Aryl groups were appended to the meso position of BODIPY in the hopes to tune the LUMO energy level of BODIPY.

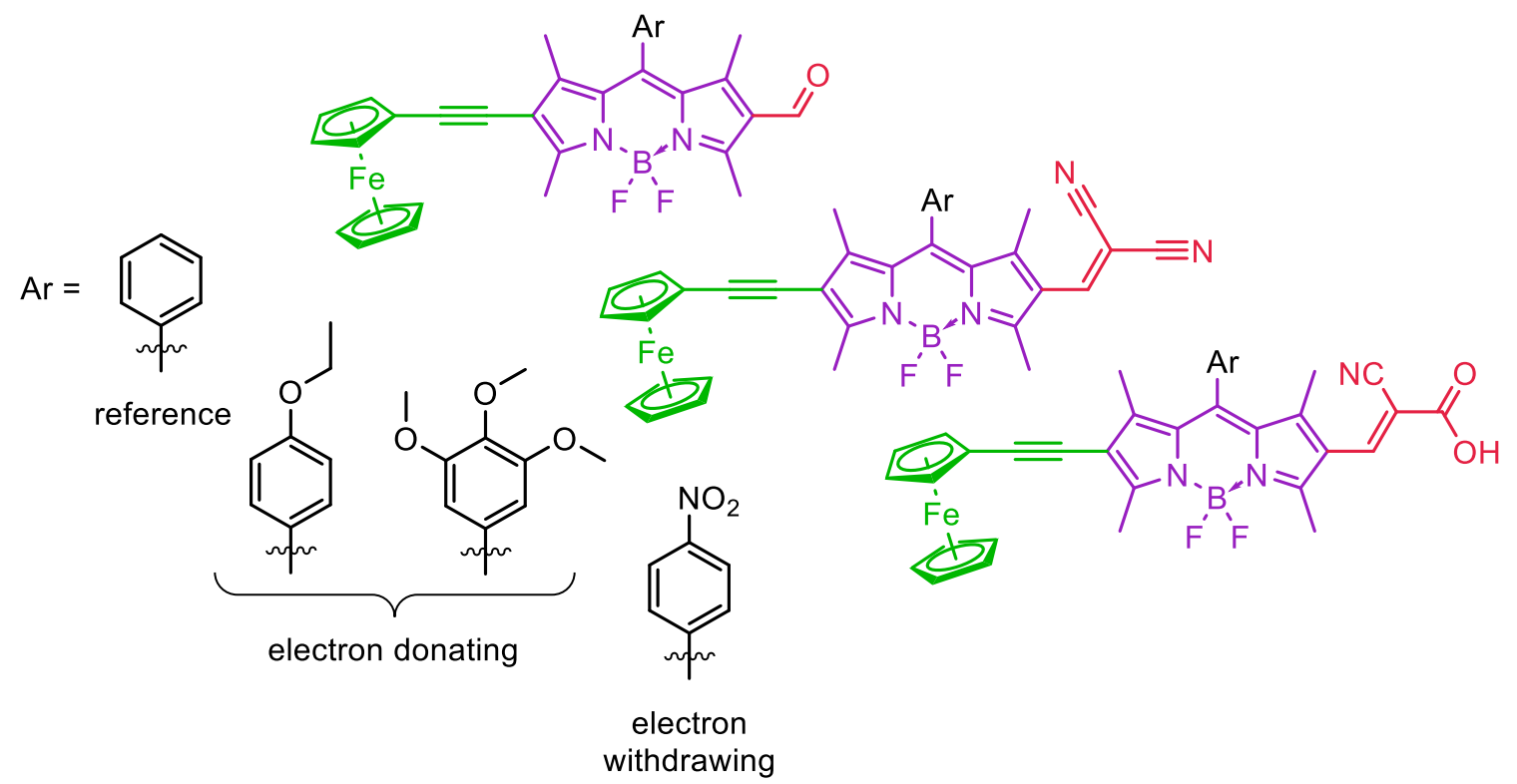

Figure 3.9. Ferrocenyl-BODIPY dyes connected through an ethynyl bridge 


\subsection{Synthesis}

\subsubsection{Synthesis of ferrocenyl BODIPY dyes}

The meso-substituted methylated BODIPY $\mathbf{3 . 2 7}$ was previously synthesized in our laboratory by Muhammad Yousaf through a condensation reaction between a benzaldehyde and 2,4dimethyl-1H-pyrrole. ${ }^{63}$ Using a literature procedure, ferrocene 3.25 was synthesized by a 'direct alkynylation' of the Cp-ring on ferrocene with the terminal alkyne of TMS-acetylene. Deprotection of $\mathbf{3 . 2 5}$ with potassium fluoride resulted in compound $\mathbf{3 . 2 6}{ }^{64}$ For this chapter, only compound $\mathbf{3 . 3 0}$ and $\mathbf{3 . 3 1}$ were synthesized and characterized (Scheme 3.1). Compound 3.29 was produced by formylation on one side of $\mathbf{3 . 2 7}$, followed by an iodination on the other side. The acetyl-ferrocene moiety was installed on $\mathbf{3 . 2 9}$ through a Sonogashira cross-coupling to form 3.30. Lastly, dye $\mathbf{3 . 3 1}$ was produced via a Knovenagel condensation with malononitrile. 

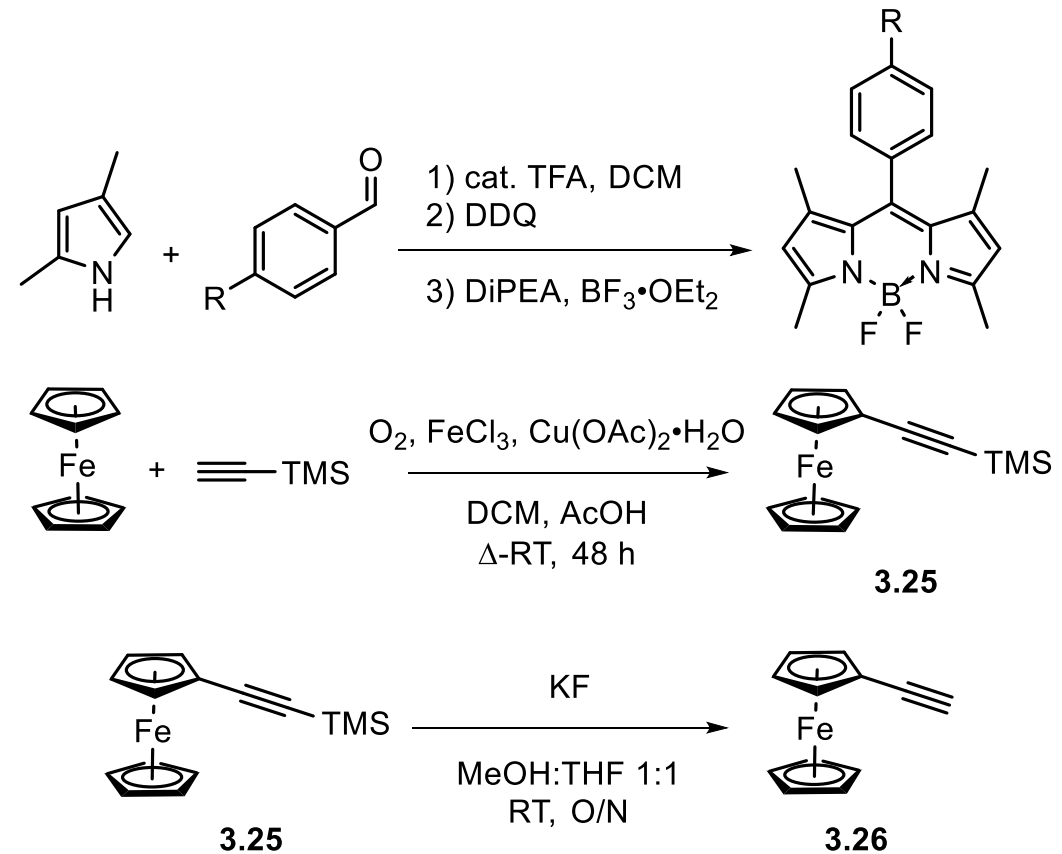<smiles></smiles>

3.27

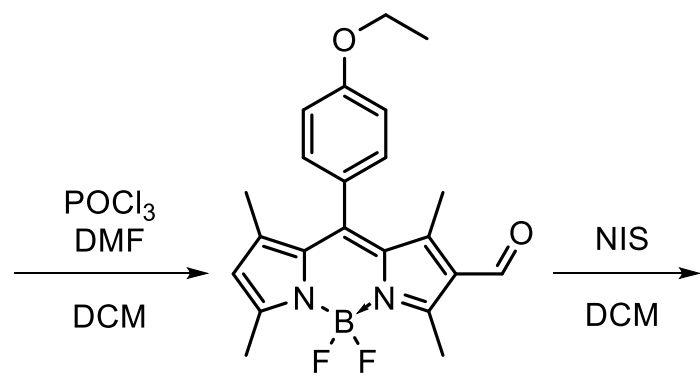

$3.28,66 \%$<smiles></smiles>

$3.29,82 \%$
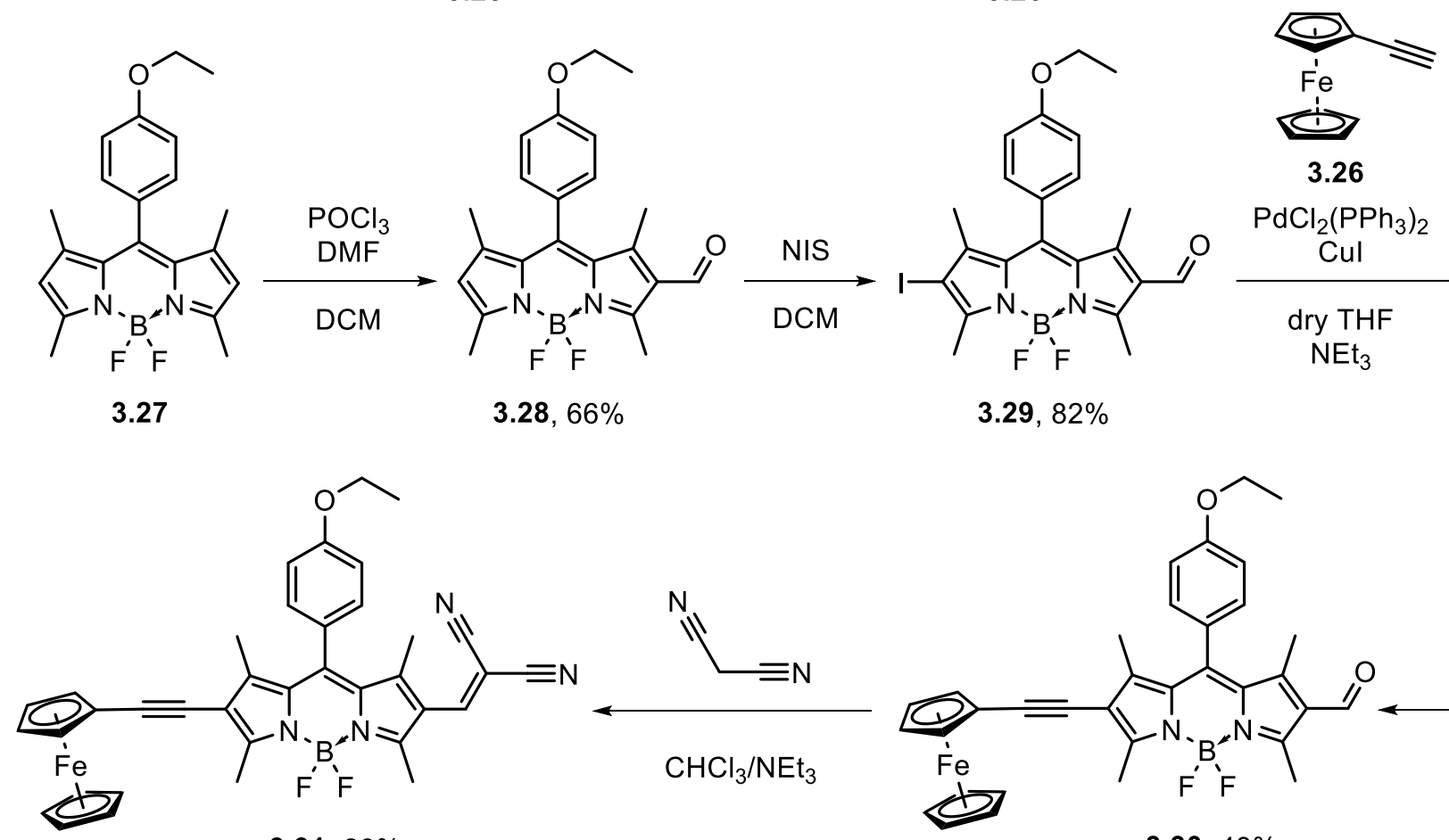

$3.31,28 \%$

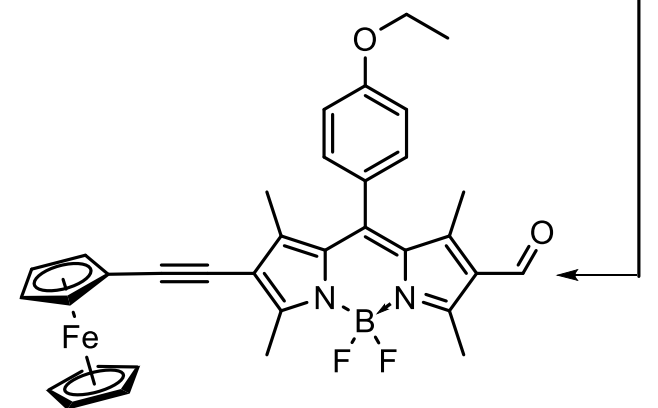

$3.30,43 \%$

Scheme 3.1. Synthetic scheme towards making ferrocenyl-BODIPY dyes 


\subsubsection{Characterization of of ferrocenyl BODIPY dyes}

The ${ }^{1} \mathrm{H}$ NMR of $\mathbf{3 . 2 8}$ shows four inequivalent singlets for the methyl groups on the BODIPY core in the aliphatic region. A singlet in the aromatic region at $6.13 \mathrm{ppm}$ is representative of the proton on the $\beta$-position of BODIPY. A singlet integrating for one proton at $9.99 \mathrm{ppm}$ is characteristic of the attached aldehyde group. lodinating $\mathbf{3 . 2 8}$ to give $\mathbf{3 . 2 9}$ resulted in absence of the singlet at $6.13 \mathrm{ppm}$ and little to no shifts in the other peaks. Cross-coupling with 3.26 resulted in three new singlets for the ferrocene moiety from $4.20 \mathrm{ppm}$ to $4.50 \mathrm{ppm}$ on $\mathbf{3 . 3 0}$. Converting the aldehyde group on $\mathbf{3 . 3 0}$ to a malononitrile group on $\mathbf{3 . 3 1}$ resulted in absence of the singlet at $9.99 \mathrm{ppm}$ and the presence of a singlet at $7.69 \mathrm{ppm}$ for the single proton on the malononitrile. The peaks corresponding to the methyl groups for BODIPY are slightly shifted up field on 3.31 compared to 3.30. The ${ }^{19} \mathrm{~F}$ NMR of 3.28, 3.29, 3.30 and $\mathbf{3 . 3 1}$ each shows four peaks due to coupling with a neighbouring ${ }^{11} \mathrm{~B}$ atom on BODIPY within the range of $-144.29 \mathrm{ppm}$ to $145.65 \mathrm{ppm}$. The ${ }^{11} \mathrm{~B}$ NMR shows a triplet due to coupling with two ${ }^{19} \mathrm{~F}$ atoms on BODIPY showing between $0.33 \mathrm{ppm}$ to $0.94 \mathrm{ppm}$. 


\subsection{Results \& Discussion}

Compounds $\mathbf{3 . 3 0}$ and $\mathbf{3 . 3 1}$ were synthesized as part of a contribution to the collection of ferrocenyl BODIPY's by our research group. ${ }^{65}$ Properties of compounds $\mathbf{3 . 3 0}$ and $\mathbf{3 . 3 1}$ were characterised by UV-Vis absorption spectroscopy, electrochemistry and density functional theory (DFT) to determine their plausibility as dyes. Their physicochemical properties will be compared and contrasted. 


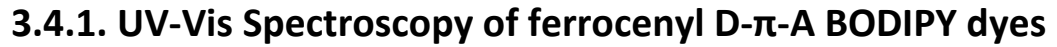

b)
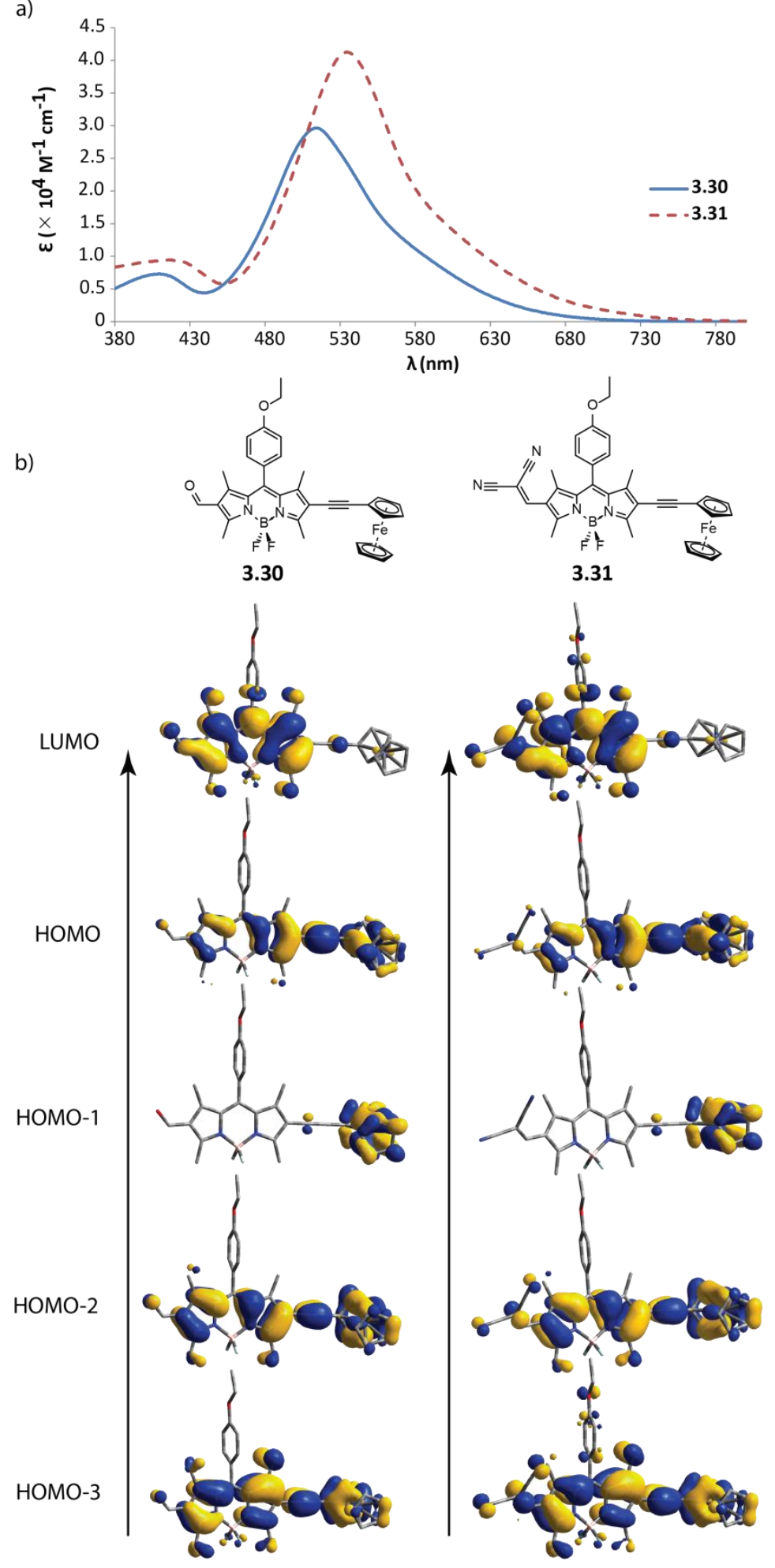

Figure 3.10. UV-Vis absorption spectra (a) and MOs (b) of BODIPY-Fc dyes $\mathbf{3 . 3 0}$ and $\mathbf{3 . 3 1}$ 
Based on computational calculations, both compounds $\mathbf{3 . 3 0}$ and $\mathbf{3 . 3 1}$ exhibit a dominant transition from the HOMO-3 to the LUMO as shown in Figure 3.10. The electron density on the HOMO-3 resides across the molecule and the electron density on the LUMO localized partially on the ethynyl group and mainly on BODIPY and the anchoring groups. This transition suggests that there is sufficient orbital overlap for electron transfer to occur. A favourable characteristic for a DSSC dye is panchromatic absorption of the visible to NIR spectrum. Compound $\mathbf{3 . 3 0}$ and 3.31 display an intense absorption in the $510-540 \mathrm{~nm}$ range characteristic of the $\pi-\pi^{*}$ transition for BODIPY. The absorption can be described as wide and asymmetric. Starting from $550 \mathrm{~nm}$, a metal-to-ligand charge transfer (MLCT) representative of ferrocene is present at the shoulder of the main absorption peak. In contrast, compound 3.31 displays a higher molar extinction coefficient and is further red shifted likely owing to the extended conjugation brought by the malononitrile anchoring unit (Table 3.2).

Table 3.2. UV-Vis absorption data of ferrocenyl-BODIPY dyes ${ }^{a}$

\begin{tabular}{lll}
\hline Compound & $\lambda_{\max }(\mathrm{nm})$ & $\varepsilon\left(\times 10^{4} \mathrm{M}^{-1} \mathrm{~cm}^{1}\right)$ \\
\hline $\mathbf{3 . 3 0}$ & 514 & 2.96 \\
$\mathbf{3 . 3 1}$ & 535 & 4.13
\end{tabular}

${ }^{a} U V-V i s$ absorptions were measured in DCM 


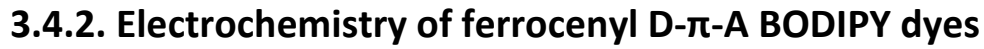
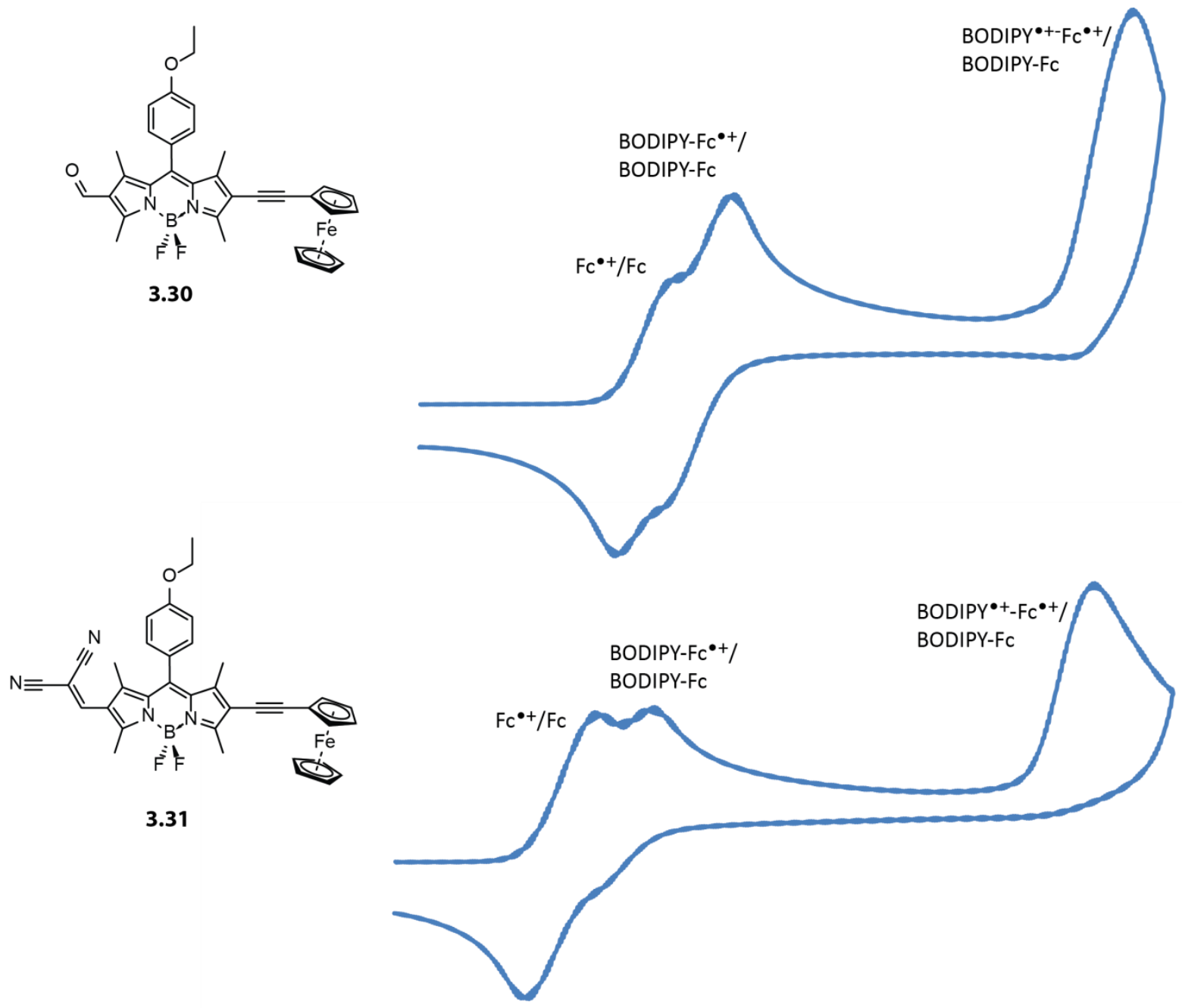

0.0 0.5
1.0
Potential (V)

1.5

Figure 3.11. Cyclic voltammogram of ferrocenyl $D-\pi-A$ BODIPY dyes 
Table 3.3. Electrochemistry data of ferrocenyl D- $\pi-A$ BODIPY dyes

\begin{tabular}{|c|c|c|c|}
\hline \multirow[b]{2}{*}{ Compound } & \multicolumn{3}{|l|}{$E_{1 / 2}(\mathrm{~V} \text { vs. NHE })^{a}$} \\
\hline & ferrocene ${ }^{\bullet+} /$ ferrocene & BODIPY"+BODIPY & BODIPY */BODIPY \\
\hline 3.30 & 0.896 & 1.767 & -0.660 \\
\hline 3.31 & 0.906 & 1.374 & -0.524 \\
\hline
\end{tabular}

${ }^{a}$ Data collected using differential pulse voltammetry (DPV) in $0.1 \mathrm{M} \mathrm{NBu}_{4} \mathrm{PF}_{6} \mathrm{DCM}$ solutions at $100 \mathrm{mV} \mathrm{s}^{-1}$ and referenced to a $\mathrm{Fc} / \mathrm{Fc}^{+}$internal standard followed by conversion to $\mathrm{NHE} ; \mathrm{Fc} / \mathrm{Fc}^{+}=+765 \mathrm{mV}$ vs. NHE in $\mathrm{DCM}$.

According to the cyclic voltammograms, $\mathbf{3 . 3 0}$ and $\mathbf{3 . 3 1}$ undergo a reversible oxidation of ferrocene, followed by a quasi-reversible oxidation of BODIPY and a quasi-reversible reduction of BODIPY. There is not much difference in the oxidation potential for ferrocene between $\mathbf{3 . 3 0}$ and 3.31, as the distance of the electron withdrawing groups from the ferrocene moiety leads to minimal influence on the HOMO energy (Table 3.3). On the other hand, the oxidation potential assigned to BODIPY is affected by substituent differences. Comparing the strength of the electron withdrawing groups (EWG), the malononitrile group on $\mathbf{3 . 3 1}$ is stronger than the aldehyde on 3.30. Compound $\mathbf{3 . 3 1}$ with the stronger EWG displays a higher oxidation potential due to destabilization of the HOMO energy. For the reduction potential, the trend follows that the stronger the EWG, the higher the reduction potential which makes $\mathbf{3 . 3 1}$ unfavourable for DSSC applications. 


\subsection{Summary \& Conclusion}

A set of ferrocenyl D-л-A BODIPY dyes were synthesized and their physico-chemical properties compared and contrasted for their feasibility in DSSC applications. UV-Vis spectroscopy and DFT calculations show that these dyes have potential. However, cyclic voltammetry studies shows that adding on strong electron withdrawing groups to the ferrocene-BODIPY system destabilizes the LUMO energy, resulting in possibility for poor electron injection into the conduction band of $\mathrm{TiO}_{2}$. Our group synthesized more ferrocenyl D- $\pi-A$ BODIPY dyes with varying phenyl substituents at the meso position of BODIPY, a full story can be found in chapter 3 of Burhan Hussein's MSc. thesis titled 'Towards Novel BODIPY Compounds for Material \& Medical Applications', the results also followed similar trends. ${ }^{65}$ After fabrication of a device for one of the dyes to test, the device performance showed an efficiency of $0 \%$ and visually the intensity of the chromophores strong purple colour diminished. This may be comparable to the case as in compound 3.5 in section 3.1.3 where decomposition of the ferrocene structure could be occurring. As future work to examine the decomposition of these dyes, further spectroelectrochemistry comparing the derivatives with and without electron withdrawing groups could elucidate as to what is happening upon redox processes. Titrations with chemical oxidant and reductants can give insight on the quenching effect of ferrocene to BODIPY. ${ }^{56}$ Performing an experiment similar to the one by Chen et al. with titration of $\mathrm{D}_{2} \mathrm{O}$ and analysis by mass spectrometry could inform if decomposition is occurring through breakage of the $\mathrm{cp}$ ring on BODIPY. ${ }^{53}$ The results from this project may not have been impressive; however understanding the mysterious processes behind this array of ferrocenyl-BODIPY dyes could unlock valuable information about this system. 


\subsection{Experimental}

\subsubsection{General Considerations}

All reagents were purchased commercially and used without further purification. Solvents used for anhydrous reactions were retrieved from either the mBraun Solvent Purification System (SPS) or from commercial jugs (Sigma Aldrich); no further purification was done, unless stated otherwise. Purification by column chromatography was carried out using silica (SiliCycle; ultrapure flash silica). Thin-layer chromatography was performed on aluminum-backed sheets precoated with silica 60 F254 adsorbent (250 $\mu \mathrm{m}$ thickness; SiliCycle) and visualized under UV light. Routine ${ }^{1} \mathrm{H},{ }^{13} \mathrm{C}\{1 \mathrm{H}\},{ }^{11} \mathrm{~B}\{1 \mathrm{H}\}$ and ${ }^{19} \mathrm{~F}$ NMR spectroscopic data was obtained at 400, 100, 128 and $376 \mathrm{MHz}$, respectively, on a Bruker Avance II 400 instrument at ambient temperature using deuterated solvent from Sigma Aldrich. Chemical shifts $(\delta)$ are reported in parts per million (ppm) from low to high field and referenced to a residual nondeuterated solvent $\left(\mathrm{CHCl}_{3}\right.$ or acetone) for ${ }^{1} \mathrm{H}$ and ${ }^{13} \mathrm{C}_{\text {nuclei, }} \mathrm{BF}_{3} \bullet \mathrm{OEt}_{2}\left({ }^{11} \mathrm{~B}\right.$ nucleus; $\left.\delta=0 \mathrm{ppm}\right)$ and $\mathrm{C}_{6} \mathrm{~F}_{6}\left({ }^{19} \mathrm{~F}\right.$ nucleus; $\delta=0$ ppm). Standard abbreviations indicating multiplicity are used as follows: $s$ = singlet; $d$ = doublet; $q=$ quartet,$b r=$ broad, and $m=$ multiplet. High resolution mass spectrometry (HRMS) results were obtained from Queens University, Kingston Ontario. Electron impact (EI) mass spectrometry and electrospray ionization (ESI) techniques were used for the ionization; time of flight (TOF) was used for analysis. UV-Vis data was taken using Cary Series UV-Vis-NIR Spectrophotometer from Agilent Technologies and dichloromethane (having the onset peak at $230 \mathrm{~nm}$ ) was used as the solvent. The GAUSSIAN 09 computational package 138 was used to perform ground-state geometry optimization calculations in the gas phase (no solvent) employing Becke's three-parameter hybrid exchange functional and the Lee-Yang-Parr nonlocal correlation functional B3LYP and optimization using the 6-31G basis set was used for all the atoms. Time-dependent density functional theory calculations were also performed using this methodology, and the first 200 singlet excited states were calculated. Calculations by the first-principles method were used to obtain accurate excitation energies and oscillator strengths. 


\subsubsection{Synthesis}

1-Ferrocenyl-2-trimethylsilylacetylene (3.25)

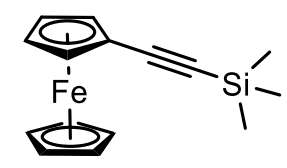

Reagents and solvents are mixed in the following order: ferrocene $(0.558 \mathrm{~g}, 3.00 \mathrm{mmol}), \mathrm{DCM}$ $(2.6 \mathrm{~mL})$, glacial acetic acid $(13 \mathrm{~mL}), \mathrm{FeCl}_{3}(0.122 \mathrm{~g}, 0.75 \mathrm{mmol})$, copper (II) acetate monohydrate $(0.108 \mathrm{~g}, 0.54 \mathrm{mmol})$, and trimethylsilylacetylene (ethynyltrimethylsilane) $(0.43 \mathrm{~mL}, 3.10 \mathrm{mmol})$. The mixture was stirred for about 1 hour at RT, brought to a reflux, stirred for an additional 1.5 hours, then let to settle to RT. Additional copper (II) acetate monohydrate ( 0.200 g, 1.00 $\mathrm{mmol}$ ) and trimethylsilylacetylene (ethynyltrimethylsilane) $(0.43 \mathrm{~mL}, 3.10 \mathrm{mmol}$ ) was added. The reaction was left stirring overnight at RT. The solution was poured into ascorbic acid $(1.0 \mathrm{~g}$, $5.68 \mathrm{mmol}$ ) in $200 \mathrm{~mL}$ of distilled water and extracted with DCM ( $3 \times 50 \mathrm{~mL}$ ), dried over sodium sulfate and filtered. Solvent was removed in vacuo and the crude product was purified by column chromatography on silica gel using hexane as the eluent to afford the product as an orange-brown solid (0.134 g, 16\%). ${ }^{1} \mathrm{H}$ NMR (400 MHz, $\left.\mathrm{CDCl}_{3}\right): \delta=4.44(\mathrm{~s}, 2 \mathrm{H}), 4.20$ (s, 5H), 4.18 (s, 2H), $0.24(\mathrm{~s}, 9 \mathrm{H}) .{ }^{13} \mathrm{C}\left\{{ }^{1} \mathrm{H}\right\} \mathrm{NMR}\left(100 \mathrm{MHz}, \mathrm{CDCl}_{3}\right): \delta$ 104.32, 90.65, 71.87, 70.26, 68.84, 64.96, 0.41 . Spectroscopic data is consistent with the literature. ${ }^{64}$

\section{2-Ferrocenylacetylene (3.26)}

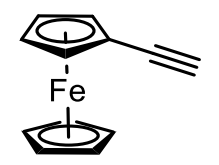

To a $100 \mathrm{~mL}$ RBF, dissolved 3.25 (0.818 g, $2.899 \mathrm{mmol})$ in $15 \mathrm{~mL}$ of THF and $15 \mathrm{~mL}$ of $\mathrm{MeOH}$. To the stirring solution, added KF $(0.509 \mathrm{~g}, 8.761 \mathrm{mmol})$. The mixture was let to stir for $4 \mathrm{~h}$ in RT under nitrogen. Additional KF (0.338 g, $5.809 \mathrm{mmol})$ was then added and the mixture stirred overnight. The reaction mixture was extracted with EtOAc and distilled $\mathrm{H}_{2} \mathrm{O}(20 \mathrm{~mL} \times 3)$. The 
organic layer was dried over $\mathrm{MgSO}_{4}$, filtered and solvent was removed in vacuo. The crude material was purified via column chromatography using 4:0.5 Hex:EtOAc as the eluent to afford the product as brown solid crystals $(0.488 \mathrm{~g}, 80 \%) .{ }^{1} \mathrm{H}$ NMR $\left(400 \mathrm{MHz}, \mathrm{CDCl}_{3}\right): \delta=4.47(\mathrm{~s}, 2 \mathrm{H})$, $4.22(\mathrm{~s}, 4 \mathrm{H}), 4.20(2,2 \mathrm{H}), 2.73(\mathrm{~s}, 1 \mathrm{H}) .{ }^{13} \mathrm{C}\left\{{ }^{1} \mathrm{H}\right\}$ NMR $\left(100 \mathrm{MHz}, \mathrm{CDCl}_{3}\right): \delta 82.73,73.67,71.88$, $70.18,68.85,63.98$. Spectroscopic data is consistent with the literature. ${ }^{64}$

\section{0-(4-ethoxyphenyl)-5,5-difluoro-1,3,7,9-tetramethyl-5H-4 $\lambda^{4}, 5 \lambda^{4}$-dipyrrolo[1,2-c:2',1'- f][1,3,2]diazaborinine-2-carbaldehyde (3.28)}

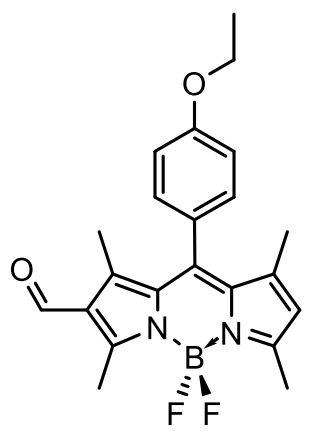

In a $250 \mathrm{~mL} R B F$, a solution of $10 \mathrm{~mL}$ of dry DMF and $\sim 30 \mathrm{~mL}$ of dry DCM was cooled to $0^{\circ} \mathrm{C}$ for 20 min then $12 \mathrm{~mL}$ of $\mathrm{POCl}_{3}$ was added dropwise over 5 min under nitrogen, the reagent stirred for $10 \mathrm{~min}$ and allowed to warm up to room temperature. To this mixture was added $\mathbf{3 . 2 7}$ $(0.103 \mathrm{~g}, 0.279 \mathrm{mmol})$ and the mixture was stirred for 3 hours at RT. The solution was slowly poured onto $200 \mathrm{~mL}$ of saturated $\mathrm{NaHCO}_{3}$ cooled at $0^{\circ} \mathrm{C}$ in an ice bath. The mixture was stirred overnight after warming up to RT. The reaction was washed with water $(3 \times 25 \mathrm{~mL})$ and DCM. The organic layers were combined, dried with $\mathrm{MgSO}_{4}$, filtered and the organic solvent removed in vacuo. The crude product was then subjected to column chromatography, using DCM as an eluent to afford the product as a solid $(0.104 \mathrm{~g}, 66 \%) .{ }^{1} \mathrm{H} \mathrm{NMR}\left(400 \mathrm{MHz}, \mathrm{CDCl}_{3}\right): \delta=9.99$ (s, $1 \mathrm{H}), 7.13(\mathrm{~d}, J=8.0 \mathrm{~Hz}, 2 \mathrm{H}), 7.01(\mathrm{~d}, J=8.0 \mathrm{~Hz}, 2 \mathrm{H}), 6.13(\mathrm{~s}, 1 \mathrm{H}), 4.09(\mathrm{q}, J=4.0 \mathrm{~Hz}, \mathrm{~J}=12.0 \mathrm{~Hz}$, $2 \mathrm{H}), 2.79(\mathrm{~s}, 3 \mathrm{H}), 2.58(\mathrm{~s}, 3 \mathrm{H}), 1.70(\mathrm{~s}, 3 \mathrm{H}), 1.47(\mathrm{~s}, 3 \mathrm{H}), 1.45(\mathrm{t}, J=8.0 \mathrm{~Hz}, 3 \mathrm{H}) .{ }^{13} \mathrm{C}\left\{{ }^{1} \mathrm{H}\right\} \mathrm{NMR}(100$ $\mathrm{MHz}_{\mathrm{CDCl}}$ ): $\delta$ 185.97, 171.17, 161.44, 160.06, 156.36, 147.44, 143.97, 142.95, 134.60, 130.30, $129.08,126.36,125.99,123.97,115.47,63.75,60.44,29.77,21.09,15.13,14.80,13.06,11.82$. 
${ }^{19} \mathrm{~F} \mathrm{NMR}\left(\mathrm{CDCl}_{3}, 376.5 \mathrm{MHz}\right): \delta=-144.69\left(\mathrm{q}, J_{\mathrm{BF}}=30.0 \mathrm{~Hz}\right) .{ }^{11} \mathrm{~B} \mathrm{NMR}\left(\mathrm{CDCl}_{3}, 128 \mathrm{MHz}\right): \delta=0.69$ $\left(\mathrm{t}, J_{\mathrm{FB}}=32.0 \mathrm{~Hz}\right)$. HRMS was not obtained.

10-(4-ethoxyphenyl)-5,5-difluoro-8-iodo-1,3,7,9-tetramethyl-5H-4 $\lambda^{4}, 5 \lambda^{4}$-dipyrrolo[1,2-c:2',1'f][1,3,2]diazaborinine-2-carbaldehyde (3.29)

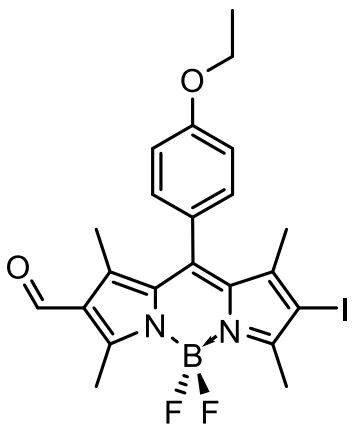

BODIPY 3.28 (0.104 g, $0.262 \mathrm{mmol})$ was dissolved in a minimum amount of DCM and NIS (0.071 g, $0.317 \mathrm{mmol}$ ) was added in one portion. The mixture was stirred overnight at RT wrapped in aluminum foil. Volatiles were evaporated and the crude material was isolated by column chromatography using DCM as the eluent to afford the product as a solid $(0.086 \mathrm{~g}, 63 \%) .{ }^{1} \mathrm{H}$ $\operatorname{NMR}\left(400 \mathrm{MHz}, \mathrm{CDCl}_{3}\right): \delta=10.02(\mathrm{~s}, 1 \mathrm{H}), 7.14(\mathrm{~d}, J=8.0 \mathrm{~Hz}, 2 \mathrm{H}), 7.05$ (d, J = 8.0 Hz, 2H), 4.12 (q, $J=8.0 \mathrm{~Hz}, J=12.0 \mathrm{~Hz}, 2 \mathrm{H}), 2.82(\mathrm{~s}, 3 \mathrm{H}), 2.69(\mathrm{~s}, 3 \mathrm{H}), 1.72(\mathrm{~s}, 3 \mathrm{H}), 1.50(\mathrm{~s}, 3 \mathrm{H}), 1.48(\mathrm{t}, J=8.0 \mathrm{~Hz}$, 3H). ${ }^{13} \mathrm{C}\left\{{ }^{1} \mathrm{H}\right\}$ NMR $\left(100 \mathrm{MHz}, \mathrm{CDCl}_{3}\right): \delta$ 185.93, 160.57, 160.34, 157.95, 148.00, 145.44, 144.26, 134.06, 130.54, 129.09, 127.11, 126.03, 115.70, 88.25, 63.89, 17.71, 16.50, 15.22, 14.87, 13.41, 12.18. ${ }^{19} \mathrm{~F} \mathrm{NMR}\left(\mathrm{CDCl}_{3}, 376.5 \mathrm{MHz}\right): \delta=-144.42\left(q, J_{B F}=34 \mathrm{~Hz}\right) .{ }^{11} \mathrm{~B} \mathrm{NMR}\left(\mathrm{CDCl}_{3}, 128 \mathrm{MHz}\right): \delta=$ $0.63\left(\mathrm{t}, J_{F B}=32 \mathrm{~Hz}\right)$. HRMS (EI-TOF): $\mathrm{m} / \mathrm{z} 522.0799\left(\mathrm{M}^{+}\right)$calculated for $\mathrm{C}_{22} \mathrm{H}_{22} \mathrm{BF}_{2} \mathrm{IN}_{2} \mathrm{O}_{2}: \mathrm{m} / z$ 522.0787. 


\section{Formyl-ferrocenyl-BODIPY (3.30)}

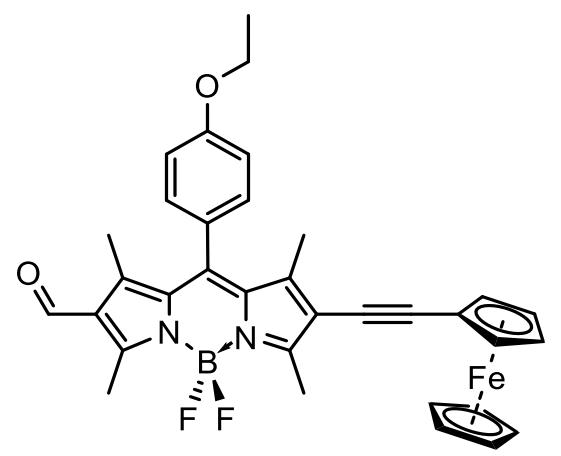

In a $100 \mathrm{~mL}$ Schlenk flask under nitrogen, BODIPY 3.28 (0.108 g, $0.206 \mathrm{mmol})$ and 3.26 (0.048 g, $0.227 \mathrm{mmol}$ ) was dissolved in anhydrous THF $(15 \mathrm{~mL})$, this mixture was sparged with nitrogen for $10 \mathrm{~min}$ followed by addition of triethylamine $(10 \mathrm{~mL}) . \mathrm{Pd}\left(\mathrm{PPh}_{3}\right)_{2} \mathrm{Cl}_{2}(0.022 \mathrm{~g}, 0.032 \mathrm{mmol})$, and $\mathrm{Cul}(0.004 \mathrm{~g}, 0.023 \mathrm{mmol})$ were added and the reaction was heated to $35^{\circ} \mathrm{C}$ overnight. Solvents were removed under high vacuum and the crude product purified by column chromatography using Hex:EtOAc, 4:1 as the eluent to afford the product as a solid $(0.054 \mathrm{~g}$, 43\%). ${ }^{1} \mathrm{H}$ NMR (400 MHz, $\mathrm{CDCl}_{3}$ ): $\delta=10.03(\mathrm{~s}, 1 \mathrm{H}), 7.11$ (dd, $5 \mathrm{H}, J=8.8 \mathrm{~Hz}, J=46.0 \mathrm{~Hz}$ ), 4.46 (t, $2 \mathrm{H}, J=1.6 \mathrm{~Hz}$ ), $4.25(\mathrm{t}, 2 \mathrm{H}, J=1.6 \mathrm{~Hz}), 4.20(\mathrm{~s}, 5 \mathrm{H}), 4.12(\mathrm{q}, 2 \mathrm{H}, J=6.8 \mathrm{~Hz}), 2.84(\mathrm{~s}, 3 \mathrm{H}), 2.73(\mathrm{~s}$, $3 \mathrm{H}), 1.74(\mathrm{~s}, 3 \mathrm{H}), 1.59(\mathrm{~s}, 3 \mathrm{H}), 1.48(\mathrm{t}, 3 \mathrm{H}, J=6.8 \mathrm{~Hz}) .{ }^{13} \mathrm{C}\left\{{ }^{1} \mathrm{H}\right\} \mathrm{NMR}\left(100 \mathrm{MHz}, \mathrm{CDCl}_{3}\right): \delta$ 185.98, 162.30, 160.24, 157.41, 146.35, 144.34, 144.08, 133.61, 130.97, 129.15, 126.73, 125.98, 119.37, 115.58, 96.98, 71.66, 70.18, 69.21, 64.88, 63.84, 29.83, 14.87, 14.23, 13.29, 12.08. ${ }^{19} \mathrm{~F} \mathrm{NMR}$ $\left(\mathrm{CDCl}_{3}, 376.5 \mathrm{MHz}\right): \delta=-144.87\left(\mathrm{q}, J_{B F}=30.0 \mathrm{~Hz}\right) .{ }^{11} \mathrm{~B} \mathrm{NMR}\left(\mathrm{CDCl}_{3}, 128 \mathrm{MHz}\right): \delta=0.65\left(\mathrm{t}, J_{F B}=\right.$ 32.0 Hz). HRMS (EI-TOF): $m / z 604.1808\left(\mathrm{M}^{+}\right.$) calculated for $\mathrm{C}_{34} \mathrm{H}_{31} \mathrm{BF}_{2} \mathrm{FeN}_{2} \mathrm{O}_{2}: \mathrm{m} / z$ 604.1796. 


\section{Malononitrile-ferrocenyl-BODIPY (3.31)}

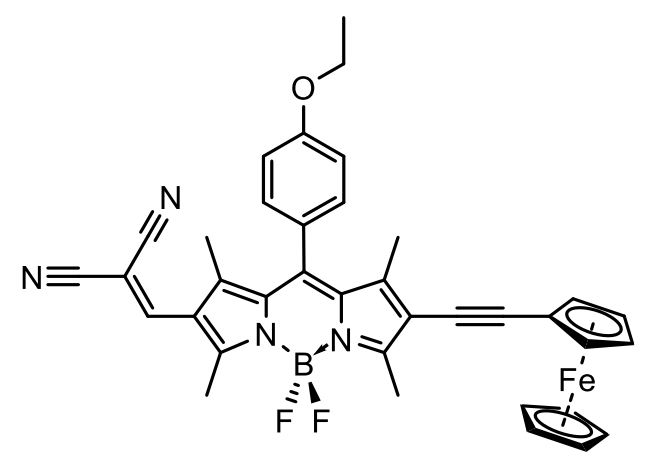

Ferrocenyl-BODIPY 3.30 (0.048 g, $0.077 \mathrm{mmol})$ and malononitrile $(0.015 \mathrm{~g}, 0.173 \mathrm{mmol})$ were dissolved in $\mathrm{CHCl}_{3}(25 \mathrm{~mL})$. The solution was stirred and heated at $40^{\circ} \mathrm{C}$. About 2-3 $\mathrm{drops}$ of $\mathrm{Et}_{3} \mathrm{~N}$ was added and the reaction was heated to reflux overnight. Solvent was removed in vacuo and the resulting residue was purified by column chromatography using DCM as the eluent to afford a solid product $(0.015 \mathrm{~g}, 28 \%) .{ }^{1} \mathrm{H}$ NMR $\left(400 \mathrm{MHz}, \mathrm{CDCl}_{3}\right): \delta=7.69(\mathrm{~s}, 1 \mathrm{H}), 7.12(\mathrm{dd}, 4 \mathrm{H}, J=8.4$ $\mathrm{Hz}, J=42.8 \mathrm{~Hz}), 4.46(\mathrm{t}, 2 \mathrm{H}, J=2.0 \mathrm{~Hz}), 4.26(\mathrm{t}, 2 \mathrm{H}, J=2.0 \mathrm{~Hz}), 4.20(\mathrm{~s}, 4 \mathrm{H}), 4.12(\mathrm{q}, 2 \mathrm{H}, J=7.2$ $\mathrm{Hz}, J=14 \mathrm{~Hz}), 2.74(\mathrm{~s}, 3 \mathrm{H}), 2.65(\mathrm{~s}, 3 \mathrm{H}), 1.60(\mathrm{~s}, 3 \mathrm{H}), 1.58(\mathrm{~s}, 3 \mathrm{H}), 1.53(\mathrm{~s}, 3 \mathrm{H}), 1.48(\mathrm{t}, 3 \mathrm{H}, J=6.8$ $\mathrm{Hz}) .{ }^{13} \mathrm{C}\left\{{ }^{1} \mathrm{H}\right\} \operatorname{NMR}\left(100 \mathrm{MHz}, \mathrm{CDCl}_{3}\right): \delta 207.03,163.73,160.43,153.51,153.35,147.09,143.66$, 140.16, 132.11, 129.19, 125.61, 123.42, 120.21, 115.77, 114.49, 113.30, 97.72, 82.59, 71.71,

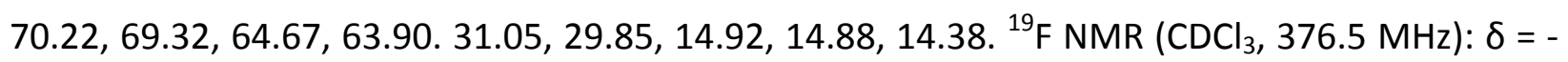
$145.54\left(q, J_{B F}=34.0 \mathrm{~Hz}\right) .{ }^{11} \mathrm{~B} \mathrm{NMR}\left(\mathrm{CDCl}_{3}, 128 \mathrm{MHz}\right): \delta=0.58\left(\mathrm{t}, J_{F B}=32.0 \mathrm{~Hz}\right)$. HRMS (El-TOF): $\mathrm{m} / z 652.1919\left(\mathrm{M}^{+}\right)$calculated for $\mathrm{C}_{37} \mathrm{H}_{31} \mathrm{BF}_{2} \mathrm{FeN}_{4} \mathrm{O}: \mathrm{m} / z 652.1908$. 


\section{CHAPTER 4.0 - EXPLORING THE REDOX INTERPLAY IN BODIPY-DYADS}

With the aim to functionalize the BODIPY core with a secondary redox active donor chromophore, ferrocene and triphenylamine have been utilized to study their effects on BODIPY's redox stability.

\subsection{Introduction}

Redox active compounds that function as both a rich electron donor and chromophore deliver an edge to DSSC dyes with a D- $\pi-A$ motif. Upon photo-oxidation of the dye molecule, the electrons from a redox active donor that is connected to the dye can transfer electrons to regenerate the dye quickly before recombination can occur. This chapter features a small library of TPA-BODIPY dyes and dyads as well as selected BODIPY dyads with redox active units.

\subsubsection{Meso-substituted TPA-BODIPY with varying substituents on TPA}

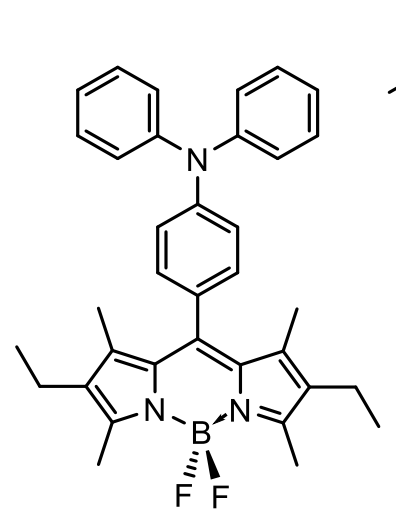

4.1

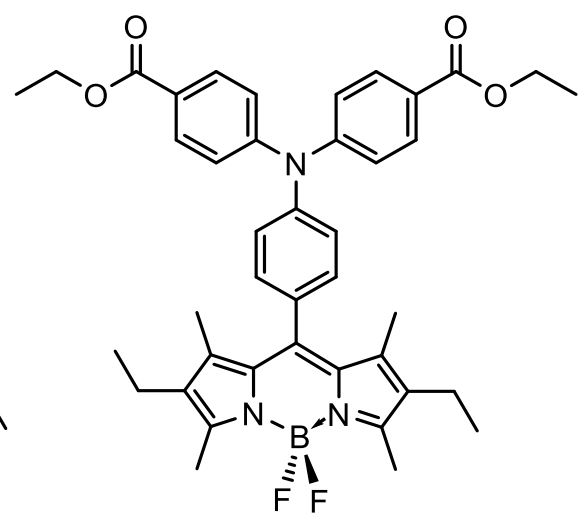

4.2

Figure 4.1. Direct meso-substituted TPA-BODIPY dyad ${ }^{66}$ 
There was no significant difference on the absorption profile between $\mathbf{4 . 1}$ and $\mathbf{4 . 2}$ despite the addition of an electron withdrawing ester group. ${ }^{66}$ Spectroelectrochemistry studies were performed and can be found in the $\mathrm{ESI}^{66}$. When both underwent reduction, the narrow absorption for BODIPY at $526 \mathrm{~nm}$ decreased dramatically, this was described as bleaching of the BODIPY moiety. As the bleaching of BODIPY occurred, two mild absorptions at $407 \mathrm{~nm}$ and 582 $\mathrm{nm}$ grew for 4.1. Compound $\mathbf{4 . 2}$ showed unclear isosbestic points, as there was no consistent rise in absorption that would have appeared at $407 \mathrm{~nm}$. This was thought to be as a result of the ester groups stabilising the BODIPY radical anion through resonance. The oxidation for the compound with ester groups follows a similar trend. Upon oxidation of compound with the ester groups, the absorption for BODIPY at $526 \mathrm{~nm}$ also showed bleaching and a growth for a peak at $407 \mathrm{~nm}$ as well, but no increase in absorption at $582 \mathrm{~nm} .^{66}$

In cyclic voltammetry studies of compound $\mathbf{4 . 1}$ and 4.2 , two oxidation peaks were shown. The second oxidation peak was associated with the triphenylamine. The electron withdrawing groups attached to compound 4.2, caused the triphenylamine to oxidize at a higher potential. Whereas, the oxidation potentials for BODIPY and TPA overlap for compound 4.1. In terms of the reduction sweep, one reduction peak is shown near $1.6 \mathrm{~V}$ for both compounds. This reversibility suggests that the radical anion formed possesses good stability. Aligning the cyclic voltammograms shows that the ester group only affects the oxidation potential and not the reduction potential. Going back to the spectroelectrochemical study, the ester group may be the reason for the increase in the peak at $582 \mathrm{~nm}$ for the reduction of $4.2{ }^{66}$ 


\subsubsection{Meso-substituted nonmethylated BODIPY dyads with polyarylamines and TPA}<smiles></smiles>

F<smiles>CN(C)c1ccc(-c2c3c(n4cccc24)=CC=C3)cc1</smiles>

部

4.4<smiles></smiles>

F

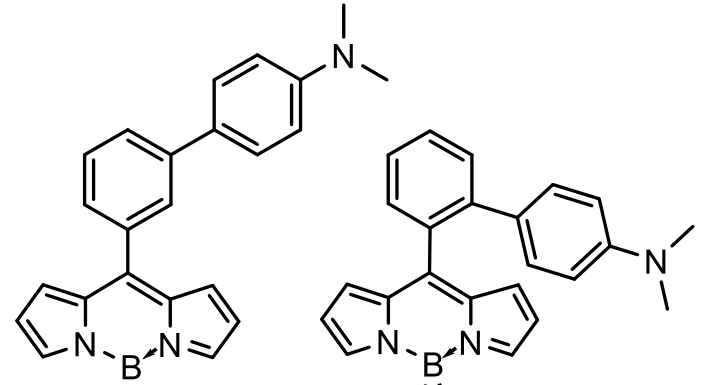

F
至

4.3<smiles></smiles>

豆

4.8<smiles></smiles>

4.9

4.10

Figure 4.2. Meso-substituted nonmethylated BODIPY with polyarylamines and TPA as redox active donors $^{67}$

Meso-polyarylamine-BODIPY compounds (Figure 4.2) were studied for Twisted Intramolecular Charge Transfer (TICT). This process can give insight into the extent of electron transfer and conformational changes upon excitation. After a donor-acceptor dyad becomes excited, a solvent dependent vibrational relaxation process occurs, resulting in a conformation 'twist' between the acceptor and donor units. Polar solvents stabilize this conformation change, 
where planarity is no longer maintained. The fluorescence emission tends to be red-shifted for these dyads in polar solvents. ${ }^{67}$

Besides solvent polarity, structural arrangements have an effect on the emission properties. Dyad 4.3 with phenyl groups on the amine shows two absorptions while 4.4 with the alkyl groups has one absorption in either cyclohexane and THF. Both have absorptions around $500 \mathrm{~nm}$ corresponding to BODIPY, but 4.3 is slightly red shifted compared to 4.4 due to enhanced electronic communication with the phenyl groups. The photoluminescence of $\mathbf{4 . 4}$ has a broader emission than 4.3 in the weakly polar solvent (THF), however the second emission band of $\mathbf{4 . 3}$ is further red shifted towards the near-IR region (ca. $750 \mathrm{~nm}$ ) compared to 4.4 (ca. $660 \mathrm{~nm}$ ). Similar trends are observed for 4.5 and $4.8 .^{67}$

The UV absorption and fluorescence emission profiles of dialkyl derivatives 4.5-4.7 are generally similar. On the other hand, the quantum yields varied in the order of $4.5>4.6>4.7$ in both cyclohexane and THF. Para-substituted derivative 4.5 have a higher quantum yield due to the TICT behaviour. The quantum yields overall in weakly polar THF were low owing to the TICT effect. ${ }^{67}$

The UV absorption spectra of 4.8-4.10 were similar as well. Both compounds 4.8 and $\mathbf{4 . 9}$ displayed one fluorescence emission peak in both cyclohexane and THF. The emission profile for 4.8 showed a peak further red shifted as well to about $690 \mathrm{~nm}$ in THF. The x-ray crystal structure of dyad 4.10 showed that the phenyl substituent is not planar to BODIPY due to the bulky triphenylamine unit appended at the ortho-position. With this twisted conformation, the TICT was predicted to occur regardless of solvent polarity. However, the fluorescence emission for 4.10 shows two emission peaks with one further red shifted to $663 \mathrm{~nm}$ in cyclohexane, whereas only one emission at $531 \mathrm{~nm}$ is shown in THF attributing to the excited state. This paper demonstrated that a number of factors, not only solvent polarity, can tune emission properties of donor-acceptor systems by utilizing the TICT. ${ }^{67}$ 


\subsubsection{TPA-BODIPY $D-\pi-A$ dyes}

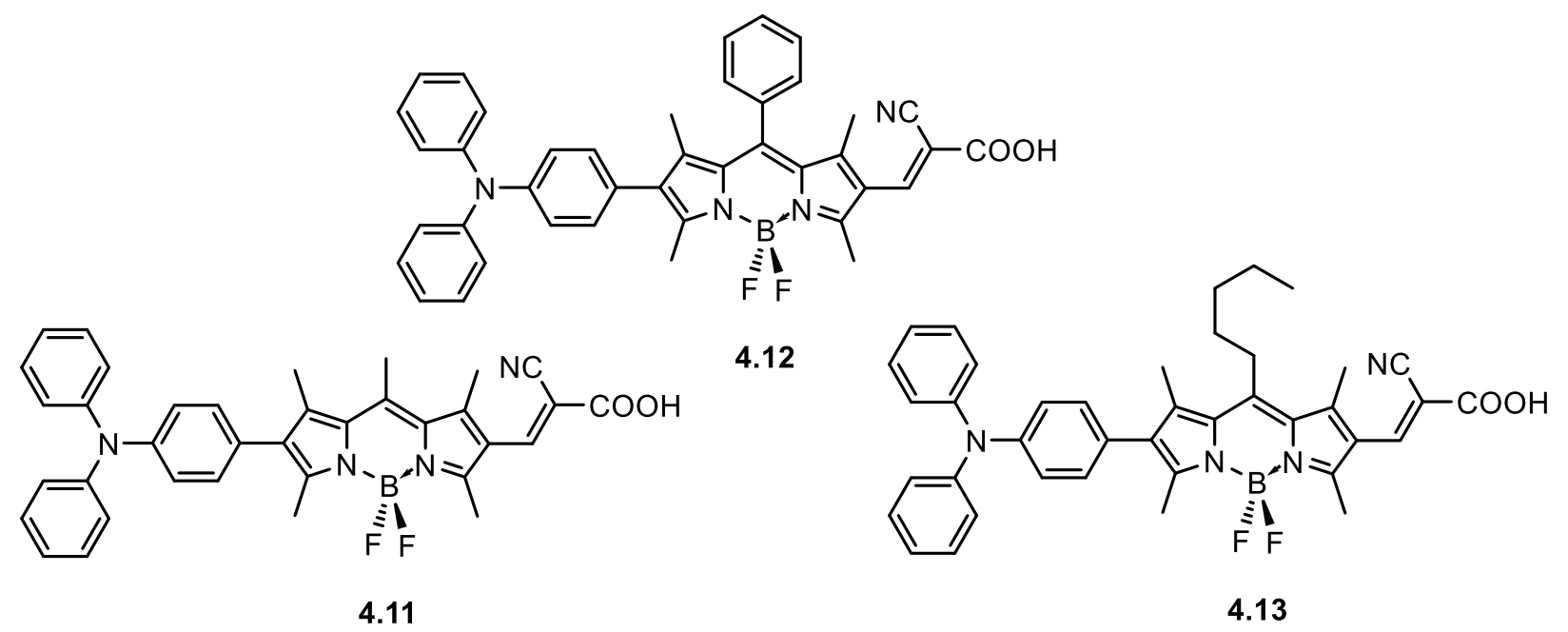

Figure 4.3. TPA-BODIPY dyes with varying meso-substituents ${ }^{68}$

A set of D- $\pi-A$ BODIPY dyes employing TPA as the donor and cyanoacetic acid as the acceptor with varying substituents on the meso-position of the BODIPY $\pi$-spacer were studied (Figure 4.3). The absorption profiles for dyes 4.11-4.12 had similar absorption corresponding to BODIPY (450-620 nm). The absorption maxima for BODIPY differ only slightly from one another, however all were red-shifted compared to standard pentamethyl-BODIPY. The electrochemical studies showed that the HOMO and LUMO energy levels are appropriate for electron injection and regeneration of the dye, making these dyes suitable candidates for the DSSC. Density functional theory (DFT) calculations confirmed sufficient overlap of electron density between the frontier molecular orbitals. Despite minor modifications, the dyes showed measurable dyesensitized solar cell performance. Dye $\mathbf{4 . 1 3}$ obtained the highest efficiency. ${ }^{68}$

Phenyl-substituted BODIPY compound $\mathbf{4 . 1 2}$ did not show good efficiency. The presence of a phenyl group may have caused dye aggregation, increasing the chances of charge recombination resulting in a low short circuit voltage. This paper demonstrated that the 
substituents on the meso-position of the BODIPY $\pi$-spacer has significance on the feasibility of 4.11-4.13 as dyes for DSSC application. ${ }^{68}$

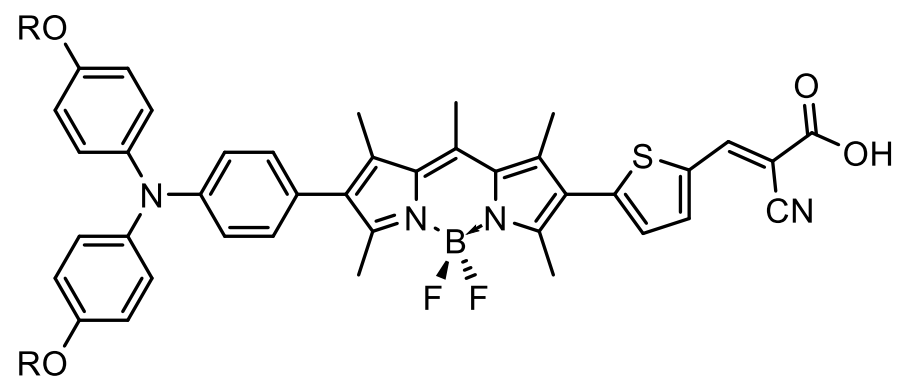

$$
\begin{aligned}
& 4.14 \mathrm{R}=\mathrm{CH}_{3} \\
& \text { 4.15 } \mathrm{R}=\mathrm{C}_{6} \mathrm{H}_{13}
\end{aligned}
$$

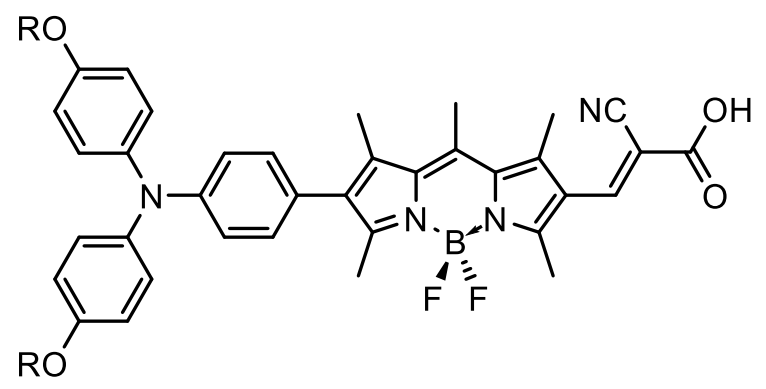

4.16 $\mathrm{R}=\mathrm{CH}_{3}$

$4.17 \mathrm{R}=\mathrm{C}_{6} \mathrm{H}_{13}$<smiles></smiles>

Figure 4.4. D- $\pi-A$ TPA-pentamethylBODIPY dyes ${ }^{27}$

Previously reported by the Koivisto research group with work by Bonnier and colleagues was a series of donor- $\pi$-spacer-acceptor dyes, employing pentamethyl-BODIPY as a $\pi$-spacer. ${ }^{27}$ When a substituent is appended on the meso- position of BODIPY, planarity between the two moieties 
is not secured, in turn conjugation is lost and electronic communication weakens. Attaching triphenylamine as the donor group and cyanoacetic acid groups as the anchoring group on the 2,6-positions resulted in improved efficiencies for dyes 4.14-4.19 (Figure 4.4). Based on DFT calculations, there was not sufficient electron density overlap from the triphenylamine localizing towards the excited state of BODIPY. When a thiophene spacer is incorporated between the donor and BODIPY, the conjugated system is retained and appropriate overlap was demonstrated. It was concluded that compound $\mathbf{4 . 1 8}$ would be an ideal dye to test due to an effective charge separation towards the cyanoacetic acid group. Nevertheless, all dyes showed broadening of the absorption spectrum and panchromatic light-harvesting. ${ }^{27}$

Table 4.1. DSSC data of TPA-BODIPY dyes $4.7-4.9^{68}$ and $4.18^{27}$

\begin{tabular}{lllll}
\hline Dye & $J_{s c}\left[\mathrm{~mA} \mathrm{~cm}^{-2}\right]$ & $V_{o c}[\mathrm{~V}]$ & FF & $\eta(\%)$ \\
\hline 4.11 & 3.92 & 0.55 & 0.59 & 1.28 \\
4.12 & 1.56 & 0.50 & 0.64 & 0.50 \\
4.13 & 4.38 & 0.58 & 0.72 & 1.83 \\
4.18 & 11.14 & 0.46 & 0.58 & 2.93
\end{tabular}




\subsubsection{Meso-substituted BODIPY dyads with quinone/hydroquinone as a redox active unit}

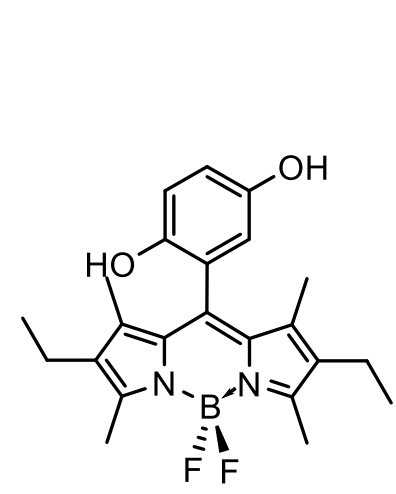

4.20

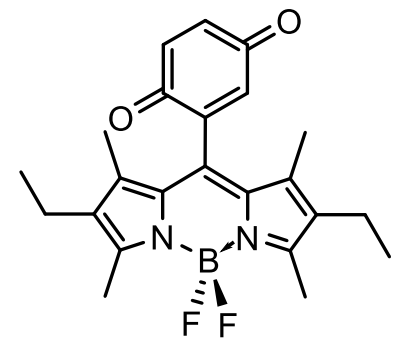

4.21

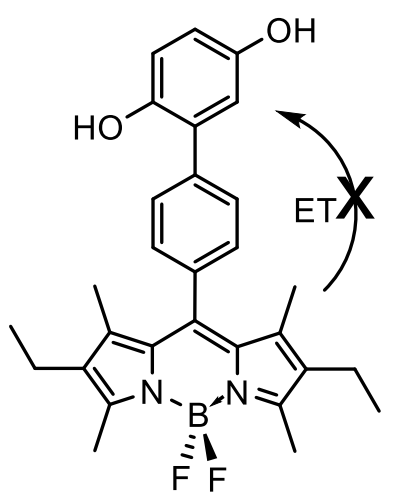

4.22

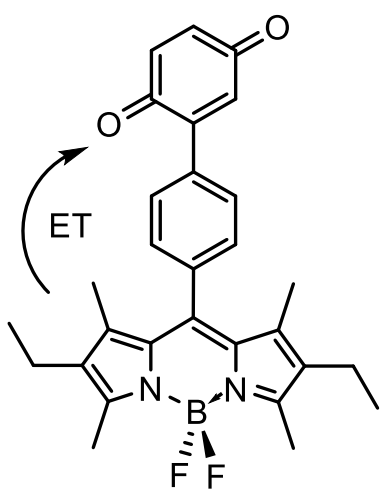

4.23

Figure 4.5. Quinone/hydroquinone BODIPY dyads ${ }^{69}$

Depending on the moieties attached, BODIPY dyads can be non-emissive or emissive. Appending quinone to the BODIPY core yielded a non-emissive species, whereby interchanging from quinone to hydroquinone converted the dyad into a strongly emissive one. Benniston et al. were interested in seeing if it was the electron transfer from the quinone to the BODIPY core that can out-compete radiative processes. To investigate this, a phenylene $\pi$-spacer was independently introduced into the system and studied (Figure 4.5 ). ${ }^{69}$ Through electrochemical studies, both 4.21 and $\mathbf{4 . 2 3}$ display a quasi-reversible reduction corresponding for the quinone moiety, with the presence of the phenyl spacer, 4.23 is more difficult to reduce compared to 4.21. The BODIPY-hydroquinone dyad undergoes redox processes easily compared to the BODIPY-quinone dyads. Spectroelectrochemistry was used to observe the fluorescence intensity recovery upon reduction of 4.23. Over $10 \mathrm{~min}$ of reducing the molecule to the semiquinone form, the fluorescence intensity increases, after $10 \mathrm{~min}$, the fluorescence intensity plateaus. When a potential of $+0.50 \mathrm{~V}$ was applied to the reduced 4.23 , the fluorescence became quenched over time due to an intramolecular electron transfer. From this work, it was demonstrated that a redox active organic species could be used to make a fluorescent molecular probe. ${ }^{69}$ 


\subsubsection{Meso-substituted BODIPY dyads with phenothiazine as a redox active unit}<smiles>c1ccc2c(c1)Nc1ccccc1S2</smiles>

PTZ

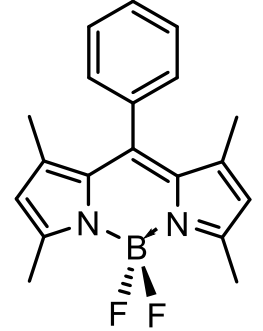

phenyl-BODIPY

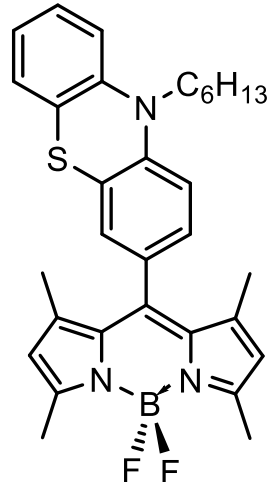

4.24<smiles></smiles>

4.25<smiles></smiles>

4.26

Figure 4.6. Phenothiazine-BODIPY dyads ${ }^{70}$

Phenothiazines (PTZ) are electron rich, can easily be oxidized and are stable in the cationic form. The moiety is not planar with a butterfly-like geometry which will deter any molecular aggregation. Phenothiazine-BODIPY dyads with varying spacers were prepared (Figure 4.6) and analysis of the UV-Vis absorption spectra of the series show that the various spacers do not provide significant changes in the absorption profiles. The molar extinction coefficient decreases from $4.24>4.26>$ 4.25. In comparing to PTZ with absorption bands at $254 \mathrm{~nm}$ and $316 \mathrm{~nm}$, each of the dyads have absorptions around $316 \mathrm{~nm}$, however two absorption bands are evident in the UV region around $254 \mathrm{~nm}$. This 'splitting' may be due to symmetry loss of PTZ upon appending to phenyl-BODIPY. There were no major differences in the cyclic voltammetry data of the dyads with respect to the varying spacers. ${ }^{70}$

Spectroelectrochemistry on $\mathbf{4 . 2 6}$ was performed to confirm the oxidation and reduction assignments. Upon applying a potential of $-1.30 \mathrm{~V}$, a decrease in the absorption band around $500 \mathrm{~nm}$ with no changes in the absorptions between 233-270 $\mathrm{nm}$ was observed. This confirms the reduction potential corresponds to the BODIPY unit. The calculated frontier molecular 
orbitals of 4.24 show the HOMO on both the PTZ and BODIPY and LUMO on BODIPY, with sufficient electronic overlap owing to conjugation. In contrast, the electronic communication of 4.25 and 4.26 is not as strong, owing to a break in conjugation with the added phenyl moiety. It was also observed that the further the bond distance between the BODIPY and PTZ unit, the less likely for photo-induced electron transfer to occur, resulting in a lower fluorescence quenching. $^{70}$

Most BODIPY dyads presented mainly comprised of redox active donor substituents appended on the meso position of BODIPY. Limited research on the direct modification of redox active donor groups appended on the 2,6-position of BODIPY provides opportunity to pursue studies in this area. 


\subsection{Thesis Objective}

With ferrocenyl ethynyl-bridged BODIPY dyes essentially unstable, we were curious to know if a system replacing ferrocene with TPA was plausible. Incompatibility between electron rich donors and BODIPY chromophores in terms of dye stability can pose a challenge for dye performance. TPA was opted as a candidate to test out the viability of this system owing to our knowledge of synthesizing various derivatives and their well-known properties in the literature. Structure-property relationships through tuning of the TPA secondary redox chromophore will be utilized. Looking in depth at the effects on stability of BODIPY dyads under redox processes will give a solid understanding of how we can manipulate this motif. 


\subsection{Synthesis}

\subsubsection{Synthesis of BODIPY dyads}

The synthesis of the TPA-BODIPY dyads begin with making the two individual building blocks; the BODIPY core with an iodo-group and an ethynyl-triphenylamine. The synthesis towards the BODIPY core starts with the construction of dimethyl pyrrole. A Paal-Knorr synthesis generates a pyrrole backbone, this involves two equivalents of ethyl acetoacetate reacting with sodium nitrite under acidic conditions followed by a reduction with zinc. A decarboxylation is done with potassium hydroxide to cleave the esters to obtain 2,4-dimethyl pyrrole after distillation. Two equivalents of 2,4-dimethyl pyrrole undergo an electrophilic aromatic substitution with acetyl chloride to make the conjugated system. A boron source is then introduced for the amines to chelate to the nitrogen atoms of the dipyrrin. ${ }^{71}$ Despite using one equivalent of NIS to iodinate BODIPY, a di-iodo BODIPY derivative is still produced. The synthesis of $\mathbf{4 . 2 8}$ was done through a Sonogashira cross-coupling reaction with TMS-acetylene using a modified procedure from Lin et al. ${ }^{72}$ Compound $\mathbf{4 . 2 8}$ with the TMS group was used as a reference due to the unstable nature of the deprotected derivative of $\mathbf{4 . 2 8}$. 
<smiles>CCOC(=O)CC(C)=O</smiles>

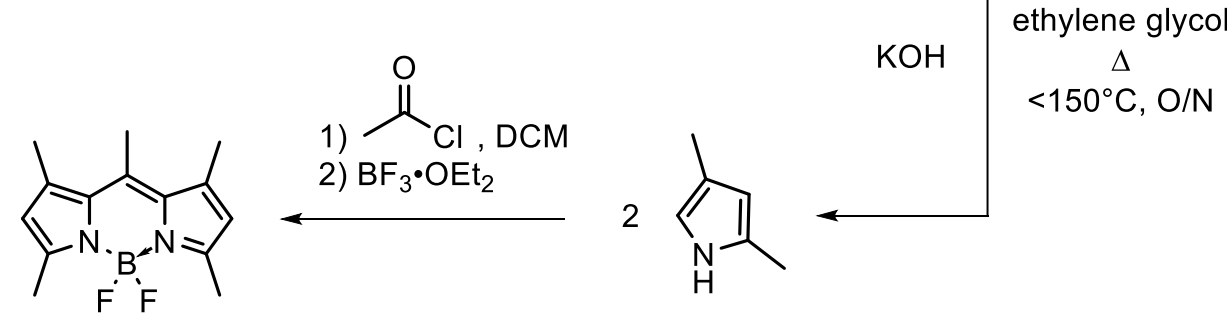

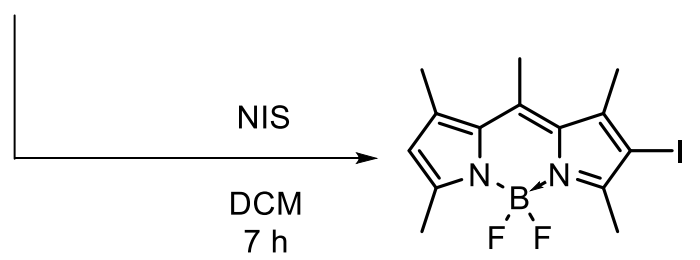

4.27

Scheme 4.1. Synthetic route towards iodo-BODIPY<smiles></smiles>

4.27

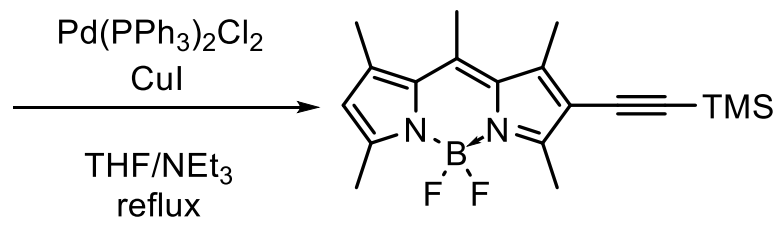

4.28

Scheme 4.2. Reaction towards reference BODIPY dyad 4.28 


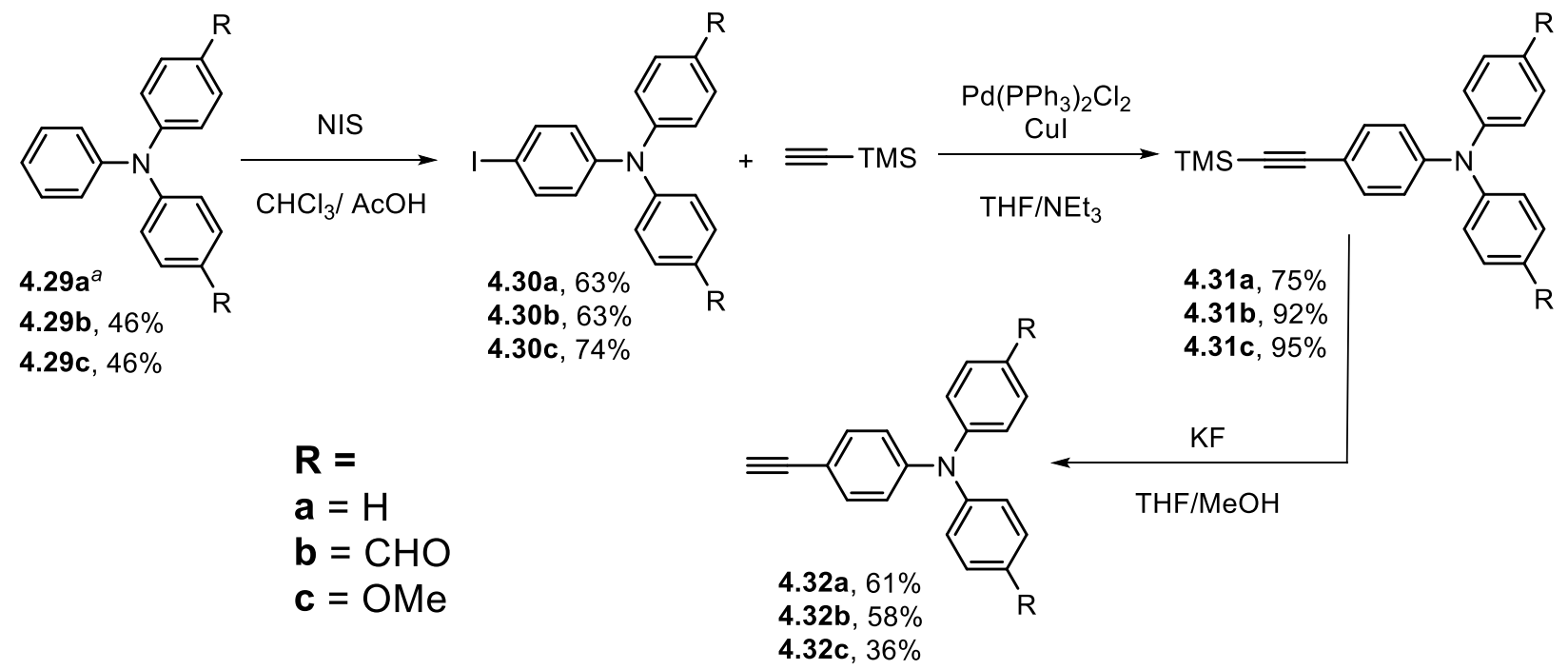

Scheme 4.3. Synthetic route towards ethynyl-TPA moiety. $a=$ commercially available

Triphenylamine was commercially available and was utilized to synthesize 4.29b via a VilsmeierHaack reaction. ${ }^{73} 4.29 \mathrm{c}$ was synthesized by an Ullmann condensation, reacting aniline with iodo-anisole under reflux. ${ }^{74}$ As shown in Scheme 4.3, iodinations were performed on each of the triphenylamine derivatives to install a good leaving group ${ }^{73,75}$, then a Sonogashira crosscoupling to TMS-acetylene, followed by a deprotection of the TMS group to yield a terminal alkyne $(4.32 a-c) .{ }^{75}$ The procedures leading up to synthesizing $4.32 a-c$ were followed from the literature with some minor modifications. 


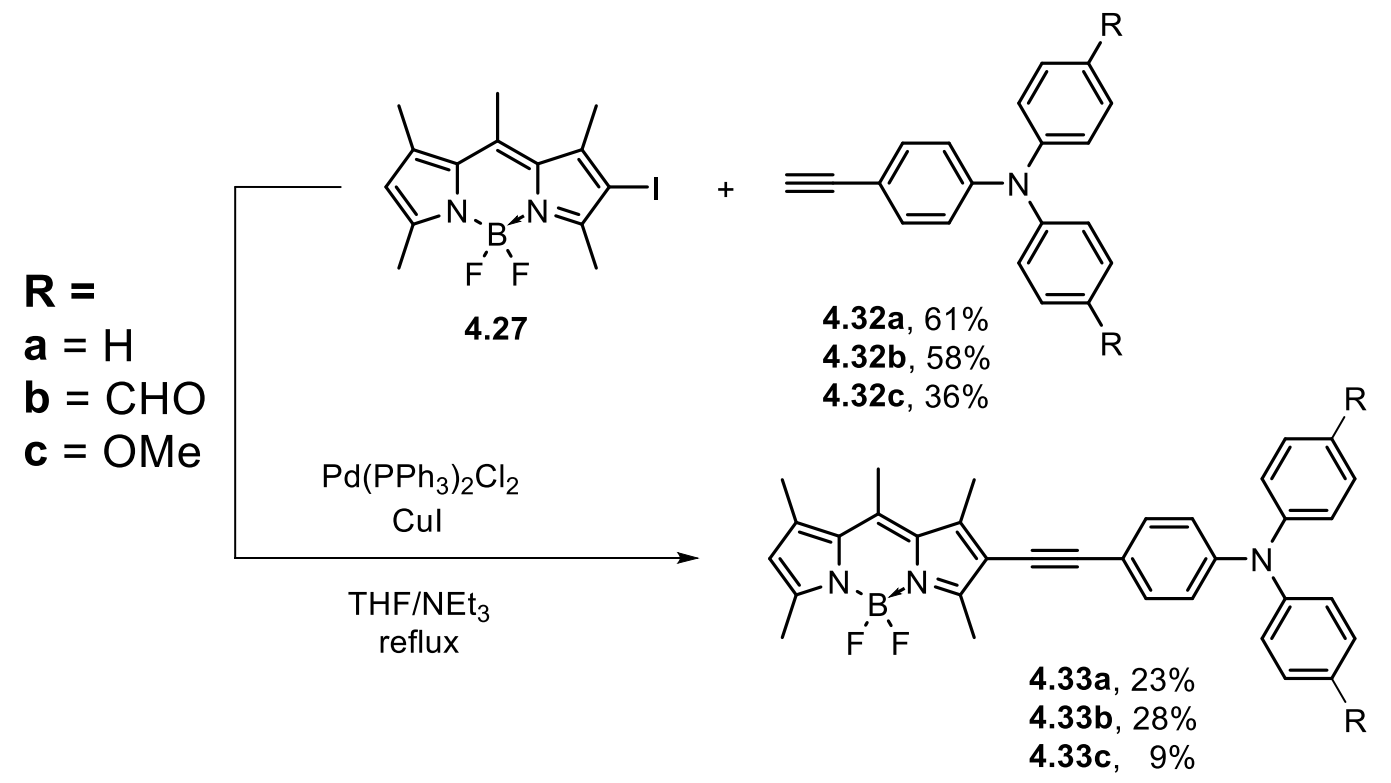

Scheme 4.4. Synthetic route towards BODIPY-ethynyl-TPA molecules

The synthesis of BODIPY dyads 4.33a-c (Scheme 4.4) and 4.34 (Scheme 4.5) were carried out following a procedure by Huang et al. ${ }^{76}$ Contrast to the synthesis of $4.31 \mathrm{a}-\mathrm{c}$, heat is required to push the cross-coupling reaction forward.<smiles></smiles>

4.27

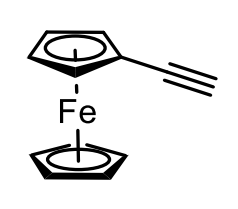

3.26

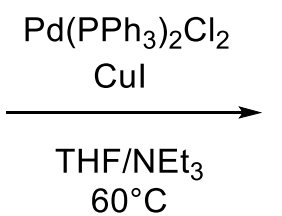

$60^{\circ} \mathrm{C}$

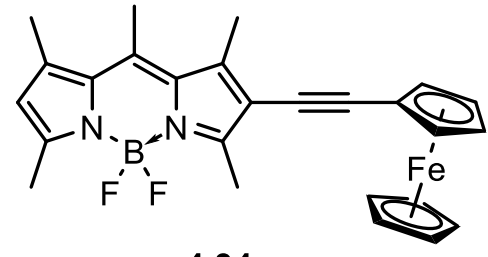

4.34

Scheme 4.5. Synthetic scheme towards synthesis of ferrocenyl-ethynyl-BODIPY dyad

\subsubsection{Characterization of BODIPY dyads}

In the ${ }^{1} \mathrm{H}$ NMR across all BODIPY dyads 4.33a-c and 4.34, there were no shifts in the methyl peaks for BODIPY that range from $2.43 \mathrm{ppm}$ to $2.65 \mathrm{ppm}$. The aromatic proton on the $\beta$ position of all BODIPY dyads lies around $6.10 \mathrm{ppm}$. Dyad 4.33a has aromatic peaks from 7.00 
ppm to 7.37 ppm correlating to TPA. Dyad 4.33b has a singlet peak at $9.91 \mathrm{ppm}$ integrating for two protons for the two aldehydes. Dyad 4.33c has a singlet peak at 3.80 ppm integrating for six protons for the two methoxy groups. Dyad 4.34 shows that there are seven protons on the $\mathrm{Cp}$ ring that possess the same chemical environment at $4.24 \mathrm{ppm}$. 


\subsection{Results \& Discussion}

A series of BODIPY dyads coupled through an alkyne bridge to triphenylamine derivatives (4.33a-c) and ferrocene (3.34) were synthesized. Properties of the BODIPY dyads were characterised by UV-Vis absorption spectroscopy, electrochemistry and density functional theory (DFT) to study their redox stability. Their physicochemical properties will be compared and contrasted to one another. 


\subsubsection{UV-Vis spectroscopy of BODIPY dyads}

a)

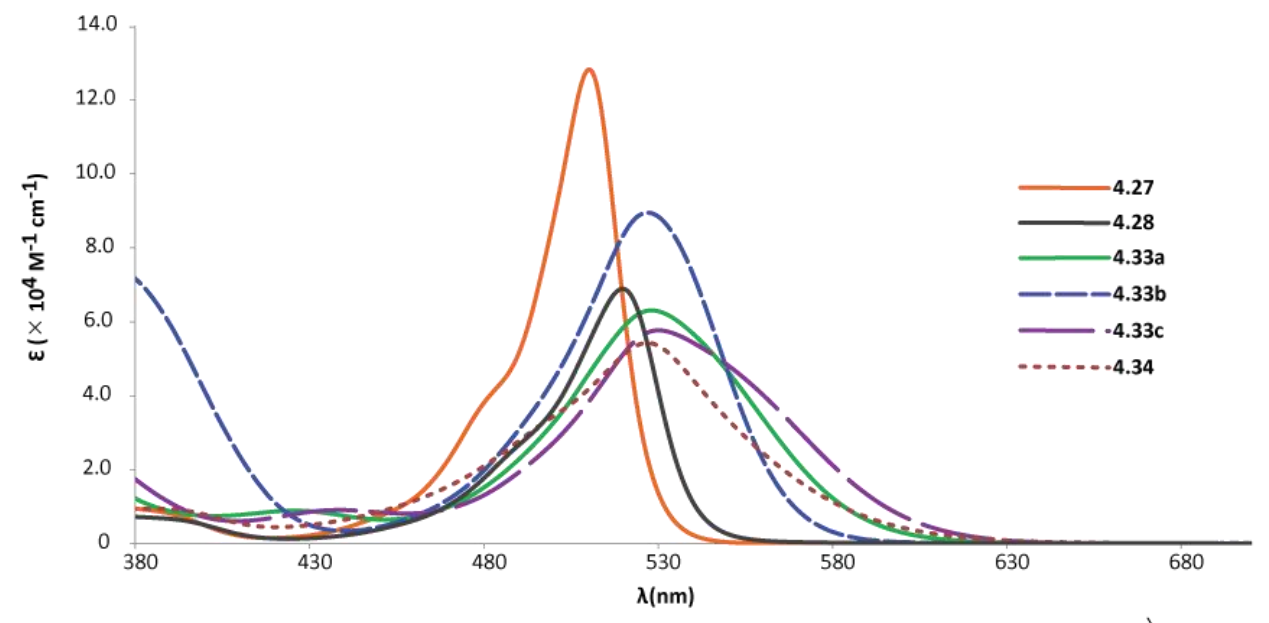

b)
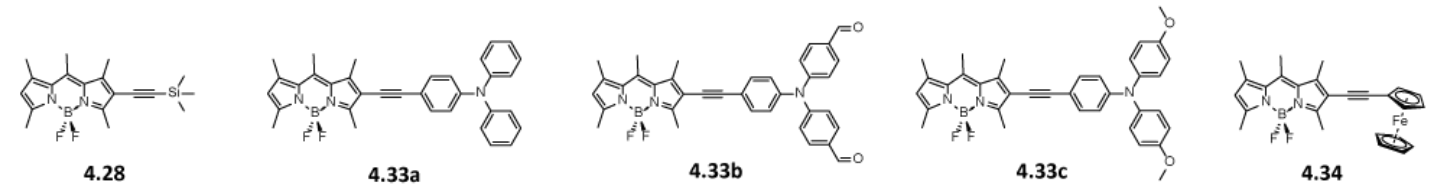

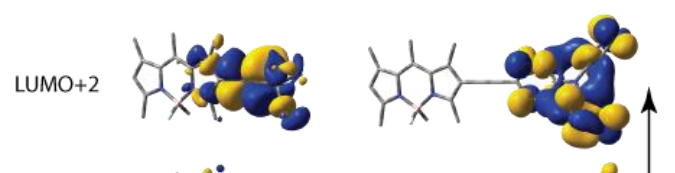
wan
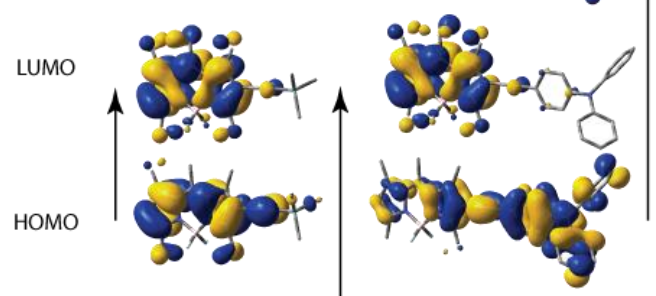

(5)
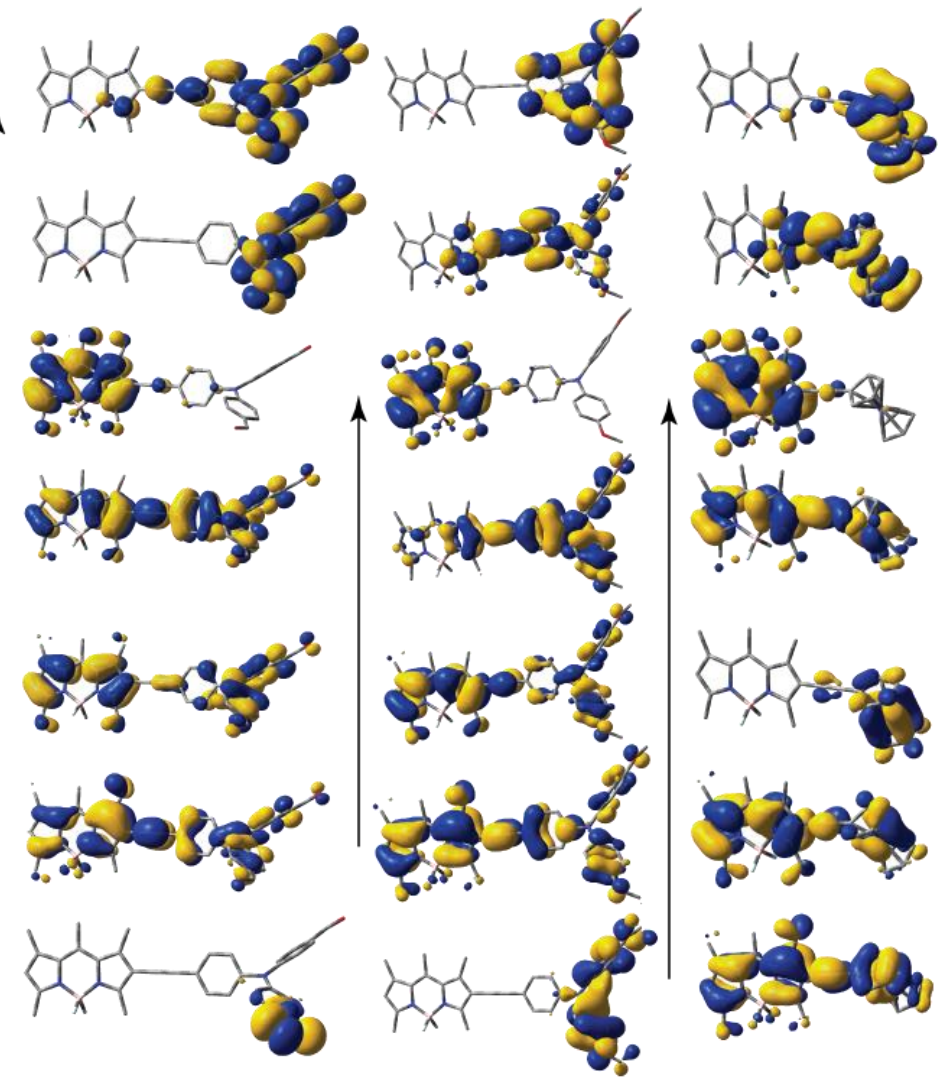

HOMO-1
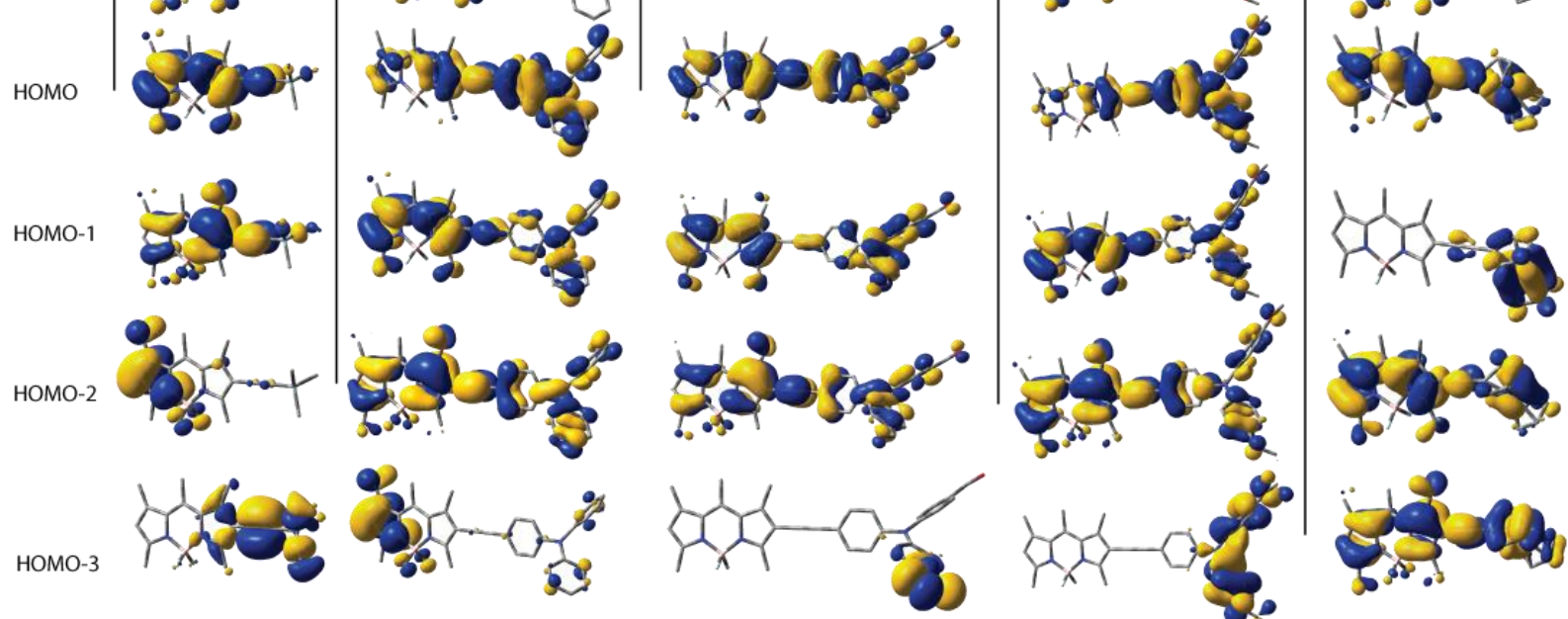

nowes

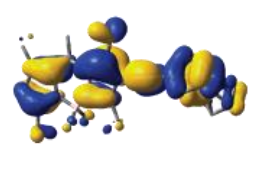

Figure 4.7. UV-Vis absorption spectra (a) and MOs (b) of BODIPY dyads 4.28, 4.33a-c and 4.34 
Table 4.2. UV-Vis data of BODIPY dyads 4.28, 4.33a-c and 4.34

\begin{tabular}{ll}
\hline Compound & $\lambda_{\max }(\mathrm{nm})$ \\
\hline 4.27 & 510 \\
4.28 & 520 \\
$4.33 a$ & 528 \\
$4.33 b$ & 527 \\
$4.33 c$ & 530 \\
4.34 & 527
\end{tabular}

The absorption profile for $\mathbf{4 . 2 7}$ is narrow compared to the other dyads. Installation of a TMSacetylene group on $\mathbf{4 . 2 8}$ red shifts the absorption slightly. Compared to the reference $\mathbf{4 . 2 8}$, the absorption maxima of the BODIPY dyads all have wider bands and are red-shifted due to extended conjugation from the triphenylamine and ferrocene moiety. The absorption maximum of each molecule resides around $500 \mathrm{~nm}$ assigned to the $\pi-\pi^{*}$ transitions for BODIPY. Oddly, the shoulder for the ferrocene MLCT band of BODIPY-Fc dyad 4.34 is not as pronounced as in ferrocenyl BODIPY $\mathbf{3 . 3 0}$ and 3.31. On the account of DFT calculations, the trimethylsilane unit on 4.28 does not contribute any significant electronic effects to the BODIPY core. Compound $4.33 \mathrm{~b}$ shows the electron density of the LUMO localizing at the formylated end of the TPA unit. BODIPY dyads 4.33a, 4.33c and 4.34 demonstrate sufficient charge transfer from the redox active unit to BODIPY in their dominant transitions (denoted by arrow). Due to the electron rich nature of the donor unit, they pose as potential candidate dyes for DSSC applications. 


\subsubsection{Electrochemistry of BODIPY dyads}

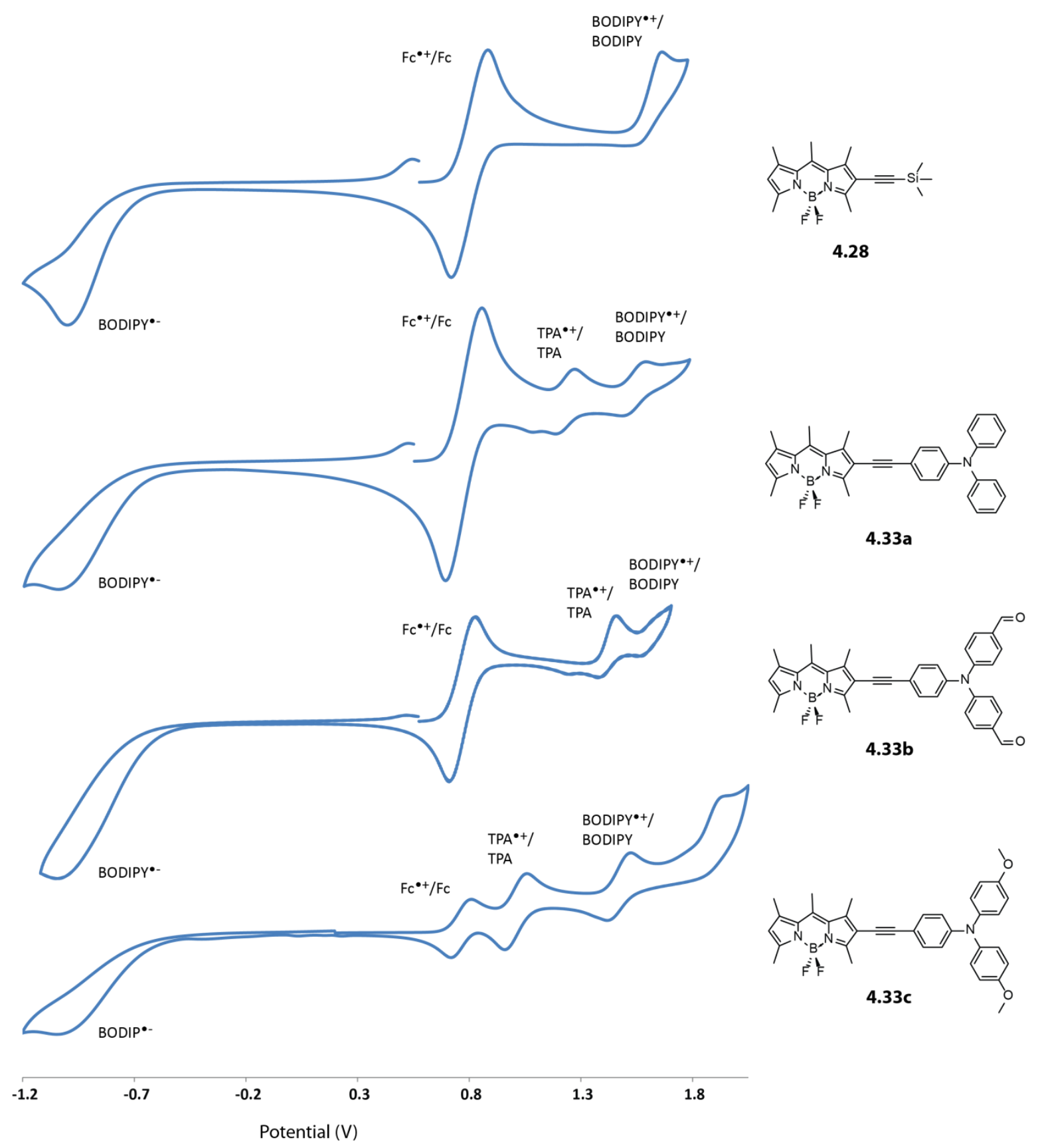

Figure 4.8. Stacked cyclic voltammogram of TPA-BODIPY dyads 
Table 4.3. Electrochemistry data of TPA-BODIPY dyads

\begin{tabular}{|c|c|c|c|}
\hline \multirow[b]{2}{*}{ Compound } & \multicolumn{3}{|l|}{$E_{1 / 2}(\mathrm{~V} \text { vs. NHE })^{a}$} \\
\hline & BODIPY/BODIPY ${ }^{\bullet-b}$ & $\mathrm{TPA}^{\bullet+} / \mathrm{TPA}$ & BODIPY $^{\bullet+} /$ BODIPY \\
\hline 4.28 & -0.958 & - & 1.593 \\
\hline $4.33 a$ & -1.000 & 1.209 & 1.511 \\
\hline $4.33 b$ & -0.995 & 1.396 & 1.587 \\
\hline $4.33 c$ & -1.045 & 1.007 & 1.469 \\
\hline
\end{tabular}

The reduction potentials assigned to BODIPY all lie around $-1.0 \mathrm{~V}$ showing no significant differences in the substituents effects towards reduction, although the reduction potential for the reference $\mathbf{4 . 2 8}$ is slightly higher than those of the TPA-BODIPY dyads. The oxidation of BODIPY dyads 4.33a-c follows expected trends. Attaching an electron withdrawing substituent causes the HOMO energy level to stabilize (higher oxidation potential), whereas an electron donating substituent would destabilize the HOMO (lower oxidation potential). Destabilization of the HOMO energy level minimizes the amount of energy needed for an electron to be oxidized. Concurrently, oxidizing a molecule with an electron donor would result in a lower potential. Comparing $4.33 a$ to $4.33 b$, the presence of electron withdrawing groups causes both the oxidation of formylated TPA and BODIPY to increase. The electron donating group on 4.33c causes the oxidation of methoxy-TPA and BODIPY to decrease with regards to 4.33a.

\subsubsection{Spectroelectrochemical studies of BODIPY dyads}

Spectroelectrochemistry is a method that marries spectroscopy and electrochemistry to pinpoint the redox active portions of the molecule as well as elucidate the stability towards oxidation and reduction. ${ }^{58,77}$ Monitoring of the redox reaction and identification of the redoxactive parts happens simultaneously, therefore in theory reactions rates could also be elucidated (but outside the scope of this thesis). 
a)

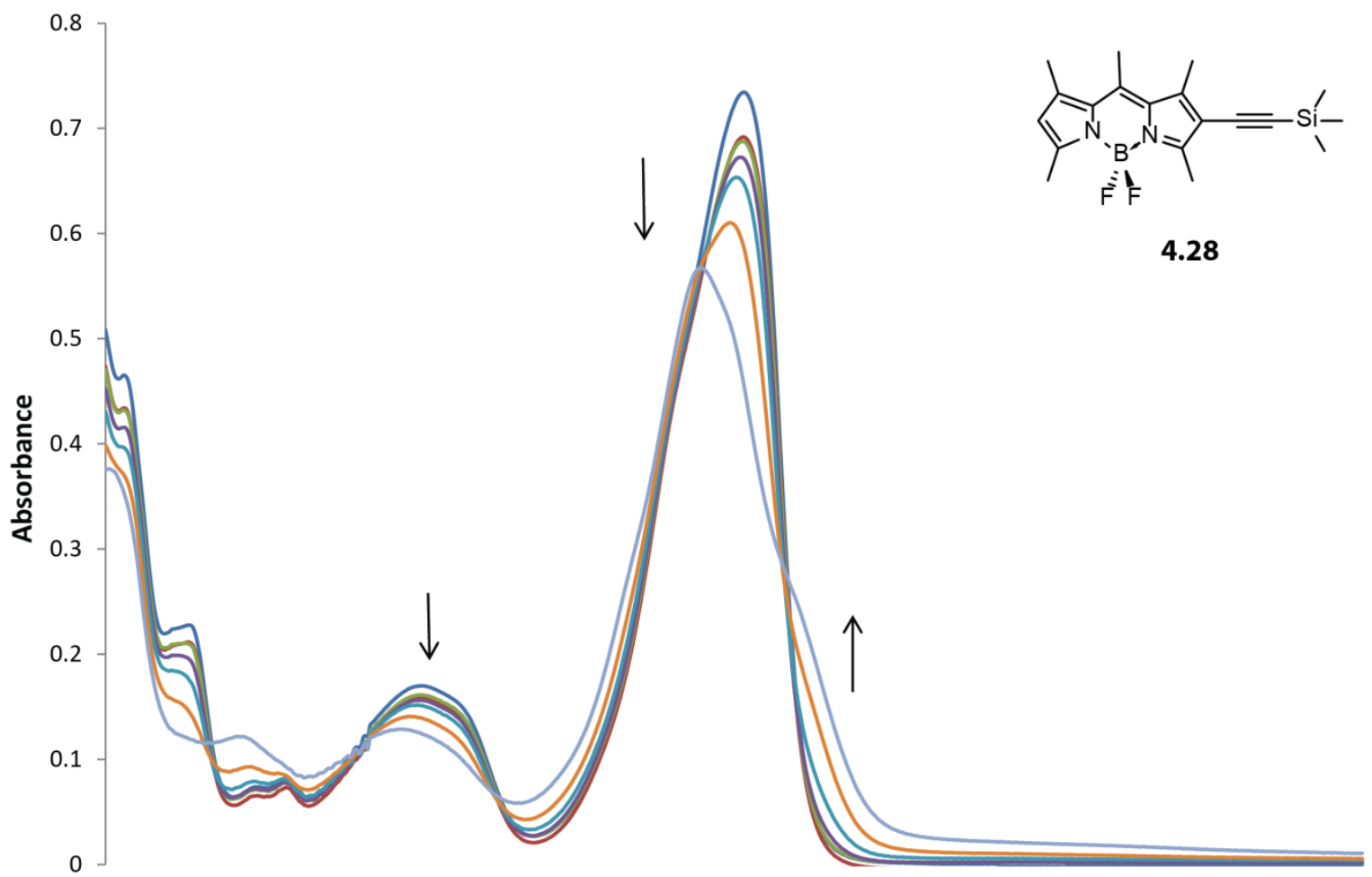

b)

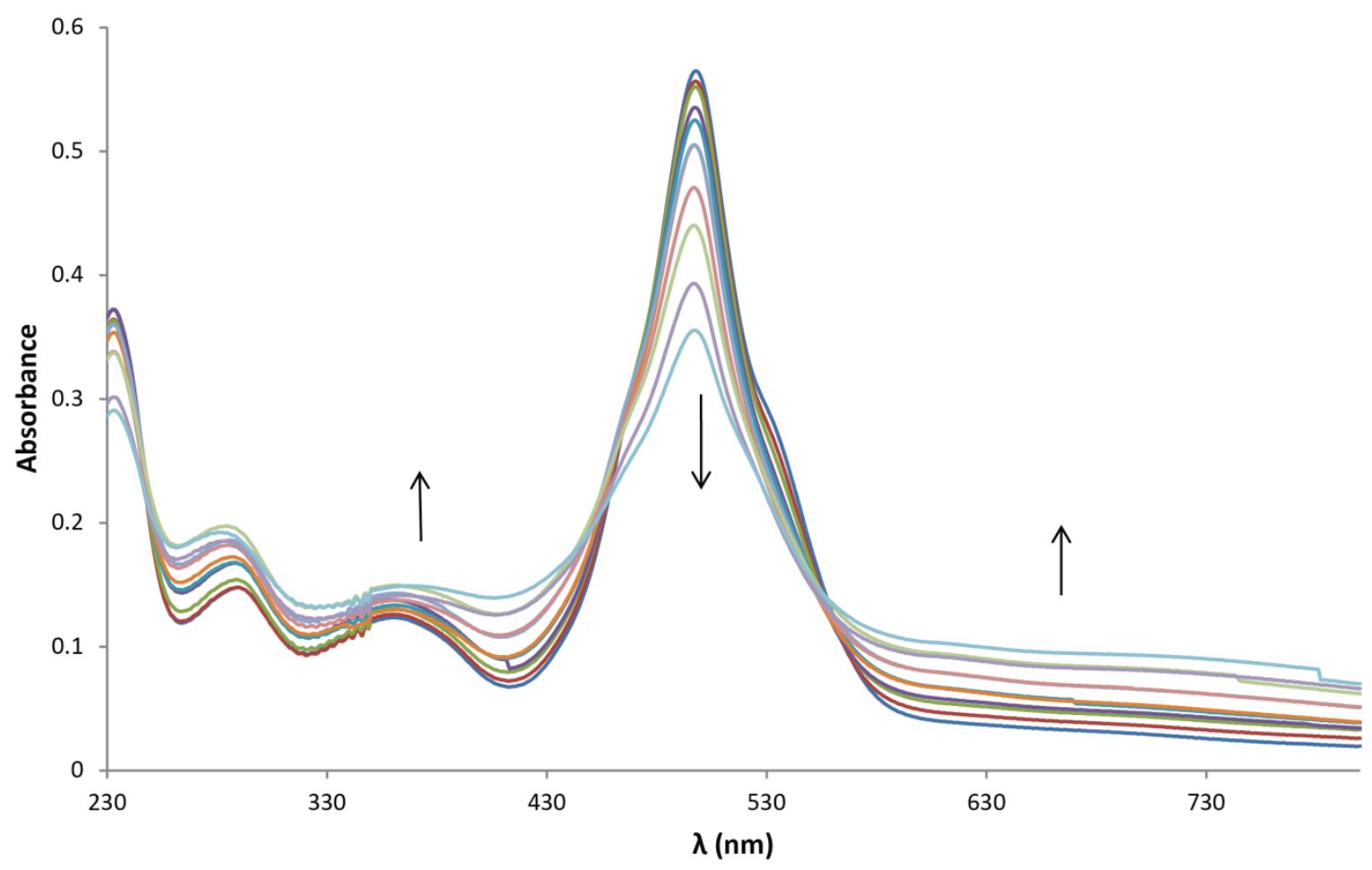

Figure 4.9. Oxidation of 4.28 - a) oxidation below $0.94 \mathrm{~V}$; b) oxidation above $0.94 \mathrm{~V}$ 
For each of the spectroelectrochemistry experiments, BODIPY dyad solutions in DCM were kept at a concentration within $10^{-3}$ to $10^{-4} \mathrm{M}$. Consider Figure 4.9 as a tutorial and baseline for our spectroelectrochemistry discussion. The top portion shows the oxidation of the BODIPY band $(\sim 500 \mathrm{~nm})$ starting at a voltage of $0.80 \mathrm{~V}$ and increasing the potential by $0.02 \mathrm{~V}$ over time (60 seconds). Upon oxidation, there is a gradual decrease in the peak corresponding to the BODIPY moiety at $520 \mathrm{~nm}$ as well as a blue-shift to $500 \mathrm{~nm}$. This could be indicative of slow decomposition or the emergence of a charge transfer band. Growth of a shoulder beyond the isosbestic point $(537 \mathrm{~nm})$ indicate the emergence of a charge transfer band within the oxidized species. Oxidizing beyond $0.94 \mathrm{~V}$, similarly emphasizes this likely conversion. Figure 4.10 shows a slightly different response where rapid decrease in the absorption owing to BODIPY suggests that the BODIPY fragment is decomposing under reduction.

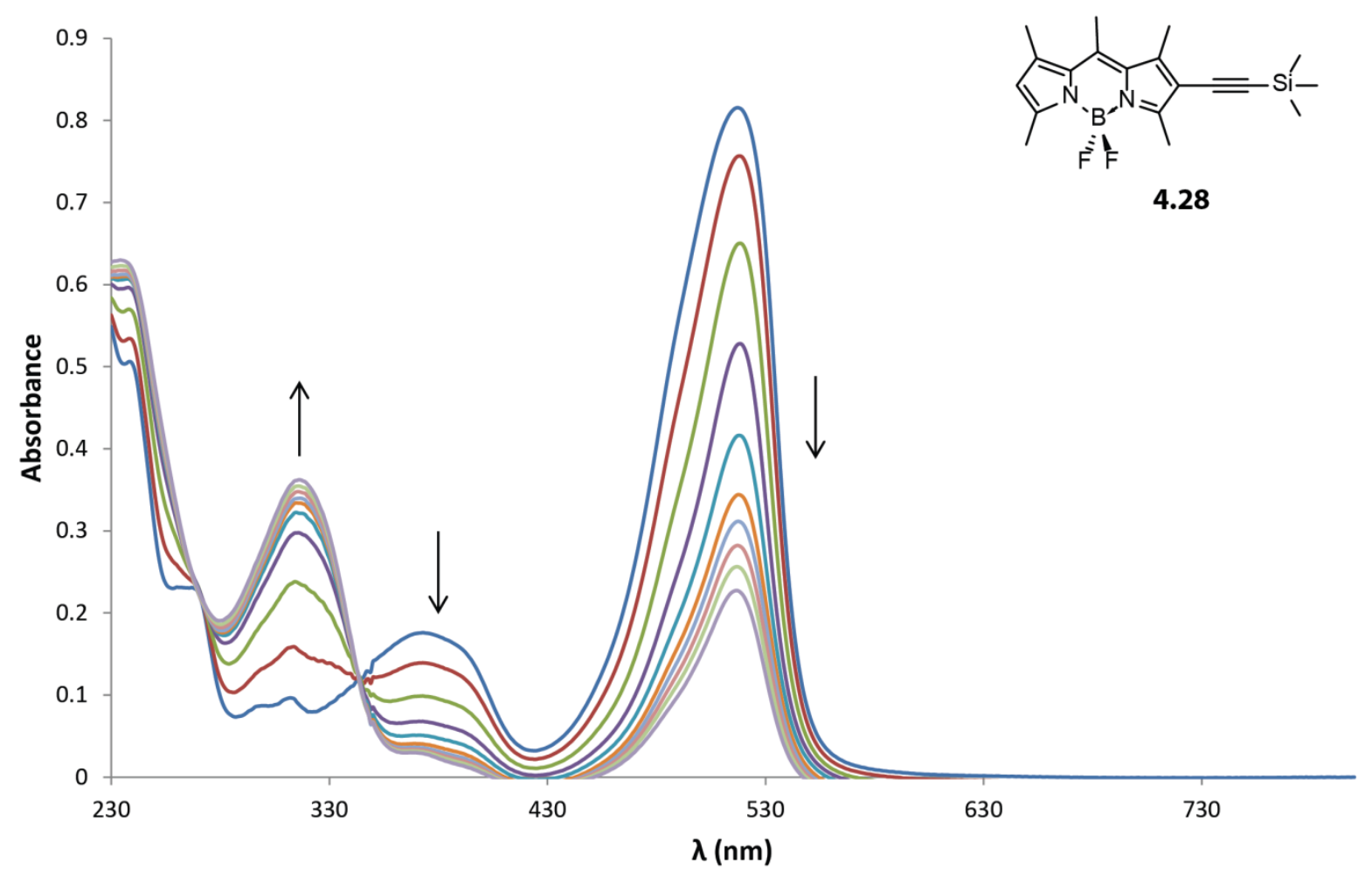

Figure 4.10. Reduction of 4.28 
a)

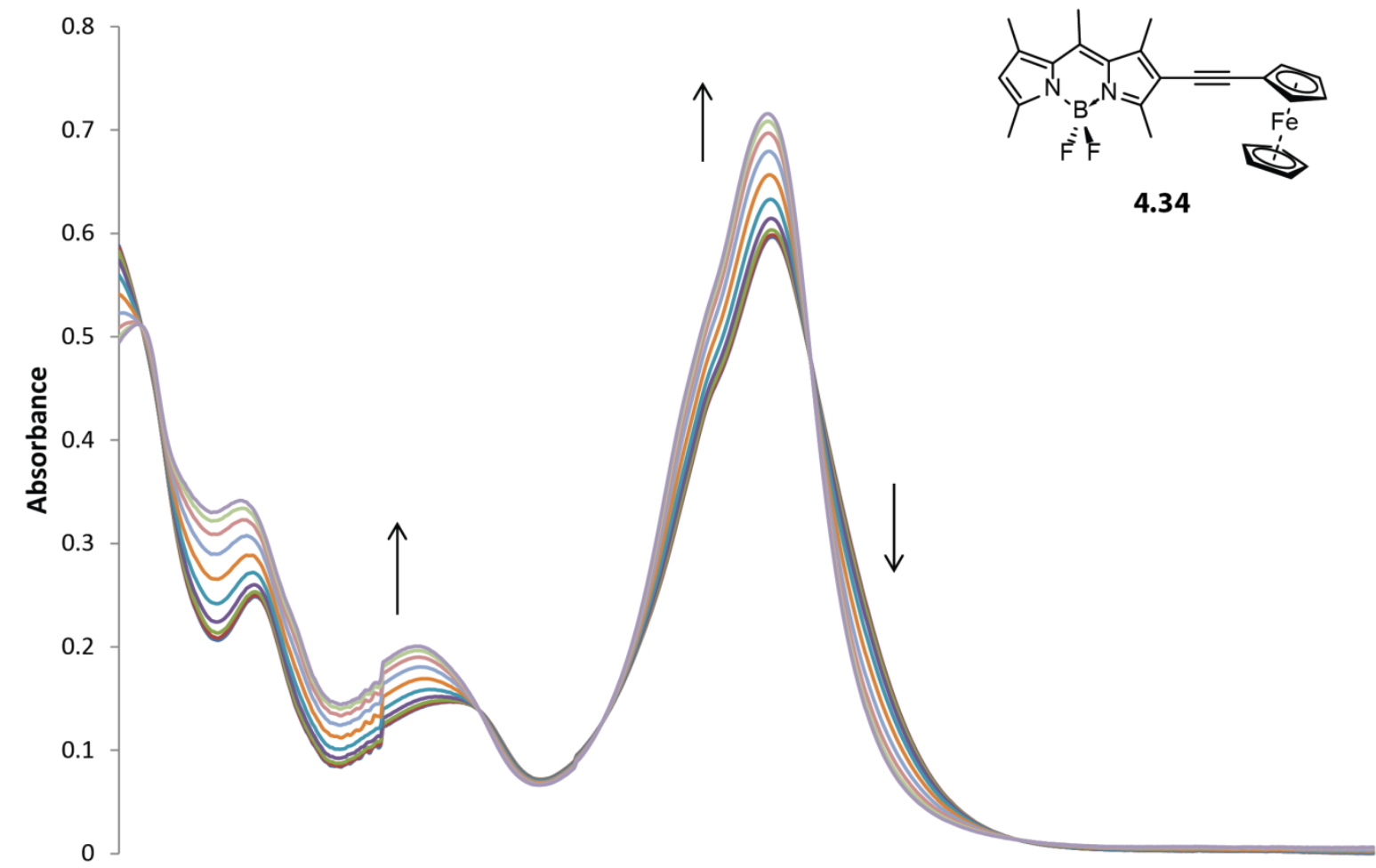

b)

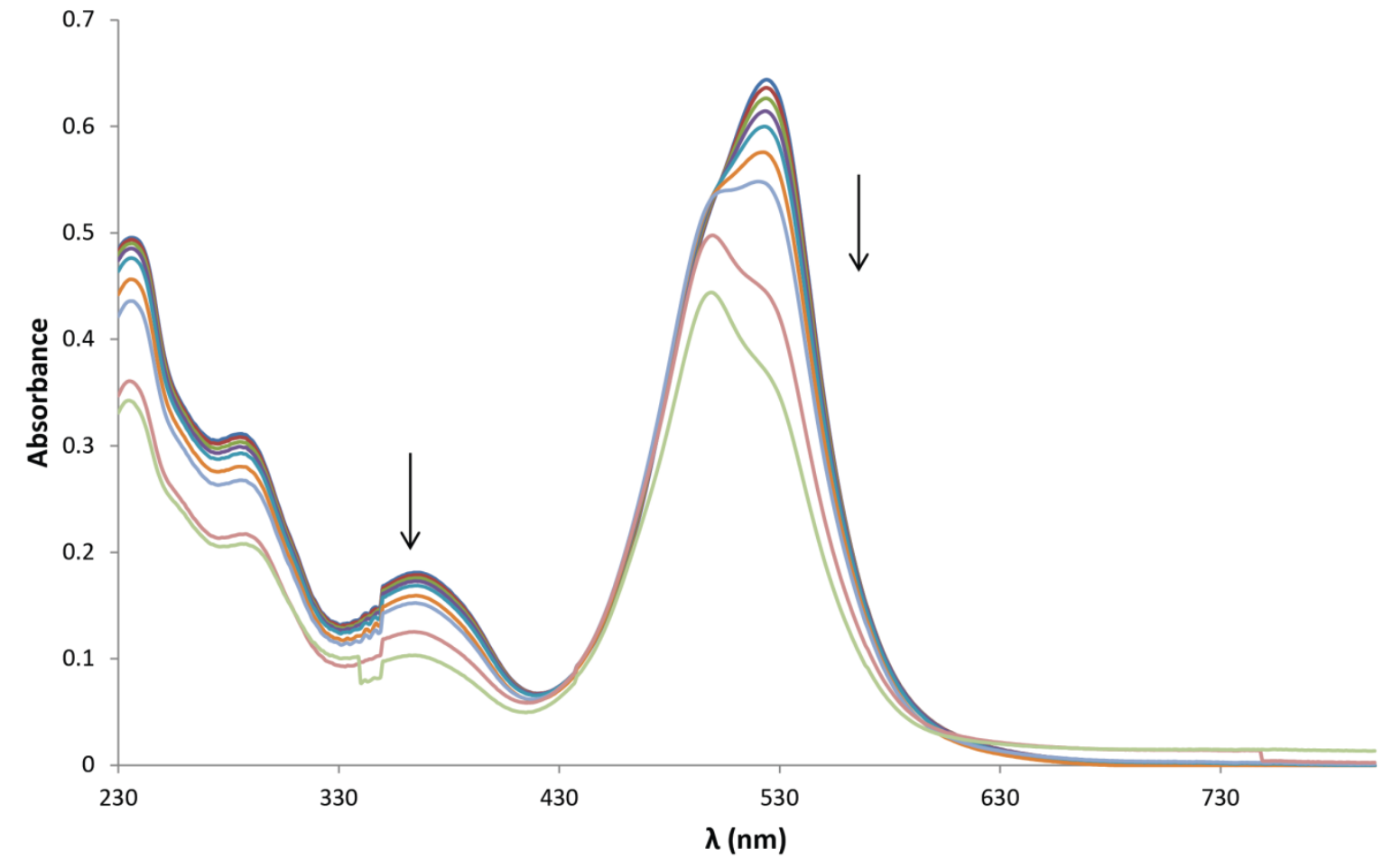

Figure 4.11. Oxidation of 4.34 - a) oxidation below $1.34 \mathrm{~V}$; b) oxidation above $1.34 \mathrm{~V}$ 
When examining the oxidation of ferrocene appended BODIPY 4.36 (Figure 4.11), nearly identical behaviour is observed when contrasted with the oxidation of 4.28. Again, Figure 4.11a shows the oxidation of the derivative starting at a voltage of $0.44 \mathrm{~V}$ and increasing the potential by $0.02 \mathrm{~V}$ over time (60 seconds). Upon oxidation, there is a noticeable difference as the BODIPY signal increases and the shoulder owing to ferrocene decreases. This behaviour suggests that the initial oxidation of the ferrocene moiety shuts down charge transfer to the BODIPY, increasing its unique absorbance (at $~ 525 \mathrm{~nm}$ ); as a result there is significant electronic communication in the ground state. Growth of a shoulder at higher potentials (beyond $1.34 \mathrm{~V}$ ) indicates the emergence of a charge transfer associated within the oxidized BODIPY species. Figure 4.12 again demonstrates that BODIPY is not stable to reduction and a rapid decrease in the absorption suggests the BODIPY fragment is decomposing under reduction. Note that short wavelength bands are more challenging to interpret as they tend to be the result of decomposition.

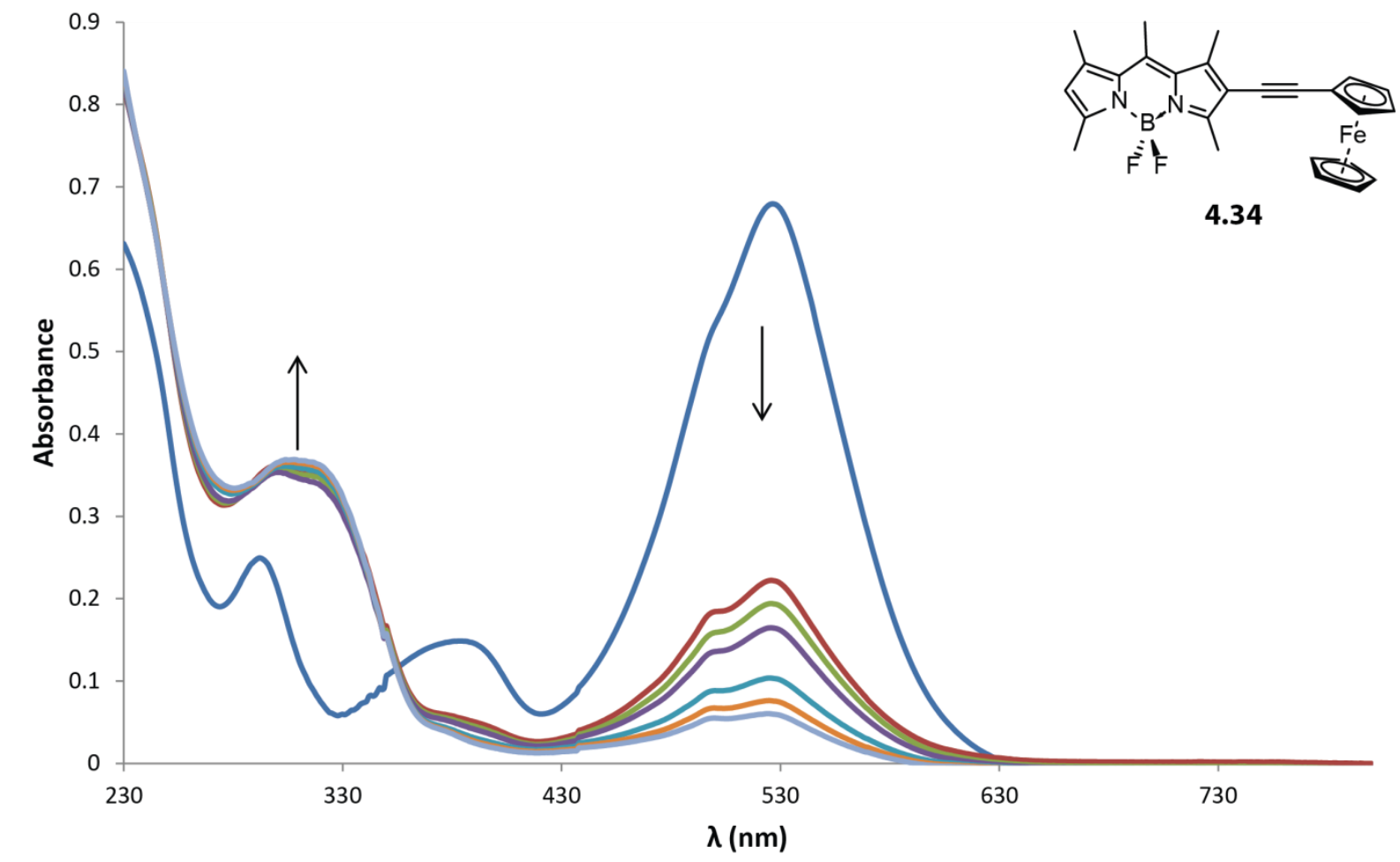

Figure 4.12. Reduction of 4.34 
a)

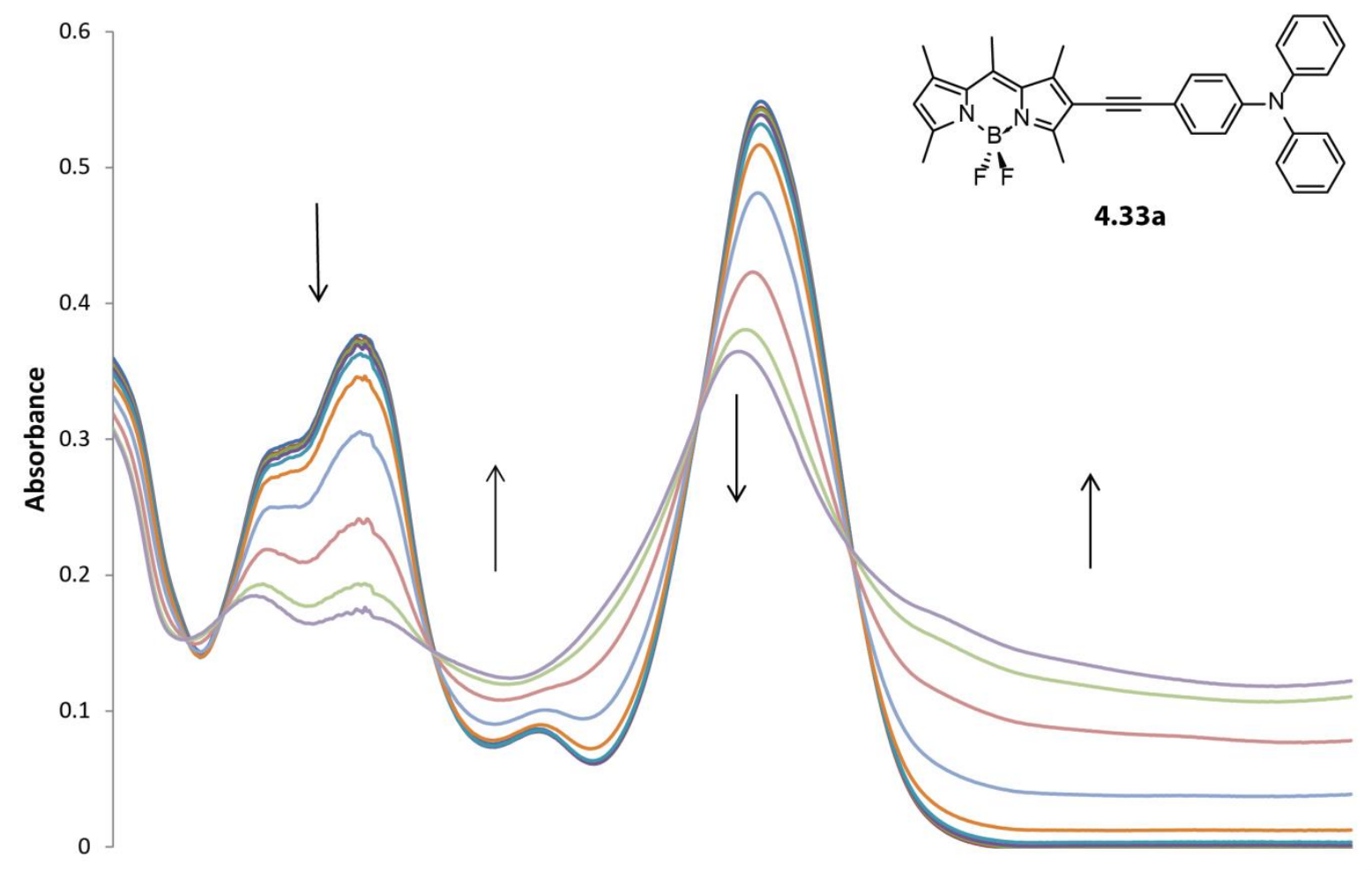

b)

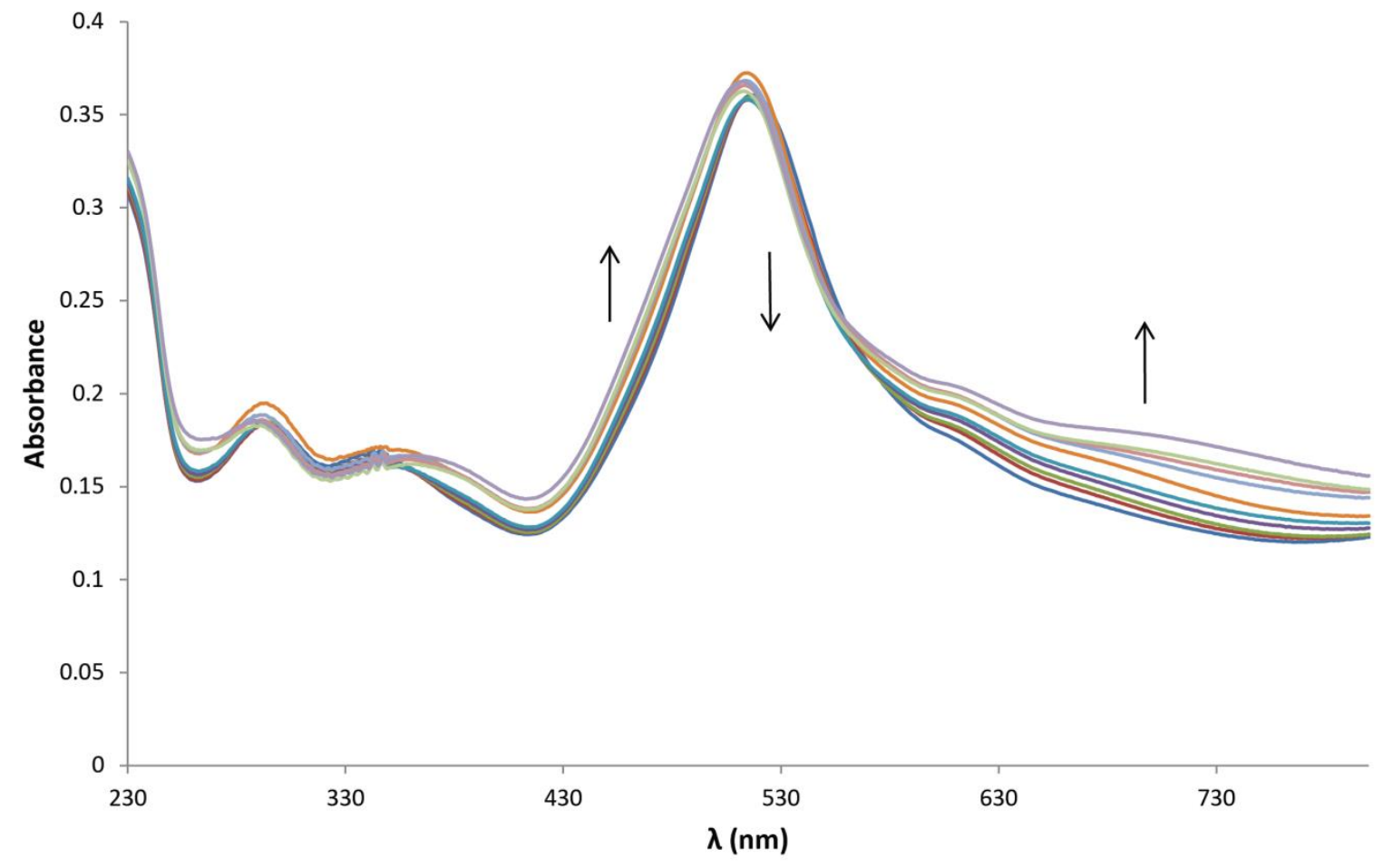

Figure 4.13. Oxidation of $4.33 \mathrm{a}-\mathrm{a}$ ) oxidation below $0.82 \mathrm{~V} ; \mathrm{b}$ ) oxidation above $0.82 \mathrm{~V}$ 
When examining the TPA appended BODIPY 4.33a (Figure 4.13 and Figure 4.14), nearly identical behaviour is observed when contrasted with 4.28, with the exception of added TPA features. Again, Figure 4.13 a shows the oxidation of the species $(\sim 520 \mathrm{~nm})$ starting at a voltage of $0.62 \mathrm{~V}$ and increasing the potential by $0.02 \mathrm{~V}$ over time (60 seconds). Upon oxidation (TPA-centred), there is a noticeable charge difference emerging at longer wavelengths and a decrease in the BODIPY band (isosbestic point at $571 \mathrm{~nm}$ ). This behaviour suggests strong electronic communication in the oxidized state, and this wide absorption at higher wavelength is characteristic of the stable triphenylamine radical cation. ${ }^{78}$ Further growth of a shoulder at higher potentials (beyond $0.82 \mathrm{~V}$ ) emphasizes coupling of this charge transfer behaviour and a lack of decomposition of the BODIPY portion suggests there is no second oxidation. Figure 4.14 again demonstrates that BODIPY is not stable to reduction and a rapid decrease in the absorption suggests the BODIPY fragment is decomposing under reduction.

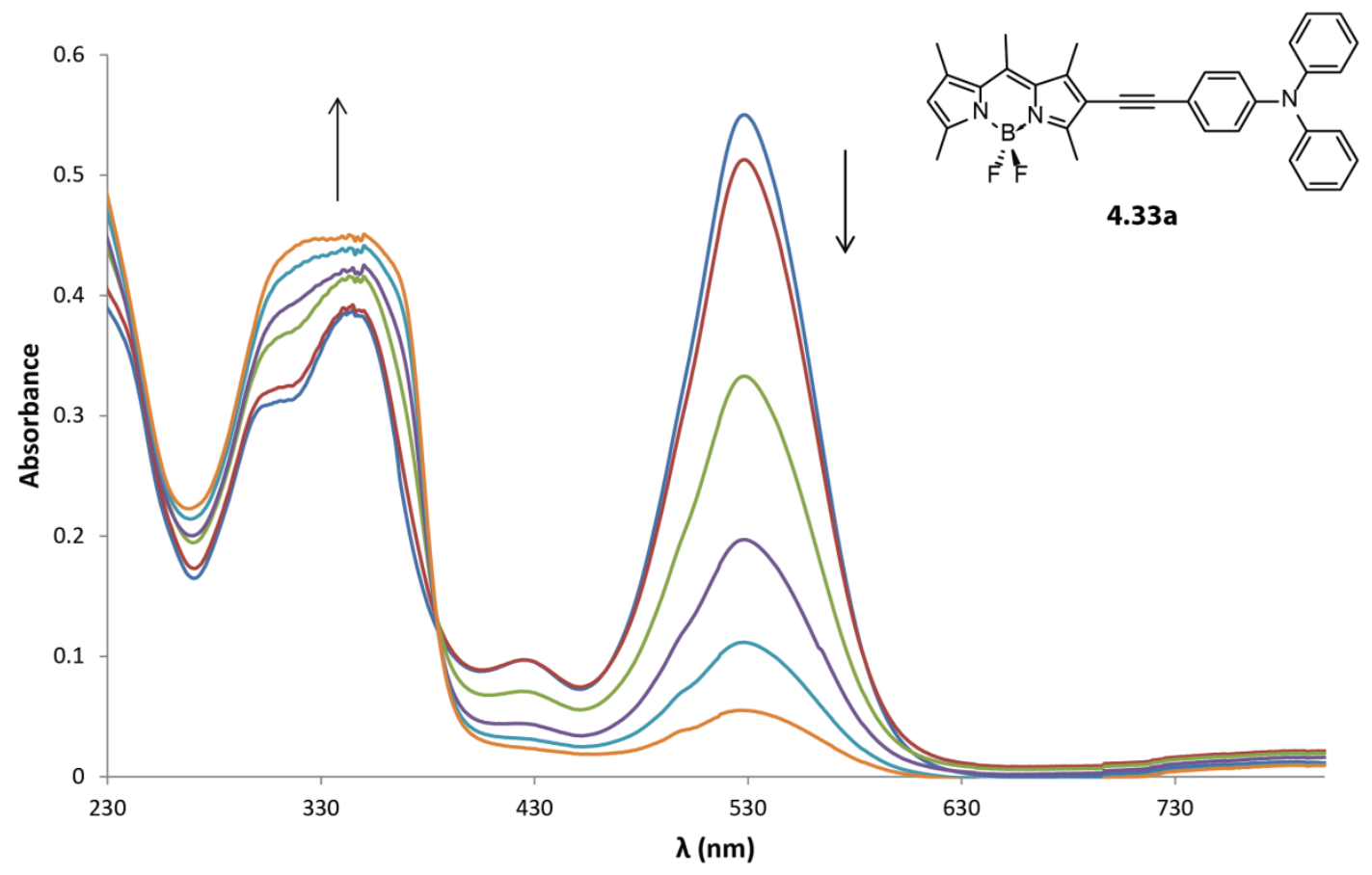

Figure 4.14. Reduction of $4.33 a$ 


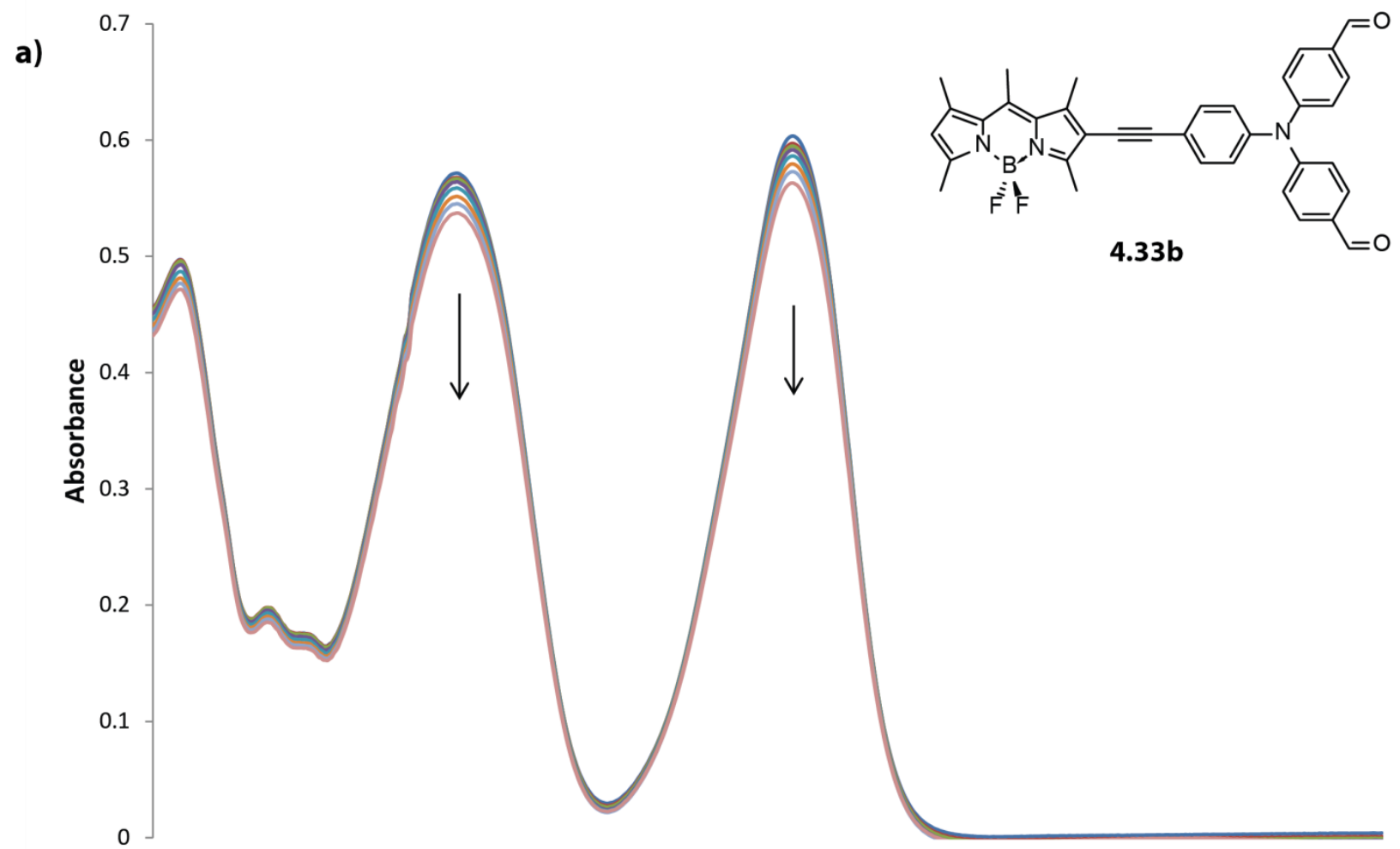

b)

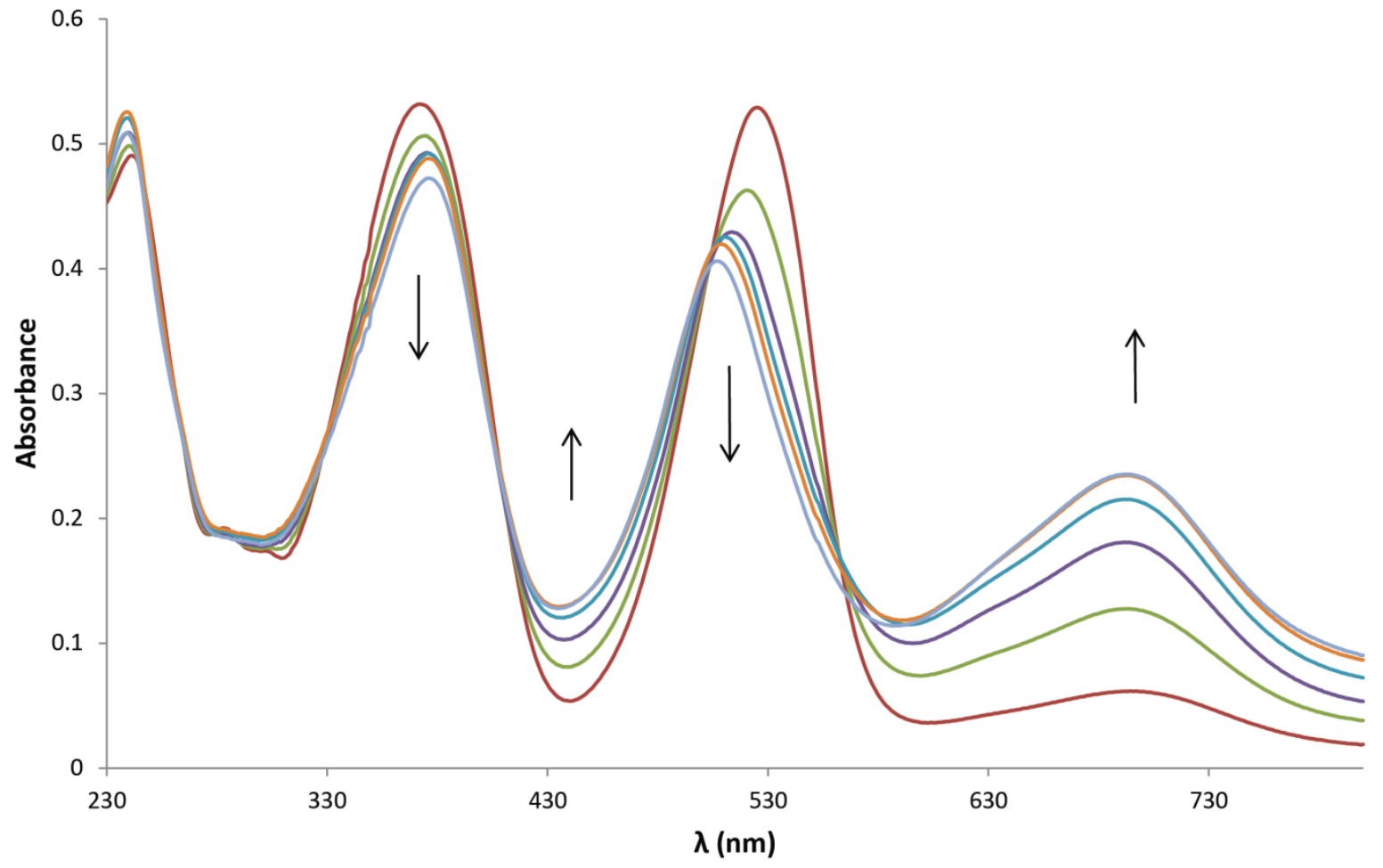

Figure 4.15. Oxidation of $4.33 b-a)$ oxidation below $0.86 \mathrm{~V}$; b) oxidation above $0.86 \mathrm{~V}$ 
When examining the formyl-TPA appended BODIPY 4.33b (Figure 4.15 and Figure 4.16), differences clearly emerge in Figure 4.15a. At low potentials starting at a voltage of $0.70 \mathrm{~V}$ and increasing the potential by $0.02 \mathrm{~V}$ over time (60 seconds), no appreciable oxidation is observed, consistent with the formyl-TPA being harder to oxidize. However, as the potential is raised (beyond $0.86 \mathrm{~V}$ ) a charge transfer band (694 $\mathrm{nm}$; characteristic to a triphenylamine radical cation) emerges and we see behaviour consistent with 4.33a. Again, a lack of decomposition of the BODIPY portion suggests there is no second oxidation. Figure 4.16 again demonstrates that BODIPY is not stable to reduction and a rapid decrease in the absorption suggests the BODIPY fragment is decomposing under reduction.

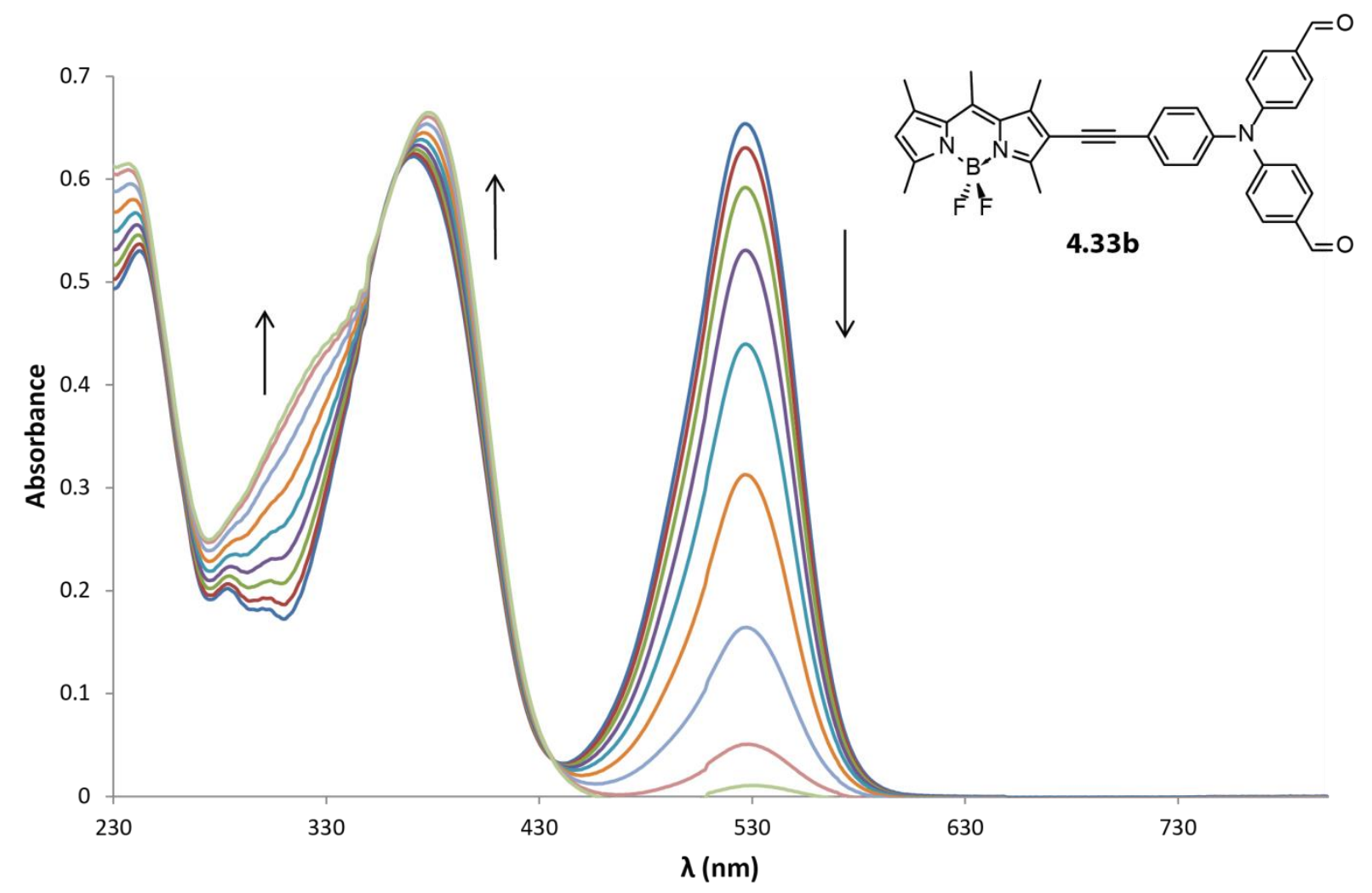

Figure 4.16. Reduction of $\mathbf{4 . 3 3 b}$ 
a)

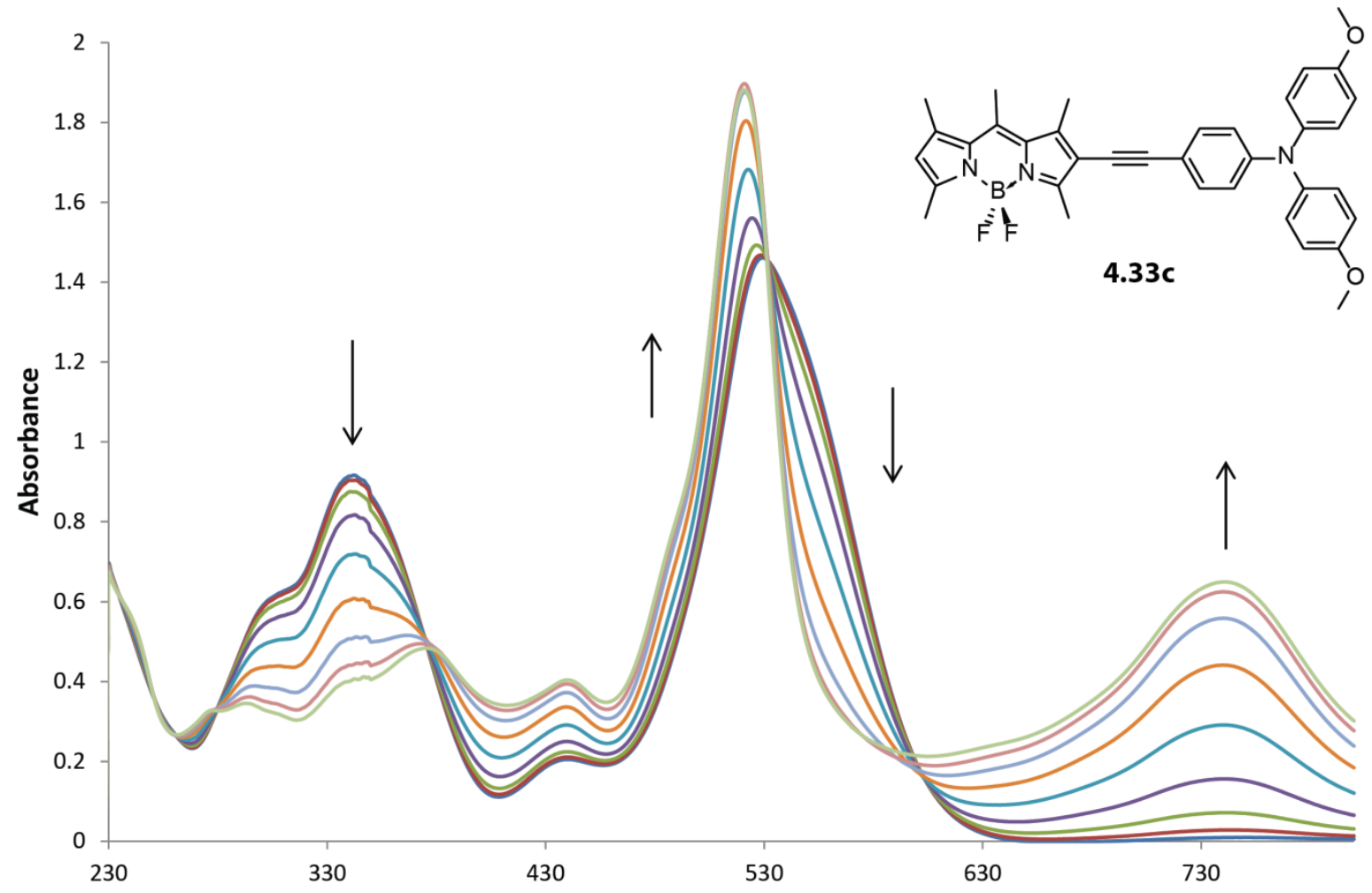

b)

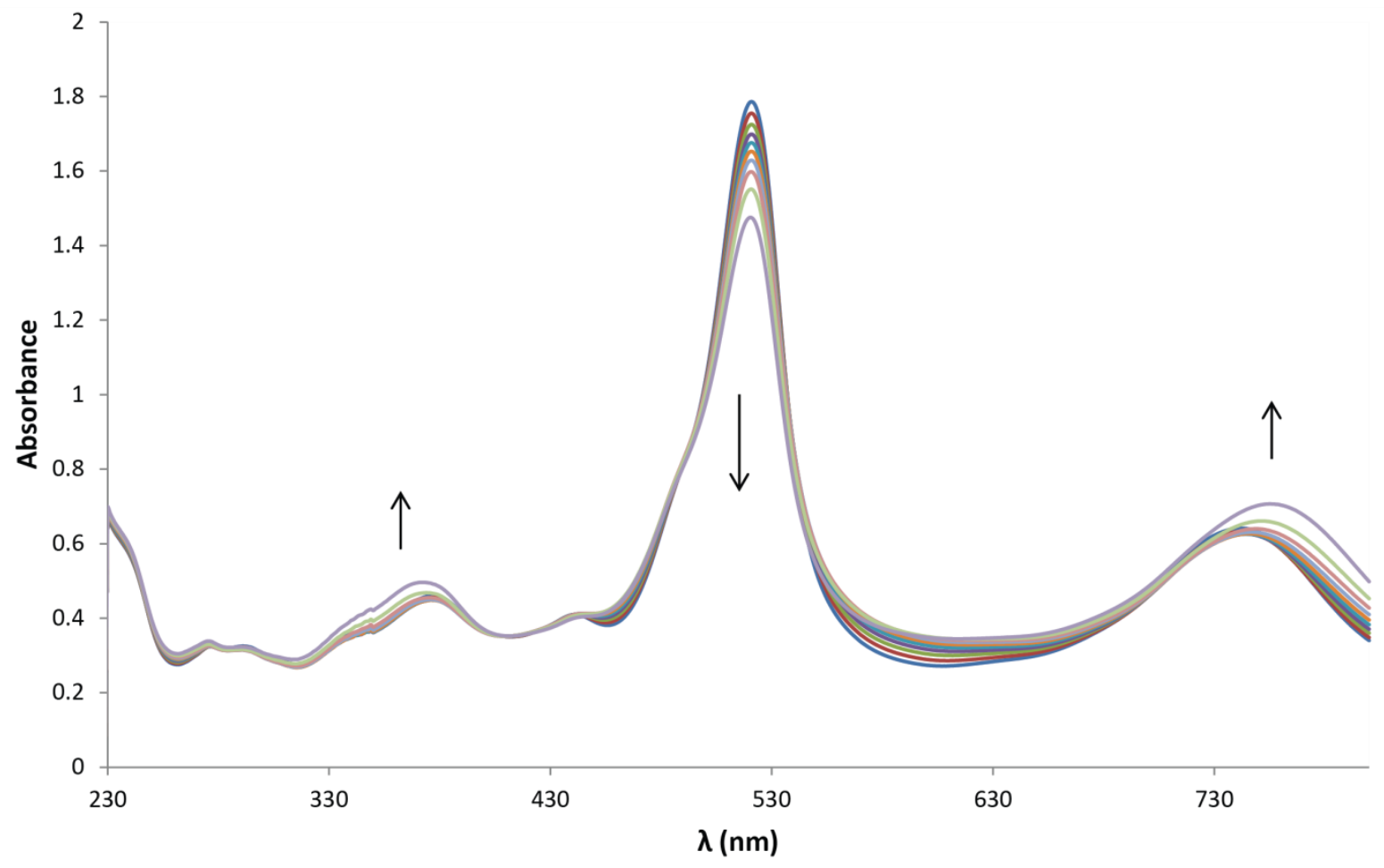

Figure 4.17. Oxidation of $4.33 \mathrm{c}-$ a) oxidation below $0.30 \mathrm{~V}$; b) oxidation above $0.30 \mathrm{~V}$ 
When examining the methoxy-TPA appended BODIPY 4.33c (Figure 4.17 and Figure 4.18), a combination of behaviours is observed. A sharpening and growth of the BODIPY absorption and loss of shoulder suggests that there is strong electronic coupling in the ground state of the electron rich dyad. Again, the top portion of Figure 4.16 shows the oxidation of the species starting at a voltage of $0.08 \mathrm{~V}$ and increasing the potential by $0.02 \mathrm{~V}$ over time (60 seconds). Upon oxidation (TPA-centred), there is a noticeable charge transfer band that emerges at longer wavelength, while the shoulder at shorter wavelength is diminished. This behaviour suggests strong electronic communication in the ground state (likely owing to the strong electron donating TPA) that is retained (although different in nature) after the formation of the

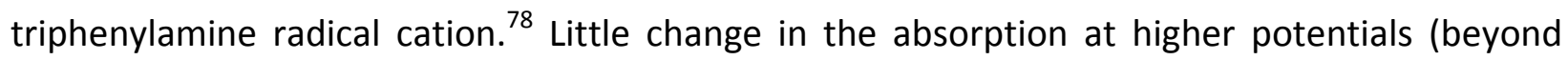
$0.30 \mathrm{~V}$ ) emphasizes that there is no further oxidation or decomposition in this robust dyad. Figure 4.18 again demonstrates that BODIPY is not stable to reduction and a rapid decrease in the absorption suggests the BODIPY fragment is the portion decomposing.

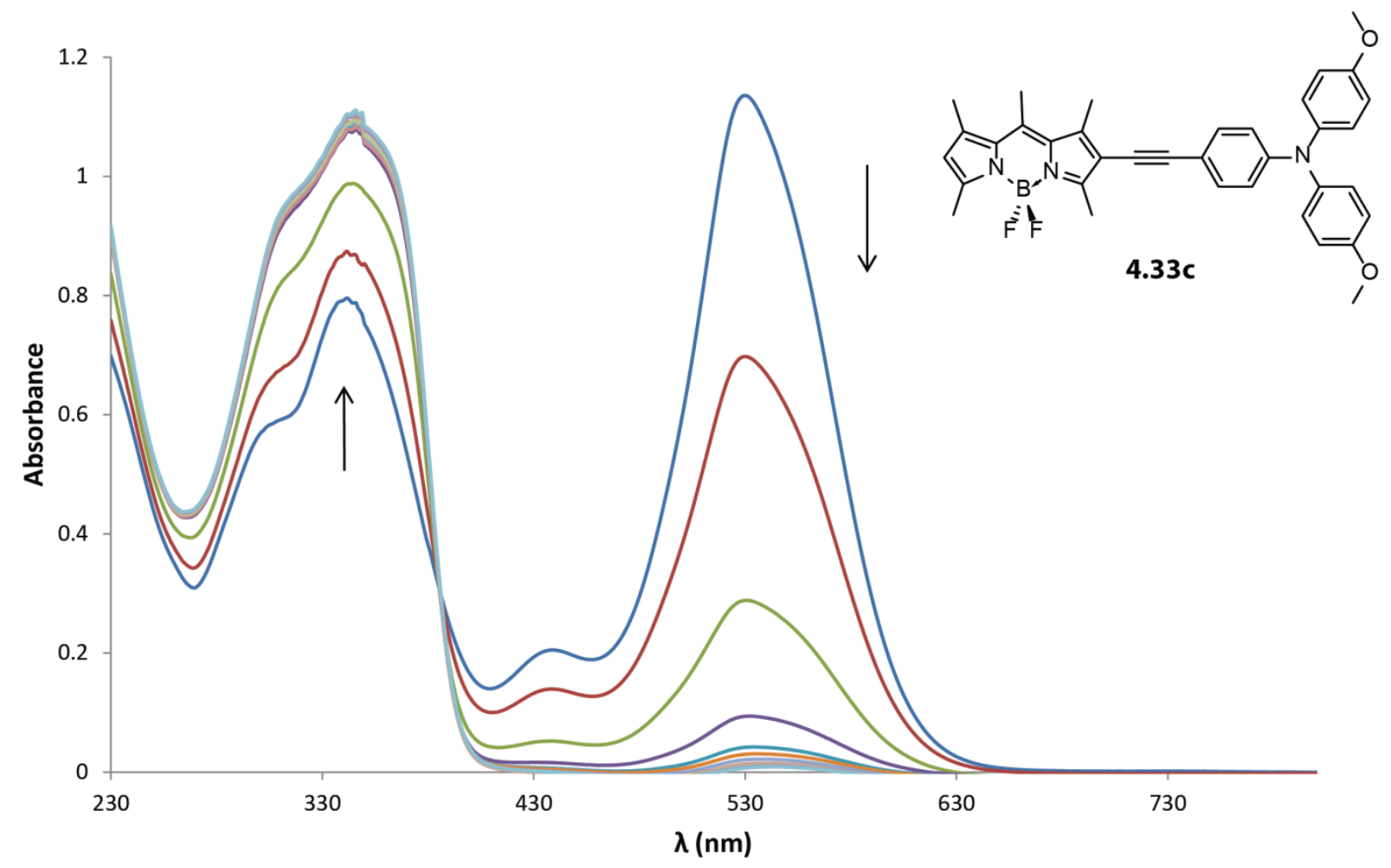

Figure 4.18. Reduction of 4.33c 


\subsection{Summary \& Conclusion}

A series of redox active BODIPY (TPA or Fc) dyads have been prepared, characterized and analysed. In Burhan Hussein's thesis (2017) ${ }^{65}$, the author concluded that instability in BODIPYferrocene dyads resulted in them being poor candidates for DSSC applications, but it was not confirmed where this instability originates from. The current family of TPA-substituted derivatives (4.33 a-c) and ferrocene derivative (4.34) reported, represent a unique series of dyads that may offer some insight into this decomposition pathway. The key observations are as follows;

- Probably the most significant observation, is that all BODIPY derivatives are unstable to reduction as evidenced by the rapid decrease in the BODIPY absorption band with spectroelectrochemistry in reductive mode.

- When the BODIPY is coupled to a redox active species, charge transfer in the ground state is observed when the TPA is electron rich (4.33c). Contrary to this, no transfer is observed for weakly donating or withdrawing species $(4.33 a, b)$.

- Strong electronic coupling is observed in the oxidized state of the TPA-BODIPY derivatives that lead to fairly robust triphenylamine radical cation charge transfer bands.

- Significant charge transfer is also observed in the neutral state of the ferrocene derivative (4.34) and ferrocene is more easily oxidized than TPA and as a result is more likely able to donate electron density to BODIPY.

To this end, it is likely that BODIPY-Fc instability is a result of auto-reduction of the BODIPY owing to electron transfer in the ground state. This phenomenon is even more exacerbated when electron withdrawing groups are added to the BODIPY, lowering its LUMO, making the process even more facile and faster. This was not observed in TPA derivatives, because electron density is more readily delocalized throughout the molecule limiting the propensity for a charge-separated ground state. 


\subsection{Experimental}

\subsubsection{General Considerations}

Please refer to section 3.6.1.

\subsubsection{Synthesis}

\section{5,5-difluoro-2-iodo-1,3,7,9,10-pentamethyl-5H-5 $\lambda^{4}, 6 \lambda^{4}$-dipyrrolo[1,2-c:2',1'-}

\section{f][1,3,2]diazaborinine (4.27)}

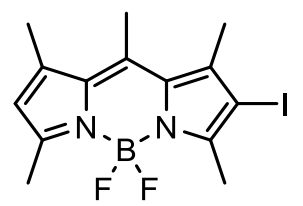

Pentamethyl-BODIPY (0.250 g, $0.960 \mathrm{mmol})$ was dissolved in DCM (16 mL) in an oven-dried 100 $\mathrm{mL}$ tear drop flask. The flask was wrapped in foil and $N$-iodosuccinimide $(0.220 \mathrm{~g}, 0.960 \mathrm{mmol})$ was added in one portion. The reaction was let to stir at RT under nitrogen for $8.5 \mathrm{~h}$. The mixture was adsorbed onto silica and solvent was removed in vacuo. The adsorbed crude was purified by column chromatography using Hex:DCM $\left(3: 2, R_{f}=0.22\right)$ as an eluent to afford the product as a bright orange fluffy solid $(0.265 \mathrm{~g}, 71 \%) .{ }^{1} \mathrm{H} \mathrm{NMR}\left(400 \mathrm{MHz}, \mathrm{CDCl}_{3}\right): \delta=6.12(\mathrm{~s}, 1 \mathrm{H})$, $2.60(\mathrm{~s}, 6 \mathrm{H}), 2.53(\mathrm{~s}, 3 \mathrm{H}), 2.45(2,3 \mathrm{H}), 2.42(\mathrm{~s}, 3 \mathrm{H}) .{ }^{13} \mathrm{C}\left\{{ }^{1} \mathrm{H}\right\} \mathrm{NMR}\left(100 \mathrm{MHz}^{\mathrm{C}} \mathrm{CDCl}_{3}\right): \delta=156.14$, 152.92 , 143.21, 141.36, 140.93, 137.69, 132.68, 131.82, 124.09, 122.56, 85.62, 84.49, 29.85, 19.59, 17.75, 17.24, 15.94, 14.76. ${ }^{19} \mathrm{~F} \mathrm{NMR}\left(\mathrm{CDCl}_{3}, 376.5 \mathrm{MHz}\right): \delta=-146.31\left(\mathrm{q}, J_{B F}=30.0 \mathrm{~Hz}\right) .{ }^{11} \mathrm{~B}$ $\operatorname{NMR}\left(\mathrm{CDCl}_{3}, 128 \mathrm{MHz}\right): \delta=0.49\left(\mathrm{t}, J_{F B}=32.0 \mathrm{~Hz}\right)$. Spectroscopic data is consistent with the literature. $^{79}$ 
5,5-difluoro-1,3,7,9,10-pentamethyl-2-((trimethylsilyl)ethynyl)-5H-5 $\lambda^{4}, 6 \lambda^{4}$-dipyrrolo[1,2$\left.c: 2^{\prime}, 1^{\prime}-f\right][1,3,2]$ diazaborinine (4.28)

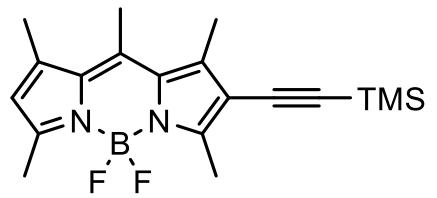

To a $200 \mathrm{~mL}$ flame dried Schlenk flask with stir bar, dissolved 4.27 (0.251 g, $0.646 \mathrm{mmol})$ in anhydrous THF $(15 \mathrm{~mL})$ and anhydrous $\mathrm{NEt}_{3}(6 \mathrm{~mL})$ under $\mathrm{N}_{2}$. The solution was sparged for $\sim 5$ min. To this solution was added $\mathrm{Pd}\left(\mathrm{PPh}_{3}\right)_{2} \mathrm{Cl}_{2}$ catalyst $(0.023 \mathrm{~g}, 0.05$ eq. $)$, and copper(I) iodide (0.014 g, 0.10 eq.), followed by addition of TMS-acetylene $(0.12 \mathrm{~mL}, 1.3$ eq.). Reaction was run at RT overnight. The solvent was removed in vacuo and the crude material was dissolved in EtOAc, extracted with sat. $\mathrm{NH}_{4} \mathrm{Cl}(30 \mathrm{~mL} \times 3)$ and the lastly with brine. The crude material was triturated with hexanes to give a red-brown solid $(0.174 \mathrm{~g}, 75 \%) .{ }^{1} \mathrm{H} \mathrm{NMR}\left(400 \mathrm{MHz}, \mathrm{CDCl}_{3}\right): \delta=$ $6.09(\mathrm{~s}, 1 \mathrm{H}), 2.59(\mathrm{~s}, 6 \mathrm{H}), 2.52(\mathrm{~s}, 3 \mathrm{H}), 2.47(\mathrm{~s}, 3 \mathrm{H}), 2.41(\mathrm{~s}, 3 \mathrm{H}), 0.26(\mathrm{~s}, 9 \mathrm{H}) .{ }^{13} \mathrm{C}\left\{{ }^{1} \mathrm{H}\right\}$ NMR $(100$ $\mathrm{MHz}_{\mathrm{CDCl}}$ ): $\delta=156.0,155.33,142.82,142.11,141.13,133.29,130.85,122.35,115.18,100.88$, $97.99,31.05,19.56,17.61,17.21,16.76,15.95,14.70,13.46,0.35$. HRMS (EI-TOF): $\mathrm{m} / \mathrm{z}$ $358.1856\left(\mathrm{M}^{+}\right)$calculated for $\mathrm{C}_{19} \mathrm{H}_{25} \mathrm{BF}_{2} \mathrm{~N}_{2} \mathrm{Si}: \mathrm{m} / z$ 358.1848. ${ }^{19} \mathrm{~F}$ NMR and ${ }^{11} \mathrm{~B} \mathrm{NMR}$ were not obtained. 


\section{4-iodo- $N, N$-diphenylaniline (4.30a)}

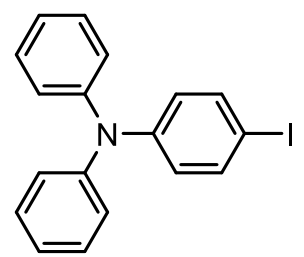

To an over-dried $250 \mathrm{~mL} \mathrm{RBF}$, dissolved triphenylamine (4.906 g, $20.0 \mathrm{mmol}$ ) in dry chloroform $(60 \mathrm{~mL})$ and sparged for $10 \mathrm{~min}$. The flask was covered in foil and $\mathrm{N}$-iodosuccinimide $(4.504 \mathrm{~g}$, $20.0 \mathrm{mmol}$ ) was added along with glacial acetic acid $(60 \mathrm{~mL})$. The reaction was stirred under nitrogen at RT for $26 \mathrm{~h}$. The reaction was monitored by TLC in 8:2 Hex:DCM. The reaction was quenched with water and then extracted with sat. solution of sodium thiosulfate $\left(\mathrm{Na}_{2} \mathrm{~S}_{2} \mathrm{O}_{3}\right)$. The organic layers were combined and dried over $\mathrm{Na}_{2} \mathrm{SO}_{4}$ and evaporated under reduced pressure and then under vacuum over several days to give a solid crude material. The obtained crude product was mixed with minimal amount of hexanes or washed with hexanes and then vacuum filtered to afford an off-white solid (4.645 g, 62\%). ${ }^{1} \mathrm{H}$ NMR (400 MHz, acetone-d): $\delta=7.57$ (d, $2 \mathrm{H}, J=8.8 \mathrm{~Hz}), 7.30(\mathrm{t}, 4 \mathrm{H}, J=7.2 \mathrm{~Hz}), 7.08(\mathrm{t}, 6 \mathrm{H}, J=7.2 \mathrm{~Hz}), 6.81(\mathrm{~d}, 2 \mathrm{H}, J=8.8 \mathrm{~Hz}) .{ }^{13} \mathrm{C}\left\{{ }^{1} \mathrm{H}\right\} \mathrm{NMR}$ (100 MHz, acetone-d): $\delta=206.04,148.82,148.13,139.22,138.99,130.38,130.17,126.56$, $125.81,125.50,124.87,124.44,123.67,84.99$. Spectroscopic data is consistent with the literature. ${ }^{80}$

\section{N,N-diphenyl-4-((trimethylsilyl)ethynyl)aniline (4.31a)}

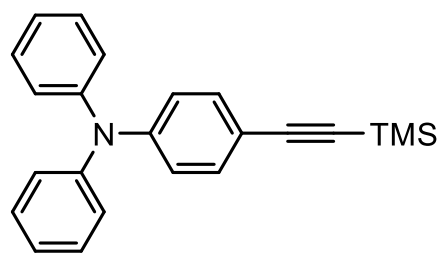

To a flame dried $200 \mathrm{~mL}$ Schlenk flask with stir bar, dissolved 4.30a (1.167 g, $3.142 \mathrm{mmol})$ in $20.0 \mathrm{~mL}$ of dry THF and $10.0 \mathrm{~mL}$ of dry $\mathrm{NEt}_{3}$. Sparged solution under nitrogen for over $30 \mathrm{~min}$. The $\mathrm{Pd}\left(\mathrm{PPh}_{3}\right)_{2} \mathrm{Cl}_{2}(0.110 \mathrm{~g}, 0.157 \mathrm{mmol})$ and $\mathrm{Cul}(0.061 \mathrm{~g}, 0.314 \mathrm{mmol})$ were added in one 
portion. Followed by TMS-acetylene $(0.89 \mathrm{~mL}, 6.425 \mathrm{mmol})$. The reaction stirred in room temperature under nitrogen for $3 \mathrm{~h}$. The dry crude was dissolved in EtOAc and extracted with sat. $\mathrm{NH}_{4} \mathrm{Cl}$ thrice, then once with brine. The organic layers were combined and dried over magnesium sulfate, filtered, and solvent was evaporated to afford a light yellow wax $(0.720 \mathrm{~g}$, 67\%). ${ }^{1} \mathrm{H}$ NMR (400 MHz, acetone-d): $\delta=7.31(\mathrm{t}, 6 \mathrm{H}, J=8.0 \mathrm{~Hz}$ ), $7.09(\mathrm{t}, 6 \mathrm{H}, J=8.0 \mathrm{~Hz}$ ), 6.91 (d, $2 \mathrm{H}, J=8.4 \mathrm{~Hz}) .{ }^{13} \mathrm{C}\left\{{ }^{1} \mathrm{H}\right\}$ NMR (100 MHz, acetone-d): $\delta=205.15,148.32,147.11,132.80,129.58$, $125.11,123.90,121.65,115.81,105.56,92.41,0.66$. Spectroscopic data is consistent with the literature. ${ }^{81}$

\section{4-ethynyl-N,N-diphenylaniline (4.32a)}

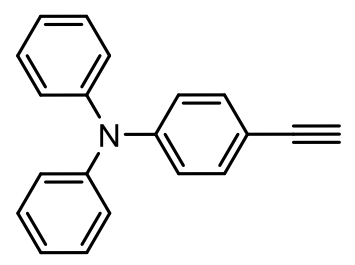

In a $50 \mathrm{~mL}$ RBF, 4.31a (0.705 g, $2.064 \mathrm{mmol})$ was dissolved in $11 \mathrm{~mL}$ of DCM, $11 \mathrm{~mL}$ of $\mathrm{MeOH}$, followed by addition of potassium carbonate ( $0.565 \mathrm{~g}, 4.128 \mathrm{mmol})$ for $4 \mathrm{~h}$ under nitrogen in RT. The reaction was quenched with water and extracted with DCM (3 $25 \mathrm{~mL})$. The organic layers were combined, dried with $\mathrm{MgSO}_{4}$, filtered, and solvent removed in vacuo. The orangeyellow oil crude was column chromatographed in 4:1 Hex:DCM to afford the product as an offwhite solid (0.339 g, 61\%). ${ }^{1} \mathrm{H}$ NMR $\left(400 \mathrm{MHz}^{\mathrm{C} C D C l}\right.$ ) $: \delta=7.37(\mathrm{~d}, 2 \mathrm{H}, J=8.4 \mathrm{~Hz}), 7.31(\mathrm{t}, 4 \mathrm{H}, J=$ $7.6 \mathrm{~Hz}$ ), $7.14(\mathrm{~d}, 4 \mathrm{H}, J=8.4 \mathrm{~Hz}), 7.10(\mathrm{t}, 2 \mathrm{H}, J=7.6 \mathrm{~Hz}), 7.01(\mathrm{~d}, 2 \mathrm{H}, J=8.4 \mathrm{~Hz}), 3.05(\mathrm{~s}, 1 \mathrm{H})$. Calibrated to water ${ }^{13} \mathrm{C}\left\{{ }^{1} \mathrm{H}\right\} \mathrm{NMR}(100 \mathrm{MHz}$, acetone-d): $\delta=148.51,147.27,133.20,129.55$, $125.19,123.78,122.20,114.91,84.07,76.31$. Spectroscopic data is consistent with the literature. $^{75}$ 


\section{4,4'-(phenylazanediyl)dibenzaldehyde (4.29b)}

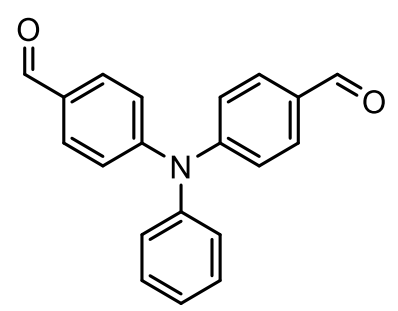

To an oven dried $100 \mathrm{~mL} \mathrm{RBF}$ with stir bar was added triphenylamine (4.006 g, $16.331 \mathrm{mmol})$. The flask was charged with nitrogen followed by the addition of $32 \mathrm{~mL}$ of anhydrous DMF. The flask was put in an ice bath and let to cool to $0^{\circ} \mathrm{C}$ for $15 \mathrm{~min}$. Then $\mathrm{POCl}_{3}(13.40 \mathrm{~mL}, 143.651$ mmol) was added dropwise. The reaction was let to warm up to room temperature, then stirred under nitrogen at $100^{\circ} \mathrm{C}$ overnight for $15 \mathrm{~h}$. After letting the reaction cool to room temperature, the mixture was poured onto ice and neutralized using sat. aqueous $\mathrm{NaOH}$. The mixture was extracted using DCM $(20 \mathrm{~mL} \times 10)$ and the combined organic layers were dried over $\mathrm{MgSO}_{4}$, filtered and volatiles were removed in vacuo. The crude material was purified via column chromatography over silica using Hex:EtOAc 4:1 $\left(R_{f}=0.18\right)$ as the eluent affording the product as a light green solid (0.225 g, 46\%). ${ }^{1} \mathrm{H}$ NMR (400 MHz, $\left.\mathrm{CDCl}_{3}\right): \delta=9.84(\mathrm{~s}, 2 \mathrm{H}), 7.72(\mathrm{~d}$, $4 \mathrm{H}, J=8.4 \mathrm{~Hz}), 7.34(\mathrm{t}, 2 \mathrm{H}, J=7.6 \mathrm{~Hz}), 7.21(\mathrm{t}, 2 \mathrm{H}, J=7.6 \mathrm{~Hz}), 7.13(\mathrm{~d}, 2 \mathrm{H}, J=8.4 \mathrm{~Hz}) .{ }^{13} \mathrm{C}\left\{{ }^{1} \mathrm{H}\right\}$ $\operatorname{NMR}\left(100 \mathrm{MHz}, \mathrm{CDCl}_{3}\right): \delta=190.57,152.06,145.55,131.37,131.33,130.23,127.13,126.33$, 122.82. ${ }^{1} \mathrm{H}$ NMR was calibrated to $\mathrm{H}_{2} \mathrm{O}(1.56 \mathrm{ppm})$. Spectroscopic data is consistent with the literature. 82 


\section{4,4'-((4-iodophenyl)azanediyl)dibenzaldehyde (4.30b)}

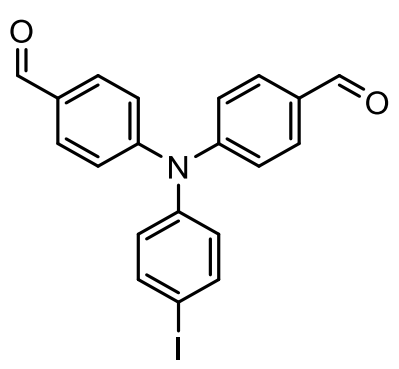

4.29b (1.0439 g, $3.464 \mathrm{mmol}$ ) was dissolved in $22 \mathrm{~mL}$ of glacial acetic acid, followed by the addition of potassium iodide $(0.582 \mathrm{~g}, 3.504 \mathrm{mmol})$ and $\mathrm{KIO}_{3}(1.042 \mathrm{~g}, 4.869 \mathrm{mmol})$. The reaction mixture was stirred for $3 \mathrm{~h}$ at $70^{\circ} \mathrm{C}$ in an oil bath. The reaction was let to cool to RT and filtered to remove the salts into a seperatory funnel. To the mixture was added $25 \mathrm{~mL}$ of water and extracted with DCM $(2 \times 25 \mathrm{~mL})$. The organic phases were combined and then washed with dilute ammonia solution until $\mathrm{pH}^{\sim}$, then washed with $25 \mathrm{~mL}$ of sat. $\mathrm{NaHSO}_{3}$ solution, then with brine. The organic phases were combined and dried over $\mathrm{MgSO}_{4}$. The solvents were evaporated in vacuo. The crude material was triturated with minimal EtOH and vacuum filtered to obtain the product as a moss green solid $(0.933 \mathrm{~g}, 63 \%) .{ }^{1} \mathrm{H} \mathrm{NMR}\left(400 \mathrm{MHz}, \mathrm{CDCl}_{3}\right): \delta=9.90(\mathrm{~s}, 2 \mathrm{H})$, $7.78(\mathrm{~d}, 4 \mathrm{H}, J=8.0 \mathrm{~Hz}), 7.68(\mathrm{~d}, 2 \mathrm{H}, J=8.0 \mathrm{~Hz}), 7.18(\mathrm{~d}, 4 \mathrm{H}, J=8.4 \mathrm{~Hz}), 6.92(\mathrm{~d}, 2 \mathrm{H}, J=8.0 \mathrm{~Hz})$. ${ }^{13} \mathrm{C}\left\{{ }^{1} \mathrm{H}\right\} \operatorname{NMR}\left(100 \mathrm{MHz}, \mathrm{CDCl}_{3}\right): \delta=190.54,151.66,145.53,139.32,131.83,131.51,128.58$, $123.22,90.12$. Spectroscopic data is consistent with the literature. ${ }^{73}$ 


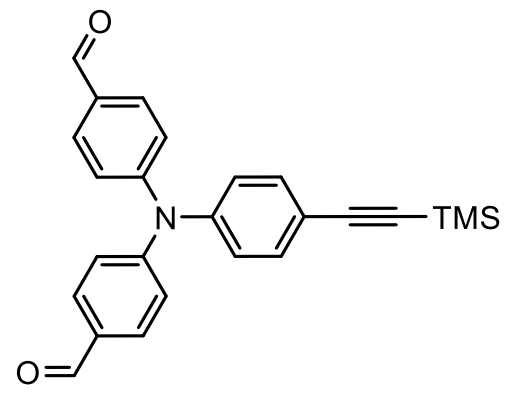

4.30b (0.856 g, $2.003 \mathrm{mmol}$ ) was taken in a flame dried $200 \mathrm{~mL}$ Schlenk flask with stir bar and dissolved in $20.0 \mathrm{~mL}$ of dry THF and $10.0 \mathrm{~mL}$ of dry triethylamine. The solution was sparged for 20 min under nitrogen. $\mathrm{Pd}\left(\mathrm{PPh}_{3}\right)_{2} \mathrm{Cl}_{2}(0.070 \mathrm{~g}, 0.100 \mathrm{mmol})$, copper(I) iodide $(0.039 \mathrm{~g}, 0.200$ $\mathrm{mmol})$ was then added, followed by the addition of trimethylsilylacetylene $(0.40 \mathrm{~mL}, 2.887$ $\mathrm{mmol})$. The mixture was let to stir for $15 \mathrm{~min}$ in RT. The solvent was removed in vacuo. The crude material was dissolved in EtOAc and extracted with sat. ammonium chloride solution (25 $\mathrm{mL} \times 3$ ) and then a final wash with brine. The organic layers were combined, dried over $\mathrm{MgSO}_{4}$, filtered and solvent was removed in vacuo. The dark brown oil crude was purified by column chromatography in Hex:EtOAc $\left(4: 1, R_{f}=0.23\right)$ in silica gel. Obtained an orange-brown wax

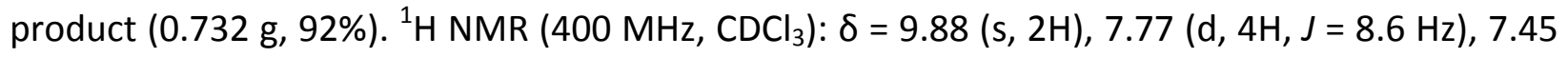
$(\mathrm{d}, 2 \mathrm{H}, J=8.5 \mathrm{~Hz}), 7.17(\mathrm{~d}, 4 \mathrm{H}, J=8.5 \mathrm{~Hz}), 7.08(\mathrm{~d}, 2 \mathrm{H}, J=8.5 \mathrm{~Hz}), 0.24(\mathrm{~s}, 9 \mathrm{H}) .{ }^{13} \mathrm{C}\left\{{ }^{1} \mathrm{H}\right\} \mathrm{NMR}(100$ $\left.\mathrm{MHz}, \mathrm{CDCl}_{3}\right): \delta=190.53,151.68,145.69,133.76,131.84,131.46,126.10,123.39,120.56$, $104.27,95.39,0.04$. Spectroscopic data is consistent with the literature. ${ }^{83}$ 


\section{4,4'-((4-ethynylphenyl)azanediyl)dibenzaldehyde (4.32b)}

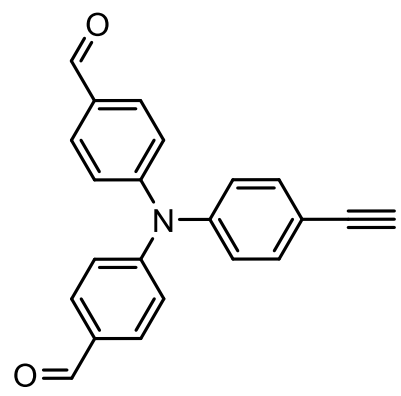

In a $50 \mathrm{~mL}$ RBF, $4.31 \mathrm{~b}(0.732 \mathrm{~g}, 1.841 \mathrm{mmol})$ was dissolved in $8 \mathrm{~mL}$ of distilled DCM and $12 \mathrm{~mL}$ of $\mathrm{MeOH}$, followed by the addition of potassium carbonate $(1.018 \mathrm{~g}, 7.362 \mathrm{mmol})$. The reaction was stirred under nitrogen at RT for $1 \mathrm{~h}$. Most of the solvent was removed under reduced pressure at RT. The crude material was dissolved in DCM and extracted with $\mathrm{H}_{2} \mathrm{O}(25 \mathrm{~mL} \times 3)$. The organic layers were combined, dried with $\mathrm{MgSO}_{4}$, filtered, and the solvent removed in vacuo. The orange-yellow oil crude was purified by column chromatography using Hex:EtOAc $\left(4: 1, R_{f}=0.14\right)$ to afford the product as a yellow powder $(0.346 \mathrm{~g}, 58 \%) .{ }^{1} \mathrm{H} \mathrm{NMR}(400 \mathrm{MHz}$, $\left.\mathrm{CDCl}_{3}\right): \delta=9.90(\mathrm{~s}, 2 \mathrm{H}), 7.79(\mathrm{~d}, 4 \mathrm{H}, J=8.4 \mathrm{~Hz}), 7.48(\mathrm{~d}, 2 \mathrm{H}, J=8.4 \mathrm{~Hz}), 7.19(\mathrm{~d}, 4 \mathrm{H}, J=8.4 \mathrm{~Hz})$, $7.10(\mathrm{~d}, 2 \mathrm{H}, J=8.4 \mathrm{~Hz})$. Spectroscopic data is consistent with the literature. ${ }^{83}$

\section{4-methoxy-N-(4-methoxyphenyl)-N-phenylaniline (4.29c)}

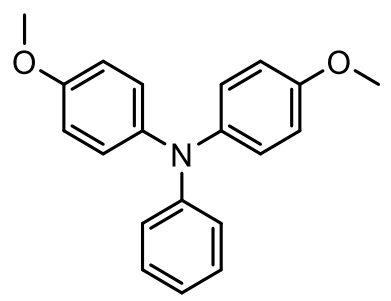

Under an atmosphere of $\mathrm{N}_{2}$, into a $100 \mathrm{~mL}$ RBF with stir bar, $p$-iodoanisole $(6.283 \mathrm{~g}, 26.847$ $\mathrm{mmol})$, aniline (1 $\mathrm{mL}, 10.960 \mathrm{mmol})$, 1,10-phenanthroline (0.395 g, $2.192 \mathrm{mmol})$ were solubilized in $40 \mathrm{~mL}$ of toluene. The mixture was heated to $100^{\circ} \mathrm{C}$ in an oil bath and was added $\mathrm{KOH}(4.855 \mathrm{~g}, 86.523 \mathrm{mmol})$, followed by $\mathrm{CuCl}(0.217 \mathrm{~g}, 2.195 \mathrm{mmol})$. The mixture was refluxed 
overnight for $20 \mathrm{~h}$. The mixture was let to cool to room temperature, and then $3 \mathrm{~mL}$ of acetic acid and $15 \mathrm{~mL}$ of toluene were added. The mixture was washed with distilled $\mathrm{H}_{2} \mathrm{O}$ once and extracted with toluene. The combined organic layers were dried over $\mathrm{MgSO}_{4}$, filtered and volatiles were removed in vacuo overnight. The crude was a dark purple solid and triturated with hexanes. Column chromatography was done in 9:1 Hex:EtOAc $\left(R_{f}=0.34\right)$ to afford the product as a pale orange solid (1.552 g, 46\%). ${ }^{1} \mathrm{H} \mathrm{NMR}\left(400 \mathrm{MHz}, \mathrm{CDCl}_{3}\right): \delta=7.17(\mathrm{t}, 2 \mathrm{H}, J=7.6$ $\mathrm{Hz}), 7.04(\mathrm{~d}, 4 \mathrm{H}, J=8.8 \mathrm{~Hz}), 6.94(\mathrm{~d}, 2 \mathrm{H}, J=8.4 \mathrm{~Hz}), 6.86(\mathrm{t}, 1 \mathrm{H}, J=7.2 \mathrm{~Hz}), 6.82(\mathrm{~d}, 4 \mathrm{H}, J=8.8$ $\mathrm{Hz}$ ). Spectroscopic data is consistent with the literature. ${ }^{75}$

\section{4-iodo-N,N-bis(4-methoxyphenyl)aniline (4.30c)}

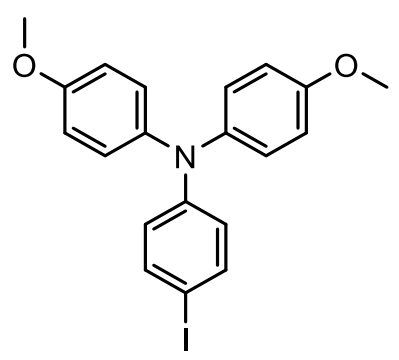

To an oven dried $250 \mathrm{~mL}$ round bottom flask with stir bar was added 4.29c (1.548 g, 5.068 $\mathrm{mmol}$ ), dissolved in $30 \mathrm{~mL}$ of dry chloroform, and sparged for $15 \mathrm{~min}$. Covered the flask in foil, then added NIS $(1.257 \mathrm{~g}, 5.589 \mathrm{mmol})$, followed by $20 \mathrm{~mL}$ of glacial acetic acid. The reaction was let to stir at room temperature for $19.5 \mathrm{~h}$. The reaction mixture was poured into $\mathrm{H}_{2} \mathrm{O}(25.0$ $\mathrm{ml}$ ) and diethyl ether $(25.0 \mathrm{ml})$. The organic layer was separated, added slowly to $25 \mathrm{~mL}$ of saturated aqueous sodium thiosulphate and extracted. The organic layer was dried over $\mathrm{MgSO}_{4}$, filtered and evaporated under reduced pressure. The crude material was subjected to column chromatography using Hex:DCM $1: 1$ as the eluent $\left(R_{f}=0.351\right)$ to afford a pale yellow solid (1.369 g, 63\%). ${ }^{1} \mathrm{H}$ NMR (400 MHz, $\left.\mathrm{CDCl}_{3}\right): \delta=7.41(\mathrm{~d}, 2 \mathrm{H}, J=8.0 \mathrm{~Hz}), 7.03(\mathrm{~d}, 4 \mathrm{H}, J=8.0 \mathrm{~Hz})$, $6.83(\mathrm{~d}, 4 \mathrm{H}, J=8.0 \mathrm{~Hz}), 6.68(\mathrm{~d}, 2 \mathrm{H}, J=8.0 \mathrm{~Hz}), 3.79(\mathrm{~s}, 6 \mathrm{H}) .{ }^{13} \mathrm{C}\left\{{ }^{1} \mathrm{H}\right\} \mathrm{NMR}\left(100 \mathrm{MHz}, \mathrm{CDCl}_{3}\right): \delta=$ $156.29,148.76,140.52,137.80,126.84,122.38,114.93,82.09$, 55.62. Spectroscopic data is consistent with the literature. $^{75}$ 


\section{4-methoxy-N-(4-methoxyphenyl)-N-(4-((trimethylsilyl)ethynyl)phenyl)aniline (4.31c)}

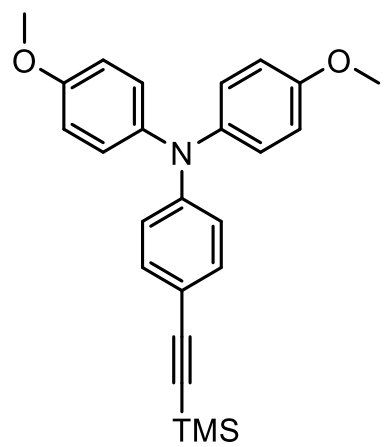

To an oven dried $200 \mathrm{~mL}$ tear-drop flask with side arm, was added 4.30c (1.351 g, $3.132 \mathrm{mmol})$ and dissolved in $\sim 33.5 \mathrm{~mL}$ of dry THF and $\sim 16.5 \mathrm{~mL}$ of $\mathrm{NEt}_{3}$, the solution was sparged for $\sim 1 \mathrm{~h}$ with nitrogen, colour was transparent yellow solution. Then added $\mathrm{PdCl}_{2}\left(\mathrm{PPh}_{3}\right)_{2}(0.110 \mathrm{~g}, 0.157$ $\mathrm{mmol})$ and $\mathrm{Cul}(0.061 \mathrm{~g}, 0.313 \mathrm{mmol})$ was added together, followed by ethynyltrimethylsilane (0.67 $\mathrm{mL}, 4.698 \mathrm{mmol}$ ) was then added drop-wise and the reaction changed colour to olive to dark olive to red-brown to brown to muddy brown-black to black with precipitates. The reaction continued stirring under RT for $6.5 \mathrm{~h}$. The solvent was evaporated in vacuo and the crude material was dissolved in EtOAc. Extraction was done with sat. ammonium chloride solution to remove any excess $\mathrm{Cul}$. The organic layers were combined and dried over $\mathrm{MgSO}_{4}$, and the solvent was evaporated in vacuo. Column chromatography was done on the crude in 1:1 DCM:Hex $\left(R_{f}=0.464\right)$ to yield a yellow-orange wax $(1.110 \mathrm{~g}, 88 \%) .{ }^{1} \mathrm{H} N M R(400 \mathrm{MHz}$, acetone- $\left.\mathrm{d}_{6}\right): \delta=7.23(\mathrm{~d}, 2 \mathrm{H}, J=8.8 \mathrm{~Hz}), 7.07(\mathrm{~d}, 4 \mathrm{H}, J=8.8 \mathrm{~Hz}), 6.90(\mathrm{~d}, 4 \mathrm{H}, J=9.2 \mathrm{~Hz}), 6.73(\mathrm{~d}$, $2 \mathrm{H}, J=8.8 \mathrm{~Hz}), 3.78(\mathrm{~s}, 6 \mathrm{H}), 0.21(\mathrm{~s}, 9 \mathrm{H}) .{ }^{13} \mathrm{C}\left\{{ }^{1} \mathrm{H}\right\} \mathrm{NMR}\left(100 \mathrm{MHz}\right.$, acetone- $\left.\mathrm{d}_{6}\right): \delta=206.00$, 157.68, 150.14, 140.61, 133.44, 128.26, 118.93, 115.73, 114.18, 106.89, 92.32, 55.71, 0.22. Spectroscopic data is consistent with the literature. ${ }^{75}$ 


\section{4-ethynyl-N,N-bis(4-methoxyphenyl)aniline (4.32c)}

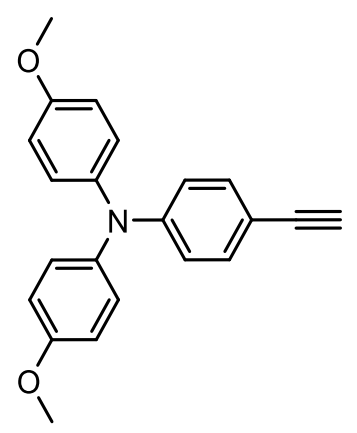

4.31c (1.101 g, $2.742 \mathrm{mmol}$ ) was dissolved in $13.5 \mathrm{~mL}$ of dry THF and $13.5 \mathrm{~mL}$ of $\mathrm{MeOH}$, potassium fluoride $(0.472 \mathrm{~g}, 8.122 \mathrm{mmol})$ was added and the mixture was stirred under nitrogen in RT. After $5.5 \mathrm{~h}$, additional potassium fluoride $(0.477 \mathrm{~g}, 8.203 \mathrm{mmol})$ was added. The reaction was quenched with distilled water after $15.5 \mathrm{~h}$. The crude material was washed with EtOAc (50 $\mathrm{mL} \times 3$ ). The organic layers were combined and dried over $\mathrm{MgSO}_{4}$, filtered and solvent reduced under pressure. Column chromatography was done in 3:2 Hex:DCM to afford an off-white solid (0.327 g, 36\%). ${ }^{1} \mathrm{H}$ NMR (400 MHz, $\left.\mathrm{CDCl}_{3}\right): \delta=7.26(\mathrm{~d}, 2 \mathrm{H}, J=8.0 \mathrm{~Hz}$ ), 7.06 (d, $4 \mathrm{H}, J=12.0 \mathrm{~Hz}), 6.83(\mathrm{~d}, 4 \mathrm{H}, J=8.0 \mathrm{~Hz}), 6.80(\mathrm{~d}, 2 \mathrm{H}, J=8.0 \mathrm{~Hz}), 3.79(\mathrm{~s}, 6 \mathrm{H}), 2.98(\mathrm{~s}, 1 \mathrm{H})$. Spectroscopic data is consistent with the literature. ${ }^{75}$

\section{4-((5,5-difluoro-1,3,7,9,10-pentamethyl-5H-5 $\lambda^{4}, 6 \lambda^{4}$-dipyrrolo[1,2-c:2',1'-f][1,3,2]diazaborinin-}

\section{2-yl)ethynyl)-N,N-diphenylaniline (4.33a)}

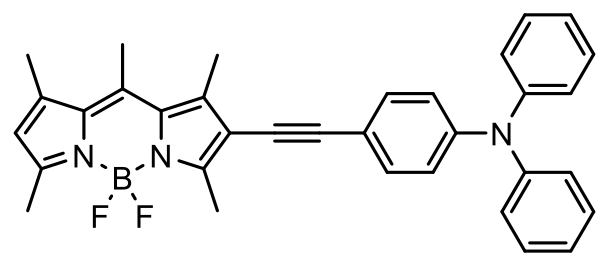

To a $200 \mathrm{~mL}$ flame dried Schlenk flask with stir bar, dissolved 4.27 (0.203 g, $0.522 \mathrm{mmol}$ ) in 6.6 $\mathrm{mL}$ of dry THF and $2.8 \mathrm{~mL}$ of dry $\mathrm{NEt}_{3}$. Sparged this solution under nitrogen for $5 \mathrm{~min}$. As the solution was warmed up to $68^{\circ} \mathrm{C}$ in an oil bath, $\mathrm{Pd}\left(\mathrm{PPh}_{3}\right)_{2} \mathrm{Cl}_{2}(0.018 \mathrm{~g}, 0.026 \mathrm{mmol})$, copper(I) iodide $(0.010 \mathrm{~g}, 0.052 \mathrm{mmol})$ were added together in one portion. Followed by $4.32 \mathrm{a}(0.155 \mathrm{~g}$, 
$0.575 \mathrm{mmol}$ ). The reaction was stirred at $68^{\circ} \mathrm{C}$ and monitored by TLC in 3:2 Hex:EtOAc. After 6 $h$, the mixture was let to cool and then solvent was removed via high vac. The crude material was dissolved in EtOAc and extracted with sat. $\mathrm{NH}_{4} \mathrm{Cl}$ solution thrice and then a final wash with brine. The organic layers were combined, dried in $\mathrm{MgSO}_{4}$ and concentrated, gave a red dry oil. Column chromatography was run in 6:2 Hex:DCM to afford a red solid powder (0.062 g, 23\%). ${ }^{1} \mathrm{H}$ NMR $\left(400 \mathrm{MHz}, \mathrm{CDCl}_{3}\right): \delta=7.36(\mathrm{~d}, 2 \mathrm{H}, J=8.4 \mathrm{~Hz}), 7.28(\mathrm{t}, 4 \mathrm{H}, J=8.0 \mathrm{~Hz}), 7.11(\mathrm{~d}, 4 \mathrm{H}, J=8.0$ Hz), $7.06(t, 2 H, J=7.2 \mathrm{~Hz}), 7.01(\mathrm{~d}, 2 \mathrm{H}, \mathrm{J}=8.8 \mathrm{~Hz}), 2.65(\mathrm{~s}, 3 \mathrm{H}), 2.62(\mathrm{~s}, 3 \mathrm{H}), 2.54(\mathrm{~s}, 6 \mathrm{H}), 2.43$ (s, 3H). ${ }^{13} \mathrm{C}\left\{{ }^{1} \mathrm{H}\right\}$ NMR $\left(100 \mathrm{MHz}, \mathrm{CDCl}_{3}\right): \delta=155.62,147.87,147.71,142.46,141.80,140.35,133.19$, 132.43, 129.53, 125.01, 123.61, 122.20, 116.78, 96.11, 81.39, 29.85, 22.84, 17.63, 16.81, 16.07, 14.71, 13.61. ${ }^{19} \mathrm{~F} \mathrm{NMR}\left(\mathrm{CDCl}_{3}, 376.5 \mathrm{MHz}\right): \delta=-146.83$ (q, $\left.J_{B F}=30.0 \mathrm{~Hz}\right) .{ }^{11} \mathrm{~B} \mathrm{NMR}\left(\mathrm{CDCl}_{3}, 128\right.$ $\mathrm{MHz}): \delta=0.52\left(\mathrm{t}, J_{F B}=30.7 \mathrm{~Hz}\right)$. HRMS (ESI-FTMS): $\mathrm{m} / z 529.2499\left(\mathrm{M}^{+}\right)$calculated for $\mathrm{C}_{34} \mathrm{H}_{30} \mathrm{BF}_{2} \mathrm{~N}_{3}: m / z 529.2501$.

\section{4,4'-((4-((5,5-difluoro-1,3,7,9,10-pentamethyl-5H-5 $\lambda^{4}, 6 \lambda^{4}$-dipyrrolo[1,2-c:2',1'-}

$f][1,3,2]$ diazaborinin-2-yl)ethynyl)phenyl)azanediyl)dibenzaldehyde (4.33b)

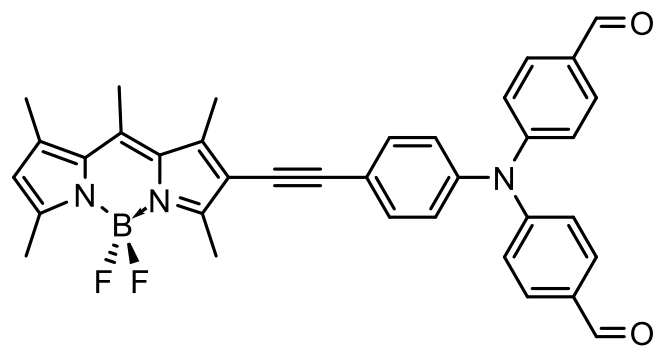

To a $200 \mathrm{~mL}$ Schlenk flask, 4.27 (0.350 g, $0.901 \mathrm{mmol}$ ) was solubilized in $11.25 \mathrm{~mL}$ of anhydrous THF and $4.50 \mathrm{~mL}$ of anhydrous $\mathrm{NEt}_{3}$. The solution was heated to $30^{\circ} \mathrm{C}$ for $20 \mathrm{~min}$, and sparged with nitrogen for $10 \mathrm{~min}$. $\mathrm{Pd}\left(\mathrm{PPh}_{3}\right)_{2} \mathrm{Cl}_{2}(0.032 \mathrm{~g}, 0.045 \mathrm{mmol})$ and copper(I) iodide $(0.018 \mathrm{~g}$, $0.090 \mathrm{mmol})$ were added together, followed by the addition of alkyne $4.32 \mathrm{~b}(0.323 \mathrm{~g}, 0.992$ $\mathrm{mmol})$. The mixture was heated to $40^{\circ} \mathrm{C}$ in an oil bath for $1.5 \mathrm{~h}$. The mixture was let to cool and solvent was removed in vacuo. The crude material was dissolved in EtOAc and extracted with sat. $\mathrm{NH}_{4} \mathrm{Cl}$ solution thrice and then a final wash with brine. The organic layers were combined, dried over $\mathrm{MgSO}_{4}$ and solvent concentrated in vacuo which gave a dark red oil. A column was 
run in Hex:EtOAc $\left(3: 2, R_{f}=0.19\right)$ to afford the product as a dark red wine solid $(0.151 \mathrm{~g}, 28 \%)$. ${ }^{1} \mathrm{H} \mathrm{NMR}\left(400 \mathrm{MHz}, \mathrm{CDCl}_{3}\right): \delta=9.91(\mathrm{~s}, 2 \mathrm{H}), 7.79(\mathrm{~d}, 4 \mathrm{H}, J=8.4 \mathrm{~Hz}), 7.50(\mathrm{~d}, 2 \mathrm{H}, J=8.4 \mathrm{~Hz}), 7.21$ (d, 4H, J = 8.4 Hz), $7.13(\mathrm{~d}, 2 \mathrm{H}, J=8.0 \mathrm{~Hz}), 6.12(\mathrm{~s}, 1 \mathrm{H}), 2.65(\mathrm{~s}, 3 \mathrm{H}), 2.62(\mathrm{~s}, 3 \mathrm{H}), 2.54(\mathrm{~s}, 6 \mathrm{H})$, 2.43 (s, 3H). ${ }^{13} \mathrm{C}\left\{{ }^{1} \mathrm{H}\right\} \operatorname{NMR}\left(100 \mathrm{MHz}, \mathrm{CDCl}_{3}\right): \delta=190.60,156.32,154.73,151.77,145.21,143.05$, 142.01, 140.26, 134.27, 133.38, 133.09, 131.83, 131.55, 131.51, 126.42, 125.80, 123.81, 123.37, 122.52, 121.26, 95.05, 83.39, 81.53, 74.76, 60.51, 29.82, 17.65, 16.80, 16.00, 14.74, 13.57. ${ }^{19} \mathrm{~F}$ $\operatorname{NMR}\left(\mathrm{CDCl}_{3}, 376.5 \mathrm{MHz}\right): \delta=-146.60\left(\mathrm{q}, J_{B F}=30.0 \mathrm{~Hz}\right) .{ }^{11} \mathrm{~B} \mathrm{NMR}\left(\mathrm{CDCl}_{3}, 128 \mathrm{MHz}\right): \delta=0.51(\mathrm{t}$, $J_{F B}=32.0 \mathrm{~Hz}$ ). HRMS (EI-TOF): $m / z 585.2411\left(\mathrm{M}^{+}\right)$calculated for $\mathrm{C}_{36} \mathrm{H}_{30} \mathrm{BN}_{3} \mathrm{O}_{2} \mathrm{~F}_{2}: \mathrm{m} / z$ 585.2399.

\section{4-((5,5-difluoro-1,3,7,9,10-pentamethyl-5H-5 $\lambda^{4}, 6 \lambda^{4}$-dipyrrolo[1,2-c:2',1'-f][1,3,2]diazaborinin-}

\section{2-yl)ethynyl)-N,N-bis(4-methoxyphenyl)aniline (4.33c)}

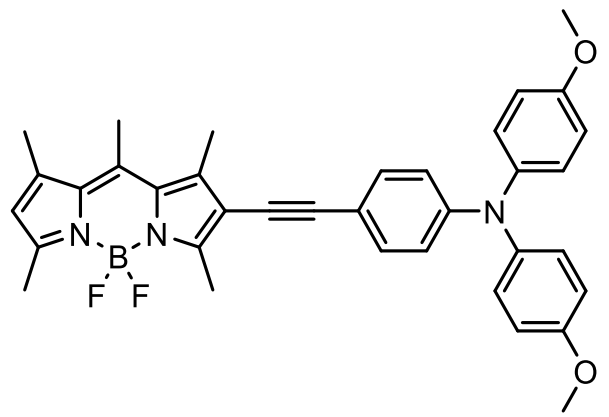

To a flame dried $200 \mathrm{~mL}$ Schlenk flask with stir bar, dissolved 4.27 (0.169 g, $0.435 \mathrm{mmol}$ ) was solubilized in $10 \mathrm{~mL}$ of anhydrous THF and $4 \mathrm{~mL}$ of anhydrous $\mathrm{NEt}_{3}$. The solution was sparged under nitrogen for $5 \mathrm{~min}$. A catalytic amount of $\mathrm{Pd}\left(\mathrm{PPh}_{3}\right)_{2} \mathrm{Cl}_{2}(0.015 \mathrm{~g}, 0.022 \mathrm{mmol})$ was added together with copper $(\mathrm{l})$ iodide $(0.018 \mathrm{~g}, 0.049 \mathrm{mmol})$, followed by the alkyne $4.32 \mathrm{c}(0.178 \mathrm{~g}$, $0.542 \mathrm{mmol}$ ). The mixture was heated stirred for $24 \mathrm{~h}$ in room temperature and solvent was removed in vacuo. The crude material was dissolved in EtOAc and extracted with sat. $\mathrm{NH}_{4} \mathrm{Cl}$ solution thrice and then a final wash with brine. The organic layers were combined, dried in $\mathrm{MgSO}_{4}$ and concentrated which gave a dark red crude oil. Column chromatography was run in toluene $\left(R_{f}=0.377\right)$ to afford the product as a dark purple solid $(0.023 \mathrm{~g}, 9 \%)$. ${ }^{1} \mathrm{H}$ NMR $(400$ $\mathrm{MHz}_{\mathrm{CDCl}}$ ): $\delta=7.29$ (d, 2H, J=8.4 Hz), 7.07 (d, $\left.4 \mathrm{H}, J=8.8 \mathrm{~Hz}\right), 6.85(\mathrm{~m}, 6 \mathrm{H}), 6.09(\mathrm{~s}, 1 \mathrm{H}), 3.80$ $(\mathrm{s}, 6 \mathrm{H}), 2.64(\mathrm{~s}, 3 \mathrm{H}), 2.62(\mathrm{~s}, 3 \mathrm{H}), 2.53(\mathrm{~s}, 6 \mathrm{H}), 2.43(\mathrm{~s}, 3 \mathrm{H}) .{ }^{13} \mathrm{C}\left\{{ }^{1} \mathrm{H}\right\} \mathrm{NMR}\left(100 \mathrm{MHz}, \mathrm{CDCl}_{3}\right): \delta=$ 
$156.41,155.31,148.77,142.27,141.72,140.46,140.30,133.08,132.30,131.26,129.19,128.38$, 127.11, 122.08, 119.64, 114.95, 114.57, 96.47, 80.71, 55.65, 17.61, 16.79, 16.07, 14.69, 13.61.

${ }^{19} \mathrm{~F} \mathrm{NMR}\left(\mathrm{CDCl}_{3}, 376.5 \mathrm{MHz}\right): \delta=-146.85\left(\mathrm{q}, J_{B F}=34.0 \mathrm{~Hz}\right) .{ }^{11} \mathrm{~B} \mathrm{NMR}\left(\mathrm{CDCl}_{3}, 128 \mathrm{MHz}\right): \delta=0.52$ $\left(\mathrm{t}, J_{F B}=30.7 \mathrm{~Hz}\right)$. HRMS (ESI-FTMS): $\mathrm{m} / z 590.2779(\mathrm{M}+\mathrm{H})^{+}$calculated for $\mathrm{C}_{36} \mathrm{H}_{35} \mathrm{BF}_{2} \mathrm{~N}_{3} \mathrm{O}_{2}: \mathrm{m} / z$ 590.2785 .

\section{BODIPY-ethynyl-ferrocene (4.34)}

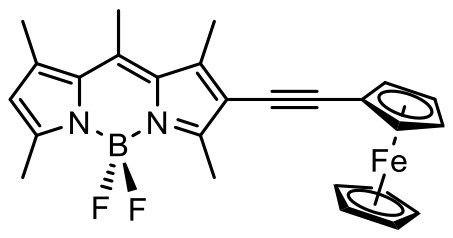

In a flame dried $200 \mathrm{~mL}$ Schlenk flask under nitrogen, 4.27 (0.388 g, $1.030 \mathrm{mmol})$ was dissolved in $7 \mathrm{~mL}$ dry THF and dry triethylamine $(3.6 \mathrm{~mL})$. The mixture was degassed for 10 minutes under nitrogen. The oil bath was set to $40^{\circ} \mathrm{C}, \mathrm{Pd}\left(\mathrm{PPh}_{3}\right)_{2} \mathrm{Cl}_{2}(0.070 \mathrm{~g}, 0.100 \mathrm{mmol})$, and $\mathrm{Cul}(0.038 \mathrm{~g}$, $0.200 \mathrm{mmol}$ ) were added. To the mixture was then added $3.26(0.236 \mathrm{~g}, 1.125 \mathrm{mmol})$. The reaction was stirred at $60^{\circ} \mathrm{C}$. After $26 \mathrm{~h}$, the reaction was let to cool to room temperature. Solvents were removed under high vac and the crude product was dissolved in ethyl acetate and washed with sat. ammonium chloride. The organic layers were collected, dried over $\mathrm{MgSO}_{4}$, filtered and solvent was removed in vacuo. The crude was purified by column chromatography in a Hex:DCM 3:1 to 1:1 eluent to afford a dark red-brown solid (0.173 g, 37\%). ${ }^{1} \mathrm{H}$ NMR (400 $\mathrm{MHz}_{\mathrm{CDCl}}$ ): $\delta=6.10(\mathrm{~s}, 1 \mathrm{H}), 4.50(\mathrm{t}, 2 \mathrm{H}, J=4.0 \mathrm{~Hz}), 4.24(\mathrm{~s}, 7 \mathrm{H}), 2.65(\mathrm{~s}, 3 \mathrm{H}), 2.62(\mathrm{~s}, 3 \mathrm{H}), 2.53$ (s, 6H), $2.43(\mathrm{~s}, 3 \mathrm{H}) .{ }^{13} \mathrm{C}\left\{{ }^{1} \mathrm{H}\right\}$ NMR $\left(100 \mathrm{MHz} \mathrm{CDCl}_{3}\right): \delta=155.42,155.06,142.36,141.76,140.37$, 133.10, 131.17, 122.10, 115.97, 94.44, 78.08, 71.59, 70.15, 68.94, 65.77, 17.60, 16.78, 16.09, 14.69, 13.63. ${ }^{19} \mathrm{~F} \mathrm{NMR}\left(\mathrm{CDCl}_{3}, 376.5 \mathrm{MHz}\right): \delta=-146.60$ (q $\left.J_{B F}=34.0 \mathrm{~Hz}\right) .{ }^{11} \mathrm{~B} \mathrm{NMR}\left(\mathrm{CDCl}_{3}, 128\right.$ $\mathrm{MHz}): \delta=0.52\left(\mathrm{t}, J_{F B}=30.7 \mathrm{~Hz}\right)$. HRMS (EI-TOF): $m / z$ 470.1438 $\left(\mathrm{M}^{+}\right)$calculated for $\mathrm{C}_{26} \mathrm{H}_{25} \mathrm{BF}_{2} \mathrm{FeN}_{2}: m / z 470.1428$. 


\section{CHAPTER 5.0 - CONCLUSIONS AND FUTURE WORK}

To summarize, three projects were attempted in the hopes of producing robust stable dyes for the DSSC. An attempt at synthesizing an appealing copper(I) dye found obstacles that led to null success. Upon further discussion with Dr. Viirre and a close look at the balanced chemical equation for the reaction to make compound 2.35, this Skraup-Doebner-von Miller reaction requires oxygen. Utilizing an oxidizing agent for future synthesis of $\mathbf{2 . 3 5}$ could improve the

yield. ${ }^{43,84}$ As for the purification of phenanthroline ligands, finding a recrystallization solvent or using triethylamine or ammonium hydroxide as additives in the column solvent conditions can help with resolving the crude mixture.

Connecting the results from chapter 3 and 4 together has shown that the BODIPY core in these systems is unstable upon reduction. Also, a strong electron withdrawing redox active chromophore appended to BODIPY does not benefit as a dye system. Further studies on ferrocenyl-BODIPY dyads with different substituents on ferrocene would be insightful in uncovering stability issues associated with the oxidation of ferrocene. 
APPENDICES

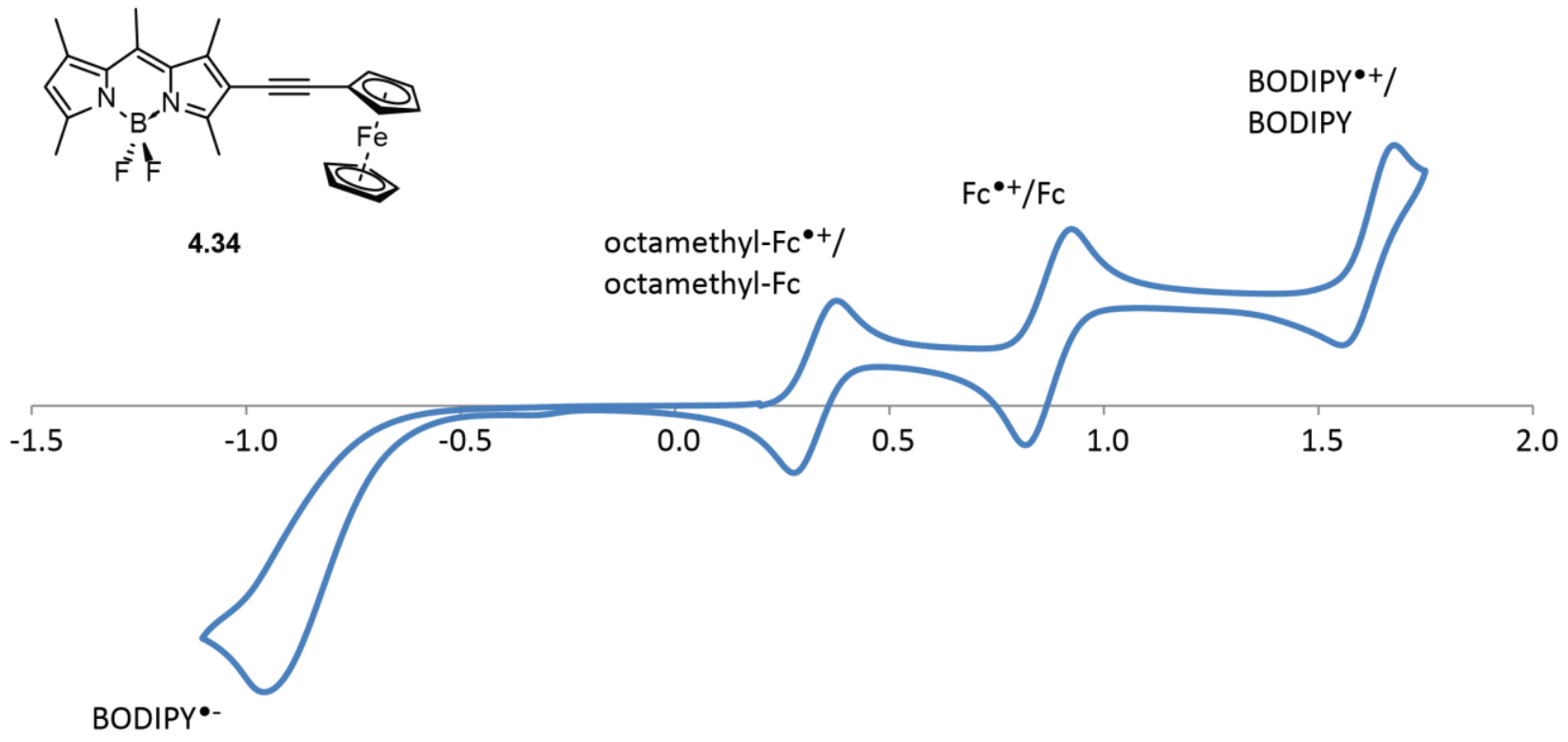

Potential (V)

Figure A1. Cyclic voltammogram of $\mathbf{4 . 3 4}$

Table A1. Electrochemistry data of $\mathbf{4 . 2 8}$ and $\mathbf{4 . 3 4}$

\begin{tabular}{|c|c|c|c|}
\hline \multirow[b]{2}{*}{ Compound } & \multicolumn{3}{|l|}{$E_{1 / 2}(\mathrm{~V} \text { vs. NHE })^{a}$} \\
\hline & BODIPY/BODIPY ${ }^{\bullet-b}$ & $\mathrm{Fc}^{\bullet+} / \mathrm{Fc}$ & BODIPY ${ }^{*+} /$ BODIPY \\
\hline $4.28^{a}$ & -0.958 & - & 1.593 \\
\hline $4.34^{b}$ & -0.958 & 0.870 & 1.616 \\
\hline \multicolumn{4}{|c|}{$\begin{array}{l}{ }^{a} \text { Data collected using } 0.1 \mathrm{M} \mathrm{NBu}_{4} \mathrm{PF}_{6} \mathrm{DCM} \text { solutions at } 100 \mathrm{mV} \mathrm{s}^{-1} \text { and referenced to a }[\mathrm{Fc}] /[\mathrm{Fc}]^{+} \text {internal } \\
\text { standard followed by conversion to } \mathrm{NHE} ;[\mathrm{Fc}] /\left[\mathrm{Fc}^{+}\right]=+765 \mathrm{mV} \text { vs. NHE in DCM. }\end{array}$} \\
\hline \multicolumn{4}{|c|}{$\begin{array}{l}{ }^{b} \text { Data collected using } 0.1 \mathrm{M} \mathrm{NBu}_{4} \mathrm{PF}_{6} \mathrm{DCM} \text { solutions at } 100 \mathrm{mV} \mathrm{s}^{-1} \text { and referenced to an [octamethyl- } \\
\text { Fc]/[octamethyl-Fc] }{ }^{+} \text {internal standard followed by conversion to } \mathrm{NHE} \text {; [octamethyl-Fc]/[octamethyl-Fc }{ }^{+} \text {] } \\
=+326 \mathrm{mV} \text { vs. NHE in DCM. }\end{array}$} \\
\hline
\end{tabular}




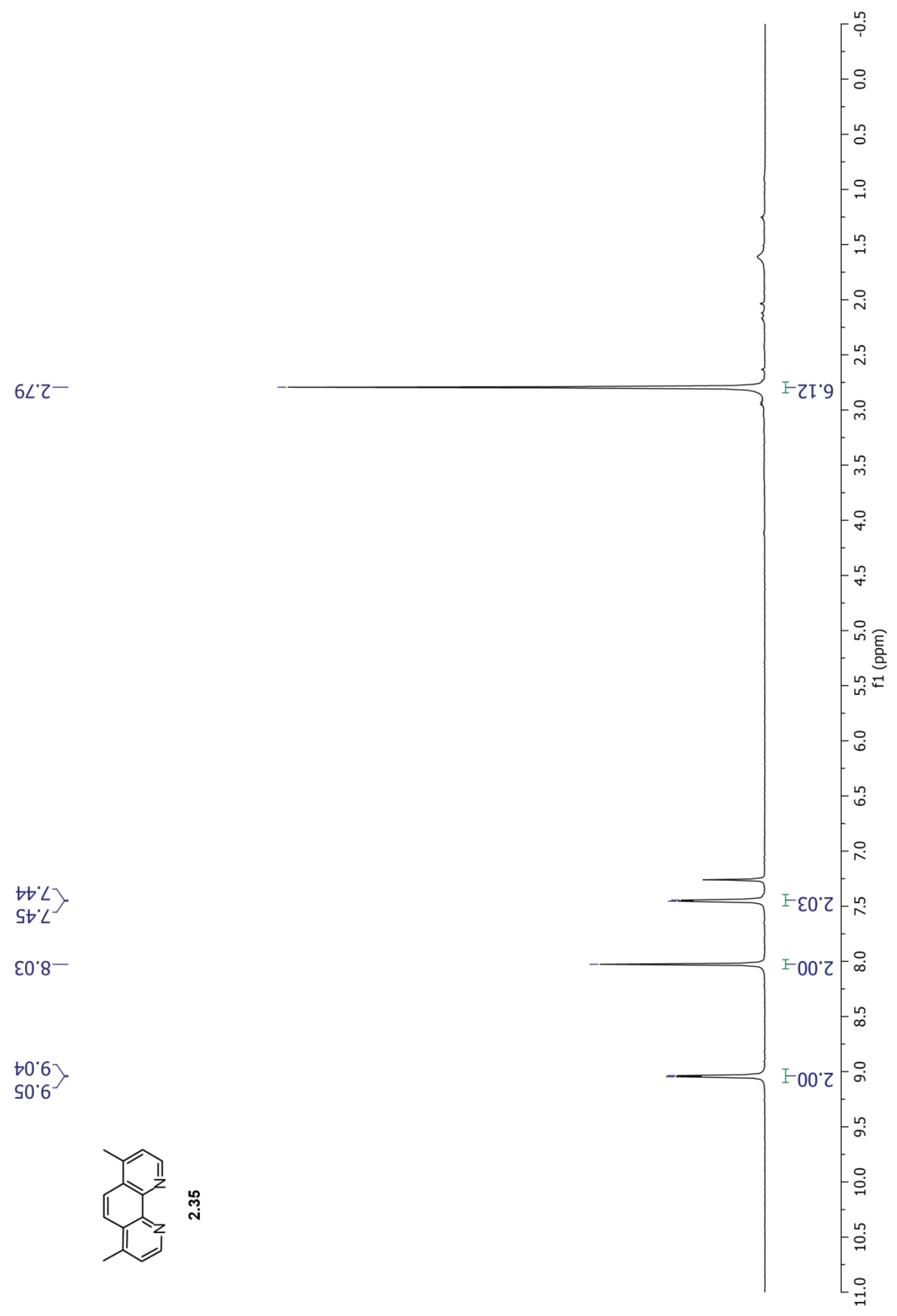

Figure A2. ${ }^{1} \mathrm{H}$ NMR spectrum of 2.35 in $\mathrm{CDCl}_{3}$ 


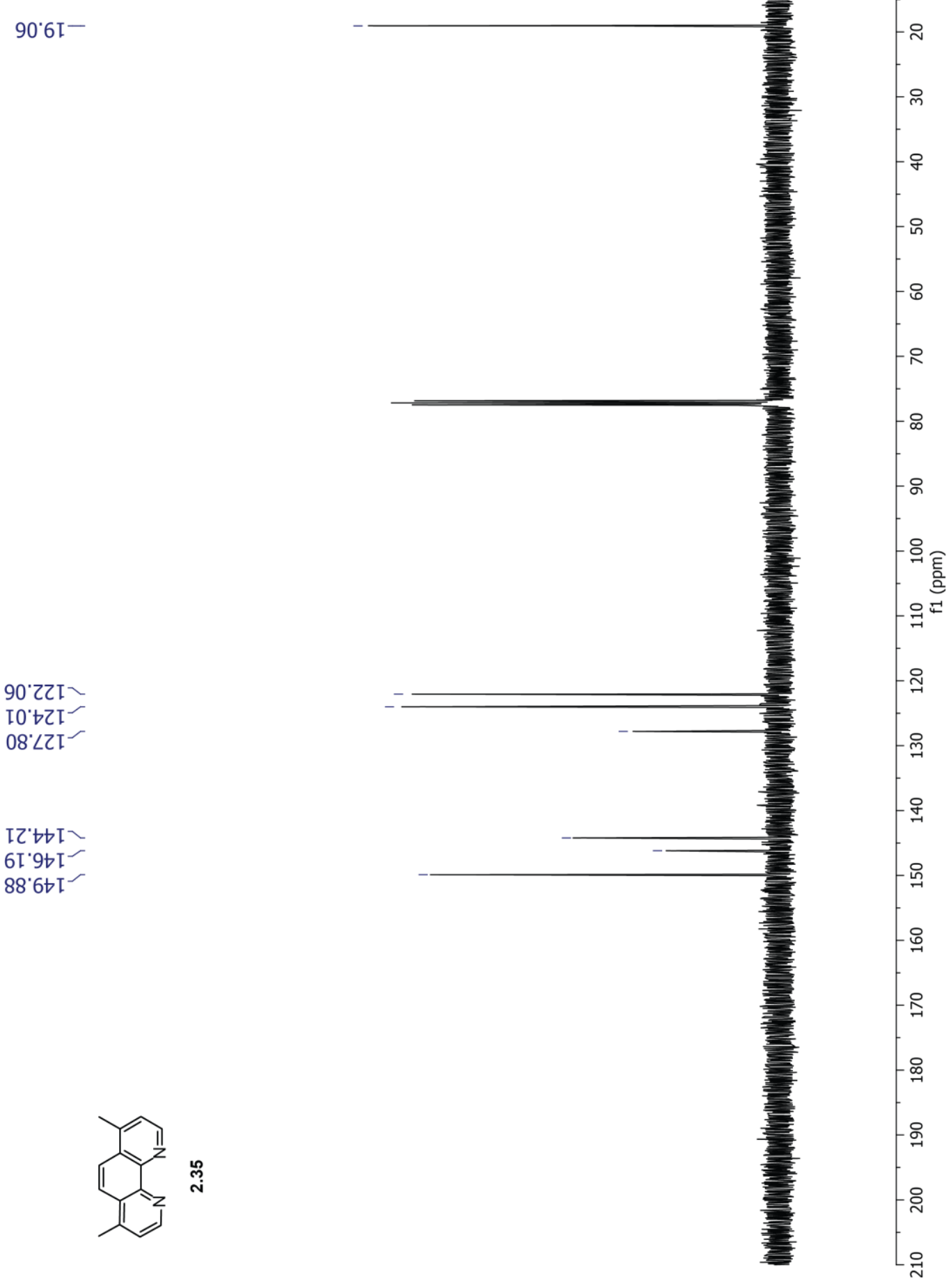

Figure A3. ${ }^{13} \mathrm{C}$ NMR spectrum of 2.35 in $\mathrm{CDCl}_{3}$ 


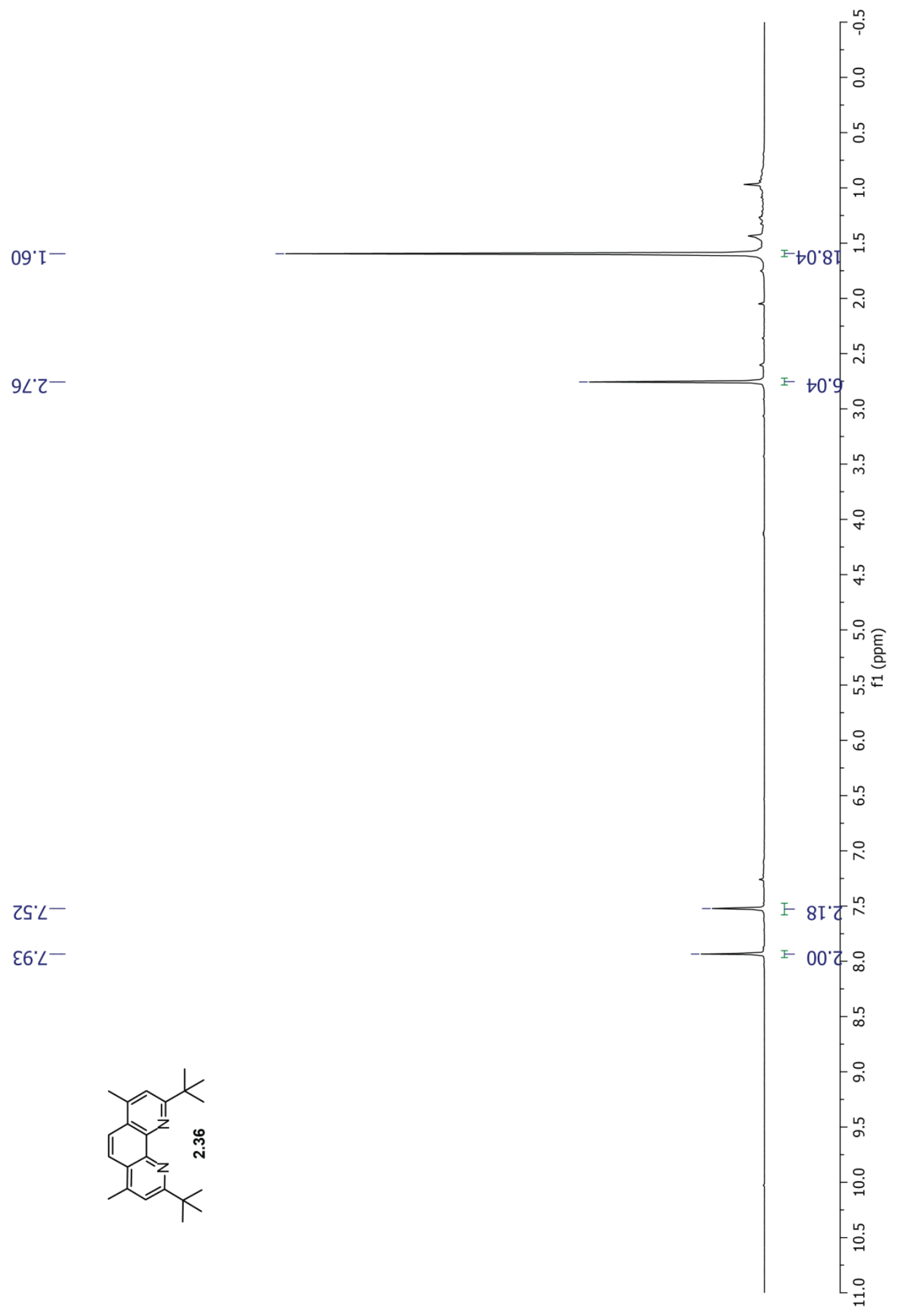

Figure A4. ${ }^{1} \mathrm{H}$ NMR spectrum of 2.36 in $\mathrm{CDCl}_{3}$ 


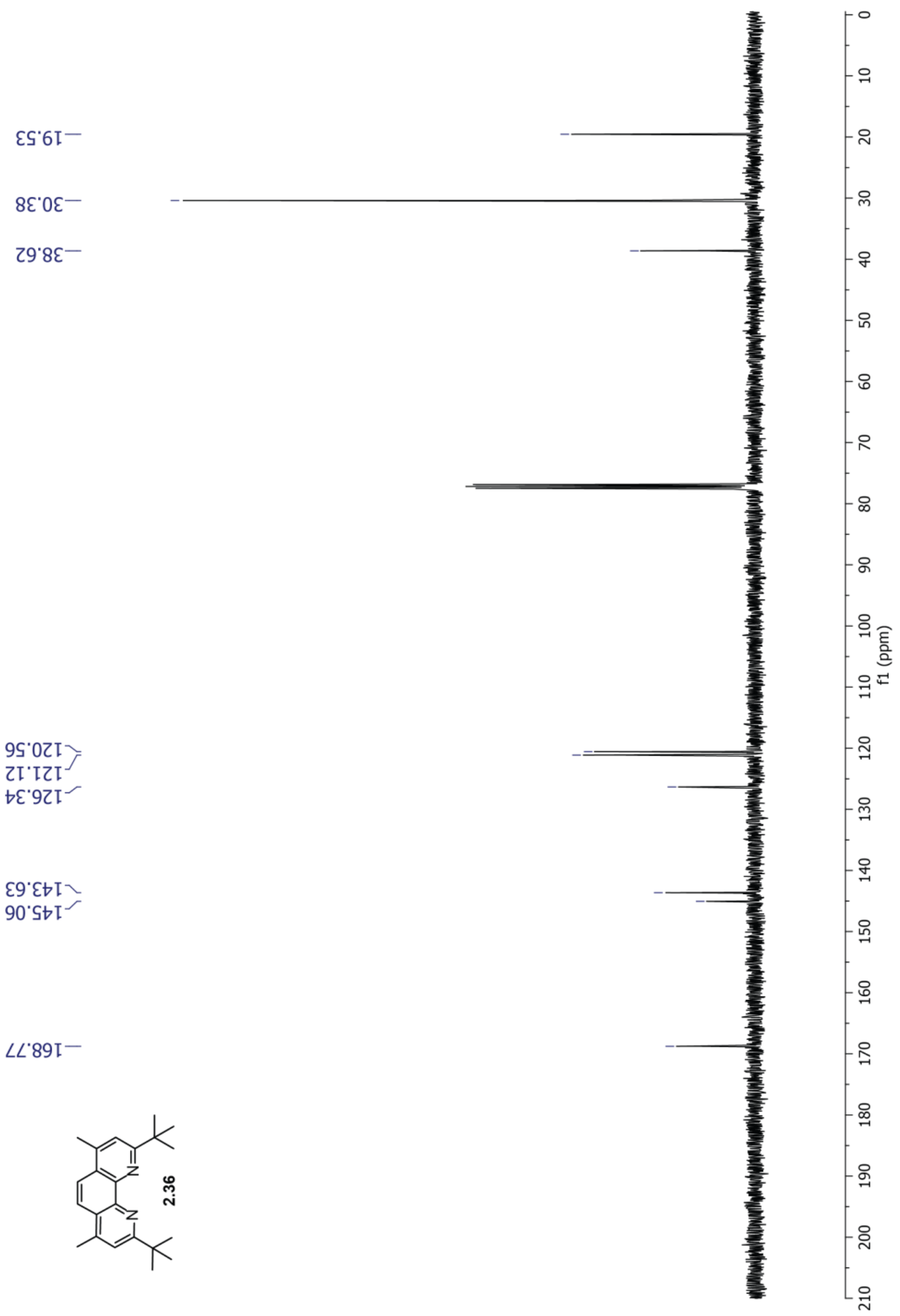

Figure A5. ${ }^{13} \mathrm{C}$ NMR spectrum of 2.36 in $\mathrm{CDCl}_{3}$ 


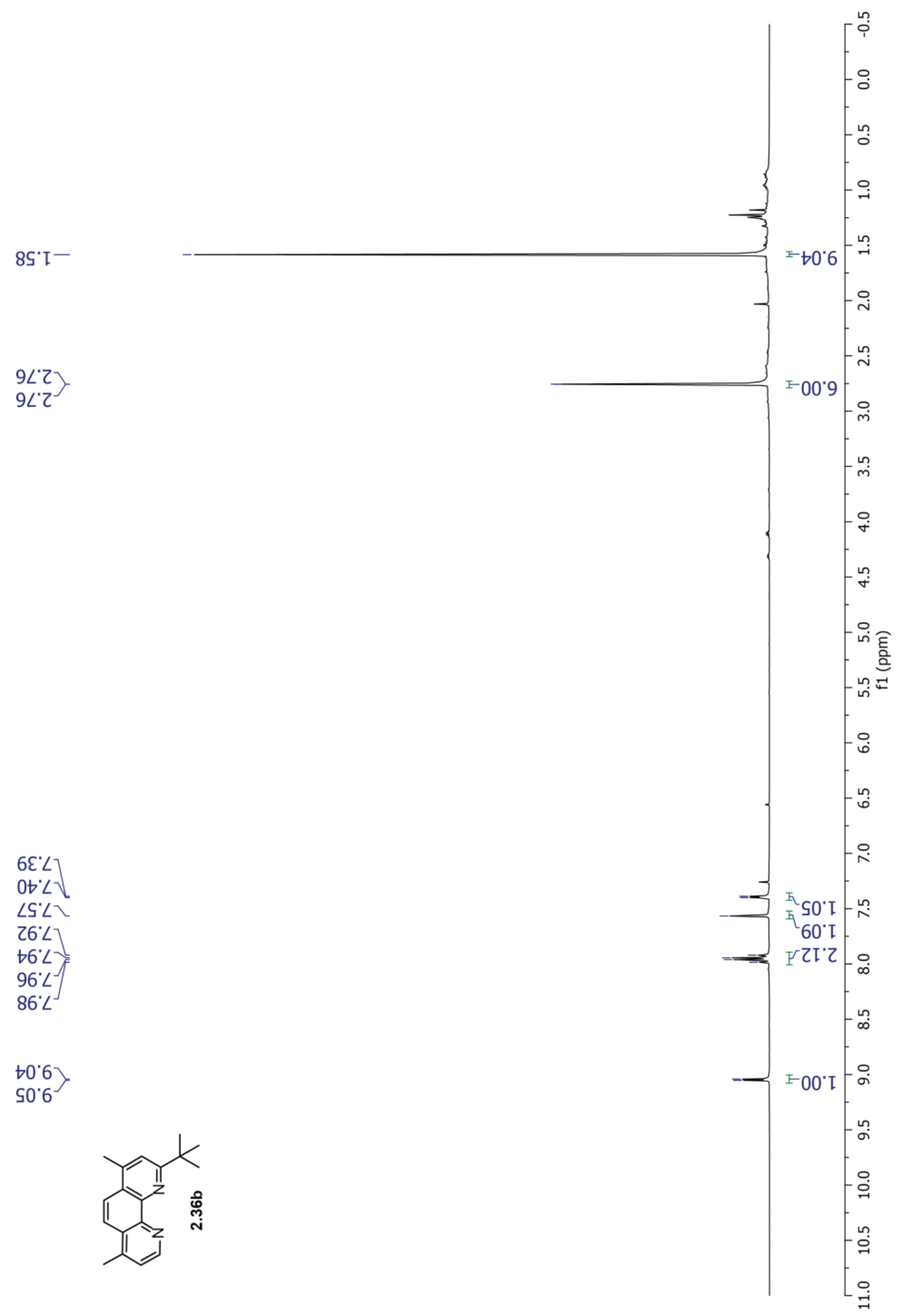

Figure A6. ${ }^{1} \mathrm{H}$ NMR spectrum of $\mathbf{2 . 3 6} \mathbf{b}$ in $\mathrm{CDCl}_{3}$ 


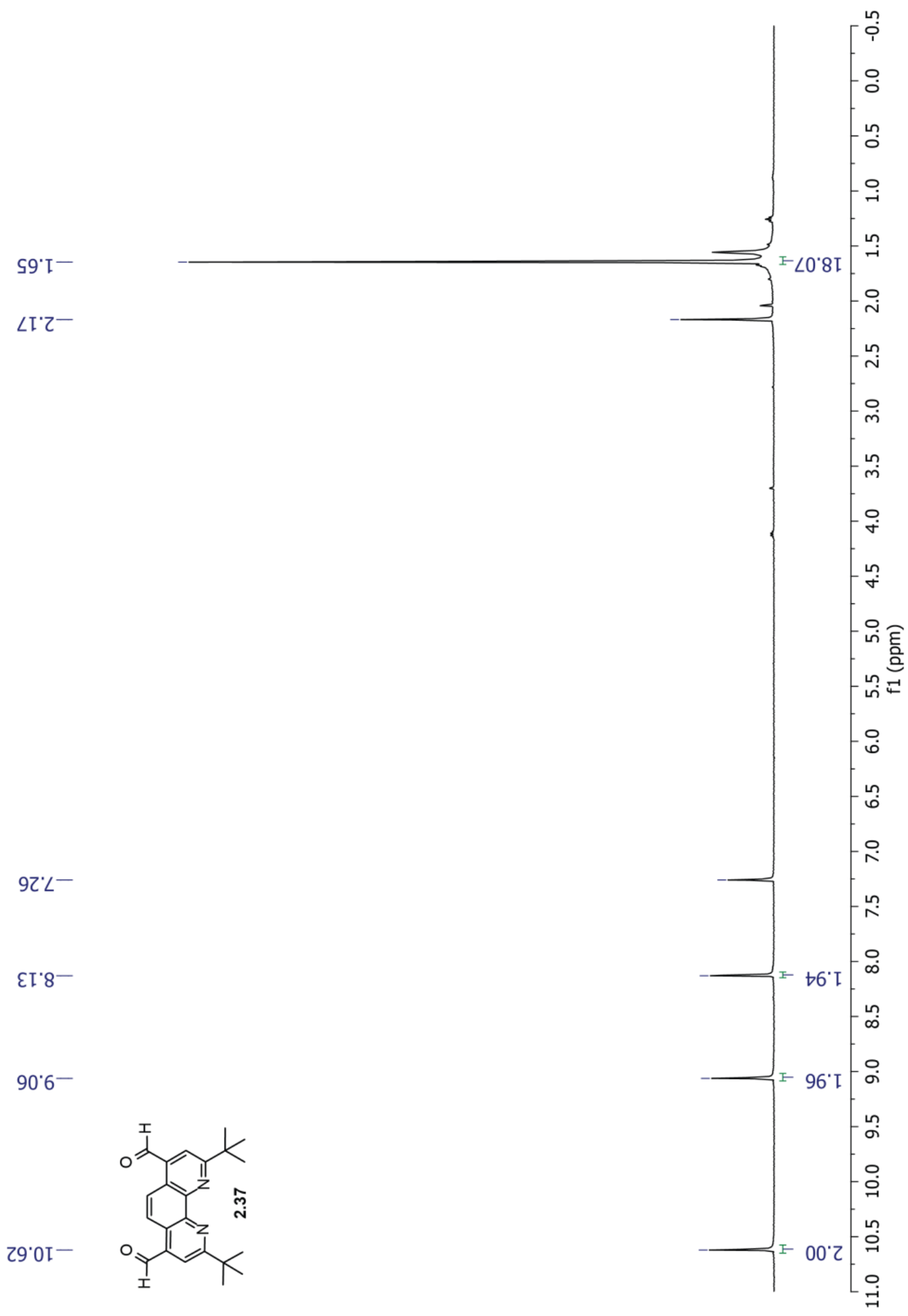

Figure A7. ${ }^{1} \mathrm{H}$ NMR spectrum of 2.37 in $\mathrm{CDCl}_{3}$ 


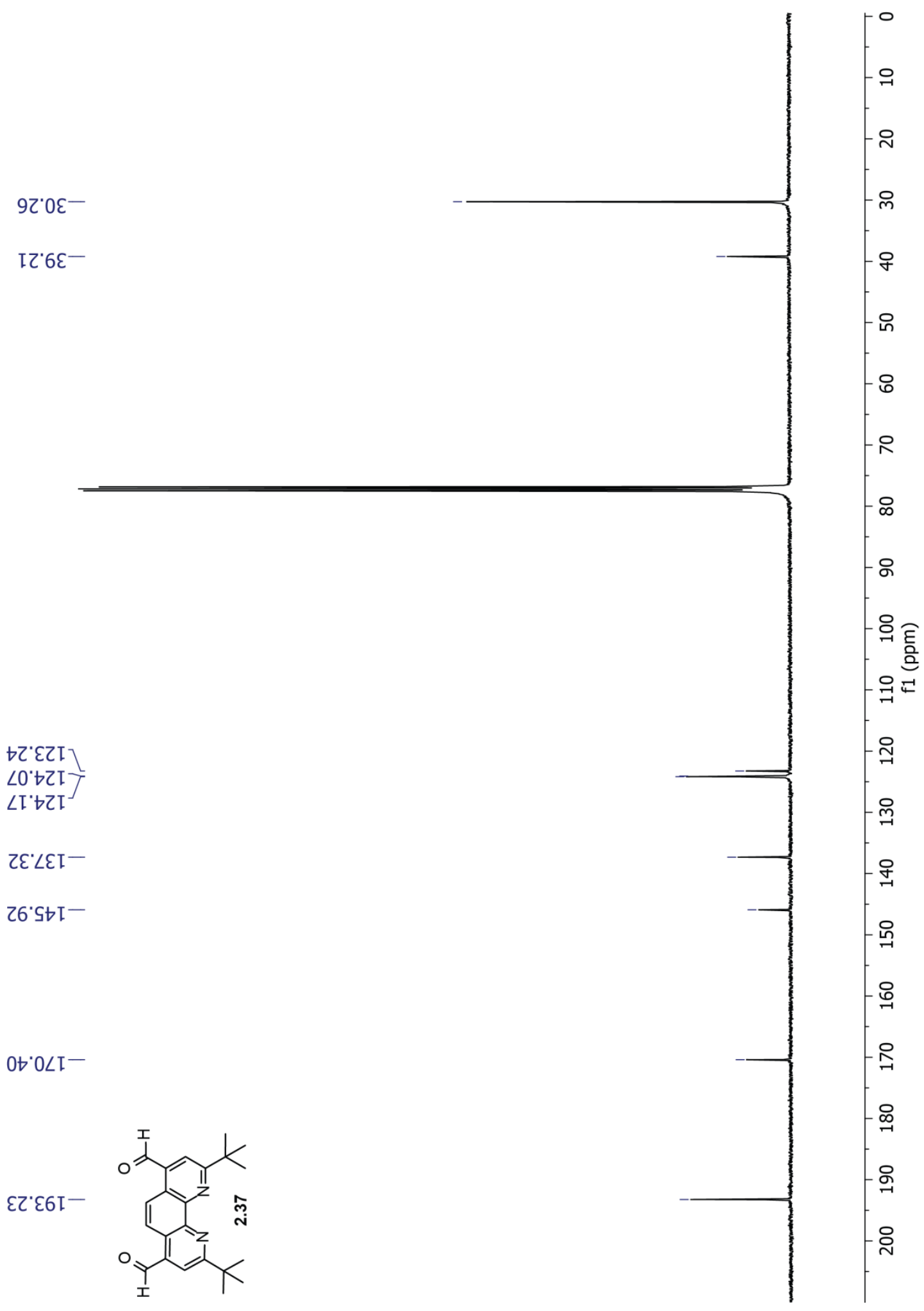

Figure A8. ${ }^{13} \mathrm{C}$ NMR spectrum of $\mathbf{2 . 3 7}$ in $\mathrm{CDCl}_{3}$ 


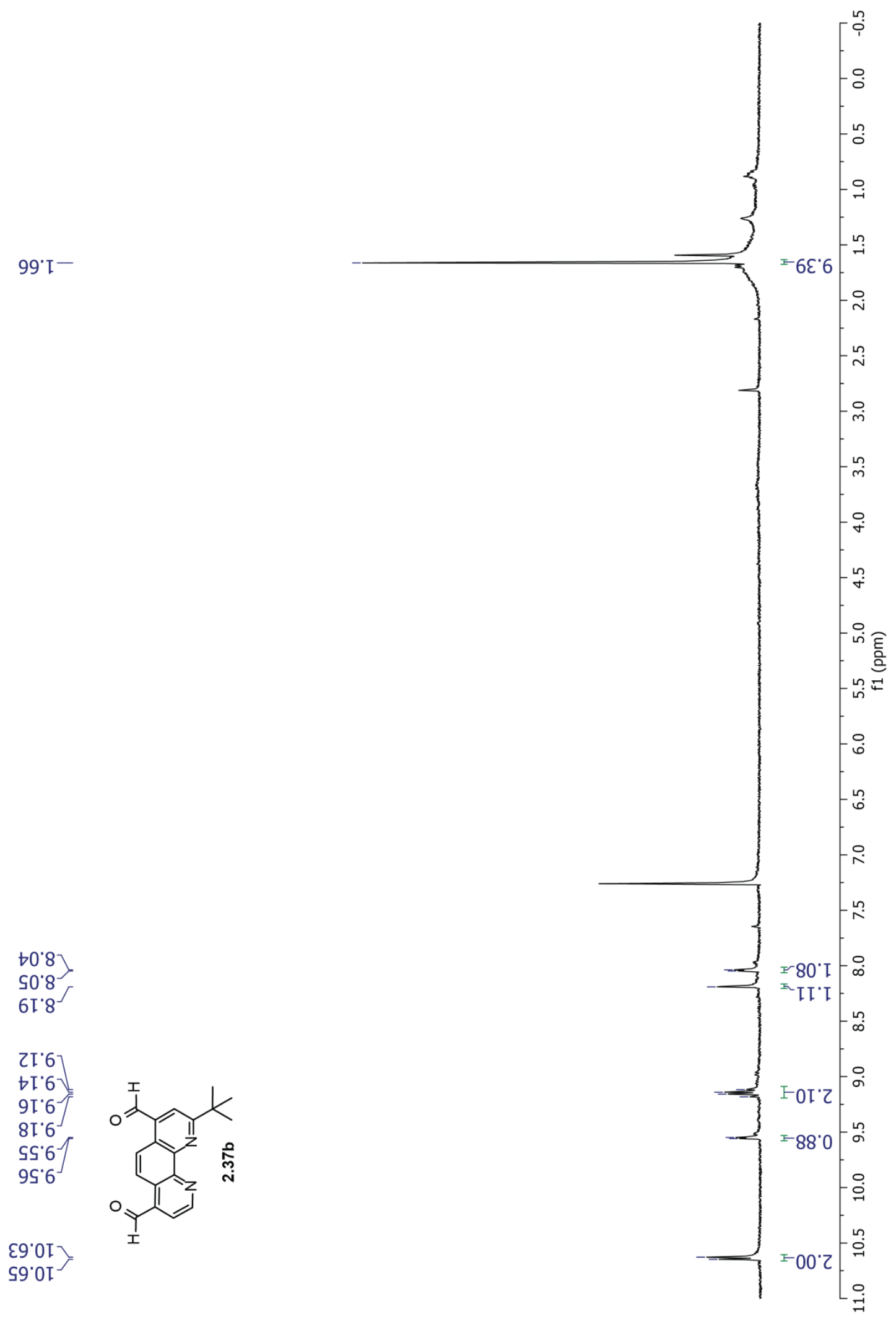

Figure A9. ${ }^{1} \mathrm{H}$ NMR spectrum of $\mathbf{2 . 3 7} \mathbf{b}$ in $\mathrm{CDCl}_{3}$ 

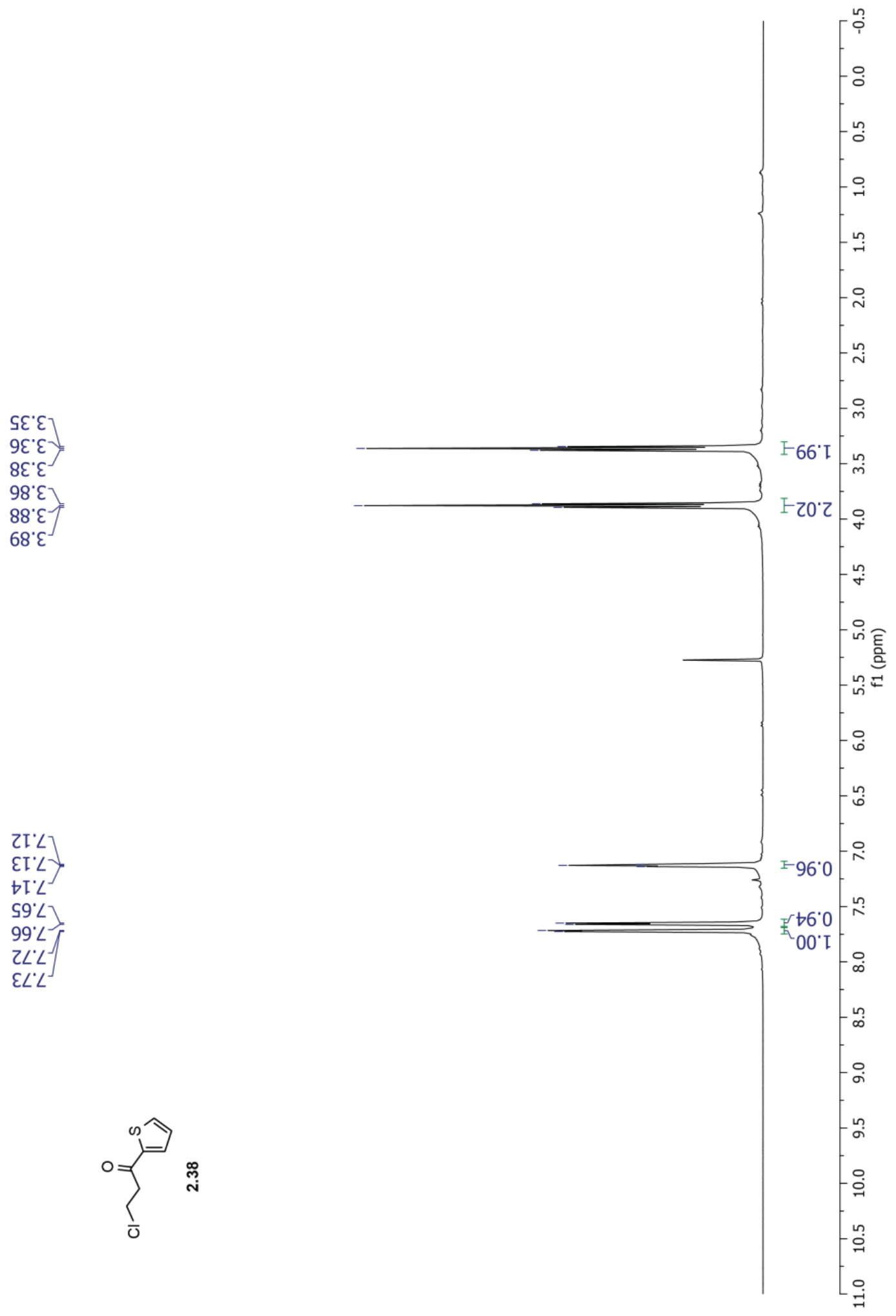

Figure A10. ${ }^{1} \mathrm{H}$ NMR spectrum of 2.38 in $\mathrm{CDCl}_{3}$ 


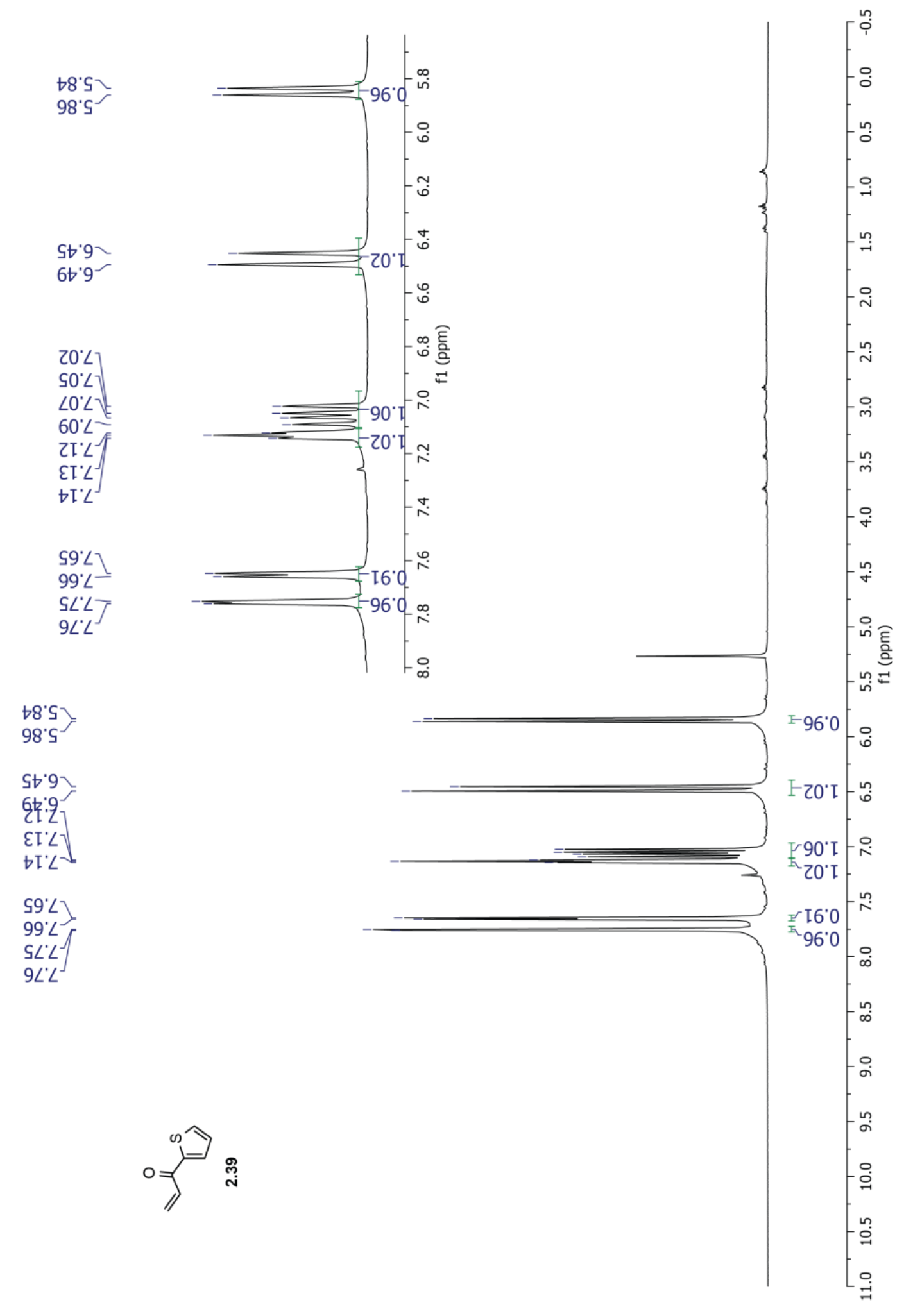

Figure A11. ${ }^{1} \mathrm{H}$ NMR spectrum of 2.39 in $\mathrm{CDCl}_{3}$ 

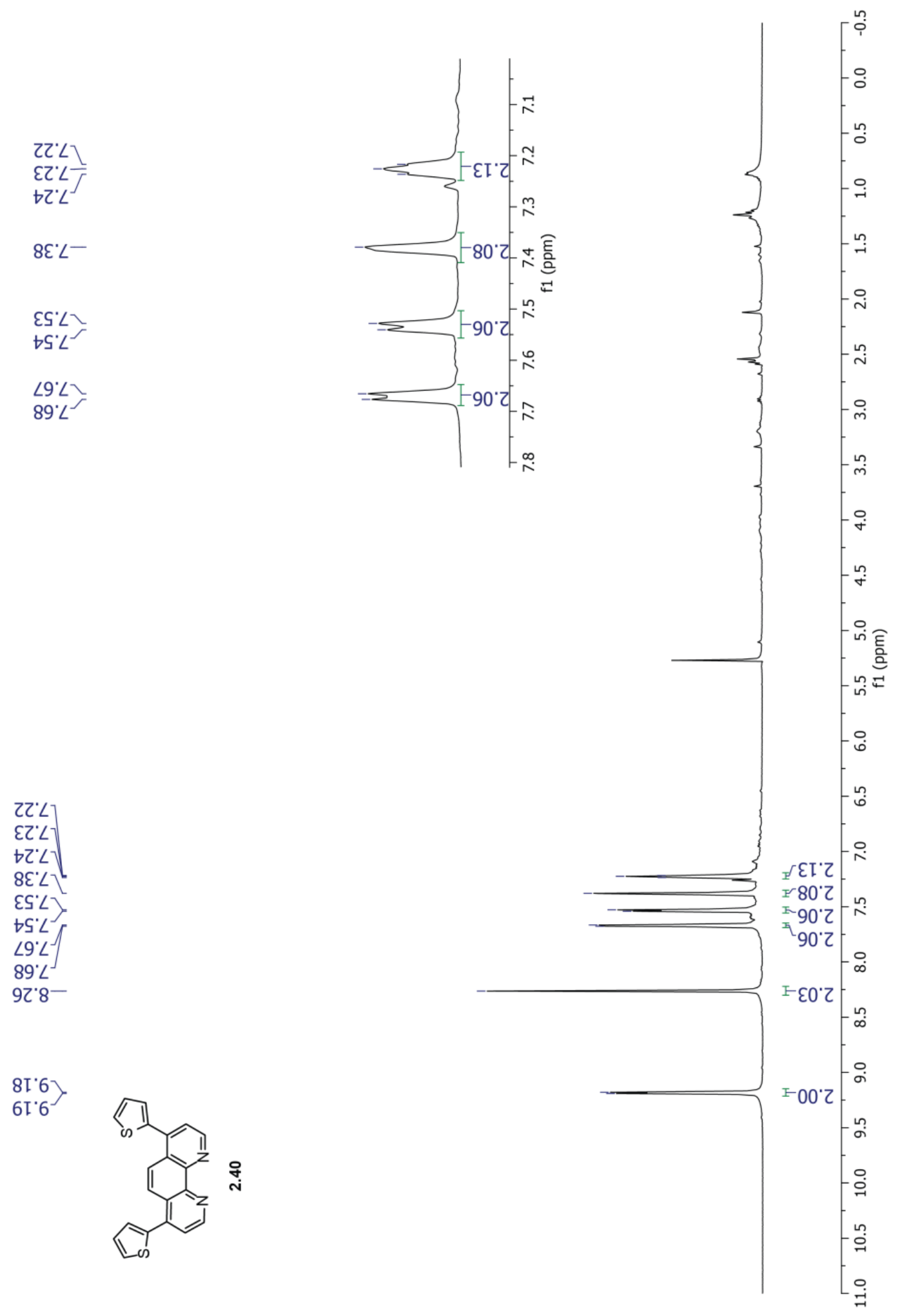

Figure A12. ${ }^{1} \mathrm{H}$ NMR spectrum of 2.40 in $\mathrm{CDCl}_{3}$ 


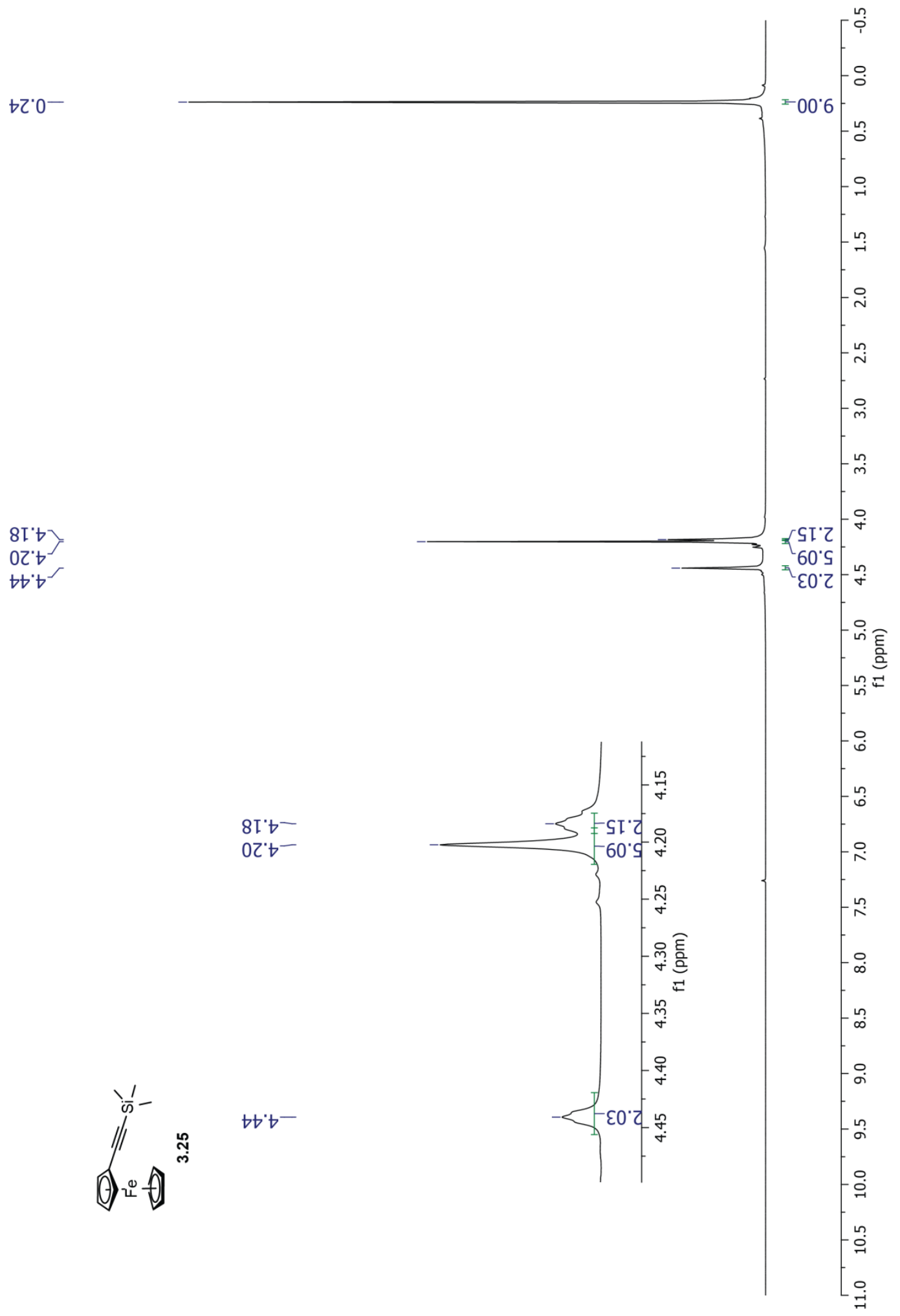

Figure A13. ${ }^{1} \mathrm{H}$ NMR spectrum of $\mathbf{3 . 2 5}$ in $\mathrm{CDCl}_{3}$ 


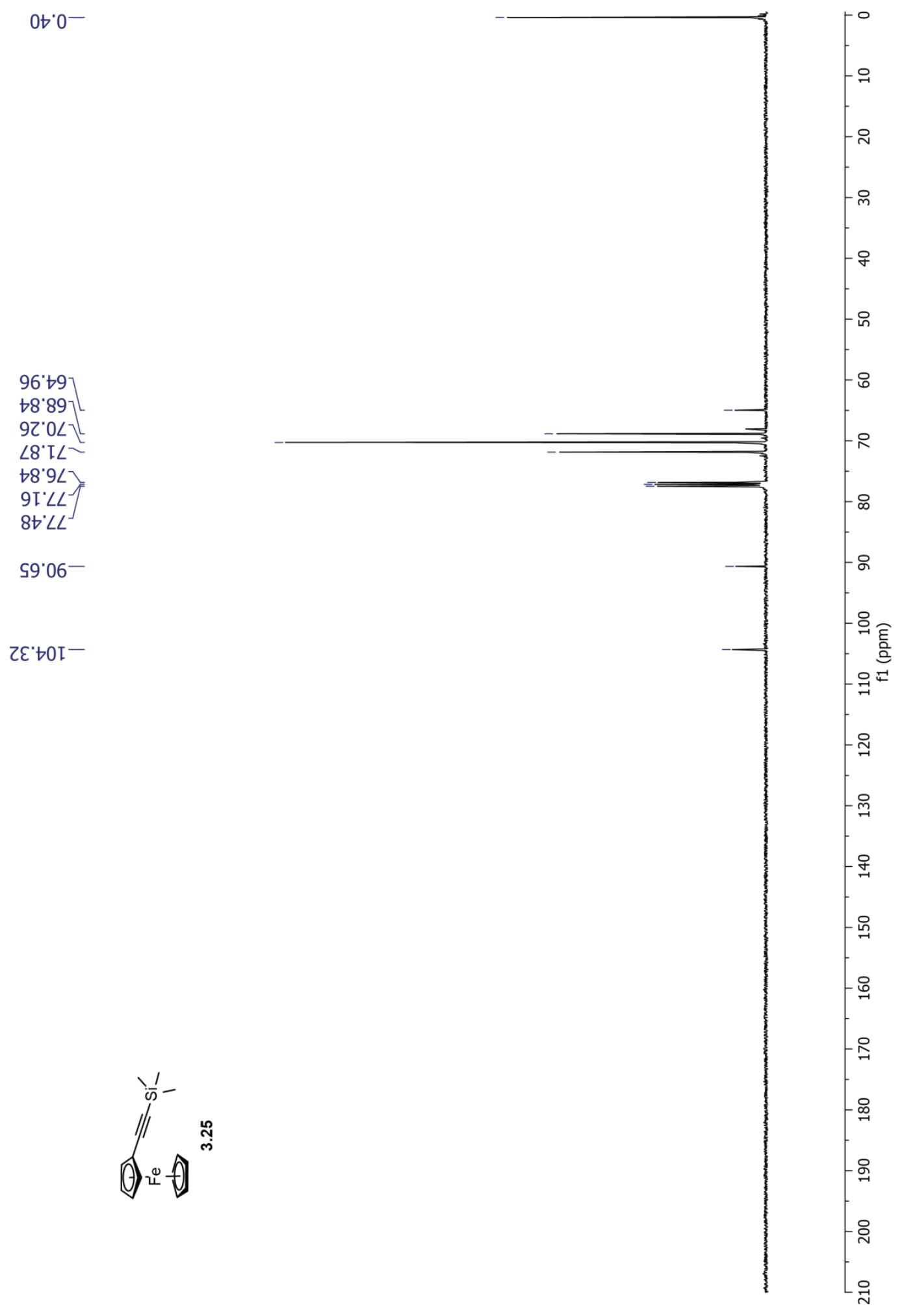

Figure A14. ${ }^{13} \mathrm{C}$ NMR spectrum of $\mathbf{3 . 2 5}$ in $\mathrm{CDCl}_{3}$ 


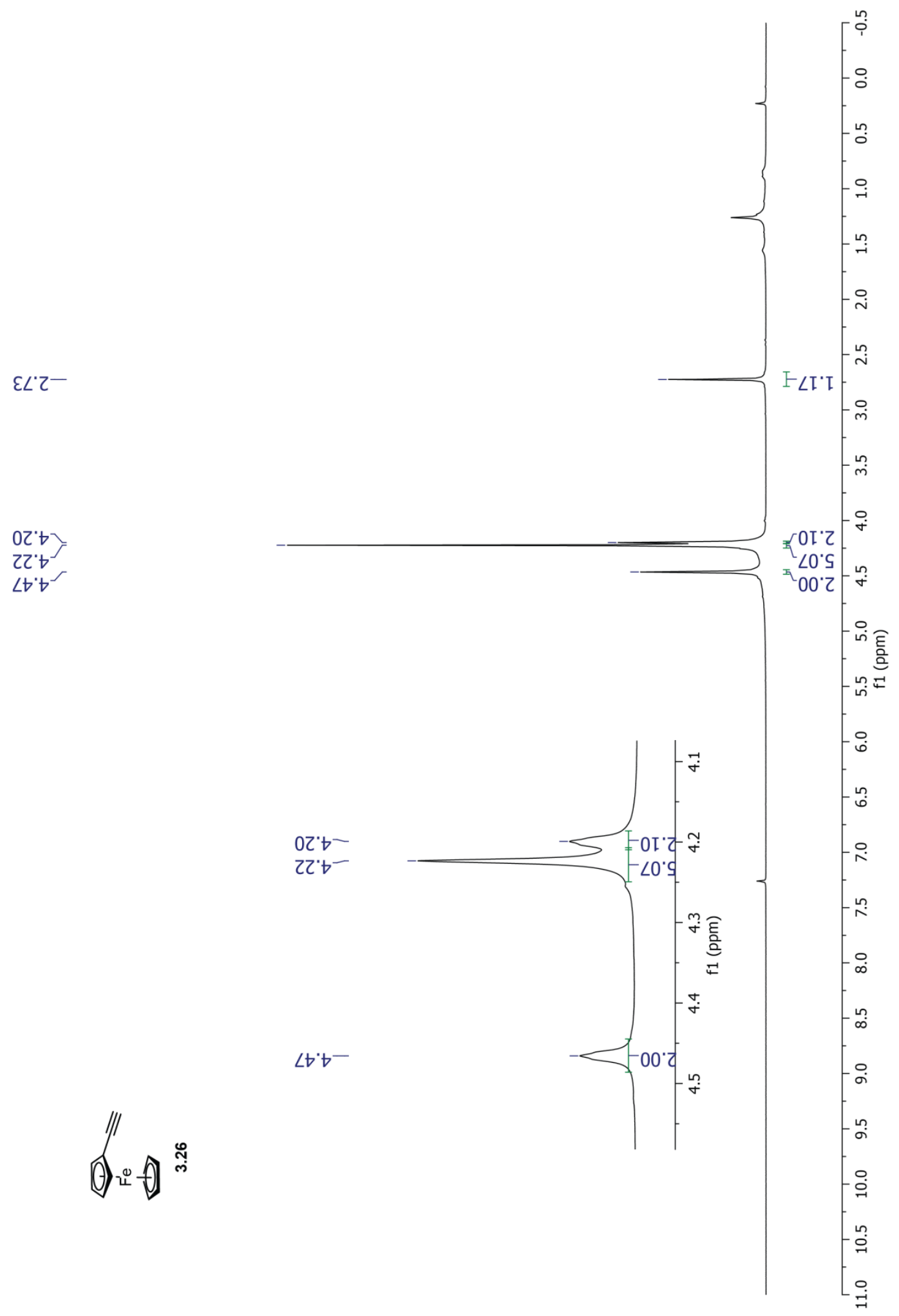

Figure A15. ${ }^{1} \mathrm{H}$ NMR spectrum of $\mathbf{3 . 2 6}$ in $\mathrm{CDCl}_{3}$ 


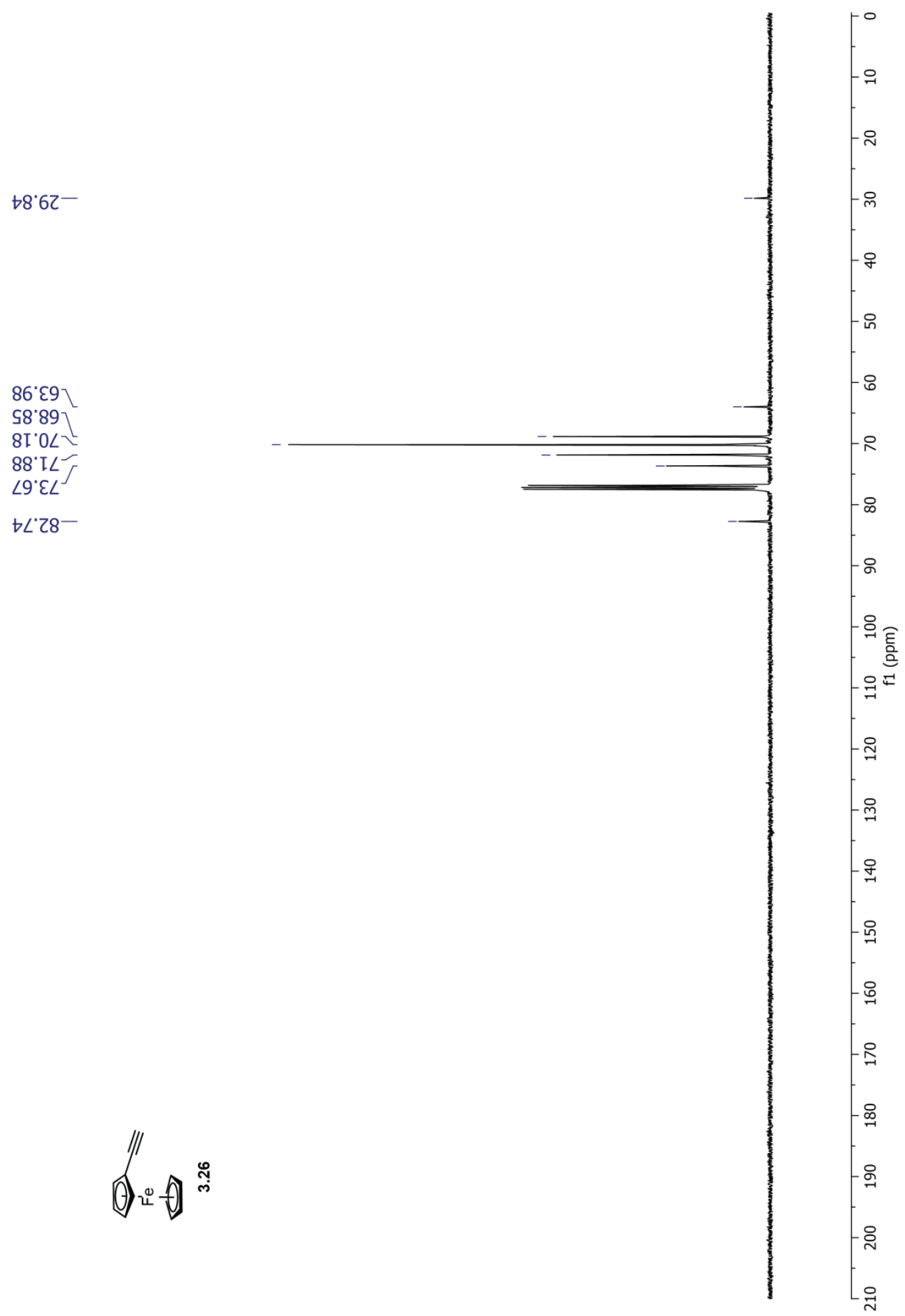

Figure A16. ${ }^{13} \mathrm{C}$ NMR spectrum of $\mathbf{3 . 2 6}$ in $\mathrm{CDCl}_{3}$ 

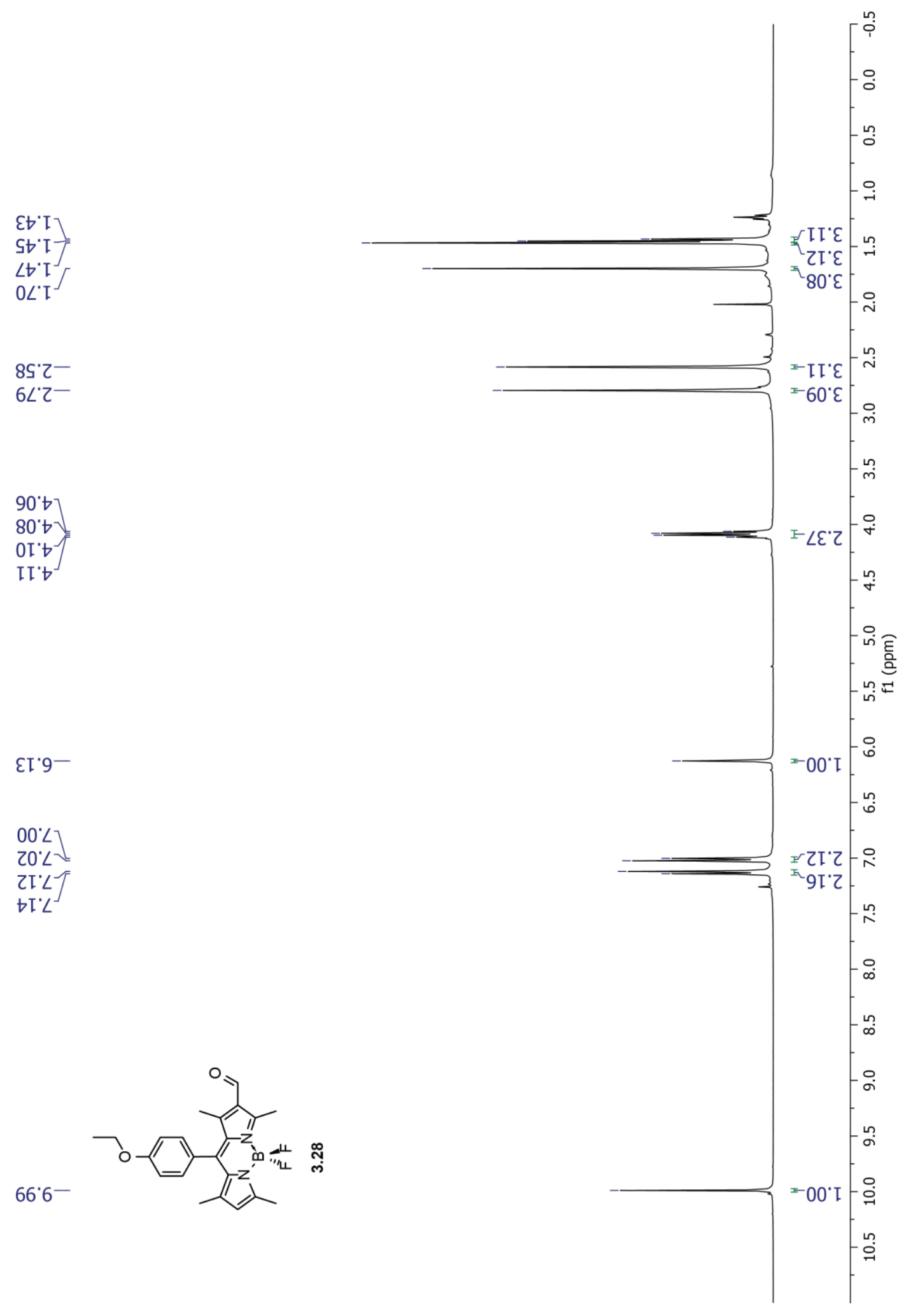

Figure A17. ${ }^{1} \mathrm{H}$ NMR spectrum of $\mathbf{3 . 2 8}$ in $\mathrm{CDCl}_{3}$ 


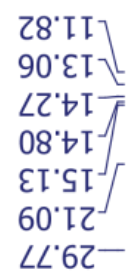

t๖.09-

SL'E9-

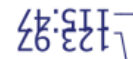

66'SZI]

9ع'9ZI L

80.6ZI -

Оह'0हा

$56^{\circ} \mathrm{Zt} \mathrm{I}$

$\angle 6^{\circ} \varepsilon \mapsto I^{\prime}$

9ع.9SI

90.09I

เt . $^{\prime} \mathrm{I}^{-}$

$\angle I^{\prime} I \angle I-$

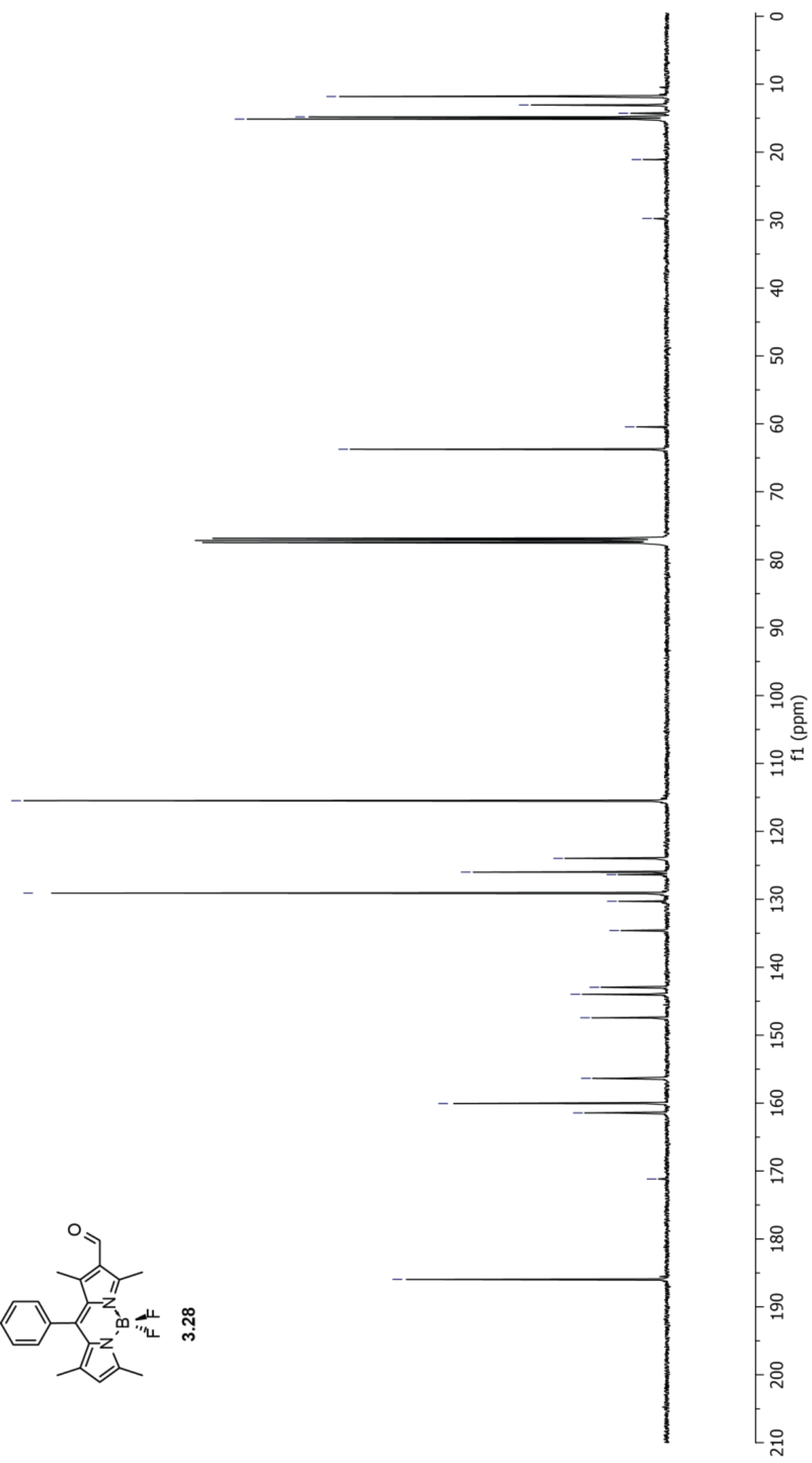

Figure A18. ${ }^{13} \mathrm{C}$ NMR spectrum of $\mathbf{3 . 2 8}$ in $\mathrm{CDCl}_{3}$ 


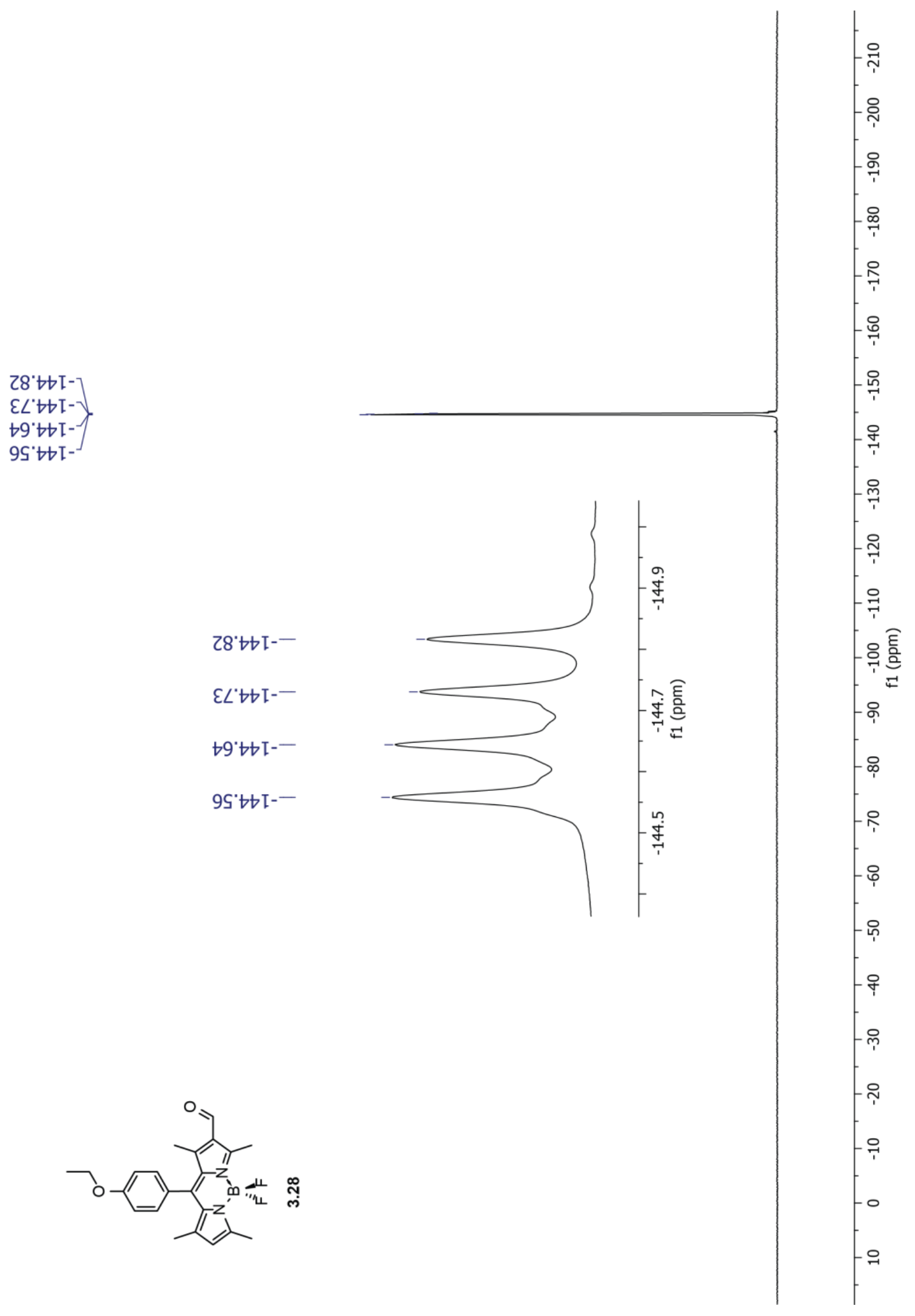

Figure A19. ${ }^{19} \mathrm{~F}$ NMR spectrum of $\mathbf{3 . 2 8}$ in $\mathrm{CDCl}_{3}$ 


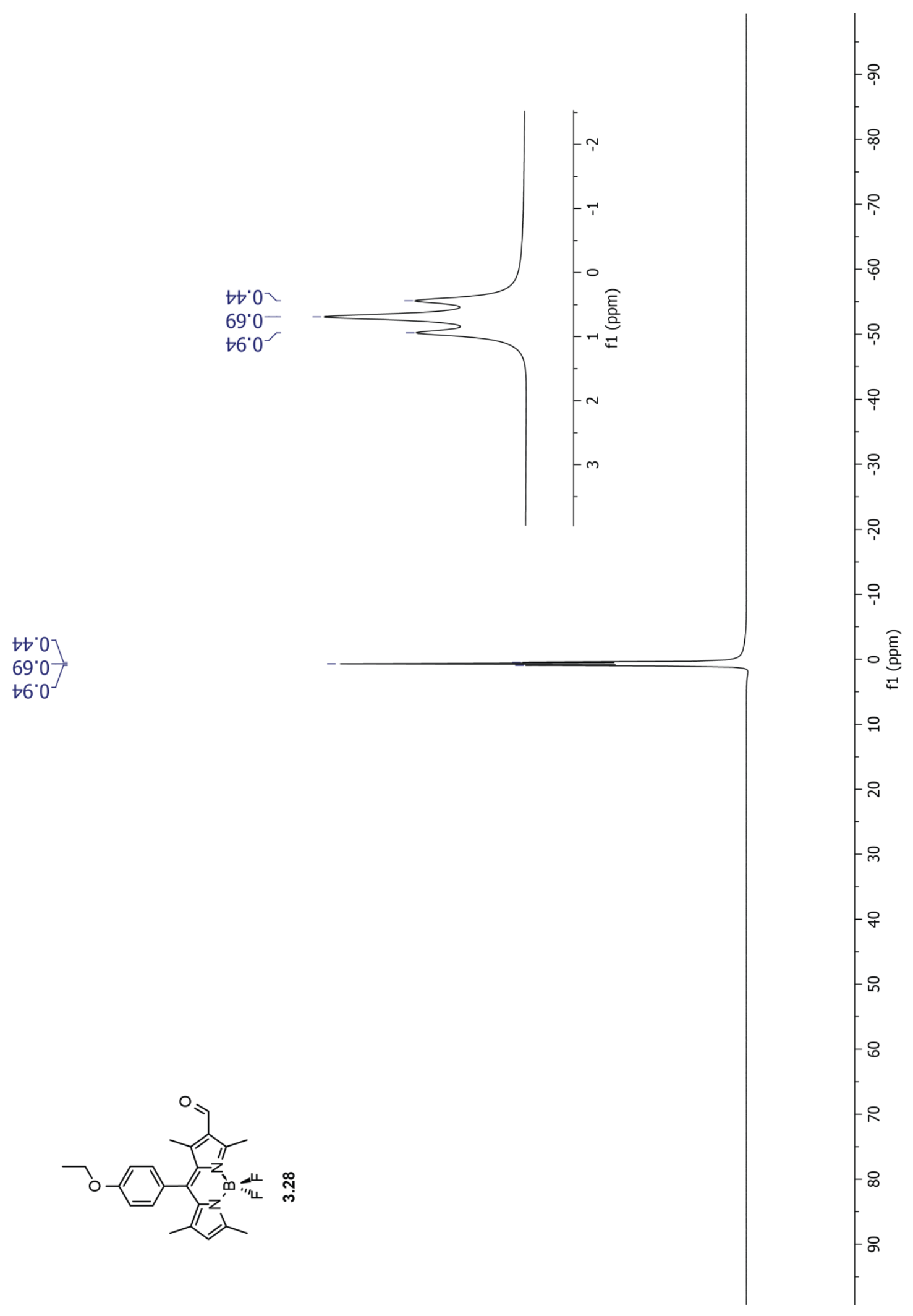

Figure A20. ${ }^{11} \mathrm{~B} N M R$ spectrum of $\mathbf{3 . 2 8}$ in $\mathrm{CDCl}_{3}$ 

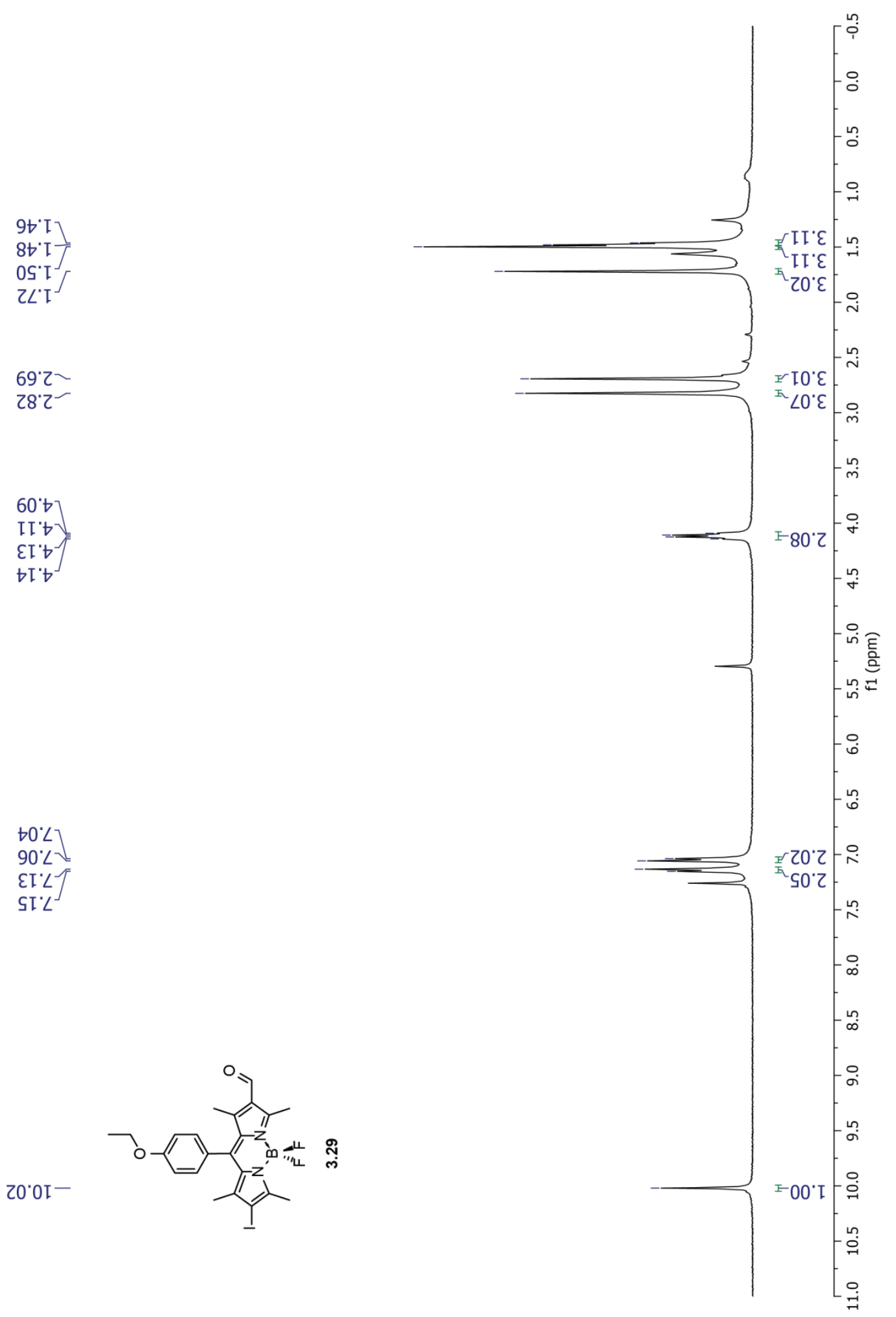

Figure A21. ${ }^{1} \mathrm{H}$ NMR spectrum of 3.29 in $\mathrm{CDCl}_{3}$ 


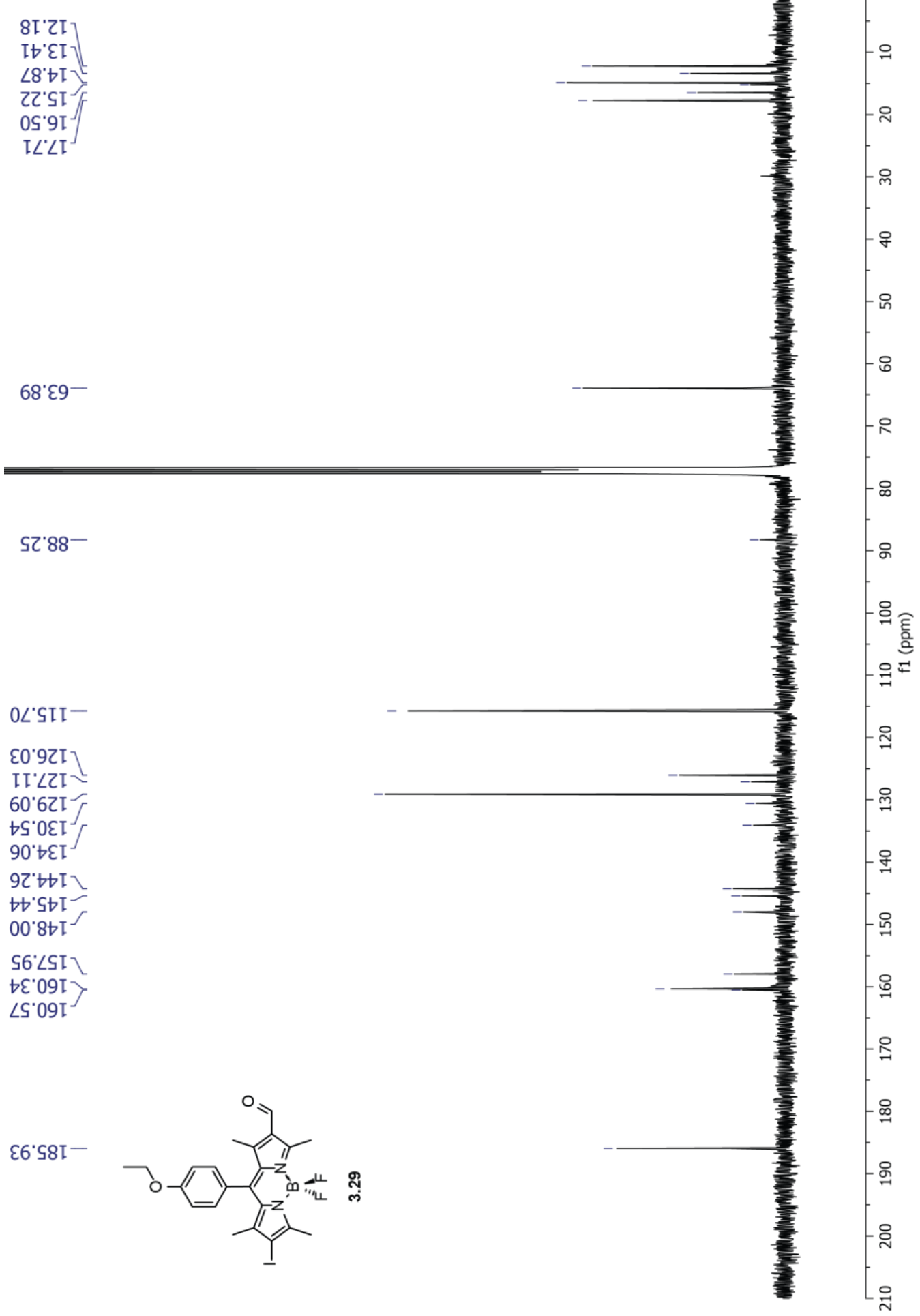

Figure A22. ${ }^{13} \mathrm{C}$ NMR spectrum of $\mathbf{3 . 2 9}$ in $\mathrm{CDCl}_{3}$ 


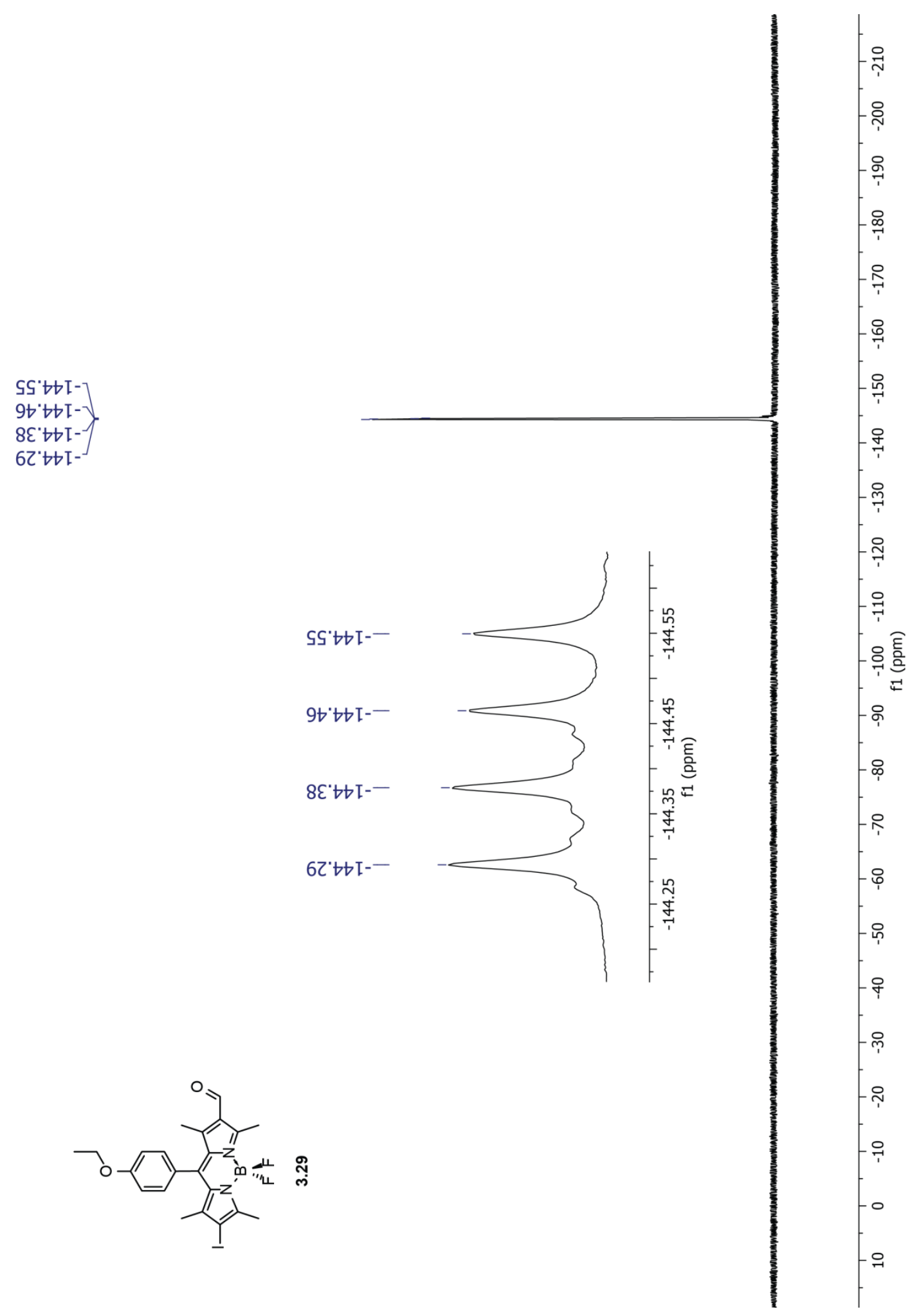

Figure A23. ${ }^{19} \mathrm{~F}$ NMR spectrum of $\mathbf{3 . 2 9}$ in $\mathrm{CDCl}_{3}$ 


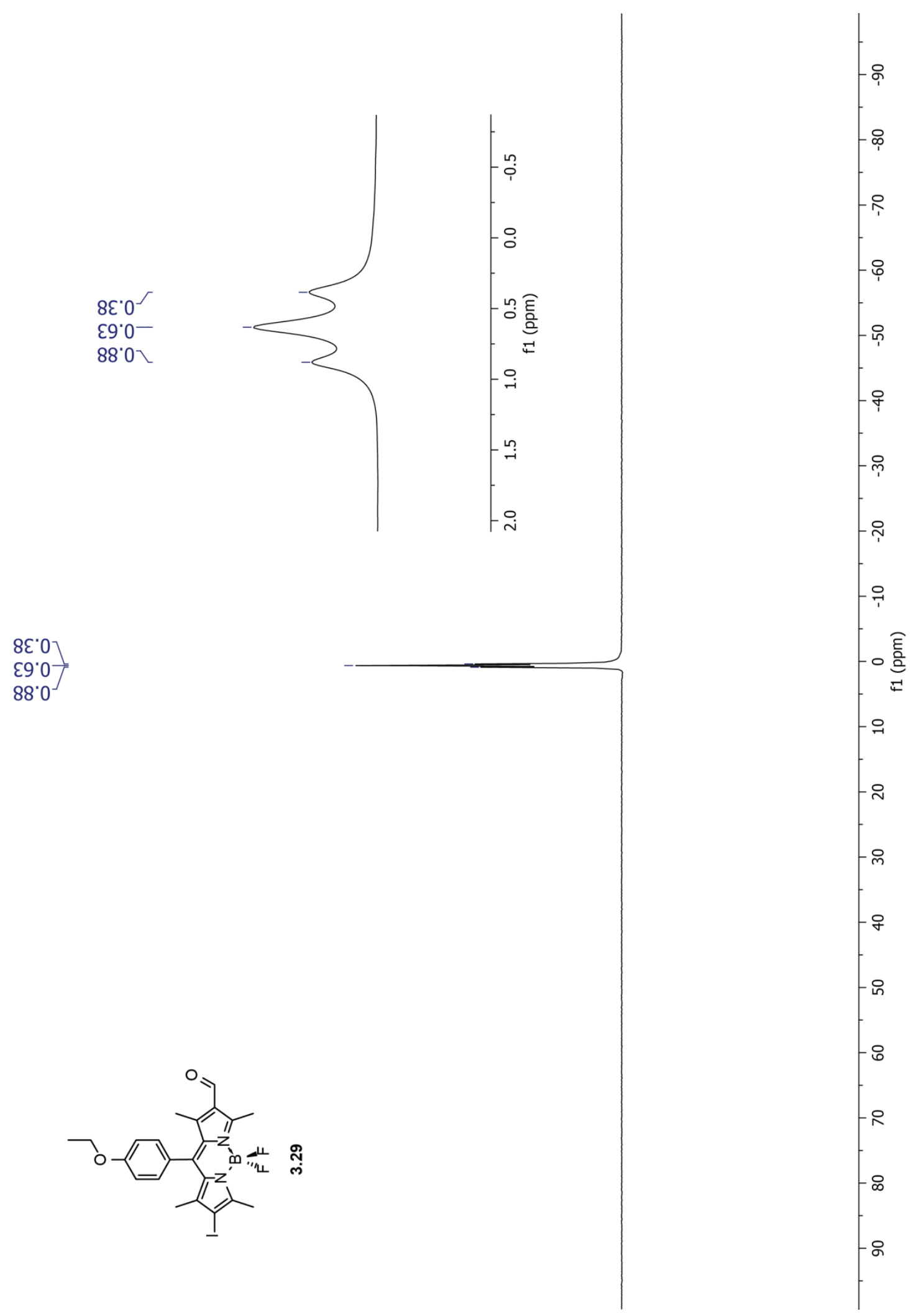

Figure A24. ${ }^{11} \mathrm{~B} N M R$ spectrum of $\mathbf{3 . 2 9}$ in $\mathrm{CDCl}_{3}$ 

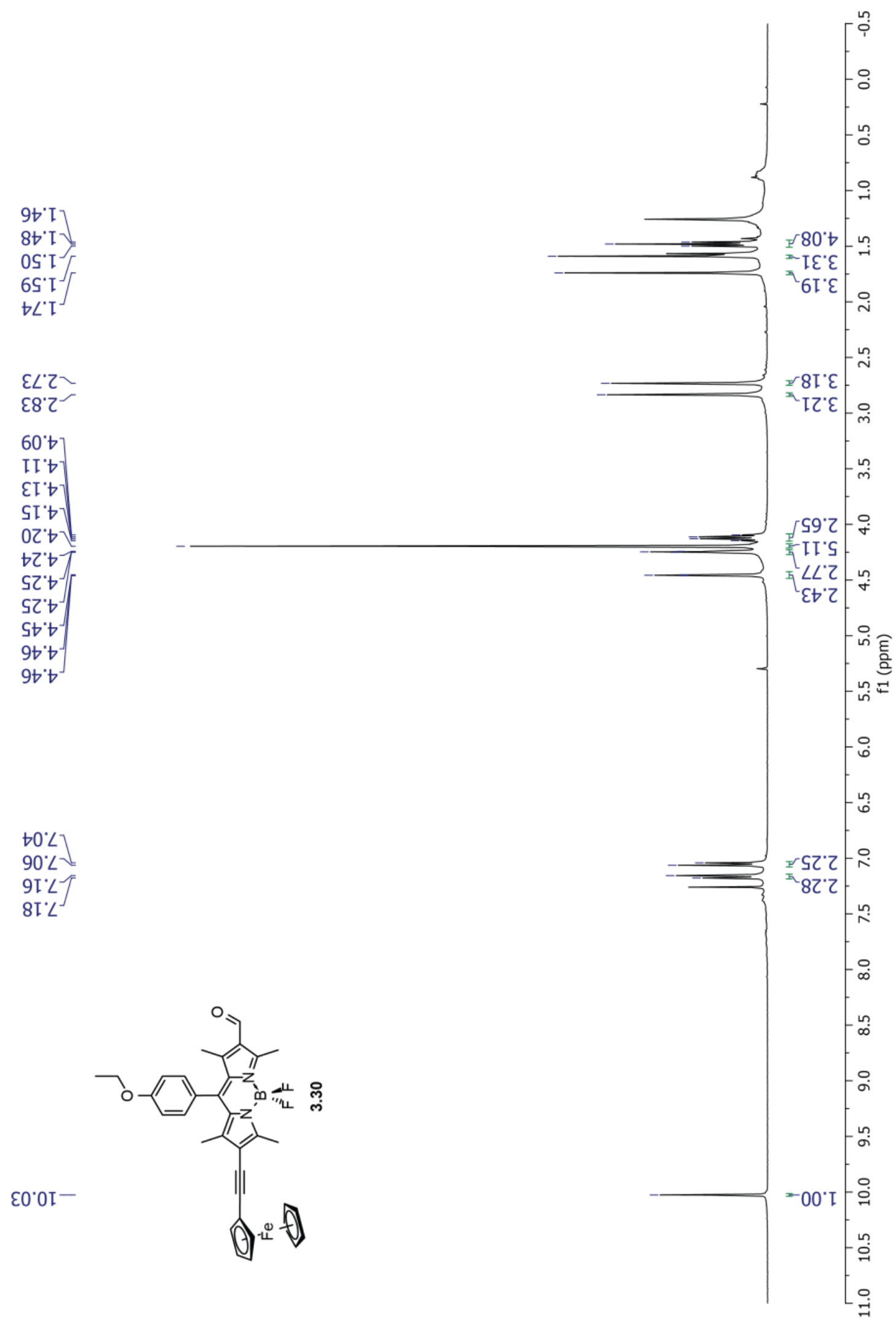

Figure A25. ${ }^{1} \mathrm{H}$ NMR spectrum of $\mathbf{3 . 3 0}$ in $\mathrm{CDCl}_{3}$ 


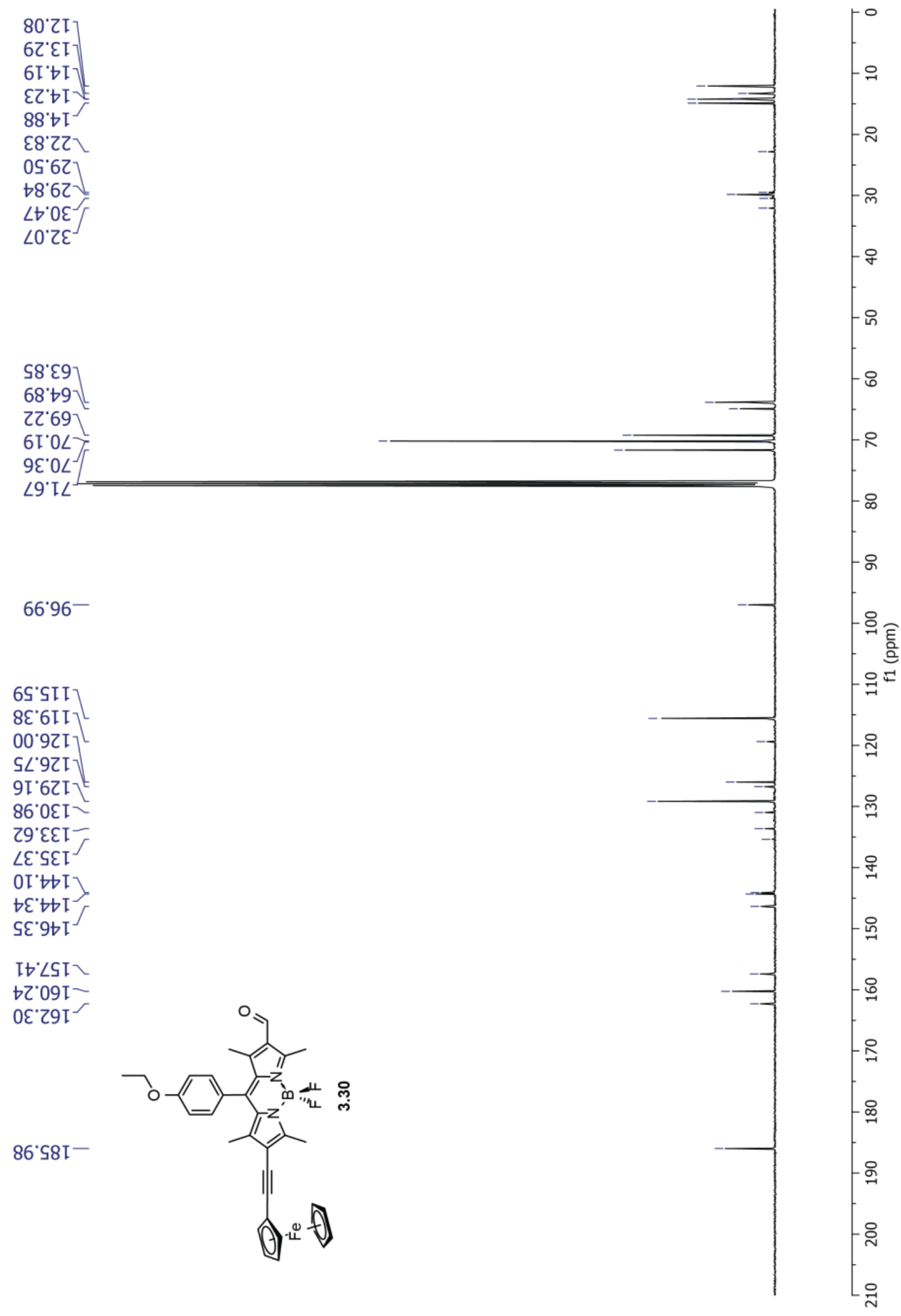

Figure A26. ${ }^{13} \mathrm{C}$ NMR spectrum of $\mathbf{3 . 3 0}$ in $\mathrm{CDCl}_{3}$ 


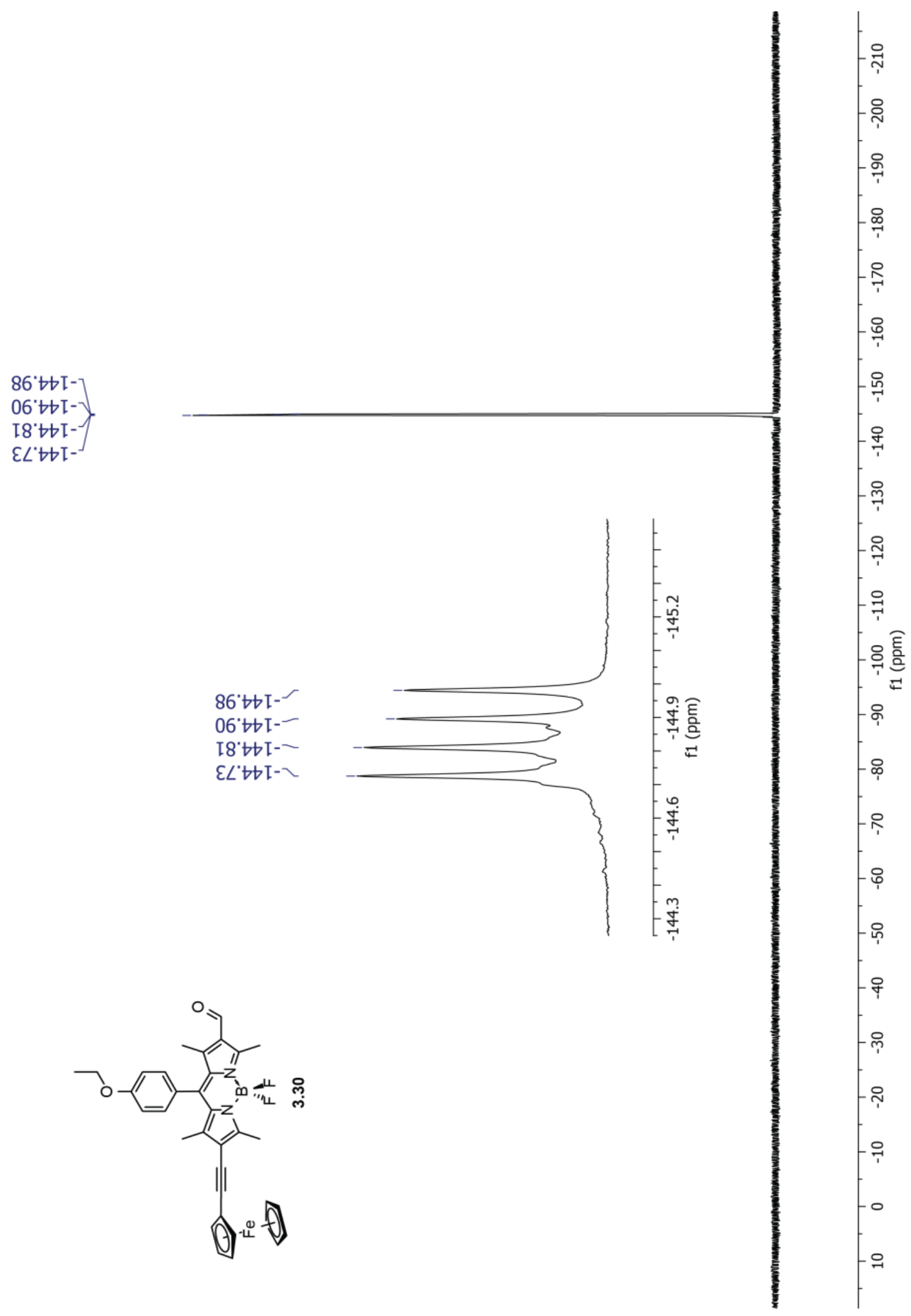

Figure A27. ${ }^{19} \mathrm{~F}$ NMR spectrum of $\mathbf{3 . 3 0}$ in $\mathrm{CDCl}_{3}$ 


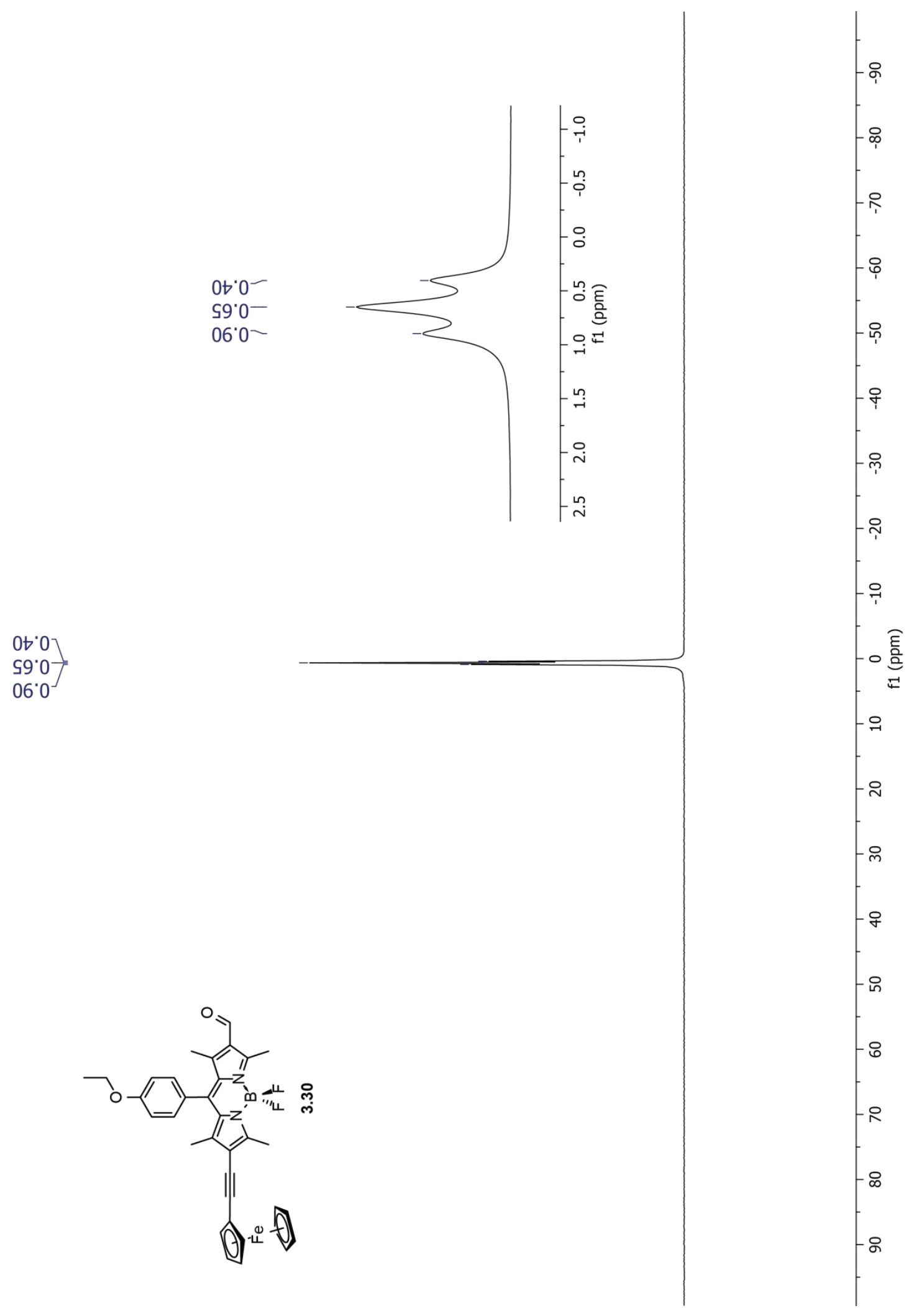

Figure A28. ${ }^{11} \mathrm{~B}$ NMR spectrum of $\mathbf{3 . 3 0}$ in $\mathrm{CDCl}_{3}$ 


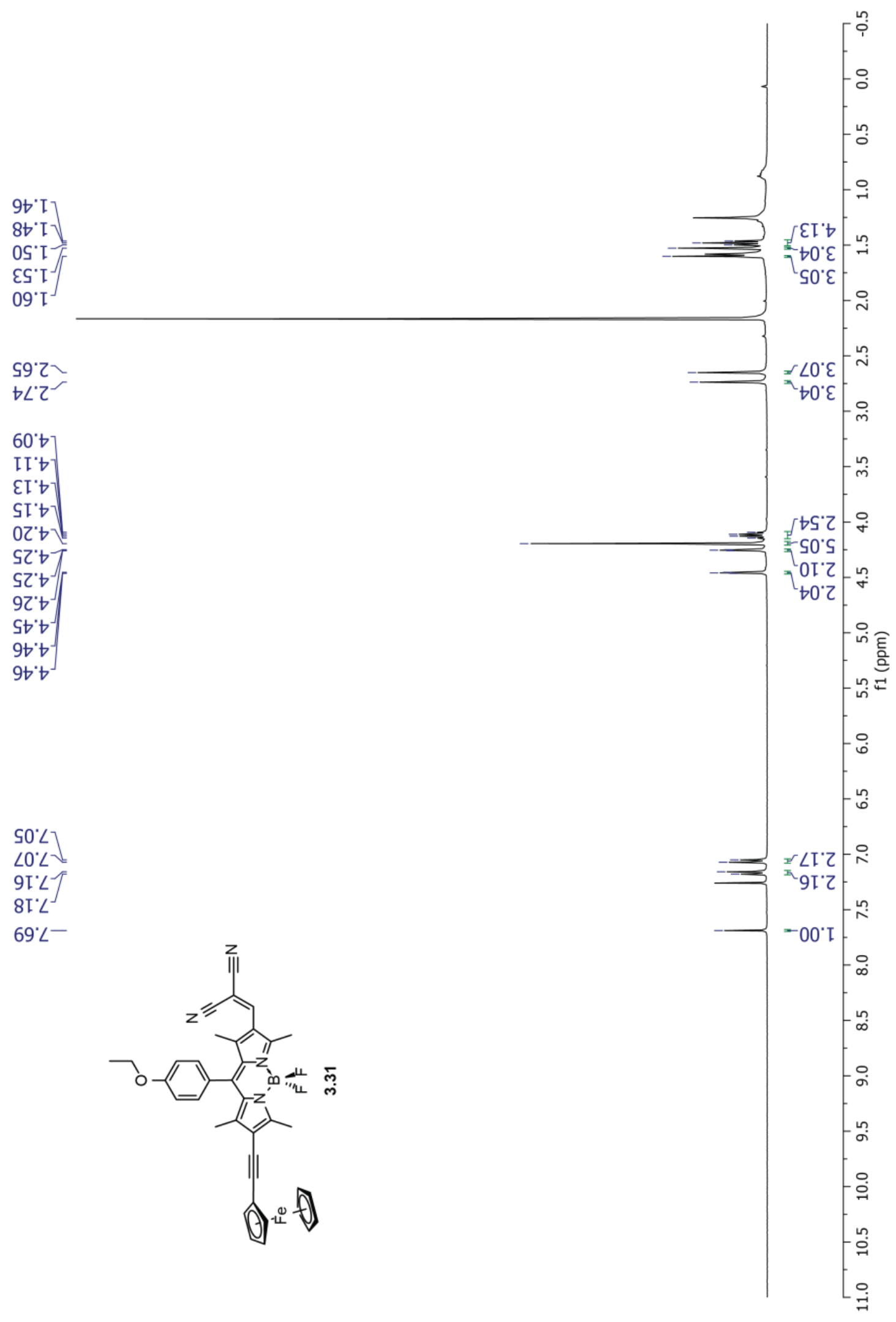

Figure A29. ${ }^{1} \mathrm{H}$ NMR spectrum of 3.31 in $\mathrm{CDCl}_{3}$ 


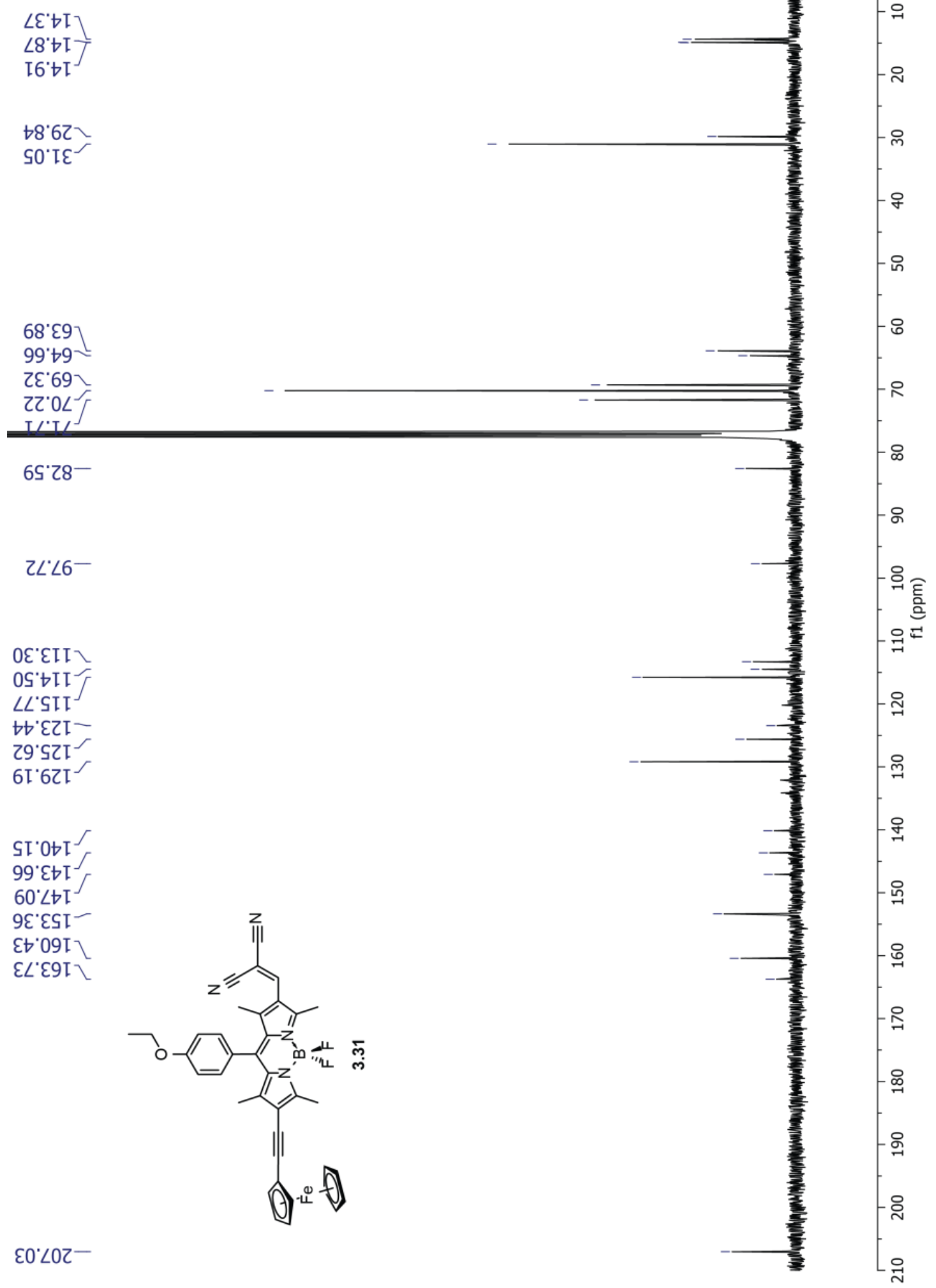

Figure $\mathbf{A} 30 .{ }^{13} \mathrm{C}$ NMR spectrum of $\mathbf{3 . 3 1}$ in $\mathrm{CDCl}_{3}$ 


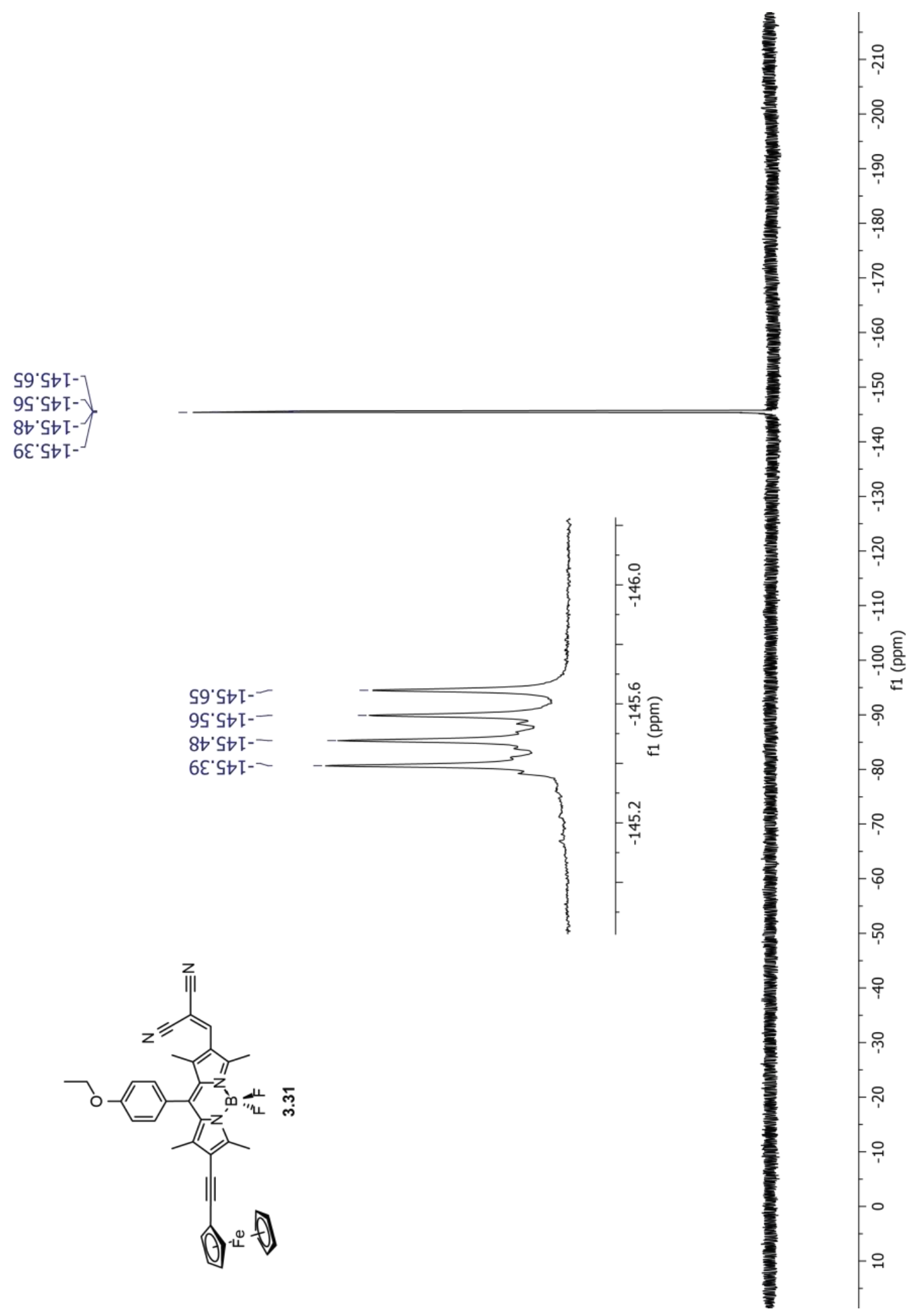

Figure A31. ${ }^{19} \mathrm{~F}$ NMR spectrum of 3.31 in $\mathrm{CDCl}_{3}$ 


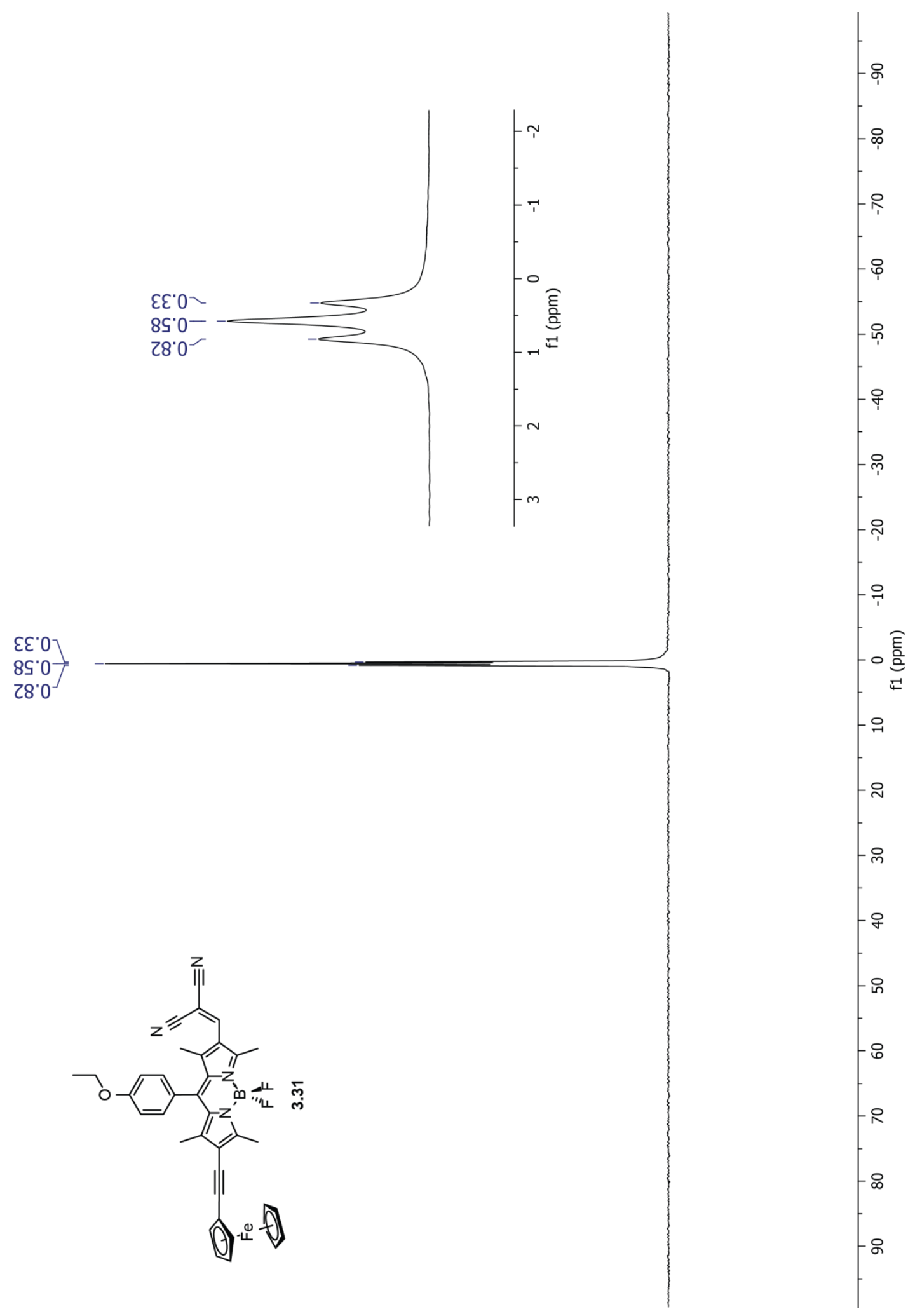

Figure A32. ${ }^{11} \mathrm{~B} N M R$ spectrum of $\mathbf{3 . 3 1}$ in $\mathrm{CDCl}_{3}$ 


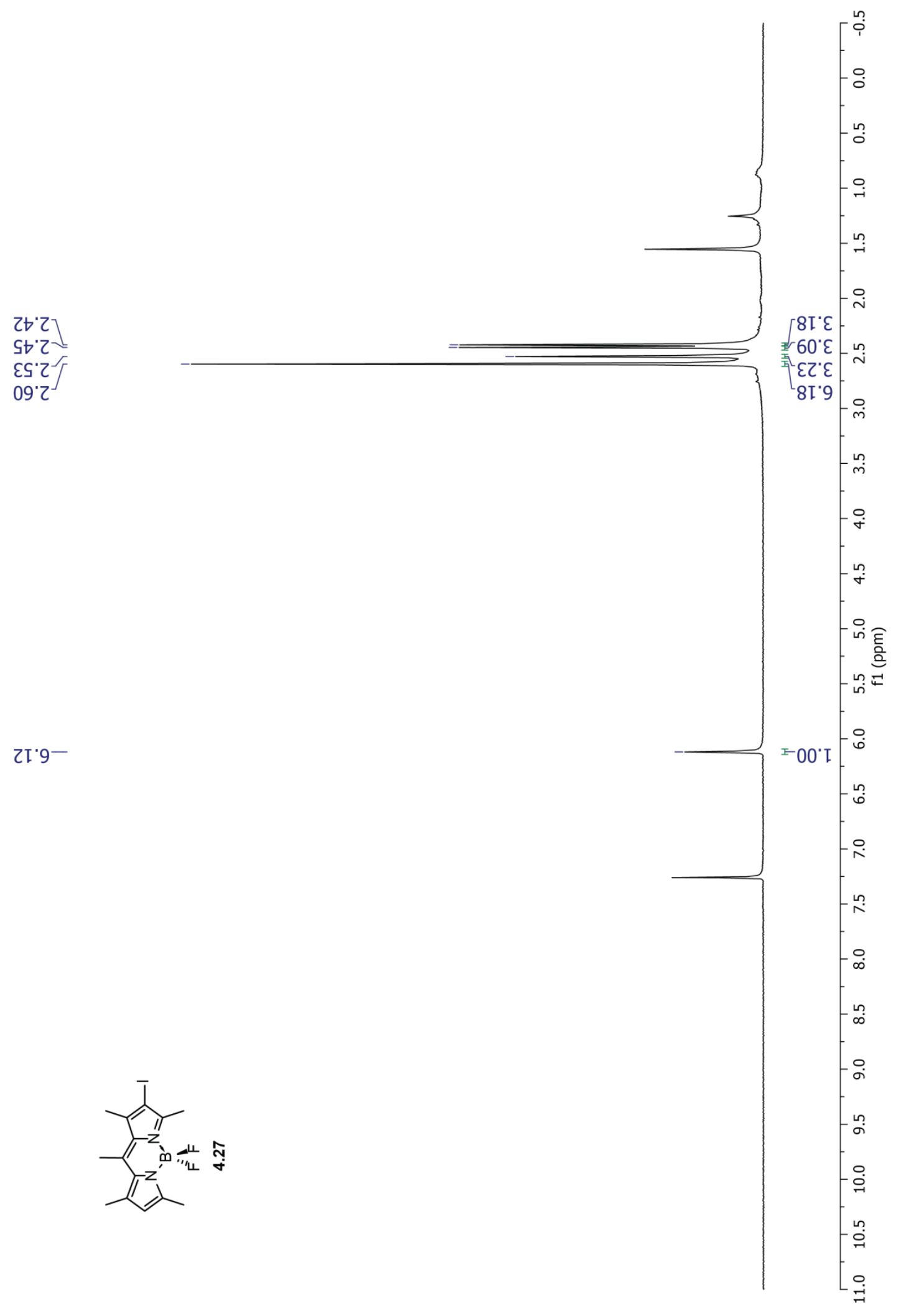

Figure A33. ${ }^{1} \mathrm{H}$ NMR spectrum of 4.27 in $\mathrm{CDCl}_{3}$ 


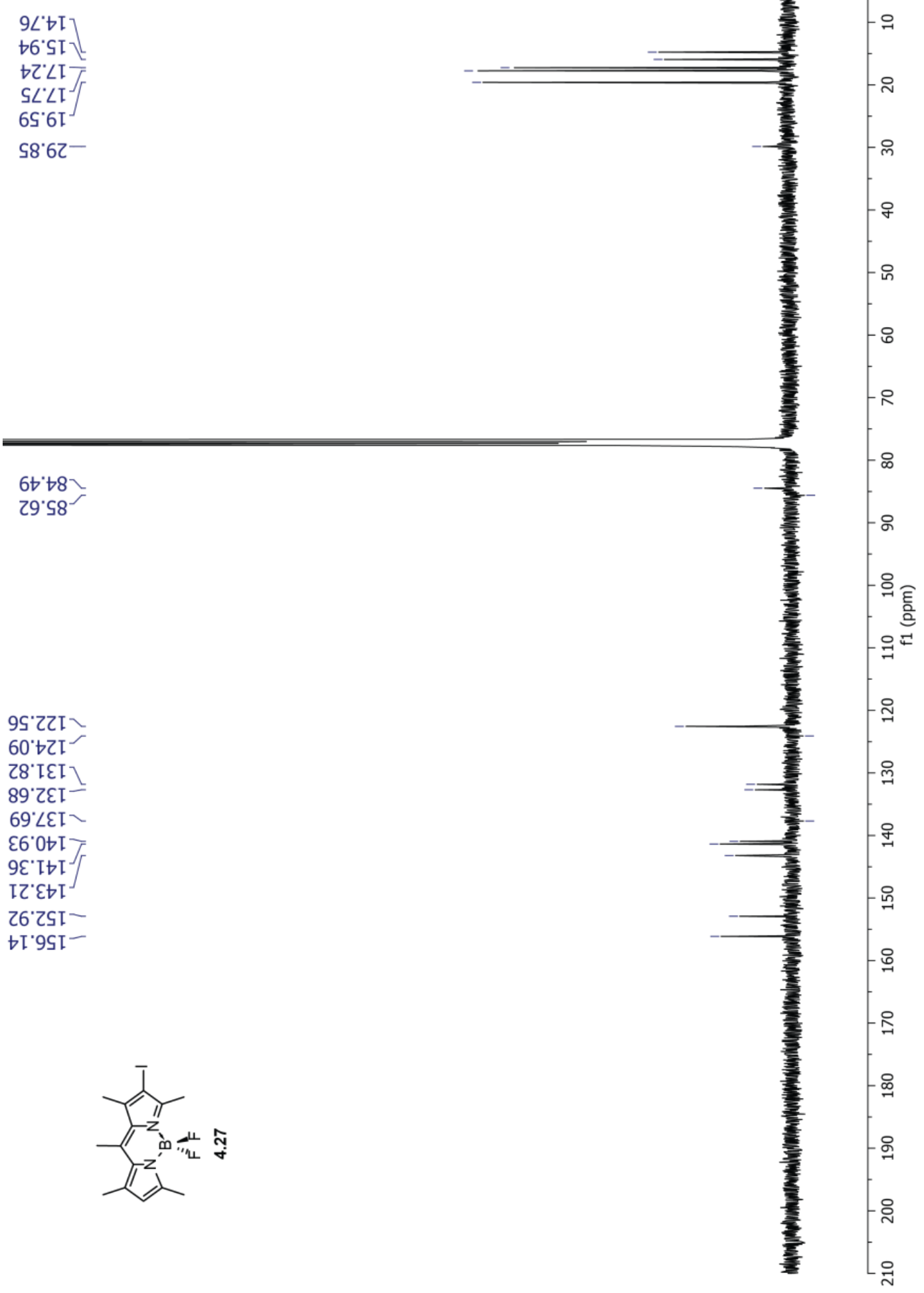

Figure $\mathrm{A} 34 .{ }^{13} \mathrm{C}$ NMR spectrum of 4.27 in $\mathrm{CDCl}_{3}$ 


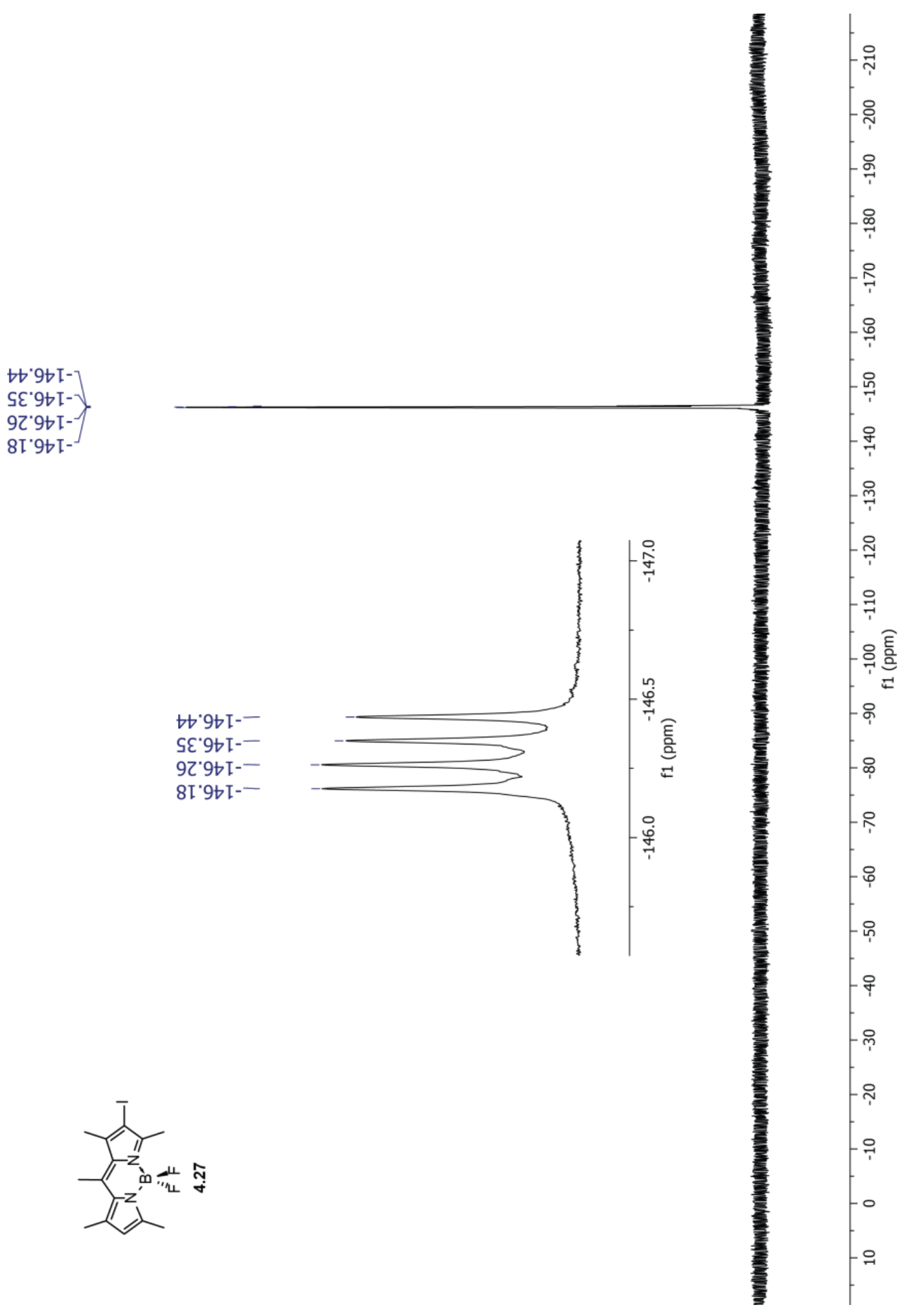

Figure A35. ${ }^{19} \mathrm{~F} \mathrm{NMR} \mathrm{spectrum} \mathrm{of} \mathbf{4 . 2 7}$ in $\mathrm{CDCl}_{3}$ 


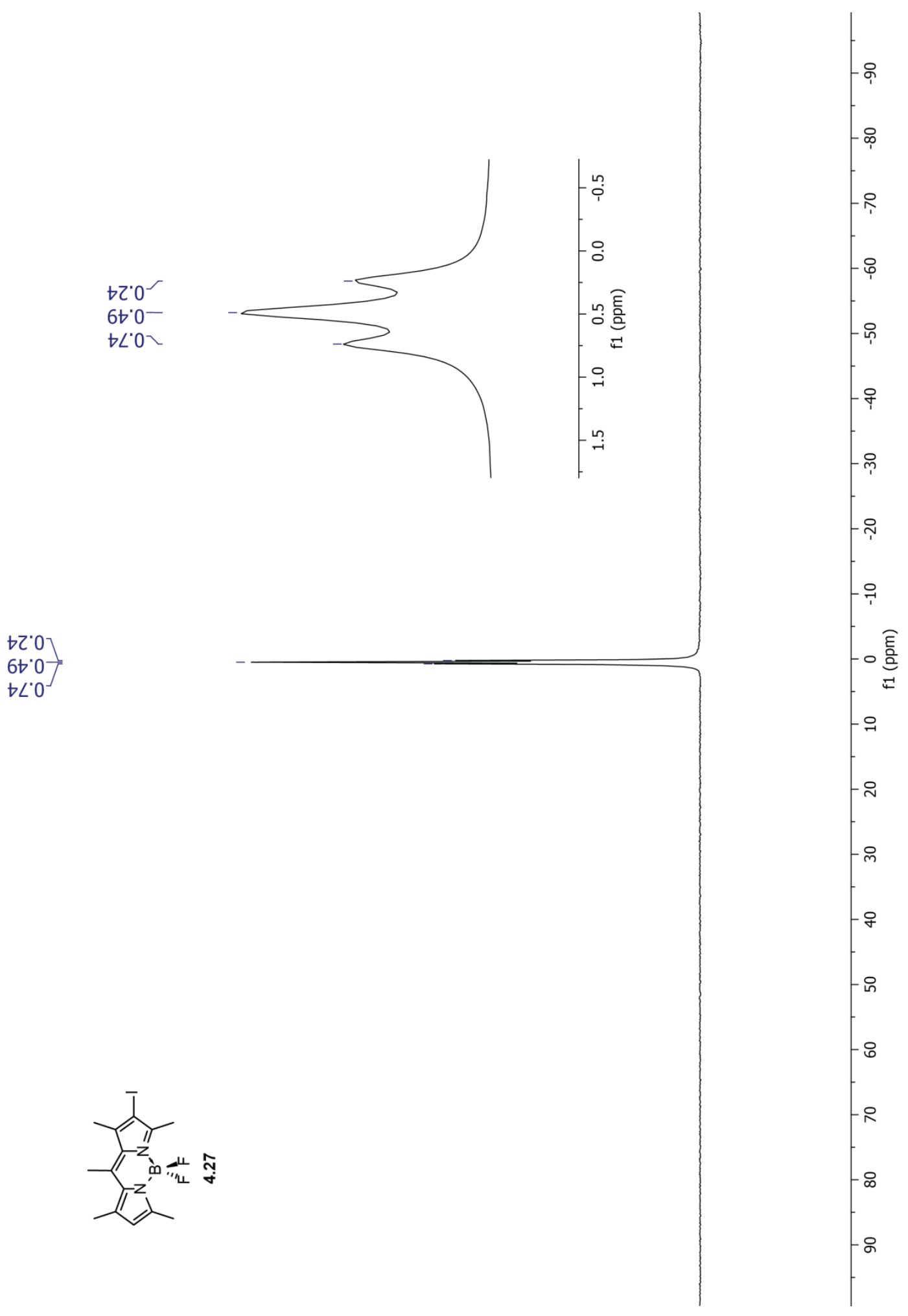

Figure $\mathrm{A} 36 .{ }^{11} \mathrm{~B} N M R$ spectrum of $\mathbf{4 . 2 7}$ in $\mathrm{CDCl}_{3}$ 
$92^{\circ} 0^{-}$

It 2

$\angle t^{\circ} 2$

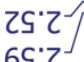

60 '9-

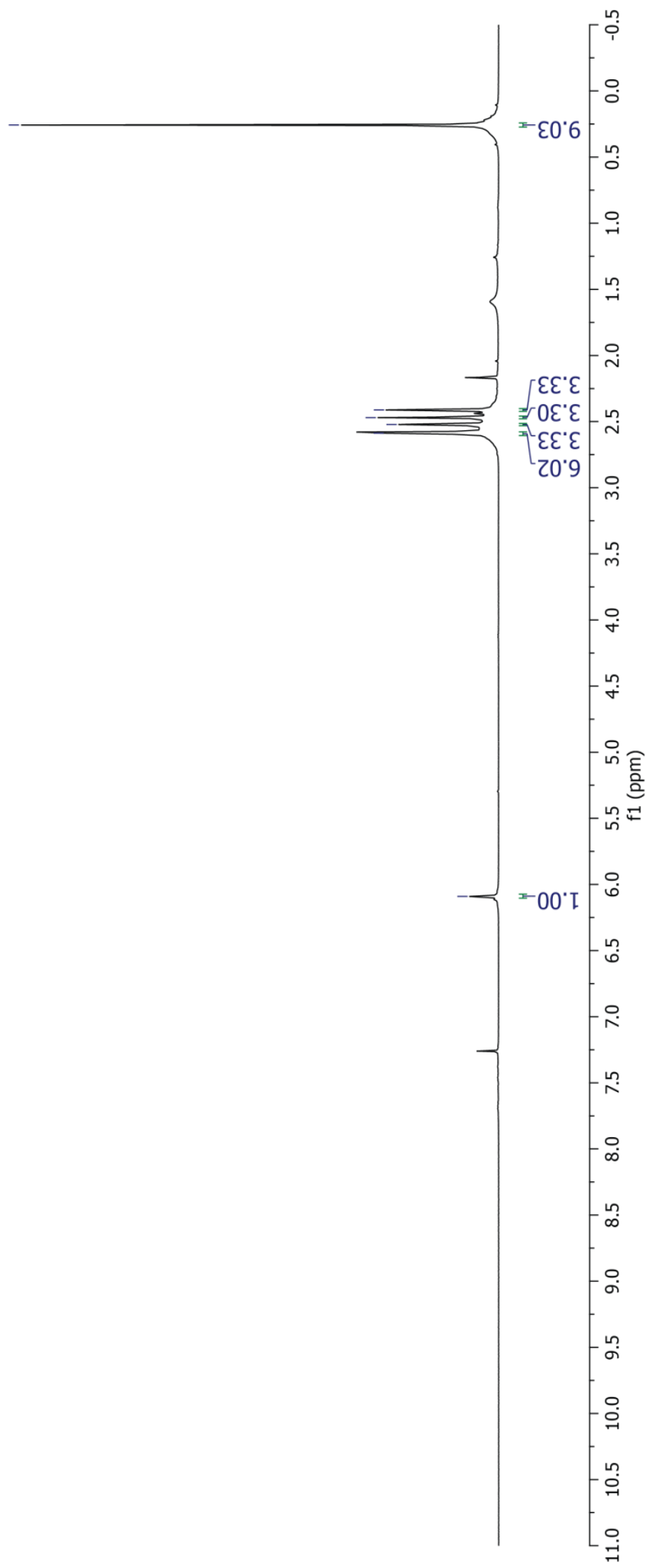

Figure A37. ${ }^{1} \mathrm{H}$ NMR spectrum of 4.28 in $\mathrm{CDCl}_{3}$ 


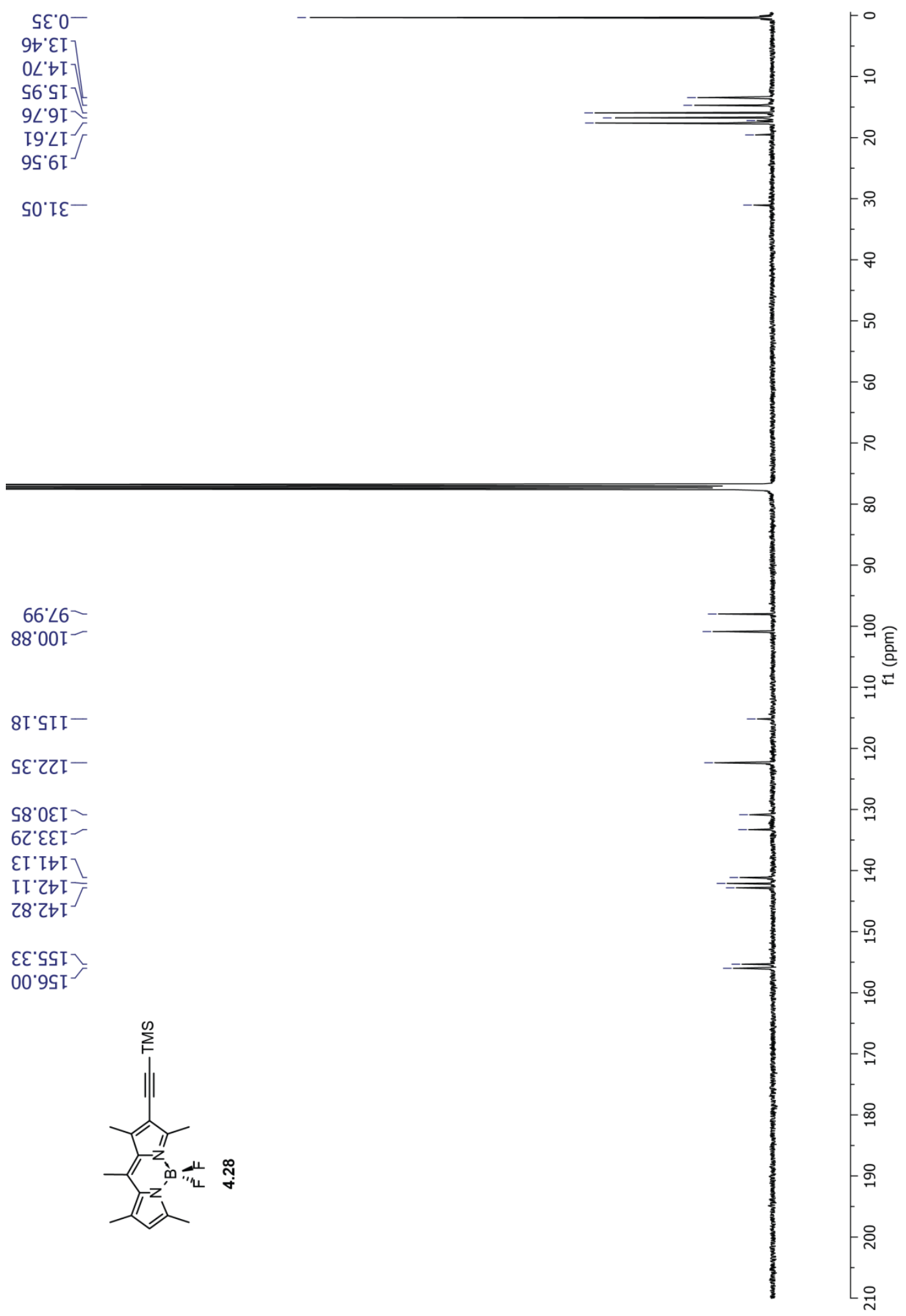

Figure A38. ${ }^{13} \mathrm{C}$ NMR spectrum of 4.28 in $\mathrm{CDCl}_{3}$ 
$\varepsilon t^{\prime} \cdot 2$
$t s^{\prime} 2$
$29 \cdot 25$
$59^{\circ} \cdot$

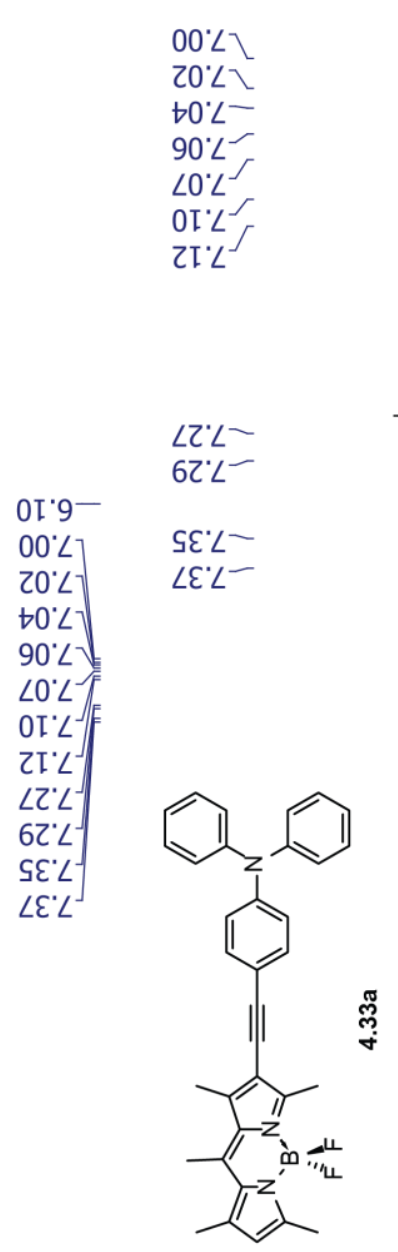

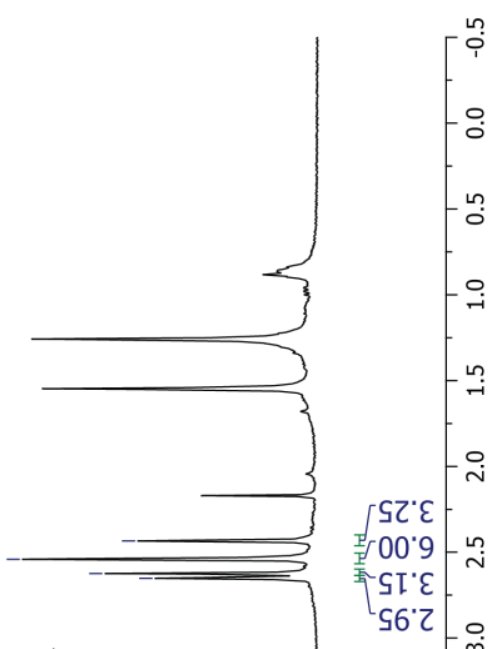
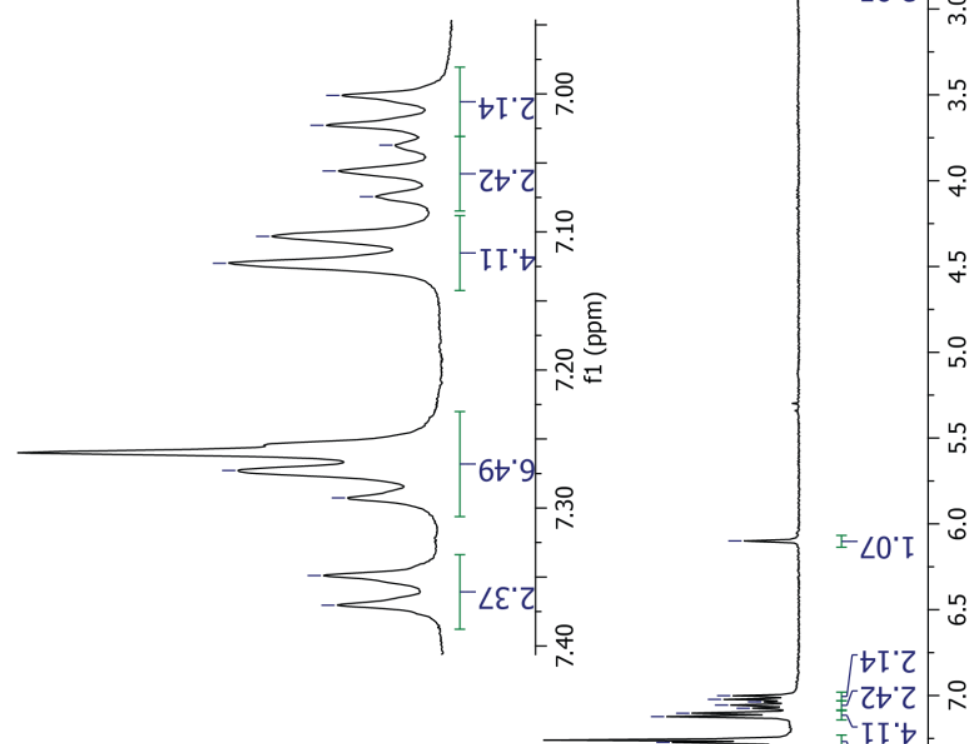

寊 $6 t^{\circ} \cdot 9$

$\angle \varepsilon^{\prime} 乙$

$\underset{\infty}{\infty}$

$\stackrel{\infty}{\infty}$

○ํ

- ำ

웅

눙

욱

Figure A39. ${ }^{1} \mathrm{H}$ NMR spectrum of $4.33 \mathrm{a}$ in $\mathrm{CDCl}_{3}$ 


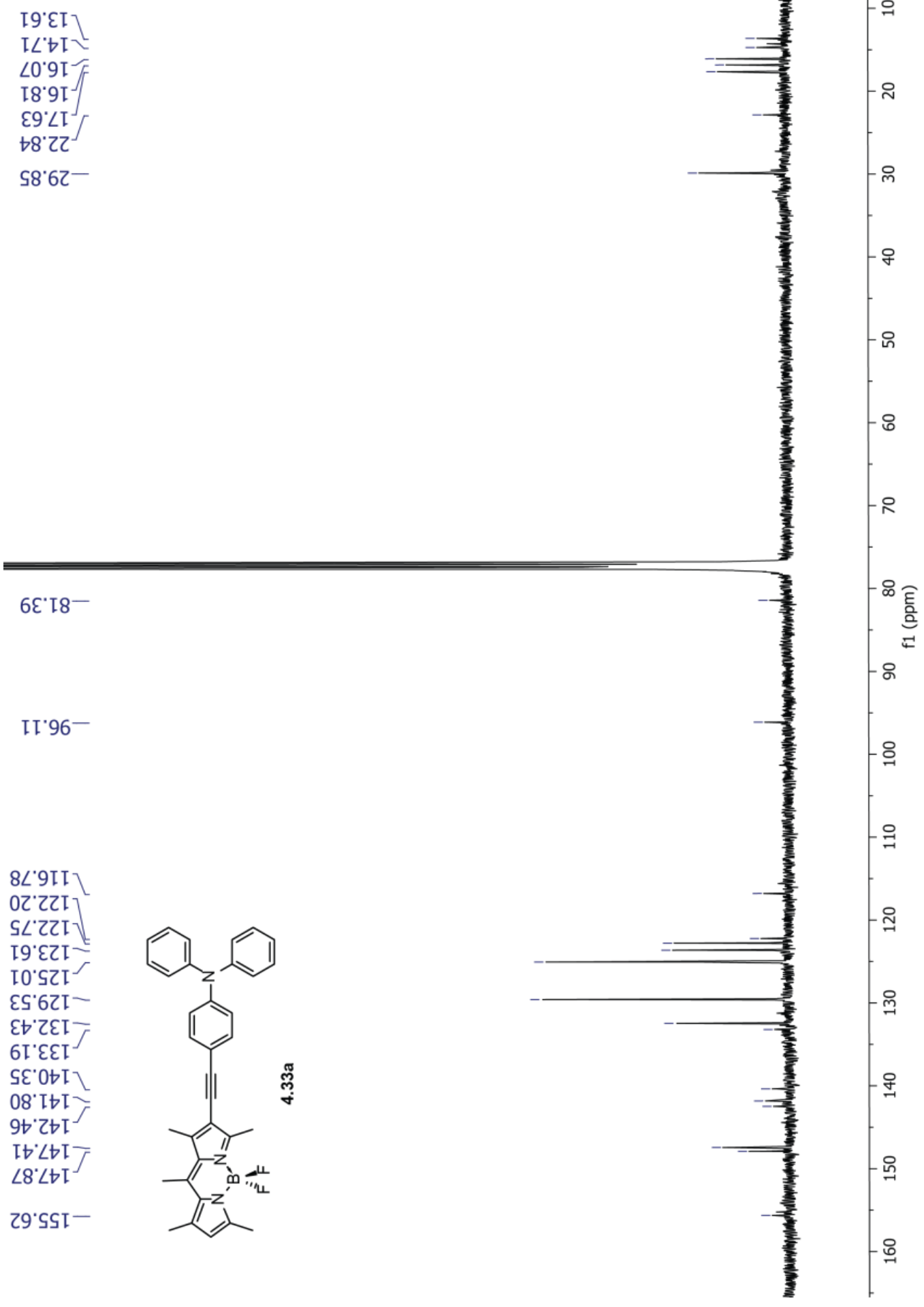

Figure A40. ${ }^{13} \mathrm{C}$ NMR spectrum of $4.33 \mathrm{a}$ in $\mathrm{CDCl}_{3}$ 


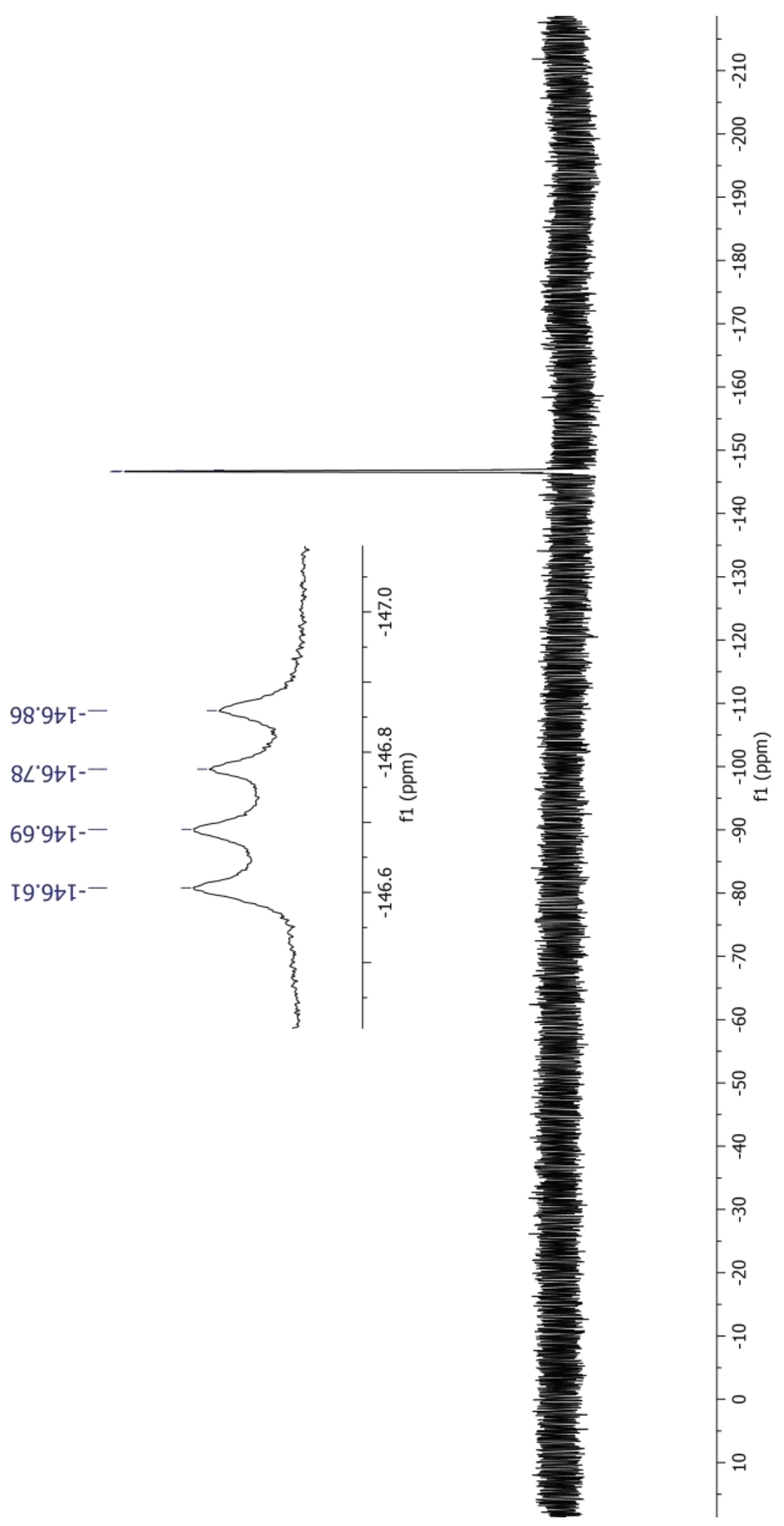

Figure A41. ${ }^{19} \mathrm{~F}$ NMR spectrum of 4.33a in $\mathrm{CDCl}_{3}$ 


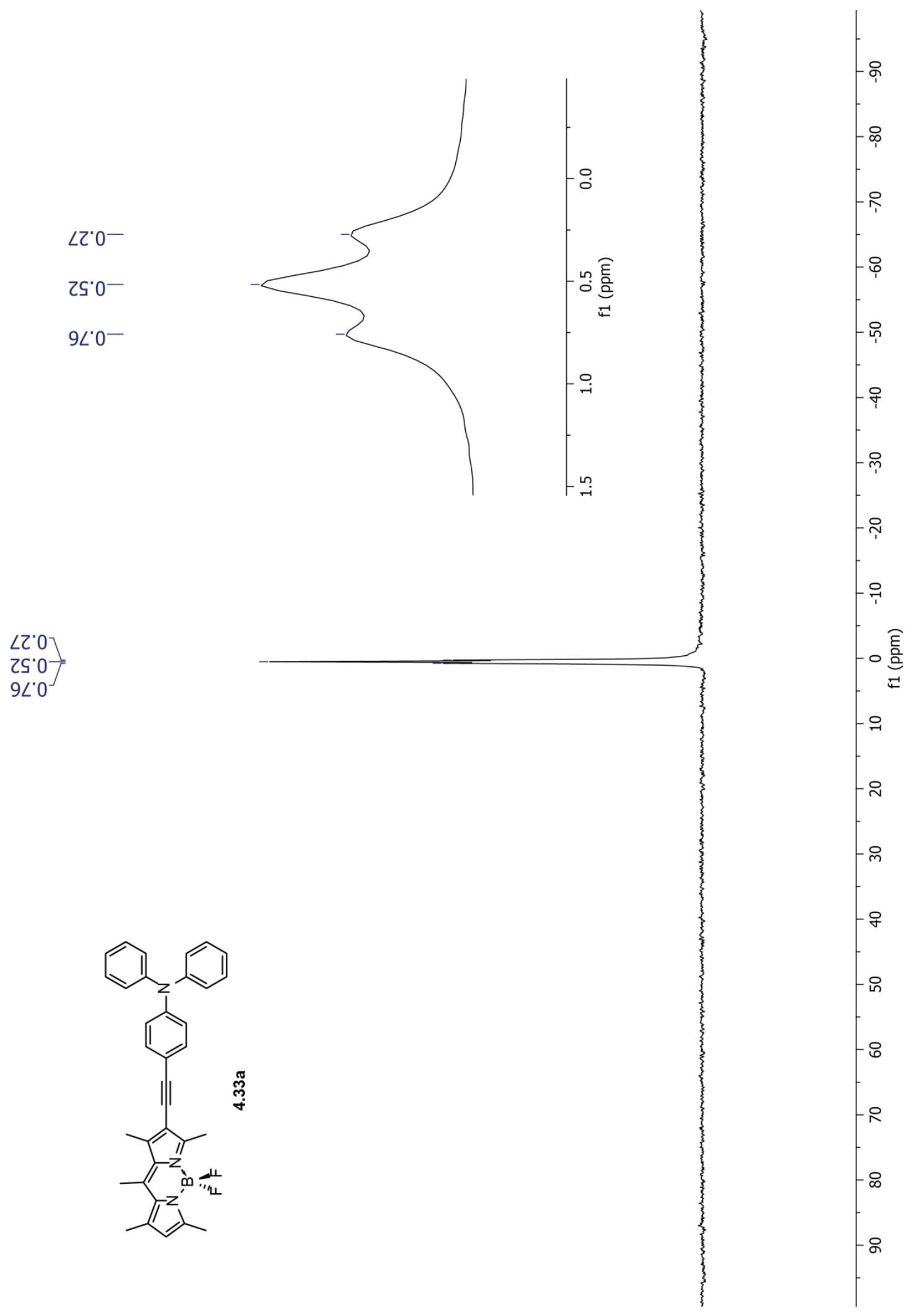

Figure A42. ${ }^{11} \mathrm{~B} N M R$ spectrum of $4.33 a$ in $\mathrm{CDCl}_{3}$ 


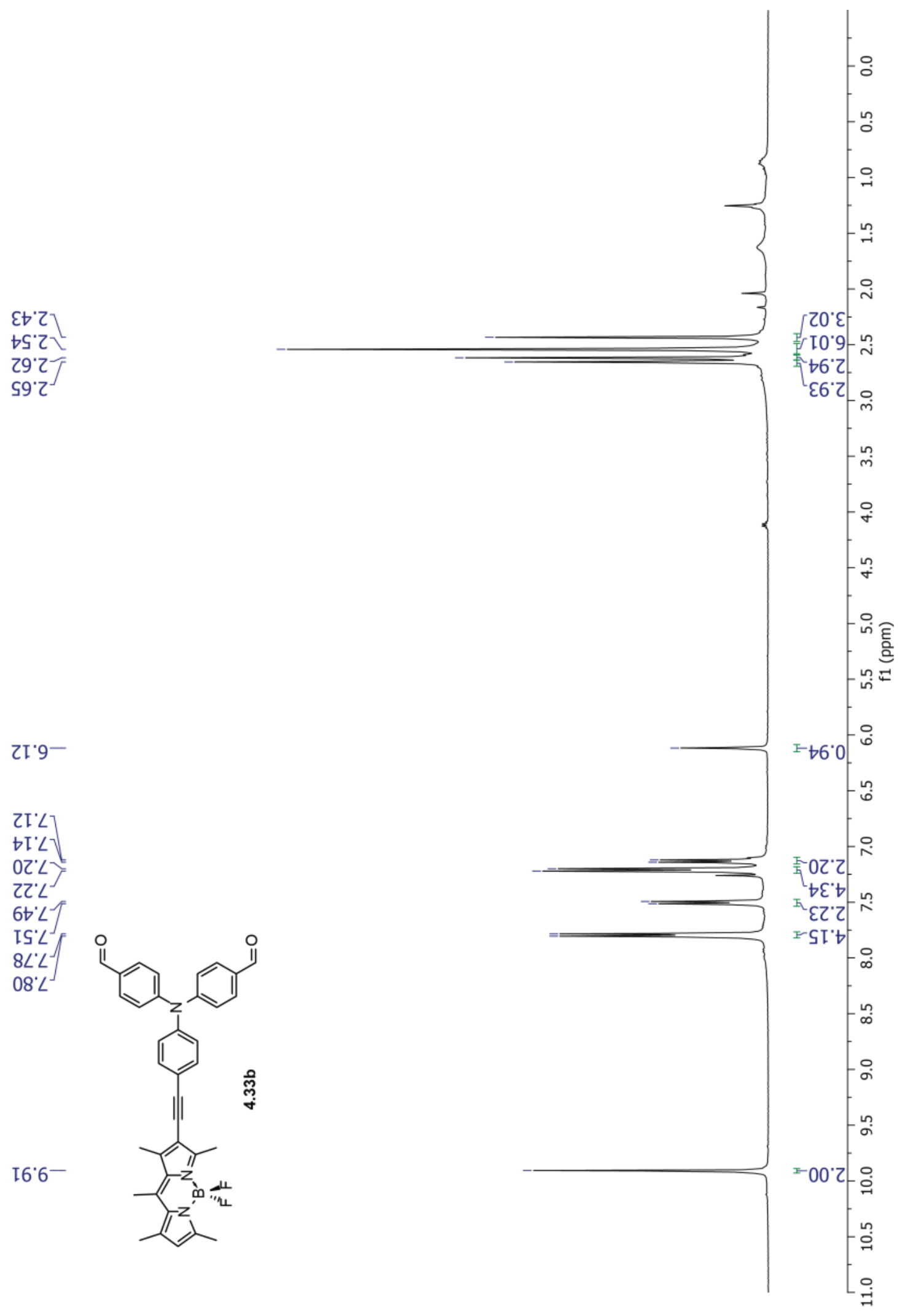

Figure A43. ${ }^{1} \mathrm{H}$ NMR spectrum of $4.33 \mathrm{~b}$ in $\mathrm{CDCl}_{3}$ 


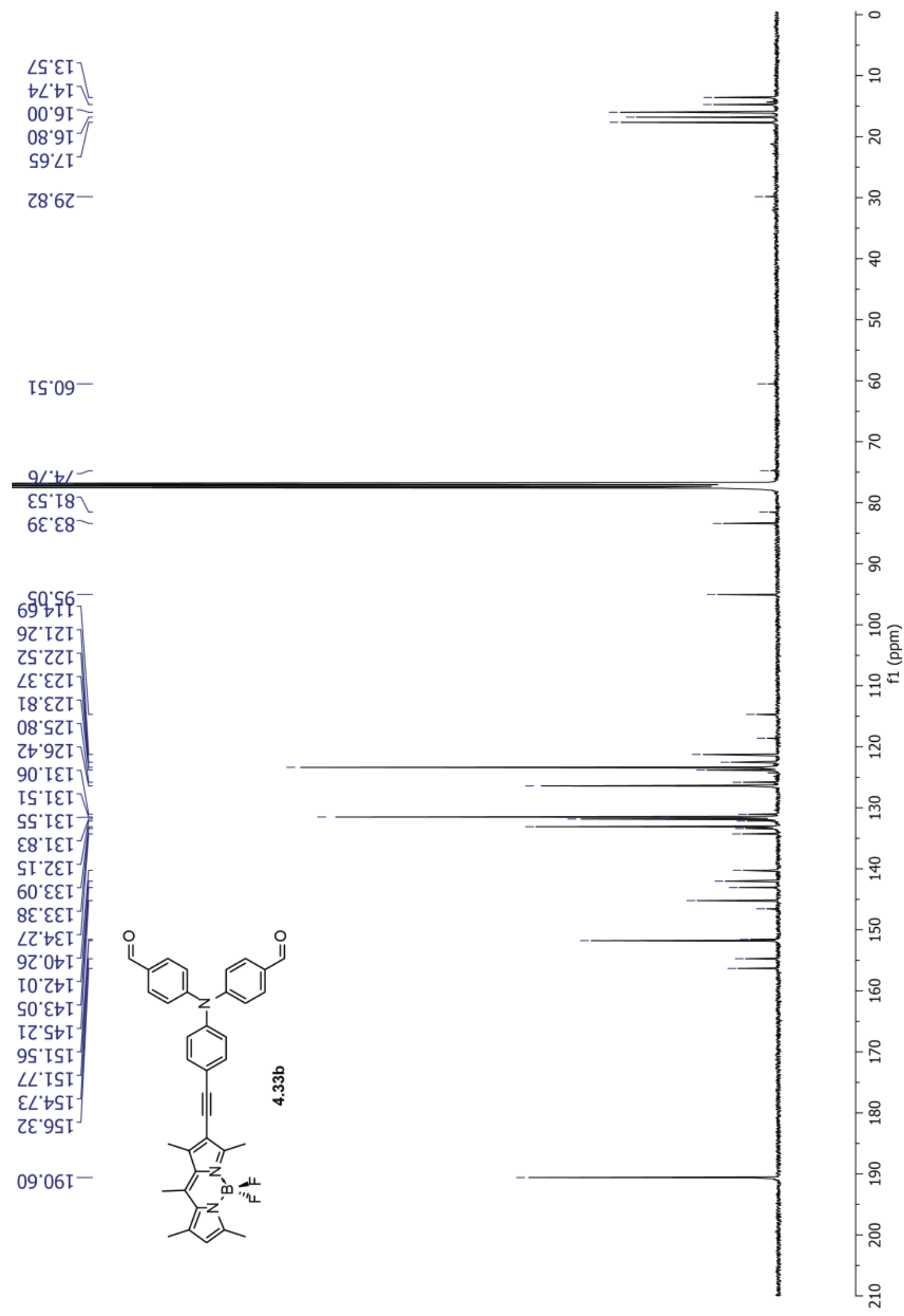

Figure A44. ${ }^{13} \mathrm{C}$ NMR spectrum of $4.33 \mathrm{~b}$ in $\mathrm{CDCl}_{3}$ 


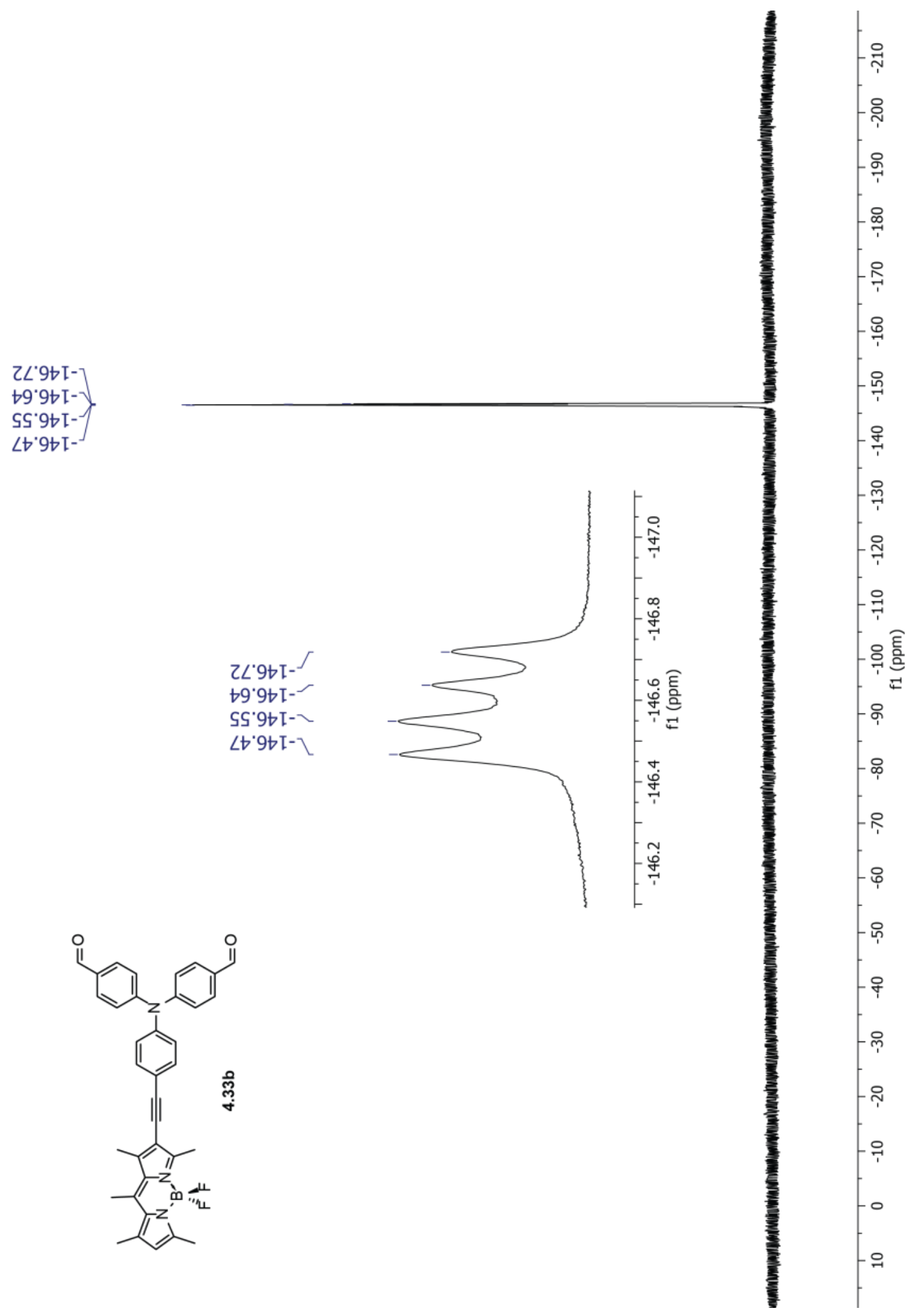

Figure A45. ${ }^{19} \mathrm{~F} \mathrm{NMR} \mathrm{spectrum} \mathrm{of} \mathrm{4.33b} \mathrm{in} \mathrm{CDCl}_{3}$ 


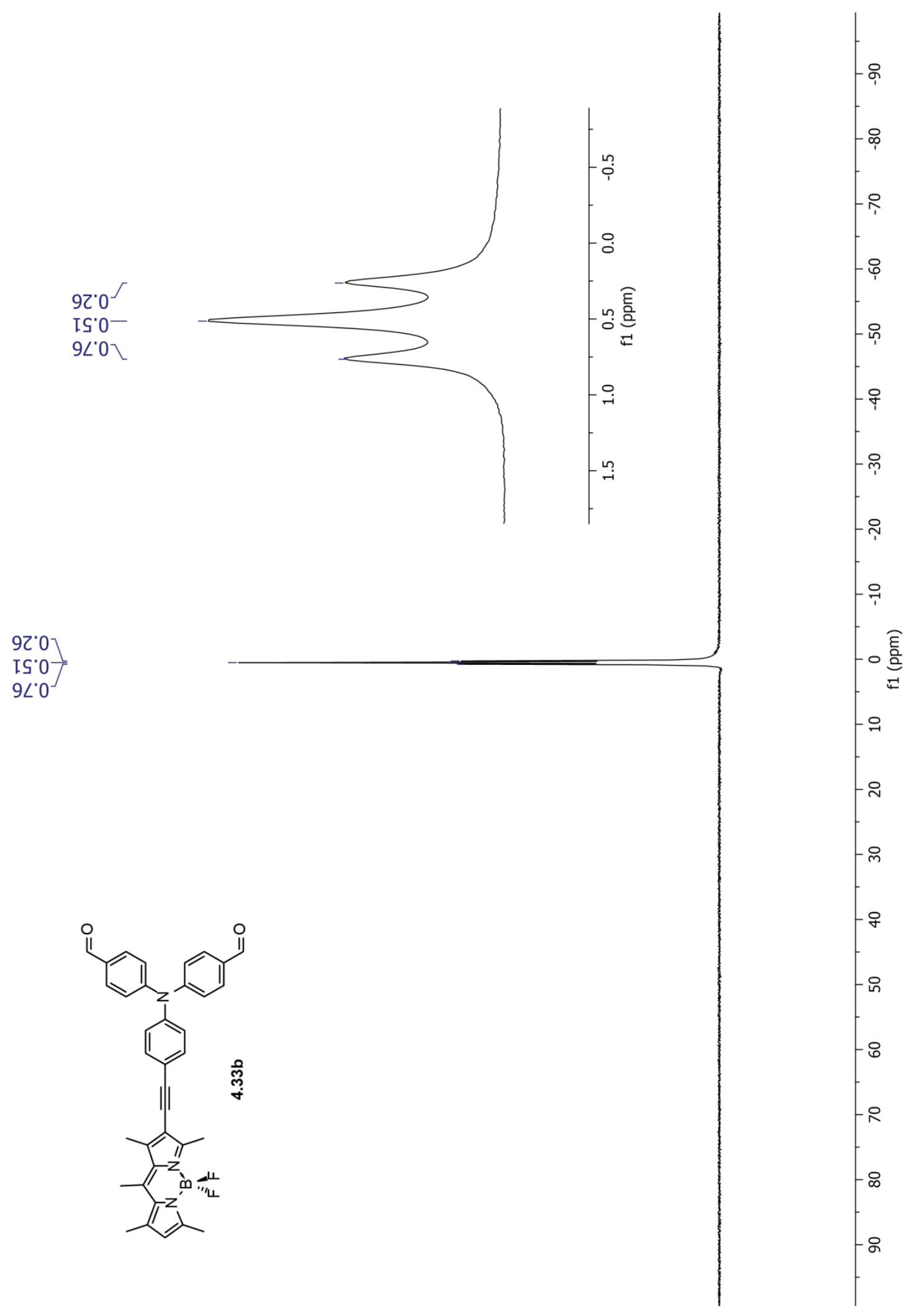

Figure A46. ${ }^{11} \mathrm{~B} N M R$ spectrum of $4.33 \mathrm{~b}$ in $\mathrm{CDCl}_{3}$ 


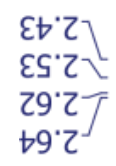

$08 \cdot \varepsilon-$

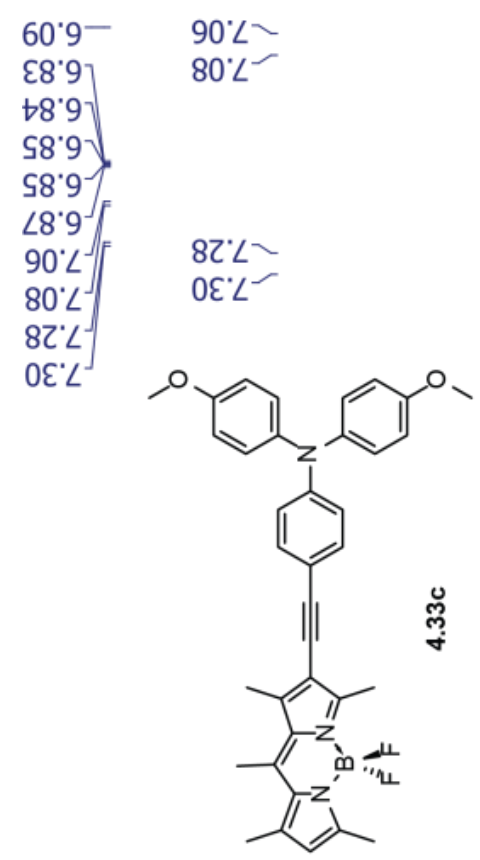

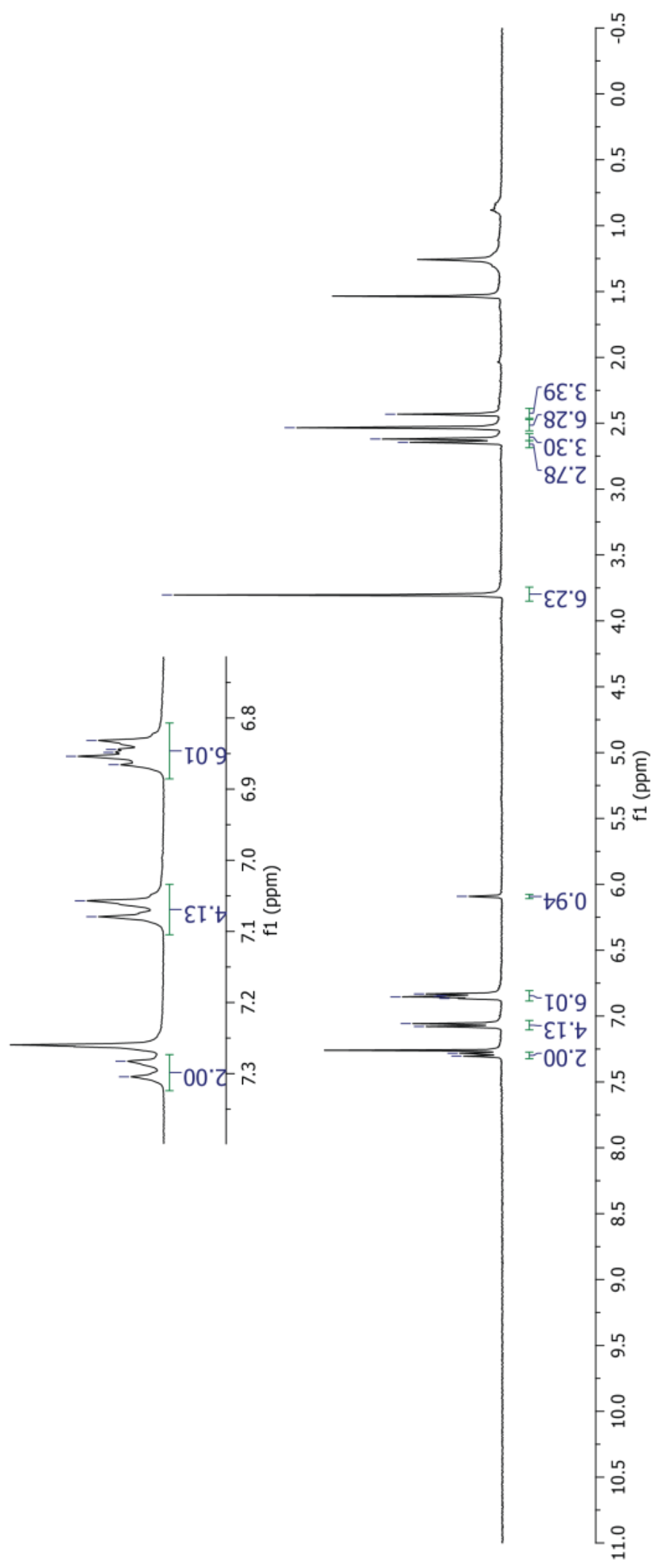

Figure A47. ${ }^{1} \mathrm{H}$ NMR spectrum of $4.33 \mathrm{c}$ in $\mathrm{CDCl}_{3}$ 


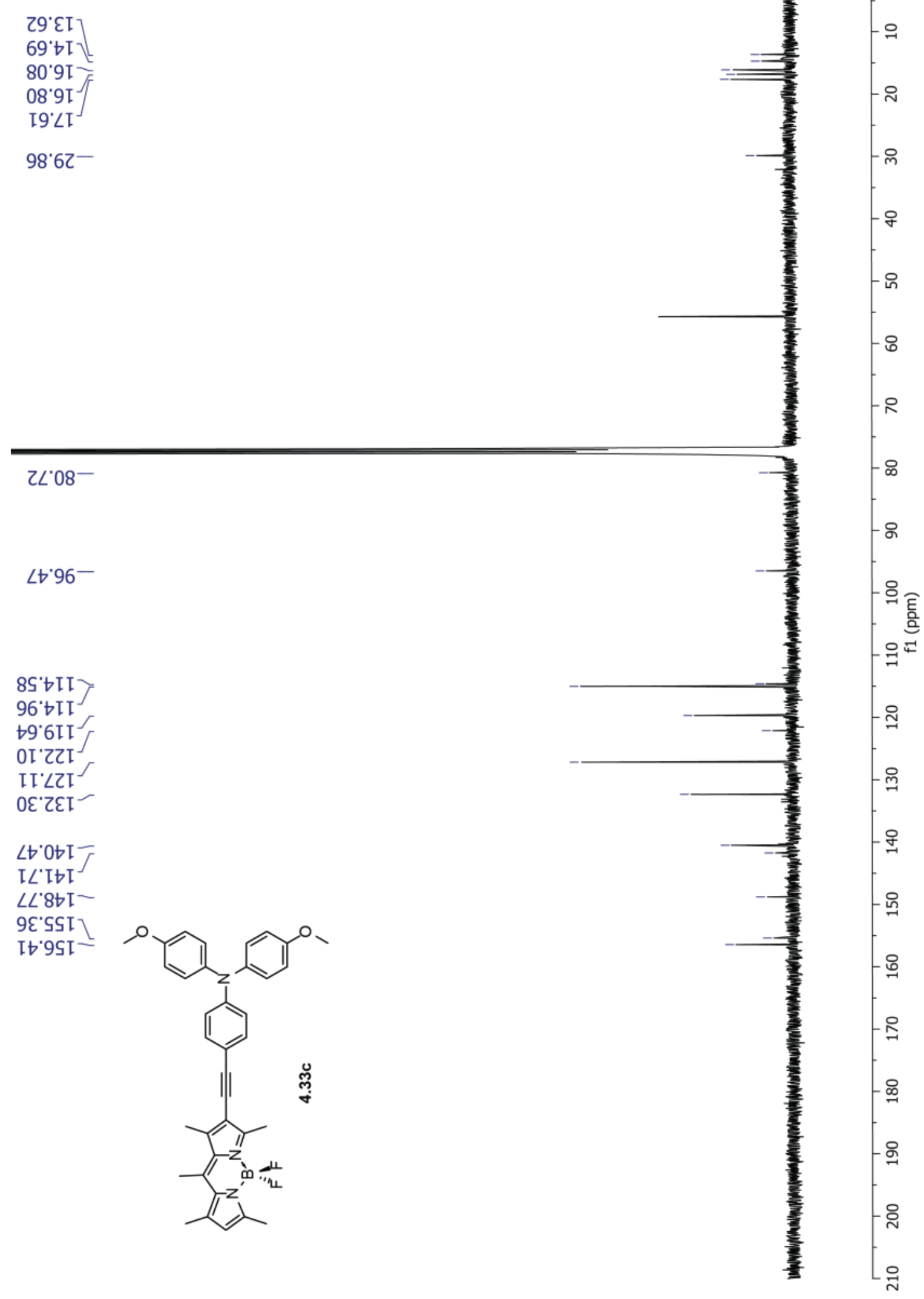

Figure A48. ${ }^{13} \mathrm{C}$ NMR spectrum of $4.33 \mathrm{c}$ in $\mathrm{CDCl}_{3}$ 

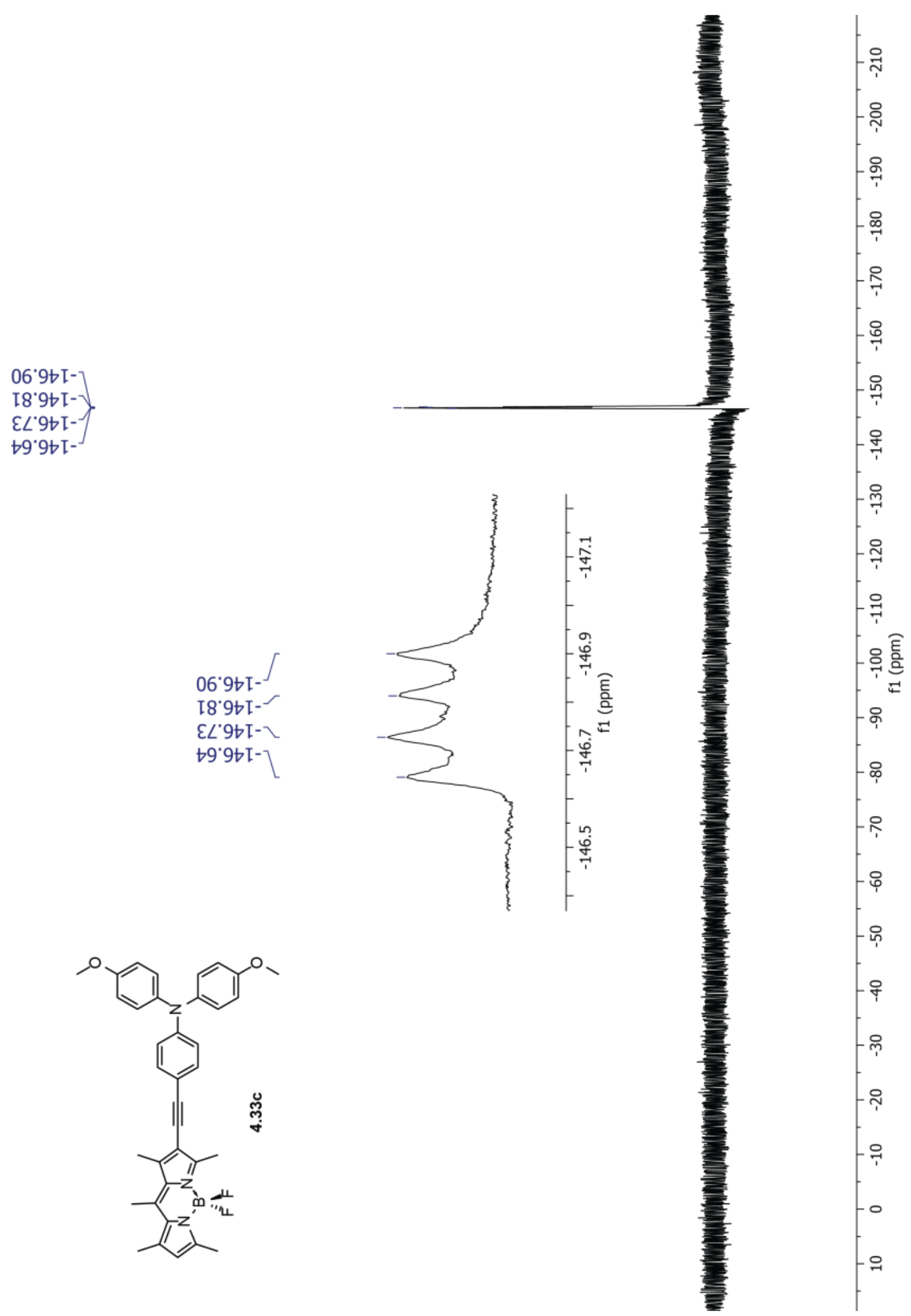

Figure A49. ${ }^{19} \mathrm{~F}$ NMR spectrum of $4.33 \mathrm{c}$ in $\mathrm{CDCl}_{3}$ 


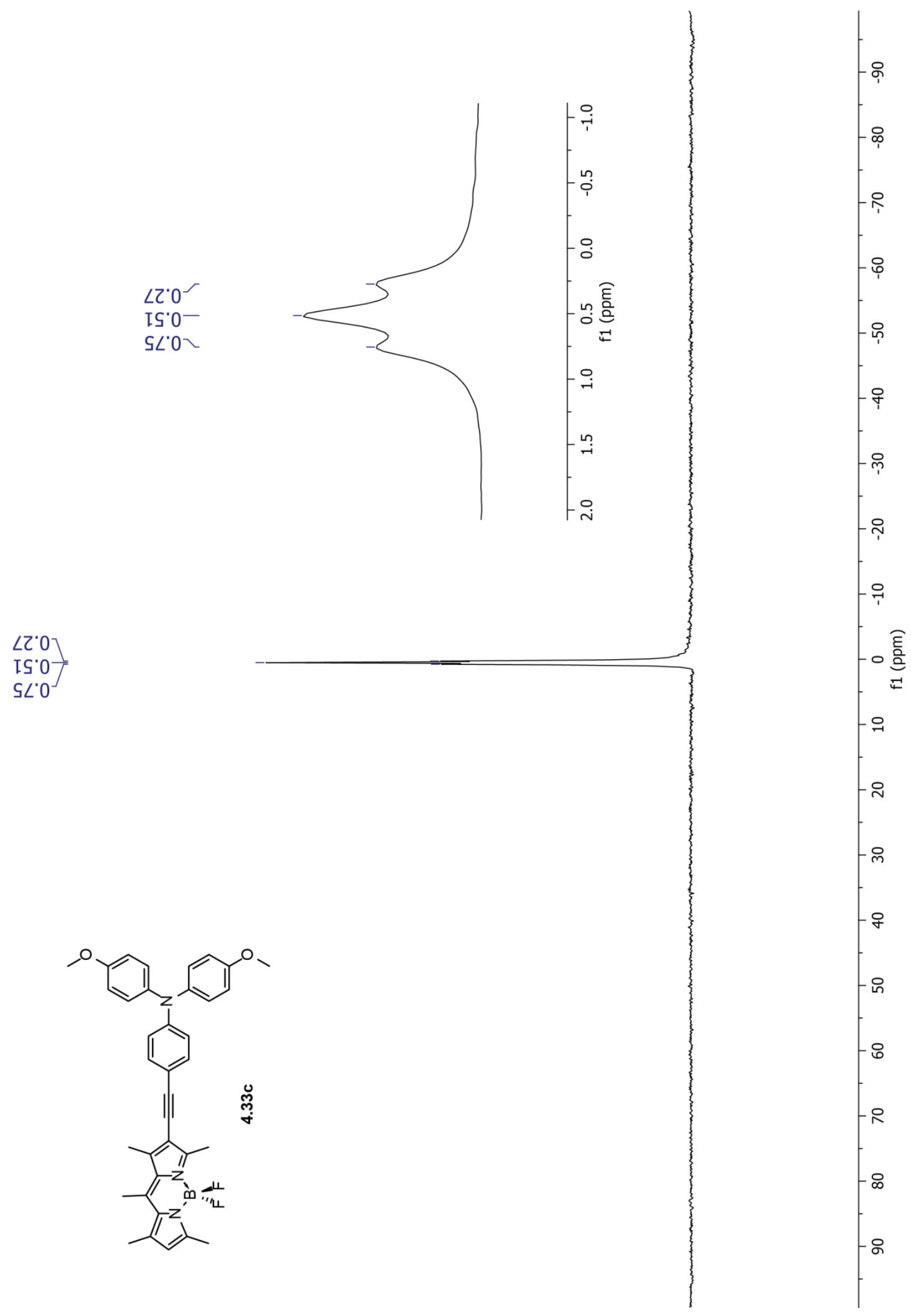

Figure A50. ${ }^{11} \mathrm{~B}$ NMR spectrum of $4.33 \mathrm{c}$ in $\mathrm{CDCl}_{3}$ 


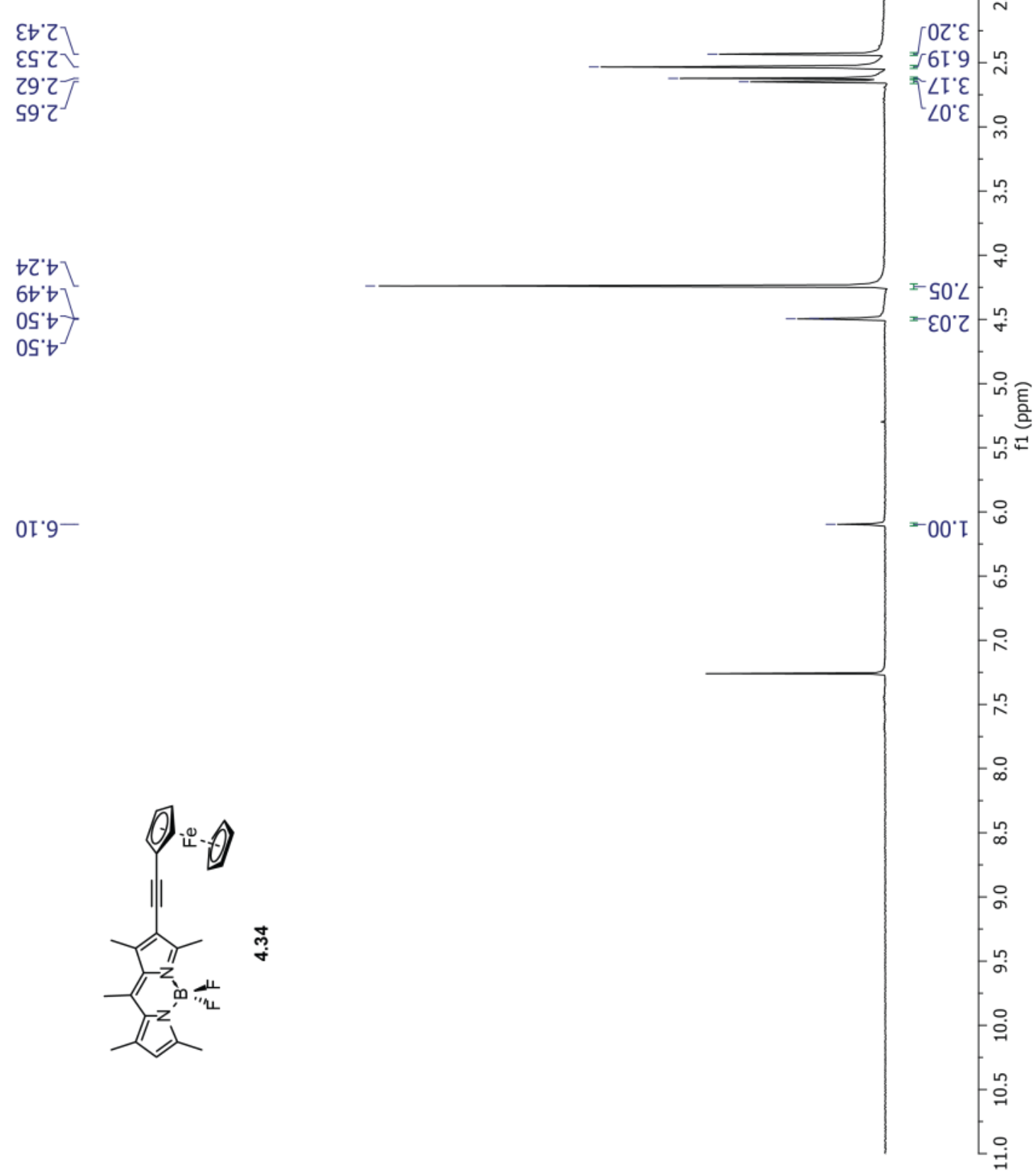

Figure A51. ${ }^{1} \mathrm{H}$ NMR spectrum of 4.34 in $\mathrm{CDCl}_{3}$ 


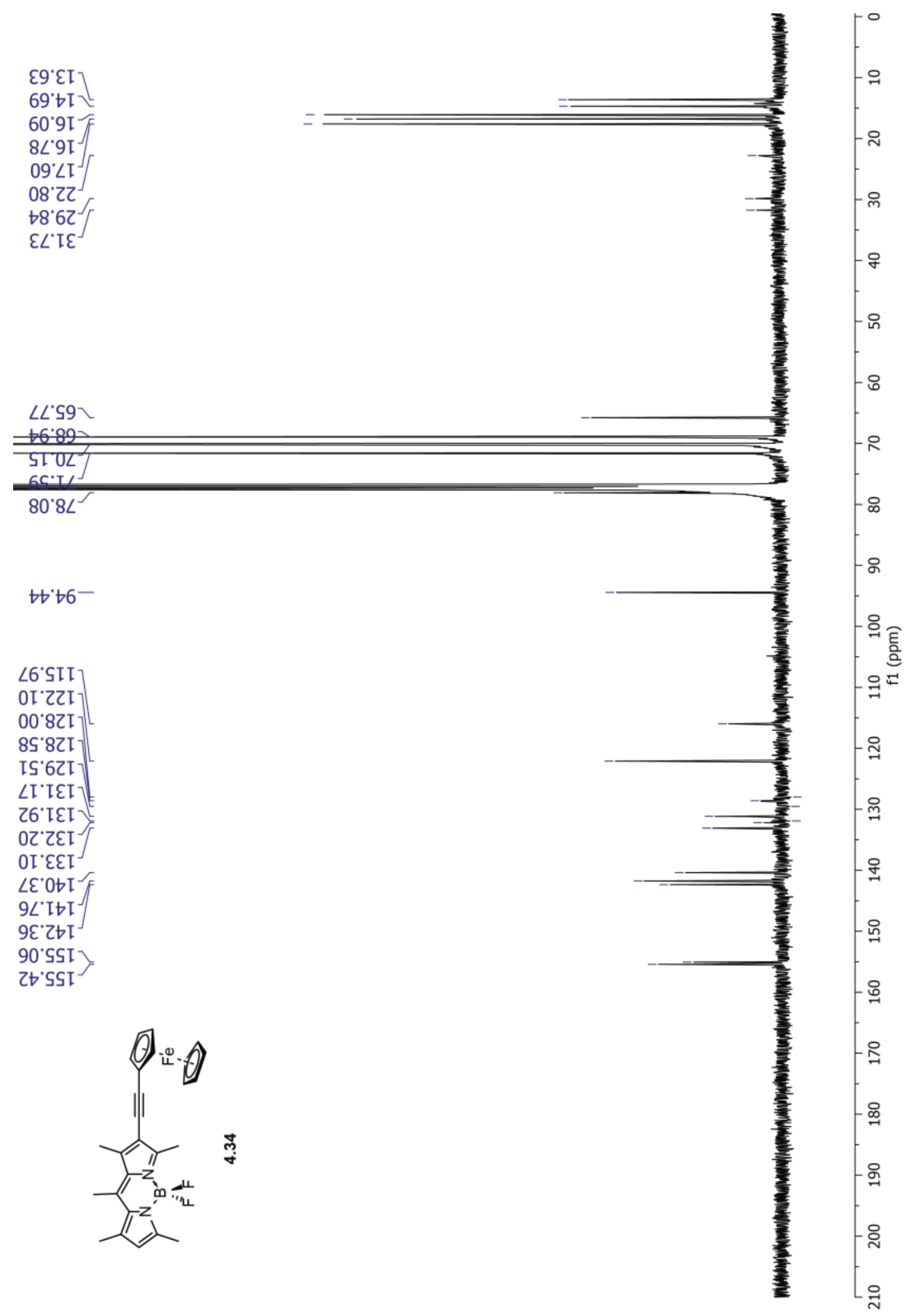

Figure A52. ${ }^{13} \mathrm{C}$ NMR spectrum of 4.34 in $\mathrm{CDCl}_{3}$ 


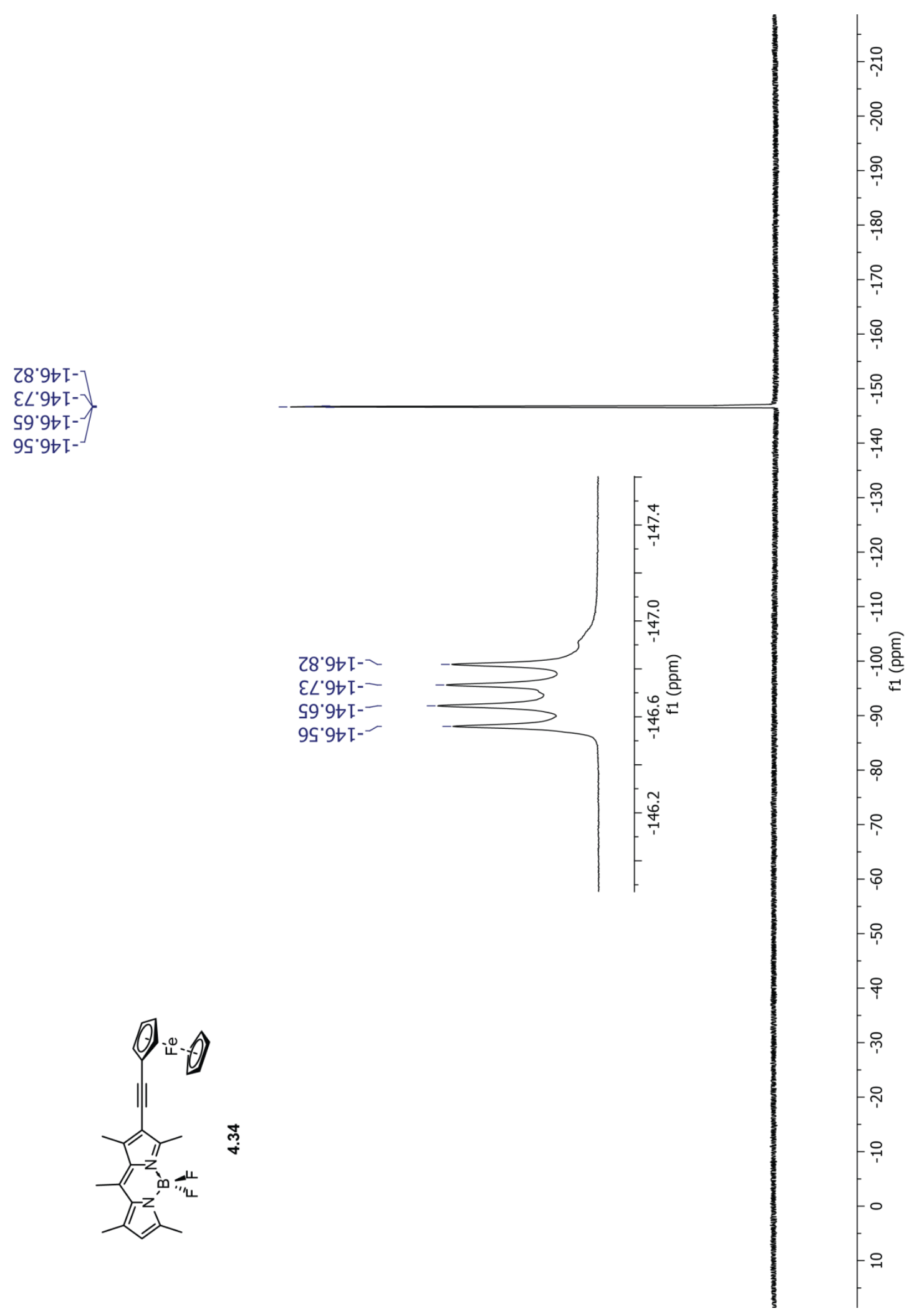

Figure A53. ${ }^{19} \mathrm{~F}$ NMR spectrum of 4.34 in $\mathrm{CDCl}_{3}$ 


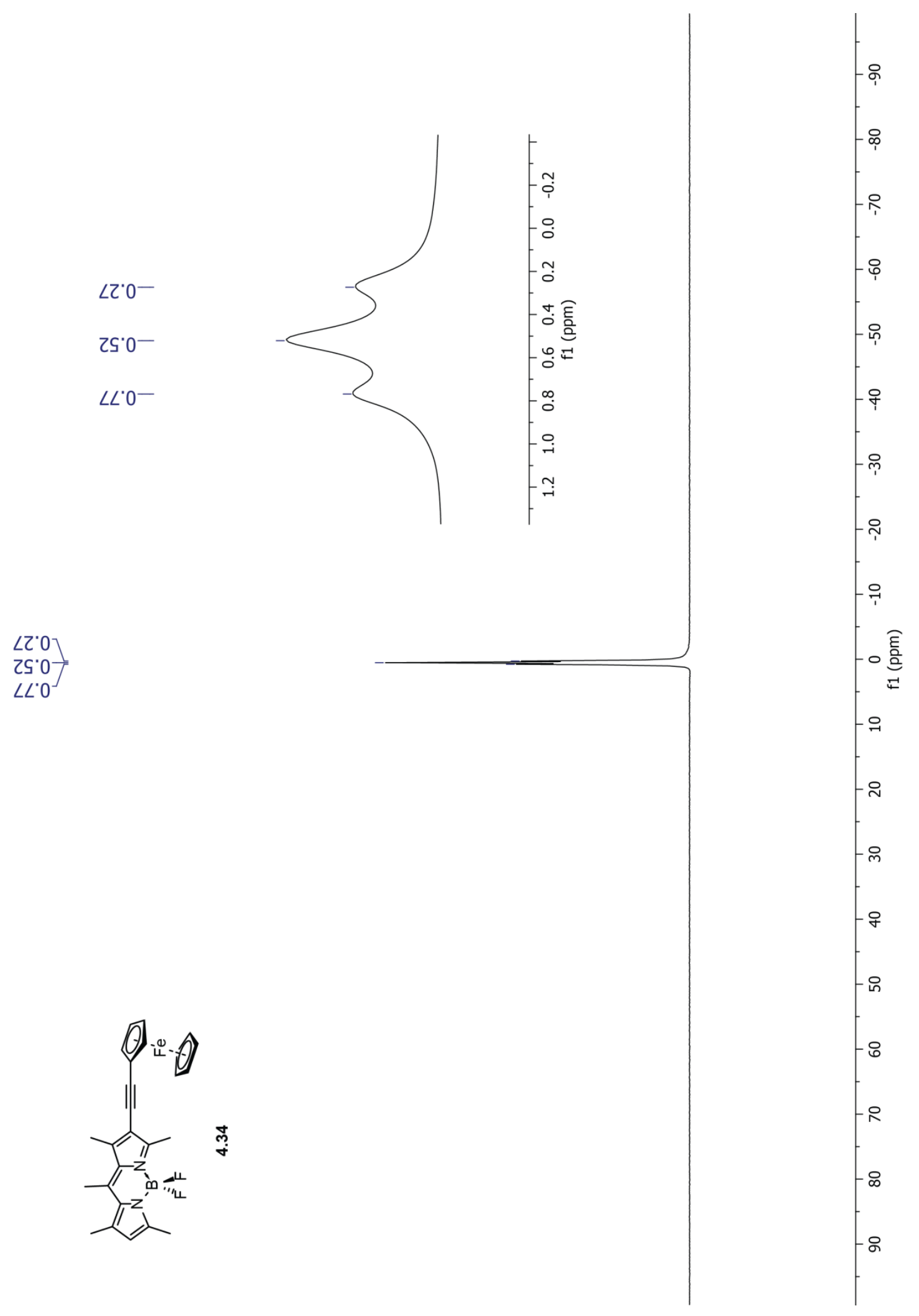

Figure A54. ${ }^{11} \mathrm{~B}$ NMR spectrum of 4.34 in $\mathrm{CDCl}_{3}$ 


\section{REFERENCES}

(1) Lewis, N. S. MRS Bull. 2007, 32, 808.

(2) Hoffert, M. I.; Caldeira, K.; Jain, A. K.; Haites, E. F.; Harvey, L. D. D.; Potter, S. D.;

Schlesinger, M. E.; Schneider, S. H.; Watts, R. G.; Wigley, T. M. L.; Wuebbles, D. J. Nature 1998, 395, 881.

(3) Reddy, K. G.; Deepak, T. G.; Anjusree, G. S.; Thomas, S.; Vadukumpully, S.; Subramanian, K. R. V; Nair, S. V; Nair, a S. Phys. Chem. Chem. Phys. 2014, 16, 6838.

(4) O’Regan, B.; Grätzel, M. Nature 1991, 353, 737.

(5) Zhang XD Numata, YH Han, LY, S. F. Y. Energy Environ. Sci. 2013, 6, 1464.

(6) Hagfeldt, A.; Boschloo, G.; Sun, L.; Kloo, L.; Pettersson, H. Chem. Rev. 2010, 110, 6595.

(7) Mishra, A.; Fischer, M. K. R.; Büuerle, P. Angew. Chemie - Int. Ed. 2009, 48, 2474.

(8) Bozic-Weber, B.; Constable, E. C.; Housecroft, C. E. Coord. Chem. Rev. 2013, 257, 3089.

(9) Nazeeruddin, M. K.; Grätzel, M. Struct. Bond. 2007, 123, 113.

(10) Amadelli, R.; Argazzi, R.; Bignozzi, C. a; Scandola, F. J. Am. Chem. Soc. 1990, 112, 7099.

(11) Nazeeruddin, M. K.; Kay, a; Miiller, E.; Liska, P.; Vlachopoulos, N.; Gratzel, M.; Lausanne, C.-; April, R. J. Am. Chem. Soc. 1993, 115, 6382.

(12) Nazeeruddin, M. K.; Péchy, P.; Renouard, T.; Zakeeruddin, S. M.; Humphry-Baker, R.; Cointe, P.; Liska, P.; Cevey, L.; Costa, E.; Shklover, V.; Spiccia, L.; Deacon, G. B.; Bignozzi, C. A.; Grätzel, M. J. Am. Chem. Soc. 2001, 123, 1613.

(13) Lenzmann, F. O.; Kroon, J. M. Adv. Optoelectron. 2007, 2007.

(14) Shalini, S.; Balasundaraprabhu, R.; Kumar, T. S.; Prabavathy, N.; Senthilarasu, S.;

Prasanna, S. Int. J. Energy Res. 2016, 40, 1303.

(15) Grätzel, M. Chem. Lett. 2005, 34, 8.

(16) Chen, C.; Wang, M.; Li, J.; Pootrakulchote, N.; Alibabaei, L.; Decoppet, J.; Tsai, J.; Gra, C.; Wu, C.; Zakeeruddin, S. M.; Gra, M. ACS Nano 2009, 3, 3103.

(17) Chen, C. Y.; Wang, M.; Li, J. Y.; Pootrakulchote, N.; Alibabaei, L.; Ngoc-Le, C. H.; Decoppet, J. D.; Tsai, J. H.; Grätzel, C.; Wu, C. G.; Zakeeruddin, S. M.; Grätzel, M. ACS Nano 2009, 3, 3103.

(18) Yu, Q.; Wang, Y.; Yi, Z.; Zu, N.; Zhang, J.; Zhang, M.; Wang, P. ACS Nano 2010, 4, 6032.

(19) Ozawa, H.; Sugiura, T.; Kuroda, T.; Nozawa, K.; Arakawa, H. J. Mater. Chem. A 2016, 4, 1762.

(20) Hagberg, D. P.; Marinado, T.; Karlsson, K. M.; Nonomura, K.; Quin, P.; Boschloo, G. J. Org. Chem. 2007, 72, 9550. 
(21) Hagberg, D. P.; Yum, J.; Lee, H.; Angelis, F. De; Marinado, T.; Karlsson, K. M.; Humphrybaker, R.; Sun, L.; Hagfeldt, A.; Grätzel, M.; Nazeeruddin, K. J. Am. Chem. Soc. 2008, 130, 6259.

(22) Mathew, S.; Yella, A.; Gao, P.; Humphry-Baker, R.; Curchod, B. F. E.; Ashari-Astani, N.; Tavernelli, I.; Rothlisberger, U.; Nazeeruddin, M. K.; Gratzel, M. Nat. Chem. 2014, 6, 242.

(23) Panda, M. K.; Ladomenou, K.; Coutsolelos, A. G. Coord. Chem. Rev. 2012, 256, 2601.

(24) Higashino, T.; Imahori, H. 2015, 448.

(25) Karolin, J.; Johansson, L. B. a; Strandberg, L.; Ny, T. J. Am. Chem. Soc. 1994, 116, 7801.

(26) Hattori, S.; Ohkubo, K.; Urano, Y.; Sunahara, H.; Nagano, T.; Wada, Y.; Tkachenko, N. V.; Lemmetyinen, H.; Fukuzumi, S. J. Phys. Chem. B 2005, 109, 15368.

(27) Bonnier, C.; Machin, D. D.; Abdi, O.; Koivisto, B. D. Org. Biomol. Chem. 2013, 11, 3756.

(28) Yella, A.; Lee, H.-W.; Tsao, H. N.; Yi, C.; Chandiran, A. K.; Nazeeruddin, M. K.; Diau, E. W.G.; Yeh, C.-Y.; Zakeeruddin, S. M.; Gratzel, M. Science. 2011, 334, 629.

(29) Magni, M.; Biagini, P.; Colombo, A.; Dragonetti, C.; Roberto, D.; Valore, A. Coord. Chem. Rev. 2016, 322, 69.

(30) Gothard, N. A.; Mara, M. W.; Huang, J.; Szarko, J. M.; Rolczynski, B.; Lockard, J. V; Chen, L. X. J. Phys. Chem. A 2012, 116, 1984.

(31) Sandroni, M.; Pellegrin, Y.; Odobel, F. Comptes Rendus Chim. 2016, 19, 79.

(32) Bessho, T.; Constable, E. C.; Graetzel, M.; Redondo, A. H.; Housecroft, C. E.; Kylberg, W.; Nazeeruddin, K.; Neuburger, M.; Schaffner, S. Chem. Commun. 2008, 3717.

(33) Wills, K. A.; Mandujano-Ramírez, H. J.; Merino, G.; Mattia, D.; Hewat, T.; Robertson, N.; Oskam, G.; Jones, M. D.; Lewis, S. E.; Cameron, P. J. RSC Adv. 2013, 3, 23361.

(34) Sandroni, M.; Kayanuma, M.; Planchat, A.; Szuwarski, N.; Blart, E.; Pellegrin, Y.; Daniel, C.; Boujtita, M.; Odobel, F. Dalton Trans. 2013, 42, 10818.

(35) Hewat, T. E.; Yellowlees, L. J.; Robertson, N. Dalton Trans. 2014, 43, 4127.

(36) Schmittel, M.; Lüning, U.; Meder, M.; Ganz, A.; Michel, C.; Herderich, M. Heterocycl. Commun. 1997, 3, 493.

(37) Fraser, M. G.; Salm, H. van der; Cameron, S. A.; Blackman, A. G.; Gordon, K. C. Inorg. Chem. 2013, 52, 2980.

(38) Bozic-Weber, B.; Brauchli, S. Y.; Constable, E. C.; Fürer, S. O.; Housecroft, C. E.; Wright, I. a. Phys. Chem. Chem. Phys. 2013, 15, 4500.

(39) Péchy, P.; Rotzinger, F. P.; Nazeeruddin, M. K.; Kohle, O.; Zakeeruddin, S. M.; Humphrybaker, R.; Grätzel, M. J. Chem. Soc. Chem. Commun. 1995, 65.

(40) Malzner, F. J.; Brauchli, S. Y.; Constable, E. C.; Housecroft, C. E.; Neuburger, M. RSC Adv. 2014, 4, 48712. 
(41) Sandroni, M.; Favereau, L.; Planchat, A.; Akdas-Kilig, H.; Szuwarski, N.; Pellegrin, Y.; Blart, E.; Le Bozec, H.; Boujtita, M.; Odobel, F. J. Mater. Chem. A 2014, 2, 9944.

(42) Butt, G.; Topsom, R. D. J. Heterocycl. Chem. 1981, 18, 641.

(43) Lund, G. K.; Holt, S. L. J. Chem. Eng. Data 1981, 26, 227.

(44) Dietrick-Buchecker, C. O.; Marnot, P. A.; Sauvage, J. P. Tetrahedron Lett. 1982, 23, 5291.

(45) Higashi, T.; Inami, K.; Mochizuki, M. J. Heterocycl. Chem. 2008, 45, 1889.

(46) Lazzari, P.; Zanda, M.; Sani, M. Preparation of propandiylbisphenyldihydrothienocyclopen tapyrazolcarboxamide derivatives and analogs for use as antiangiogenic agents. Eur. Pat. Appl. EP 2789619 A1, 2014.

(47) Cashman, J. R.; Ghirmai, S. Bioorg. Med. Chem. 2009, 17, 6890.

(48) Zhang, W.; Dai, L.; Cai, Fei, L.; Zhao, H. One-step synthetic method of symmetrical 1,10phenanthroline derivatives. PCT Int. Appl. CN 200910083629 A1, 2009.

(49) Lebedev, M. V; Nenajdenko, V. G.; Balenkova, E. S. Synthesis (Stuttg). 1998, 89.

(50) Astruc, D.; Ruiz, J. J. Inorg. Organomet. Polym. Mater. 2015, 25, 330.

(51) Ferrere, S.; Gregg, B. A. J. Am. Chem. Soc. 1998, 120, 843.

(52) Chauhan, R.; Trivedi, M.; Bahadur, L.; Kumar, A. Chem. Asian. J. 2011, 6, 1525.

(53) Chen, S.; Chen, W.; Shi, W.; Ma, H. Chem. Eur. J. 2012, 18, 925.

(54) Yin, X.; Li, Y.; Zhu, Y.; Jing, X.; Li, Y.; Zhu, D. Dalton Trans. 2010, 39, 9929.

(55) Wu, X.; Wu, W.; Cui, X.; Zhao, J.; Wu, M. J. Mater. Chem. C 2016, 4, 2843.

(56) Kaur, N.; Van Steerteghem, N.; Singla, P.; Kaur, P.; Clays, K.; Singh, K. Dalt. Trans. 2017, 1124.

(57) Chu, G. M.; Guerrero-Martínez, A.; Ramírez de Arellano, C.; Fernández, I. Inorg. Chem. 2016, 55, 2737.

(58) Zatsikha, Y. V.; Maligaspe, E.; Purchel, A. A.; Didukh, N. O.; Wang, Y.; Kovtun, Y. P.; Blank, D. A.; Nemykin, V. N. Inorg. Chem. 2015, 54, 7915.

(59) Zatsikha, Y. V; Didukh, N. O.; Nemez, D.; Schlachter, A. C.; Karsenti, P.; Kovtun, Y. P.; Harvey, D.; Nemykin, V. N. Chem. Commun. 2017, 53, 7612.

(60) Zatsikha, Y. V; Didukh, N. O.; Blesener, T.; Kayser, M. P.; Kovtun, Y. P.; Blank, D. A.; Nemykin, V. N. Eur. J. Inorg. Chem. 2017, 318.

(61) Höfler, S.; Scheja, A.; Wolfram, B.; Bröring, M. Z. Anorg. Allg. Chem. 2016, 642, 107.

(62) Sritharan, S. R.; Hussein, B. A.; Machin, D. D.; Adjei, J. A.; Singh, J. K.; Pau, J. T. H.; Dhindsa, J. S.; Lough, A. J.; Koivisto, B. D. RSC Adv. 2017, 7, 8922.

(63) Yousaf, M. SUPRAMOLECULAR BODIPY DYE ARCHITECTURES FOR ADVANCED LIGHT- 
HARVESTING AND ENERGY TRANSFER APPLICATIONS, Ryerson University, 2016.

(64) Dyadchenko, V. P.; Dyadchenko, M. A.; Okulov, V. N.; Lemenovskii, D. A. J. Organomet. Chem. 2011, 696, 468.

(65) Hussein, B. A. TOWARDS NOVEL BODIPY COMPOUNDS FOR MATERIAL \& MEDICAL APPLICATIONS, Ryerson University, 2017.

(66) Summers, G. H.; Lefebvre, J.-F.; Black, F. A.; Stephen Davies, E.; Gibson, E. A.; Pullerits, T.; Wood, C. J.; Zidek, K. Phys. Chem. Chem. Phys. 2016, 18, 1059.

(67) Lager, E.; Liu, J.; Tang, B. Z. J. Org. Chem. 2009, 74, 2053.

(68) Wang, J. B.; Fang, X. Q.; Pan, X.; Dai, S. Y.; Song, Q. H. Chem. Asian. J. 2012, 7, 696.

(69) Benniston, A. C.; Copley, G.; Elliott, K. J.; Harrington, R. W.; Clegg, W. European J. Org. Chem. 2008, 2705.

(70) Duvva, N.; Sudhakar, K.; Badgurjar, D.; Chitta, R.; Giribabu, L. J. Photochem. Photobiol. A Chem. 2015, 312, 8.

(71) Mirri, G.; Schoenmakers, D. C.; Kouwer, P. H. J.; Veranič, P.; Muševič, I.; Štefane, B. ChemistryOpen 2016, 5, 450.

(72) Lin, H.; Huang, W.; Chen, Y.; Chou, H.; Hsu, C. Chem. Commun. 2012, 48, 8913.

(73) Li, Z.; Ye, T.; Tang, S.; Wang, C.; Ma, D.; Li, Z. J. Mater. Chem. C 2015, 3, 2016.

(74) Dei, D. K.; Lund, B. R.; Wu, J.; Simon, D.; Ware, T.; Voit, W. E.; Macfarlane, D.; Li, S. M.; Smith, D. W. ACS Macro Lett. 2013, 2, 35.

(75) Yamaguchi, Y.; Ochi, T.; Matsubara, Y.; Yoshida, Z. J. Phys. Chem. A 2015, 119, 8630.

(76) Huang, D.; Zhao, J.; Wu, W.; Yi, X.; Yang, P.; Ma, J. Asian J. Org. Chem. 2012, 1, 264.

(77) Kaim, W.; Fiedler, J. Chem. Soc. Rev. 2009, 3373.

(78) Yen, H.-J.; Guo, S.-M.; Liou, G.-S. J. Polym. Sci. Part A Polym. Chem. 2010, 48, 5271.

(79) Bonardi, L.; Ulrich, G.; Ziessel, R. Org. Lett. 2008, 10, 2183.

(80) Safaei-Ghomi, J.; Akbarzadeh, Z. Ultrason. - Sonochemistry 2015, 22, 365.

(81) Dong, L.; Zheng, Z.; Wang, Y.; Li, X.; Hua, J.; Hu, A. J. Mater. Chem. A 2015, 3, 11607.

(82) Wang, Y.-X.; Leung, M. Macromolecules 2011, 44, 8771.

(83) Hammerer, F.; Garcia, G.; Chen, S.; Poyer, F.; Achelle, S.; Maillard, P. J. Org. Chem. 2014, 79, 1406.

(84) Wu, Y.; Liu, L.; Li, H.; Wang, D. J. Org. Chem. 2006, 71, 6592. 